\title{
Experimental Testing of Cooling by Low Pressure Adsorption in a Zeolite
}

C.M. Redman

New Mexico Solar Energy Institute

January 1985

Prepared by

New Mexico Solar Energy Institute for Pacific Northwest Laboratory under Contract DE-AC06-76RLO 1830

with the U.S. Department of Energy

Pacific Northwest Laboratory

Operated for the U.S. Department of Energy

by Battelle Memorial Institute 


\title{
DISCLAIMER
}

This report was prepared as an account of work sponsored by an agency of the United States Government. Neither the United States Government nor any agency thereof, nor any of their employees, makes any warranty, express or implied, or assumes any legal liability or responsibility for the accuracy, completeness, or usefulness of any information, apparatus, product, or process disclosed, or represents that its use would not infringe privately owned rights. Reference herein to any specific commercial product, process, or service by trade name, trademark, manufacturer, or otherwise, does not necessarily constitute or imply its endorsement, recommendation, or favoring by the United States Government or any agency thereof. The views and opinions of authors expressed herein do not necessarily state or reflect those of the United States Government or any agency thereof.

\author{
PACIFIC NORTHWEST LABORATORY \\ operated by \\ BATTELLE \\ for the \\ UNITED STATES DEPARTMENT OF ENERGY \\ under Contract DE-AC06-76RLO 1830
}

\begin{tabular}{|c|c|}
\hline \multicolumn{2}{|c|}{ Printed in the United States of America } \\
\hline \multicolumn{2}{|c|}{ Available from } \\
\hline \multicolumn{2}{|c|}{ National Technical Information Service } \\
\hline \multicolumn{2}{|c|}{ United States Department of Commerce } \\
\hline \multirow{2}{*}{\multicolumn{2}{|c|}{$\begin{array}{c}5285 \text { Port Royal Road } \\
\text { Springfield, Virginia } 22161\end{array}$}} \\
\hline & \\
\hline \multirow{2}{*}{\multicolumn{2}{|c|}{$\begin{array}{l}\text { NTIS Price Codes } \\
\text { Microfiche A01 }\end{array}$}} \\
\hline & \\
\hline \multicolumn{2}{|c|}{ Printed Copy } \\
\hline & Price \\
\hline Pages & Codes \\
\hline $001-025$ & $\mathrm{~A} 02$ \\
\hline $026-050$ & $\mathrm{~A} 03$ \\
\hline 051-075 & $\mathrm{A} 04$ \\
\hline 076-100 & A05 \\
\hline $107-125$ & $\mathrm{~A} 06$ \\
\hline $126-150$ & $\mathrm{~A} 07$ \\
\hline 151.175 & $A 0 B$ \\
\hline $176-200$ & $\mathrm{~A} 09$ \\
\hline $201-225$ & A010 \\
\hline $226 \cdot 250$ & A011 \\
\hline $257-275$ & $\mathrm{~A} 012$ \\
\hline $276-300$ & $A 013$ \\
\hline
\end{tabular}


EXPERIMENTAL TESTING OF COOLING BY LOW PRESSURE ADSORPTION IN A ZEOLITE

C. M. Redman (a)

January 1985

Prepared by

New Mexico Solar Energy Institute for Pacific Northwest Laboratory under Contract DE-ACO6-76RLO 1830 with the U.S. Department of Energy Subcontract B-B5238-A-0

Pacific Northwest Laboratory Richland, Washington 99352

(a) New Mexico Solar Energy Institute New Mexico State University 



\section{FOREWORD}

Seasonal thermal energy storage (STES) involves storing thermal energy, such as winter chi11, summer heat, and industrial waste heat, for future use in heating and cooling buildings or for industrial processes. Widespread development and implementation of STES would significantly reduce the need to generate primary energy in the U.S. In fact, 1980 data indicate that STES is technically suitable for providing 5 to $10 \%$ of the nation's energy with major contributions in the comnercial, industrial, and residential sectors.

Part of the Pacific Northwest Laboratory's (PNL) objective with the STES Program is to identify new and promising methods for STES. Under sponsorship of the U.S. Department of Energy, PNL (operated by 8attelle Memorial Institute) issued a request for proposals for development of innovative methods for performing or augmenting seasonal chill storage for space or process cooling. In response to this request for proposal, a contract was awarded to New Mexico Solar Energy Institute to design, construct, and operate a small-scale facil$i$ ty to tast the use of zeolite adsorption of water vapor to augment chill storage in ice for conventional space cooling. The facility uses solarderived energy for the heat source and evaporatively chilled water for the heat sump. Cooling is provided by sublimation of the ice instead of melting. This report describes the design and construction phases, as well as system performance.

The system, as configured for the experiments described in this report, has substantial parasitic energy requirements. These requirements might be avoided by using other adsorbents or by developing new adsorbents having improved adsorption/desorption properties. (This latter alternative is now being explored and could result in dramatic reduction of parasitic energy requirements while improving the effectiveness per cycle by as much as a factor of 5.) Because water vapor flows at low pressure in the system, high vapor flow rates are necessary. However, these high flow rates were not a limiting factor in the testing. Additional study is being considered in selected technical areas supportive to both seasonal and diurnal energy storage with adsorbents. 



\section{SUMMARY}

The New Mexico Solar Energy Institute, under contract to Pacific Northwest Laboratory (operated for the U.S. Department of Energy by Battelle Memorial Institute) designed, constructed, and utilized a small scale facility to test the use of zeolite adsorption of water vapor to augment chill storage in ice for conventional space cooling. The facility uses solar-derived energy, * for the heat source and evaporatively chilled water for the heat sump. The product cooling uses sublimation of ice instead of melting. The specific tasks of this project were to 1) develop and design a detailed specification for a solar zeolite chill-augmented storage system, which includes a zeolite tank, ice tank, and heat exchanger; 2) construct the system as approved by PNL; 3) instrument and test the system; 4) perform a study of adsorbers; and 5) analyze and report the findings.

The ZCAT facility utilizes a heat pumping technique in which a water vapor adsorbent functions as the compressor and condenser. The design was based on use of $13 X$ zeolite as the adsorber because of its high adsorbence at low pressures. However, as a result of the work done on this project it has been determined that other materials such as silica gel should give superior performance. Table S-1 below shows that while zeolite 13X holds more water in the pressure and temperature ranges of interest, silica gei cycles more water and has less residue water. Both points are very important in the design of an efficient and cost effective system.

\footnotetext{
₹To speed up the overall test schedule an electric water heater was added to the test apparatus.
} 
TABLE S-1. Adsorber Comparison

Temperature

$\left({ }^{\circ} \mathrm{F}\right)$

167

77
Pressure

(psia/torr)

$0.256 / 13.2$

$0.087 / 4.5$
Silica Gel

Zeolite

(1bs water $/ 100$ lbs adsorber)

3.1

20.2

10.2

23.6

Water cycled

7.1

3.4

Residual water
3.1

20.2

DESIGN AND CONSTRUCTION

The ZCAT facility consists of three primary subsystems. 1) The central part of the facility is the evacuated system consisting of 64 zeolite tubes, 64 condenser tubes, manifold, ice tank, and a daily cooling storage tank. 2) The thermal drive is a solar water heating system. 3) The heat sump is an evaporative water chiller. Design and construction details are provided in Appendix $D$ of this report. The solar panel and evaporative water chiller were avaitable from previous projects and were not optimized for this project.

\section{OPERATIONAL CONCEPT}

The ZCAT facility utilizes zeolites in a heat-pumping mode, which reduces the pressure below 0.0887 psia. Heat from stored ice is transferred via water vapor to the zeolite. The vapor sublimated releases jts heat to the zeolite upon adsorption. The heat of adsorption varies inversely with zeolite temperature, but in the temperature range of most interest it is typically between 1200 and $1400 \mathrm{Btu}$ per pound. Circulating water carries the heat from the zeolite to the heat sump. The $1218.7 \mathrm{Btu}$ removed from the ice for each pound of ice sublimated can be used to freeze an additional 8.5 pounds of water, cool ice, or cool a heat load.

Zeolite is a good compressor-condenser only when it is sufficiently dry. The major complexity of this heat-pumping technique is the process 
for drying the zeolite. The "dryness" increases with increasing temperature and decreasing pressure in the zeolite. The ZCAT facility utilizes hot water from a solar heating system and condensing water from an evaporative water chiller to dry the zeolite.

\section{SYSTEM TESTING}

Systems testing of the zeolite heat pumping system was initiated on January 30, 1984. In the next 7 weeks, 17 test runs were made, critical temperatures were plotted, adsorption and desorption end points were plotted on zeolite isobars, and desorption versus time plots were drawn. Performance analysis was done and estimates of system effectiveness were made.

Table S-2 sumnarizes the performance of 14 test runs. These test runs averaged 141 percent in performance when comparing actual water processed (cooling furnished) to the theoretical water processed. The average time to 90 percent of desorption was 70 minutes. Since the ZCAT facility did not have a vapor flow meter, adsorption time was not determined. The table also shows that performance increased significantly after long vacuum pumping (typically 6 to 10 hours) and then decreased with time if significant vacuum pumping was not done.

Oetailed data for these runs are provided in the report and appendices.

\section{CONCLUSIONS}

The zeolite chill-augmented test facility was designed, constructed, and tested and found to conform to the theory based on the zeolite manufacturer's data. Other noteworthy factors are listed below.

1. Testing results indicate that the ZCAT facility performance is dependent on the duration of vacuum pumping done prior to initiation of testing. No method of measuring the "cleanness" of the zeolite was available but indications of "gas poisoning" are implied by some test data. 
IABLE S-2. Summary of Performance

\begin{tabular}{lcccc}
$\begin{array}{c}\text { Date of } \\
\text { Test }\end{array}$ & $\begin{array}{c}\text { Desorbed } \\
\text { Water, Lbs }\end{array}$ & $\begin{array}{c}\text { Percent }{ }^{2} \\
\text { of Theoretical }\end{array}$ & $\begin{array}{c}\text { Desorption } \\
\text { Time }\end{array}$ & $\begin{array}{c}\text { Time to }{ }^{6} \\
\text { T0\% of } \\
\text { Desorption }\end{array}$ \\
\cline { 1 - 2 } $1 / 30$ & 10.40 & $179^{4}$ & 140 & 82 \\
$1 / 31$ & 6.85 & 134 & 168 & 132 \\
$2 / 2$ & 5.64 & 115 & 183 & 140 \\
$2 / 7$ & 4.30 & 88 & 47 & 28 \\
$2 / 10$ & 6.40 & 121 & 81 & 47 \\
$2 / 14$ & 6.80 & 1554 & 119 & 36 \\
$2 / 18$ & 5.15 & 123 & 79 & 52 \\
$2 / 24$ & 6.00 & 140 & 120 & 55 \\
$3 / 1$ & 6.15 & 1545 & 87 & 56 \\
$3 / 6$ & 5.50 & 131 & 100 & 80 \\
$3 / 11$ & 1.64 & 51 & 120 & 59 \\
$3 / 12$ & 4.74 & 296 & 123 & 80 \\
$3 / 13$ & 4.75 & 151 & 120 & 76 \\
$3 / 14$ & 5.06 & 144 & 130 & 63 \\
& Average & 141 & 116 & 70
\end{tabular}

\footnotetext{
1 Desorbed water as measured with a graded cylinder.

2 Percent of measured water to that determined by pressure and temperature measurements and zeolite manufacturer's data.

${ }^{3}$ Time in minutes to reach the desorption.

4 Long vacuum pumping the day before the test.

${ }^{5}$ Long vacuum pumping the night before the test.

${ }^{6}$ Time in minutes to reach 90 percent of final desorption.
}

2. Indications are that both adsorption and desorption flow rates were higher than projected. 
3. The speeds of adsorption and desorption seem to be limited by the rate of heat flow out of and into the zeolite and out of the vapor during condensation.

4. The zeolite used for this test was not optimum. Other materials have been found to process more water (furnish product cooling) and leave less residual water.

The general design of the system was suitable for this project. However, the tanks housing the zeolite, condenser, and manifold sections did not allow differential pressurization, and operational problems resulted. Thermal insulation of the system was marginal, allowing some ambient air and solar derived heating. Also, a bidirectional low pressure vapor flowmeter should be used to more thoroughly analyze system performance.

\section{RECOMMENDATIONS}

A parallel program of laboratory investigations to include old adsorbers and new adsorbers with better structural design for low pressure operation should be carried out. This would include a theoretical investigation of adsorbers to identify new designs with the low pressure high water adsorption of zeolite $13 X$ and the low pressure low temperature drying characteristics of silica gel. These new materials should then be tested in the ZCAT facility.

While the general design of the ZCAT facility was suitable for analysis of pumping heat from ice, some design changes are recommended. A technique for allowing some differential pressurization of the water in the zeolite and condenser tanks would greatly ease test operation. Additional hot and cool water storage would lower the temperature transients and improve the accuracy of the temperature measurements. A better pressure transducer for the 0.01 to 1.00 psia range and differential temperature measurements for the zeolite tank and condenser tank water inputs and outputs would substantially improve analysis capabilities. Also a bidirectional water vapor flow meter for use down to 0.01 psia is necessary for complete analysis of the ZCAT facility performance. 


\section{ACKNOWLEDGMENTS}

The initial design for the zeolite tubes was done by Mr. Robert Sabin of the New Mexico State University Physical Science Laboratory. Mr. Sabin also furnished extensive support in the areas of system design and testing. Or. Kenneth McCorkle of the Chemical Engineering Department, New Mexico State University, furnished considerable advice concerning performance of zeolite and was responsible for the zeolite materials study portion of this contract. Dr. R. J. Liefeld of the Physics Department, New Mexico State University, furnished a mass spectrometer helium leak detector and technical support in its use as well as other very helpful guidance on vacuum techniques.

We wish to thank the U.S. Department of Energy for financial support and Dr. Landis Kannberg of the Battelle Pacific Northwest Laboratories for his technical support which greatly aided in the success of this project. We aiso wish to thank New Mexico State University students John Bauer and Jerry Tyree for the construction and testing of the zeolite chillaugmented test facility. 



\begin{tabular}{|c|c|c|c|c|c|c|c|c|c|c|c|}
\hline SUMMARY & $\cdot$ & $\cdot$ & $\cdot$ & - & · & . & . & . & $\cdot$ & & v \\
\hline ACKNOWLEDGMENTS & . & . & . & . & . & . & . & . & . & $\theta^{\circ}$ & $x i$ \\
\hline INTRODUCTION . & $\cdot$ & $\cdot$ & $\cdot$ & . & . & . & - & - & • & $\theta^{\circ}$ & 1 \\
\hline BACKGROUND & . & . & . & . & . & . & . & . & . & $\theta^{\circ}$ & 1 \\
\hline OBJECTIVES . & - & . & . & . & . & - & . & . & . & 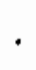 & 1 \\
\hline ZEOLITE CHILL-AUGMEN & VTED & TEST & FACIL & ITY & . & . & . & . & . & ${ }^{\circ}$ & 3 \\
\hline DESIGN & . & . & . & . & . & - & . & . & . & $\cdot$ & 4 \\
\hline PERFORMANCE & . & . & . & . & . & . & . & . & . & - & 15 \\
\hline CALCULATED PERF & ORMA & WCE & . & . & . & . & . & . & . & 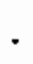 & 17 \\
\hline SYSTEMS CHECKOU & & . & . & . & . & . & . & . & . & $\theta^{\circ}$ & 18 \\
\hline Zeolite Tu & ube & $\cdot$ & . & . & . & . & . & . & . & ${ }^{\circ}$ & 18 \\
\hline Manifold-C & Conde & enser. & . & . & . & . & . & . & . & ${ }^{\circ}$ & 22 \\
\hline Condensate & $\operatorname{Rec}$ & veiver & . & . & . & . & . & . & . & ${ }^{\circ}$ & 23 \\
\hline Ice Tank & . & . & . & . & . & . & - & . & . & ${ }^{\circ}$ & 23 \\
\hline SYSTEMS TESTING & & . & . & . & . & . & . & . & . & & 23 \\
\hline TEST AND ANALYS & & . & . & . & . & . & . & . & . & ${ }^{\circ}$ & 25 \\
\hline Electrical & Ana & lysis & . & . & . & . & . & . & . & 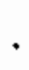 & 44 \\
\hline PROPERTIES OF ZEOLIT & TES $F$ & $=O R$ ADS & SORPT & ION & REFRIG & ER & $\mathrm{ON}$ & STEMS & . & ${ }^{\circ}$ & 46 \\
\hline REFERENCES & . & . & . & . & . & . & . & . & . & • & 56 \\
\hline APPENDIX A - SUMMARY & OF & TEST & RUNS & $\cdot$ & $\cdot$ & . & . & . & . & ${ }^{\circ}$ & A. 1 \\
\hline APPENDIX B - EXHIBIT & of & DATA & FROM & TEST & RUNS & . & . & . & . & ${ }^{\circ}$ & B. 1 \\
\hline APPENDIX C - CALIBRA & ATION & IS OF & TEMPE & RATU & IRES AN & & DEI & TE REC & & & C. I \\
\hline APPENDIX D - DETAILS & 5 OF & CONSTI & RUCTI & & . & - & . & . & . & $\cdot$ & D. 1 \\
\hline Evaporative Wat & ter $\mathrm{C}$ & Chiller & & . & . & . & . & . & . & . & D. 3 \\
\hline Zeolite Tank & . & . & . & . & . & . & . & . & . & . & D. 12 \\
\hline Condenser Manif & fold & . & . & . & . & - & . & . & . & ${ }^{\circ}$ & D. 15 \\
\hline Condensate Rece & eiver & . & . & - & . & . & . & . & . & . & D. 25 \\
\hline Solar System & . & - & - & . & . & . & . & - & . & . & 0.25 \\
\hline Vacuum Gauges & - & . & . & . & . & - & . & . & . & 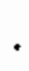 & D. 25 \\
\hline Ice Tank . & $\cdot$ & $\cdot$ & . & . & . & - & - & . & - & • & D. 25 \\
\hline Labor and Mater & rial & 8 reakc & down & . & . & . & . & . & . & . & 0.34 \\
\hline
\end{tabular}




\section{CONTENTS (continued)}

Data Collection . . . . . . . . . 0.42

Test Control. . . . . . . . . 0.46 


\section{FIGURES}

\begin{tabular}{|c|c|c|c|c|c|c|}
\hline 1 & Solar Zeolite Adsorptive Cooling & - & . & • & · & . \\
\hline 2 & Zeolite Tube & . & . & . & . & . \\
\hline 3 & Solar Zeolite System, Looking East. & - & . & . & . & - \\
\hline 4 & Solar Zeolite System, Looking North & 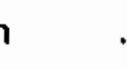 & · & • & · & . \\
\hline 5 & System Looking East. . . . . & . & - & • & . & . \\
\hline 6 & System Looking West. . . . & . & . & · & . & - \\
\hline 7 & Solar Day Heat Flow, $82.7^{\circ} \mathrm{F}$ to $180^{\circ} \mathrm{F}$ & $\mathrm{F}$ & . & . & . & . \\
\hline \multirow[t]{2}{*}{8} & Constant Moisture, $56^{\circ} \mathrm{F}$ to $82.7^{\circ} \mathrm{F}$, & 0.0887 & 7 psia & a to & 0.222 & \\
\hline & psia. $\quad . \quad$. & . & . & . & . & . \\
\hline 9 & Nocturnal Heat Flow, $147.7^{\circ} \mathrm{F}$ to $56^{\circ} \mathrm{F}$ & $\mathrm{F}$ & . & . & . & - \\
\hline \multirow[t]{2}{*}{10} & Constant Moisture, $180^{\circ} \mathrm{F}$ to $147.7^{\circ} \mathrm{F}$ & F, 0.22 & $22 \mathrm{psi}$ & ia to & 0.08 & 387 \\
\hline & psia. $. \quad . \quad . \quad . \quad . \quad$. & . $\quad$. & . & 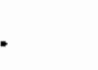 & $\cdot$ & . \\
\hline 11 & Molecular Sieve $13 X$ Isobars & . & . & - & . & - \\
\hline 12 & Zeolite Isobars & . & - & • & . & - \\
\hline 13 & Temperatures for March 14 Test Run . & . & . & - & . & . \\
\hline 14 & Desorption Response. & . & . & & & . \\
\hline
\end{tabular}

\section{APPENDIX B}

\begin{tabular}{|c|c|c|c|c|c|c|c|c|c|}
\hline$B-1-a$ & Zeolite Isobars & . & - & . & . & & . & . & B. 5 \\
\hline$B-1-b$ & Oata Run, January 30 , & , 1984 & . & . & . & & & . & B. 6 \\
\hline$B-1-c$ & Desorption Response . & . $\quad$. & - & - & . & & 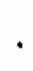 & . & B. 7 \\
\hline $8-1-d$ & Data Printout . . & . & . & . & . & & & . & B. 8 \\
\hline$B-2-a$ & Zeolite Isobars , & . & . & . & . & $\cdot$ & 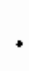 & - & B. 9 \\
\hline$B-2-b$ & 0ata Run, January 31, & 1984 & . & - & . & & & . & B. 10 \\
\hline$B-2-C$ & Desorption Response. & . & $\cdot$ & - & . & & & . & B. 11 \\
\hline$B-2-d$ & Data Printout . . & . & . & . & . & • & & . & B. 12 \\
\hline$B-3-a$ & Zeolite Isobars & . & - & - & - & & & . & B. 13 \\
\hline$B-3-b$ & Oata Run, February 2, & 1984 & . & . & . & & & . & B. 14 \\
\hline$B-3-c$ & Desorption Response. & • & . & . & . & & & . & B. 15 \\
\hline$B-3-d$ & Data Printout . . & . & . & . & - & $\cdot$ & & . & B. 16 \\
\hline$B-4-a$ & Zeolite Isobars & . & . & . & . & • & . & . & B. 17 \\
\hline
\end{tabular}


B-4-b Data Run, February 7, $1984 \quad$. . . . . . . . B. 18

B-4-C Desorption Response. . . . . . . . . . B. 19

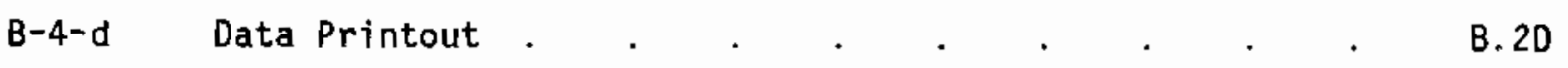

B-5-a Zeolite Isobars . . . . . . . . . . . B.21

B-5-b Data Run, February 10, 1984 . . . . . . . B. 22

B-5-C Desorption Response. . . . . . . . . B. . . . . . . . . . . .

B-5-d Data Printout . . . . . . . . . . B. . . . . . . . . .

B-6-a Zeolite Isobars . . . . . . . . . B. . . . . . . . . . . .

B-6-b Data Run, February 14, 1984 . . . . . . . . . B. 26

B-6-C Desorption Response. . . . . . . . . B. 27

B-6-d Data Printout . . . . . . . . . . B. . . . . . . . .

B-7-a Zeolite Isobars . . . . . . . . . . . B.29

B-7 b Data Run, February 18, 1984 . . . . . . B. 30

B-7-c Desorption Response. . . . . . . . . . . B. 31

B-7-d Data Printout . . . . . . . . . . . B. . . . . . . . .

B-8-a Zeolite Isobars . . . . . . . . . . B.33

B-8-b Data Run, February 24, 1984 . . . . . . . . . B. 34

B-8-c Desorption Response. . . . . . . . B. 35

B-8-d Data Printout . . . . . . . . . B. . . . . . . . . . . . .

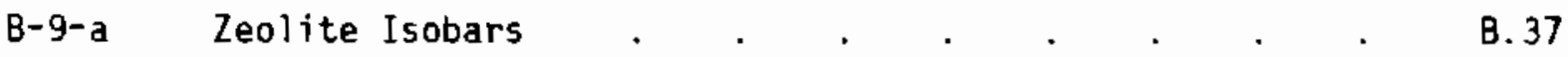

B-9-b Data Runs, February 28, 1984 . . . . . . . . B.39

B-9-c Desorption Response. . . . . . . . . . . B.41

B-9-d Data Printout . . . . . . . . . . B.42

B-10-a Zeolite Isobars . . . . . . . . . . . . B.44

B-10-b Data Run, March 1, 1984 . . . . . . . B.45

B-10-C Desorption Response. . . . . . . . B.46

B-10-d Data Printout . . . . . . . . . . . B.47

B-11-a Zeolite Isobars . . . . . . . . . . B.48

B-11-b Data Run, March 6, 1984 . . . . . . . . . . B.49

B-11-c Desorption Response. . . . . . . . . . B.50

B-11-d Data Printout . . . . . . . . . . B.51

B-12-a Zeolite Isobars . . . . . . . . . . . B.52

B-12-b Data Run, March 11, 1984 . . . . . . . . B.53

B-12-c Desorption Response : . . . . . . . . . B.54 
B-12-d Data Printout . . . . . . . . . B.55

B-13-a Zeolite Isobars . . . . . . . . . . B.56

B-13-b Data Run, March 12, 1984 . . . . . . . B.57

8-13-c Desorption Response. . . . . . . . . . . B.58

B-13-d Data Printout . . . . . . . . . . . . . . . . . . . . . . . . .

B-14-a Zeolite Isobars . . . . . . . . . B.6D

B-14-b Data Run, March 13, 1984 . . . . . . . . . . B.61

B-14-C Desorption Response. . . . . . . . . B. . . . . . . . .

B-14-d Data Printout . . . . . . . . . B. . . . . . . . . . . . .

B-15 Data Printout . . . . . . . . B.64

APPENDIX C

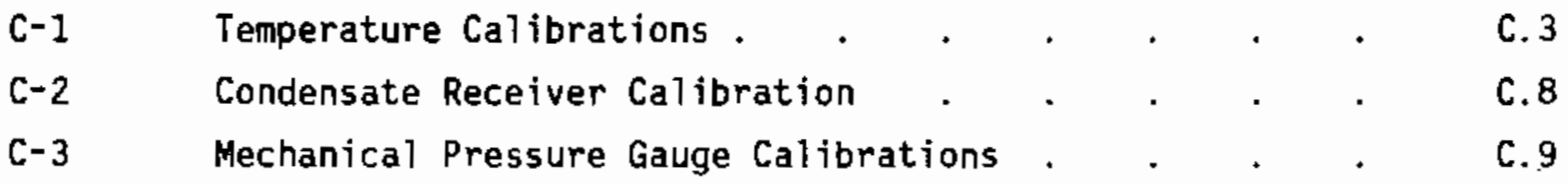

APPENDIX D

D-1

Solar Zeolite System, Looking East. . . . . . . 0.5

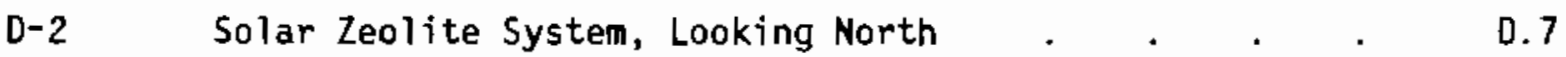

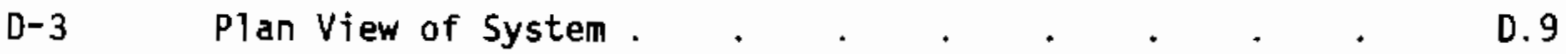

D-4 Hypothetical Performance, Psychrometric Plot. . . 0.11

D-5 Geometry of Zeolite Tubes in Zeolite Tank . . . . 0.13

D-6 Plan View, Manifold. . . . . . . . . D.17

D-7 Cut-Away of Condenser-Manifold, Section DD . . . . D.21

D-8 Cut-Away of Condenser-Manifold, Section EE . . . D. D 23

D-9 Construction Details, Ice Tank . . . . . . . . D.27

D-10 Ice Tank System, Plan View . . . . . . . . . . 0.31

D-11 Variation of $\Delta T$ Versus Time for Miscellaneous Material Samples . . . . . . . . . . . . . . . . . . . . .

D-12 System, Looking East . . . . . . . . . . D.35

D-13 System, Looking West . . . . . . . . . D.36

D-14 System, Looking North . . . . . . . . . . . . . . 37

D-15 System, Looking Northwest . . . . . . . . . . $\quad$ D. 38

D-16 Zeolite Tubes and Condenser . . . . . . . . . . D. 39 


\section{TABLES}

S-1 Adsorber Comparison . . . . . . . . . . . . . . . vi

5-2 Summary of Performance . . . . . . . . . . . . . . . . . . . . .

1 Summary of Performance . . . . . . . . . . . . . . 16

2 Sumnary of Energy Flow . . . . . . . . . 18

3 Zeolite Tank Temperature and Heat Input Data,

March 14, $1984 . .5 . .56$

4 Condenser Tank Temperature and Heat Removal Data,

March 14, 1984 . . . . . . . . . . . 36

5 Test Summary . . . . . . . . . . . . . . . . 41

APPENDIX D

D-1 Materials Breakdown, ZCAT Facility . . . . . . D. 40

D-2 System Performance Measurements . . . . . . . 0.43 
EXPERIMENTAL TESTING OF COOLING BY LOW

PRESSURE ADSORPTION IN A ZEOLITE

INTRODUCTION

BACKGROUND

This project was subcontracted to the New Mexico Solar Energy Institute by the Pacific Northwest Laboratory (PNL) operated for the U.S. Department of Energy by Battelle Memorial Institute. PNL has the responsibility of managing the Seasonal Thermal Energy Storage (STES) program for the Division of Energy Storage Technology, U.S. Department of Energy. The goal of the STES program is to develop the technology for economic storage and retrieval of energy on a seasonal basis to the point of adoption by entrepreneurial groups. Concepts that utilize heat or cold available on a seasonal basis from waste sources or other surplus sources to reduce peak period energy demand, reduce the peaking requirements of electric utilities, or contribute to favorable economics for district heating and cooling systems are within the scope of program study.

\section{OBJECTIVES}

Part of PNL's mission in managing the STES program is to identify new and promising methods for STES. Pursuant to this, PNL released a request for proposals for development of innovative methods for performing or augmenting seasonal chill storage for space or processing cooling. In response, the New Mexico Solar Energy Institute proposed and received a contract for the construction and use of a test facility for examining a concept for augmenting ice storage with sublimation heat pumping utilizing solar-dried zeolites. This facility uses solar-derived energy for the heat source and evaporatively chilled water for the heat sump. For cooling, sublimation of ice is used instead of melting. The specific objectives of this project were to 1 ) develop a detailed specification for a solar zeolite chill-augmented storage system, which includes a zeolite tank, ice tank, and heat exchanger for testing purposes; 2) construct the system as 
approved by PNL; 3) instrument and test the system; 4) perform a study of zeolites; and 5) analyze and report the findings. 


\section{ZEOLITE CHILL-AUGMENTED TEST FACILITY}

Ice storage can furnish 143.3 Btu of cooling for each pound melted or 1218.7 Btu of cooling for each pound sublimated. However, sublimation requires a pressure of 0.0887 psia or less, which makes it a more difficult process. The ZCAT facility utilizes zeolites in a heat-pumping mode to reduce the pressure below 0.0887 psia. Heat from stored ice is transferred via water vapor to the zeolite, where it is sorbed by the zeolite. The vapor sublimated releases its heat to the zeolite upon adsorption. The heat of adsorption varies inversely with zeolite temperature, but in the temperature range of most interest it is typically between 1200 and 1400 Btu per pound. Circulating water then carries the heat away from the zeolite. The 1218.7 Btu removed from the ice for each pound of ice sublimated can be used to freeze an additional 8.5 pounds of water, cool ice, or cool a heat load.

Zeolite is a good heat pump when it is sufficiently dry. The major complexity of this heat-pumping technique is the drying process. The ZCAT facility utilizes hot water from a solar heating system along with condensing water from an evaporative water chiller to "pump" the system. The dryness of the zeolite increases with increasing temperature and decreasing pressure. The pressure is held low by the cooling water, which circulates around the condenser tubes causing vapors desorbed from the zeolite to be condensed. The condensate is periodically measured and removed from the system.

The ZCAT facility has high vapor flow rates. Saturated vapor at 0.0887 psia has a volume of 3500 cubic feet per pound. Moving ten pounds of the vapor per hour through the 5 -inch section of the manifold gives a velocity of 71.0 feet per second. The 0.5 -inch diameter condenser tubes are scaled so all have similar flow rates. Condensing, however, is done under higher pressures and has substantially lower volume flow rates. 


\section{DESIGN}

The design, shown in Figure 1, consists of three primary subsystems: 1) The central part of the facility is the evacuated system consisting of 64 zeolite tubes, 64 condenser tubes, manifold, ice tank, and a daily cooling storage tank. 2) The thermal drive is from a solar water heating system. 3) The heat sump is an evaporative water chiller. Note that the solar panel and evaporative water chiller were available from previous projects; neither item was optimized for this project. Optimizing these subsystems should lead to a substantial reduction in the electrical energy used for blowing air and circulating water.

Subsystem (1) is an evacuated system that consists of the condenser manifold, the condensate receiver, the ice tank, and the 64 zeolite tubes in a tube-in-shell heat exchange configuration. A zeolite tube is shown in detail in figure 2. The zeolite is contained between 1/2-inch copper pipes and 1-1/2-inch copper pipes. Holes in the 1/2-inch pipes allow vapor to enter and exit the zeolite with a maximum path length of $1 / 2 \mathrm{inch}$. The zeolite tank section is 54 inches long. The 64 zeolite tubes hold approximately 100 pounds of zeolite and are completely sealed except for the end that connects to the condenser.

Subsystems (2), the solar thermat drive, and (3), the heat sump, consist of on-hand equipment and are discussed in Appendix D, Details of Construction.

The layout of the system is shown in Figures 3 and 4 and photographs are given in Figures 5 and 6 . The 64 zeolite tube assemblies are installed in the top section of the 18-inch diameter solar zeolite fiberglass tank shown in Figures 3 and 4 . This tank is the tall object of Figures 5 and 6 (photographs). The 64 tube assemblies are connected via silicon thermal break tubing to 64 heat exchange tubes which in turn are manifolded into one 5-inch copper tube. The heat exchange tubes and manifold are in the bottom of the 18-inch diameter solar zeolite fiberglass tank. Thermal insulation isolates the zeolite tube assemblies from the heat exchange and manifold assemblies. This allows hot water to circulate around the zeolite tubes while cool water circulates around the lower heat exchanger. The water is thereby driven from (desorbed) the zeolite and condensed in the 


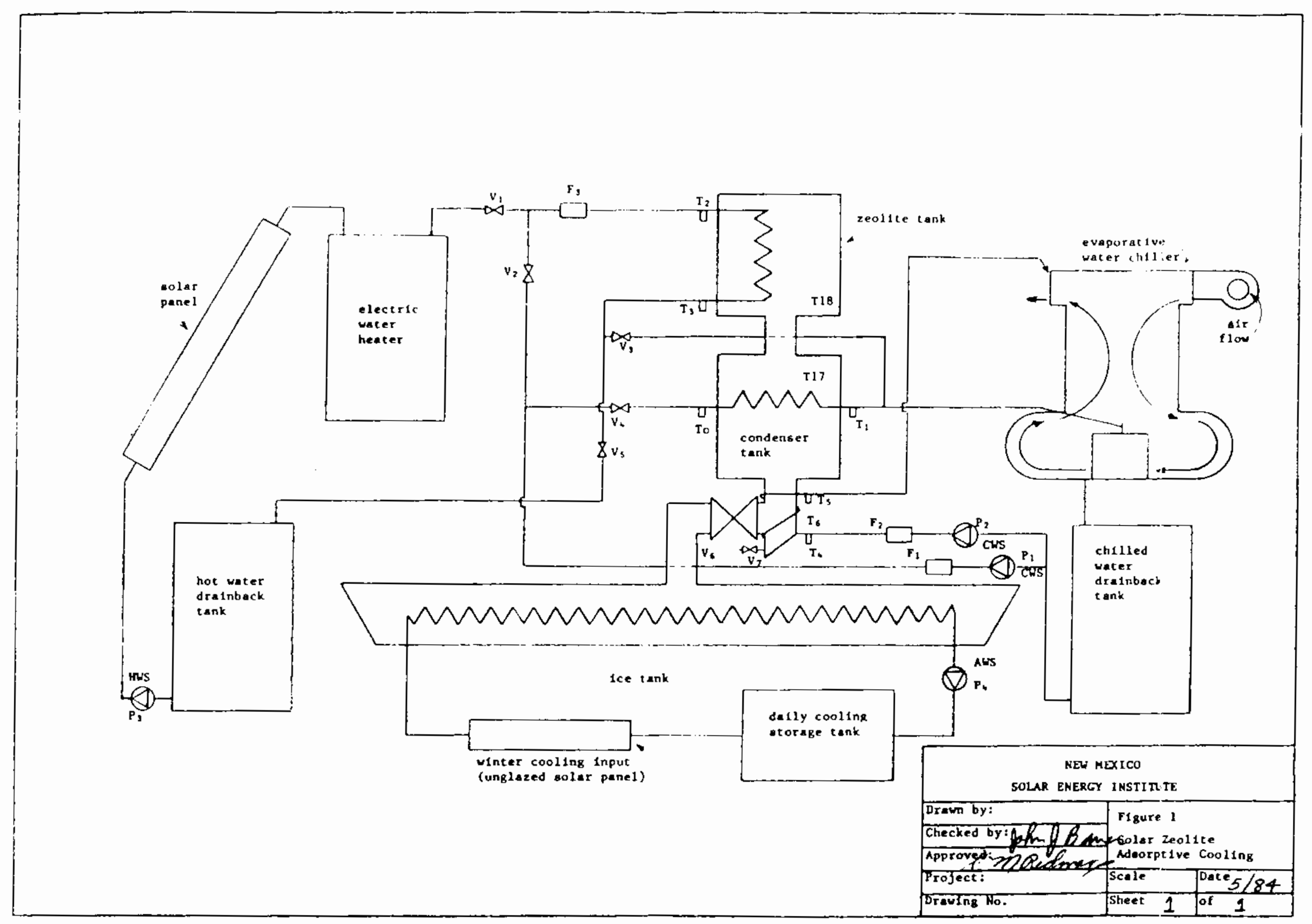

FIGURE 1. Solar Zeolite Adsorptive Cooling 
Figure 1 legend

$v_{1}$ Valve to block hot water

$v_{2}$ valve to switch hot and cold water to zeolite tank

$v_{3}$ Valve to switch hot and cold water from zeolite tank

$V_{4}$ Valve to block condenser water flow

$V_{5}$ Valve to block cooled water flow

$v_{6}$ Three-inch vacuum valve

$V_{7} \quad 3 / 8-i n c h$ vacuum valve

$\mathrm{F}_{1}$ Cooling water flow meter, zeolite tank/condenser

$\mathrm{F}_{2}$ Cooling water flow meter, condensate receiver

$\mathrm{F}_{3}$ Water flow meter, zeolite tank

AWS Ice tank heat exchanger water source

HWS Hot water source

CWS Chilled water source

$\mathrm{T}_{0}$ Condenser input water thermocouple

$T_{1}$ Condenser output water thermocouple

$\mathrm{T}_{2}$ Zeolite tank input water thermocouple

$\mathrm{T}_{3}$ Zeolite tank output water thermocouple

$\mathrm{T}_{4}$ Condensate receiver cooling input thermocouple

$\mathrm{T}_{5}$ Condensate receiver cooling output thermocouple

$T_{6}$ Condensate receiver thermocouple

$\mathrm{T}_{7}, \mathrm{~T}_{8}, \mathrm{~T}_{9}, \mathrm{~T}_{10}, \mathrm{~T}_{11}, \mathrm{~T}_{12}, \mathrm{~T}_{13}, \mathrm{~T}_{14}, \mathrm{~T}_{15}, \mathrm{~T}_{16}$

These thermocouples measured the dry bulb and wet bulb air temperature at 5 points on the evaporative water chiller

$\mathrm{T}_{17}$ Condenser mix thermocouple

$T_{18}$ Zeolite tank mix thermocouple

$T_{19}, T_{23}$ Ice tank bottom thermocouples

$\mathrm{T}_{20}, \mathrm{~T}_{21}, \mathrm{~T}_{22}$ Ice tank top

$\mathrm{P}_{1}$ Chilled water circulating pump, zeolite tank/condenser

$P_{2}$ Chilled water circulating pump, condensate receiver

$P_{3} \quad$ Hot water circulating pump

$\mathrm{P}_{4}$ Ice tank heat exchange cold water circulating pump

Note: $T_{22}$ and $T_{23}$ were switched half way through the test program to check $T_{0}$ and $T_{1}$ 


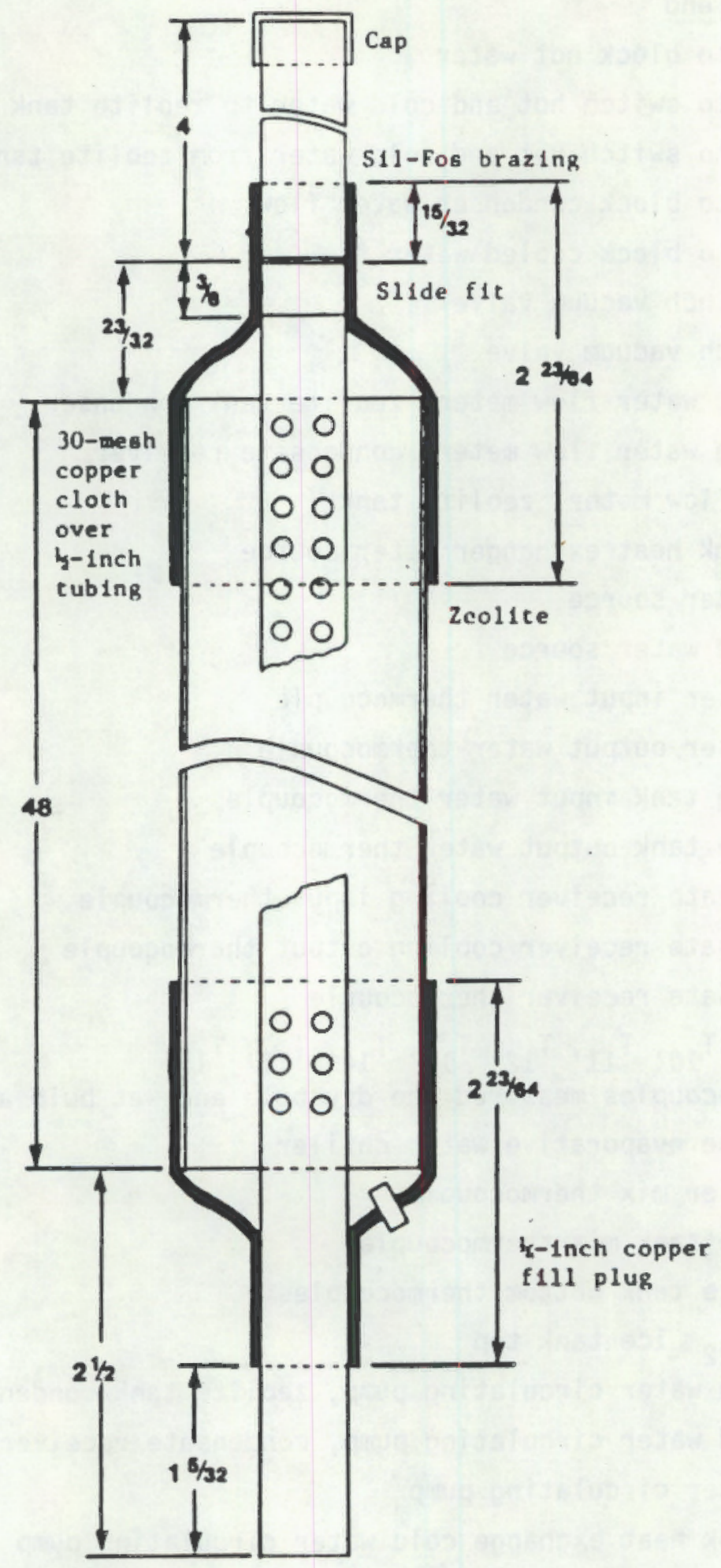

FIGURE 2. Zeolite Tube 


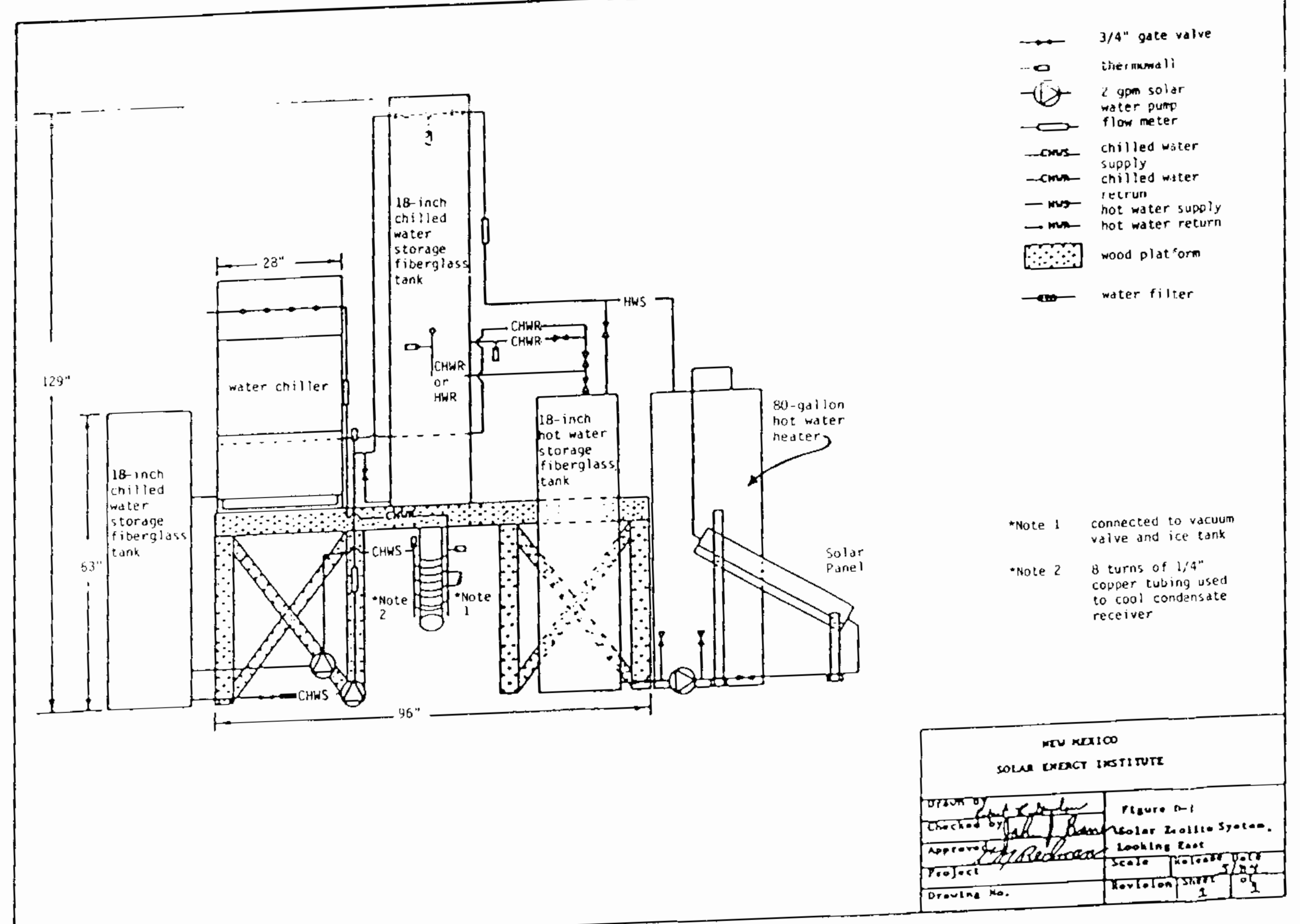

FIGURE 3. Solar Zeolite System, Looking East 



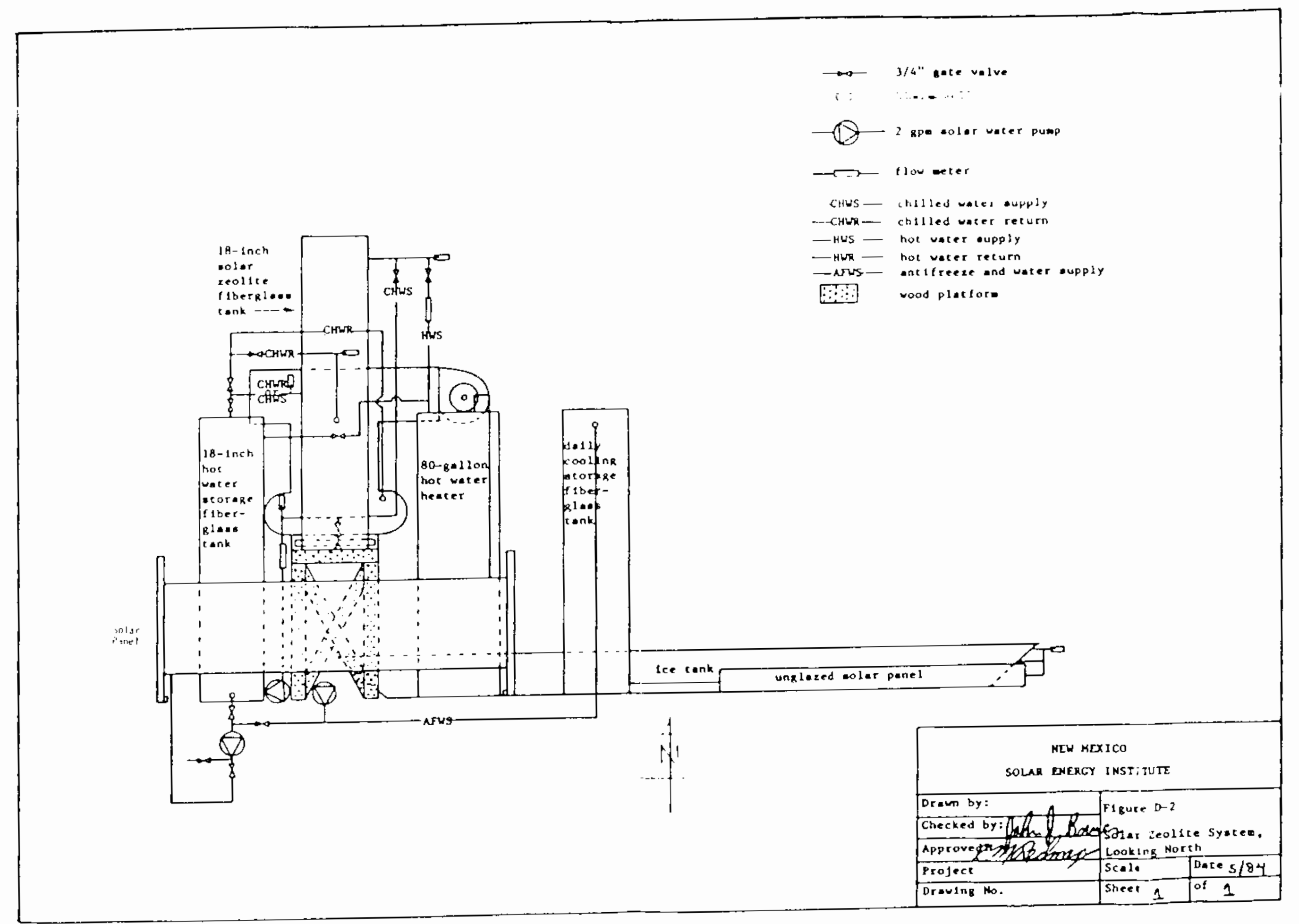

FIGURE 4. Solar Zeolite System, Looking North 
$\cdot \cdot \cdot \cdot \cdot \cdot \cdot$. 


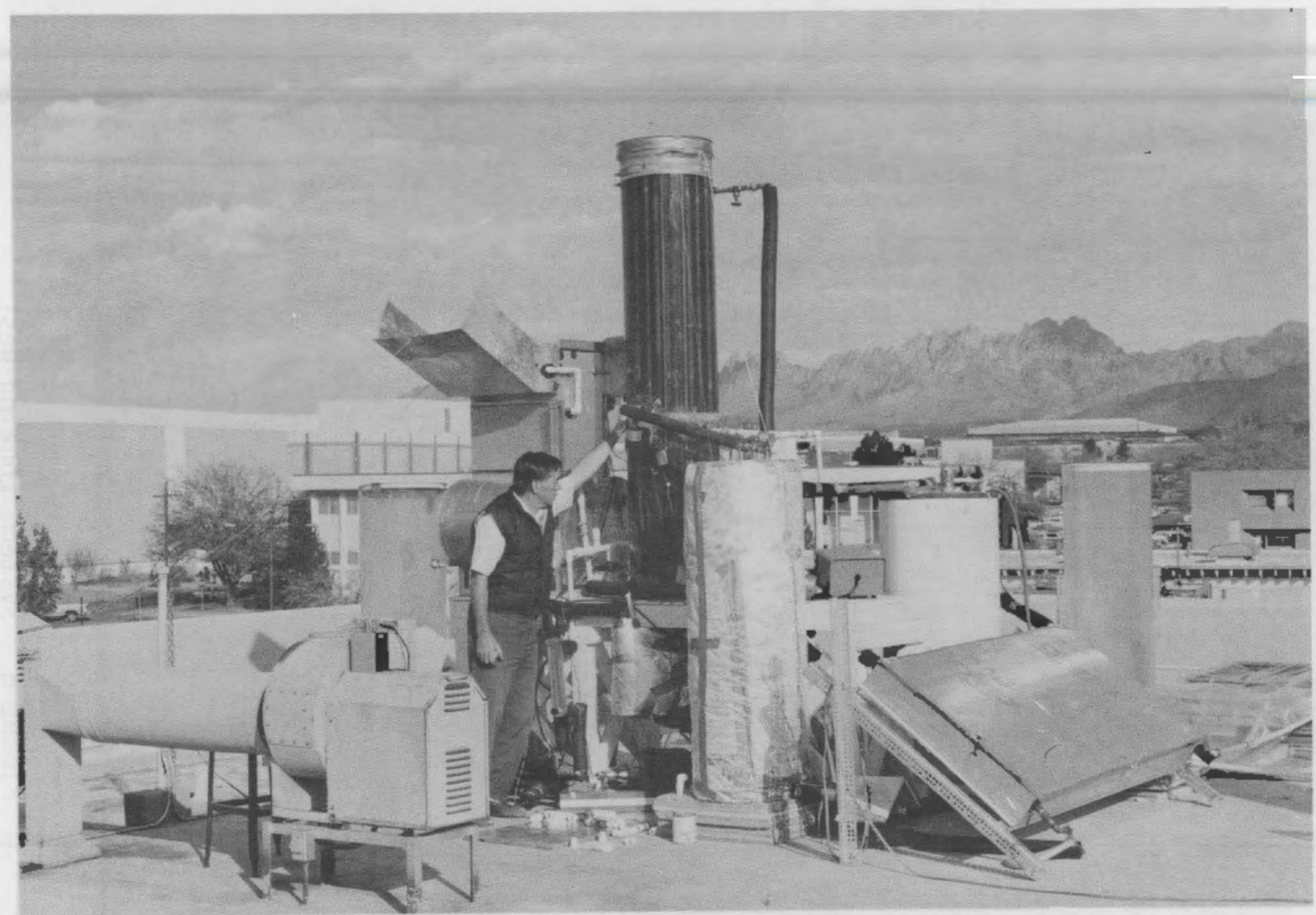

FIGURE 5. System, Looking East 


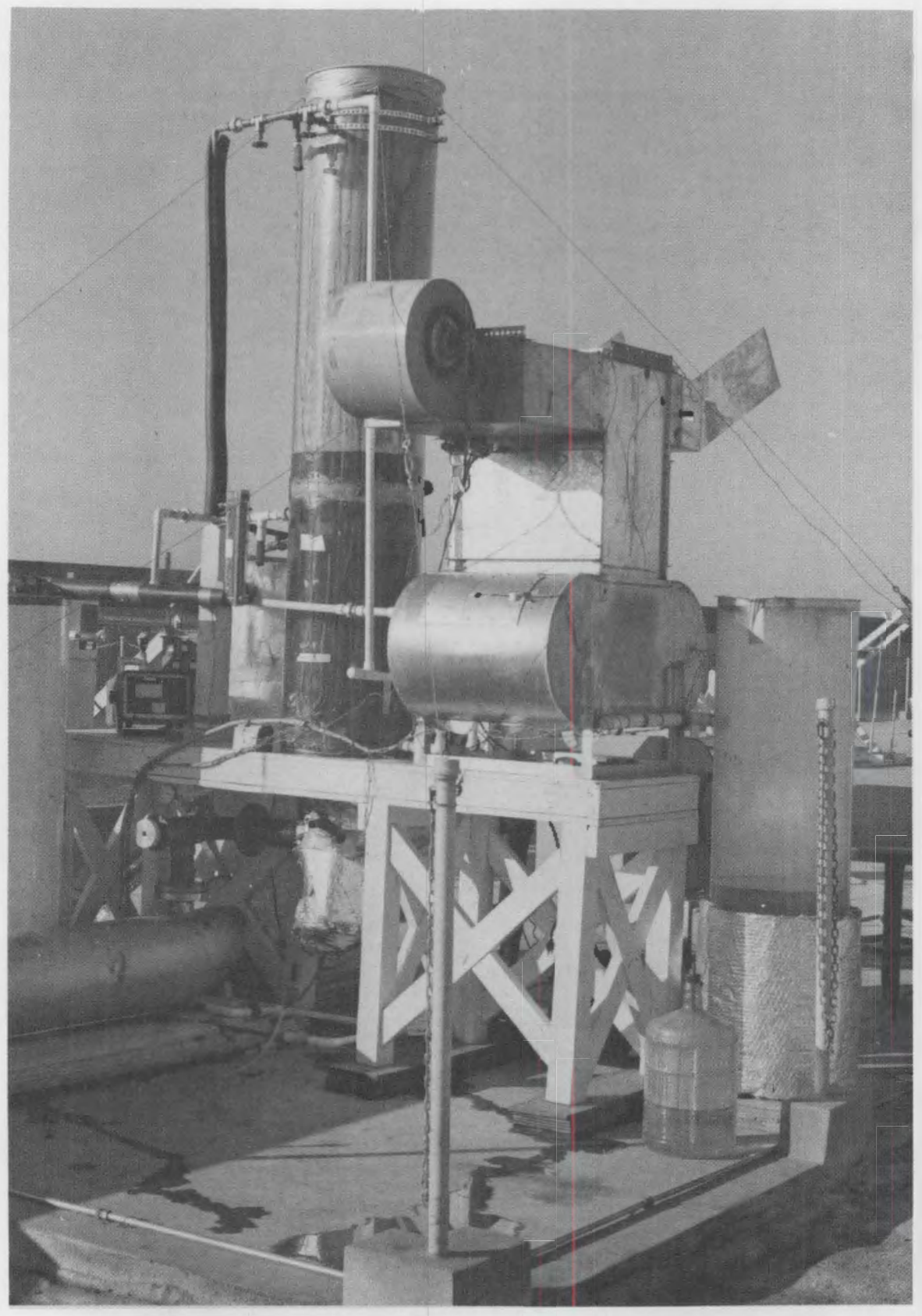

FIGURE 6. System, Looking West 
heat exchanger-manifold section to dry the zeolite. Cool water in the entire tank then causes adsorption to take place in the zeolite which in turn causes heat to be pumped by means of water vapor from the ice tank to the zeo'ite tank and then removed by water circulated around the zeolite tubes.

The ice tank is shown in Figure 4. It is a 15-foot long, 12-inch diameter stainless steel tank layed horizontally on the roof of the building. The picture shows the tank uninsulated as it was during early testing. It was insulated during later tests. The ice tank is connected to the manifold via a condensate receiver section which is shown below the solar zeolite fiberglass tank in Figure 3.

The cooling system to remove heat from the zeolite and condenser is shown in Figures 3 and 4 as the water chiller, chilled water storage, and interconnecting plumbing and pumps. It is an evaporative cooler with blower, heat exchanger, water spray, evaporative pad, and ducting.

The hot water system shown in figures 3 and 4 consists of a solar panel, backup electric water heater, a hot water storage tank, and connecting plumbing and pumps. Figure 5 shows the solar panel on the right, the hot water storage to its left, and the electric water heater back of the panel.

\section{PERFORMANCE}

Table 1 lists results from 14 test runs. Three additional speed-of-response tests were performed on February 28 but since they are not directly comparable, they are not included in the table.

Table 1 gives the measured values, in pounds of water desorbed, for each test run. The percent of measured water to that projected is also tabulated. The table also lists the time that desorption was 90 percent of the finat desorption.

The data shows the significant improvenent in performance after a long vacuum pumping cycle. The data also shows that in 12 out of 14 tests the performance was above theoretical. 
TABLE 1. Summary of Performance

\begin{tabular}{|c|c|c|c|c|}
\hline $\begin{array}{l}\text { Date of } \\
\text { Test } \\
\end{array}$ & $\begin{array}{l}\text { Desorbed }{ }^{1} \\
\text { Water, Lbs }\end{array}$ & $\begin{array}{c}\text { Percent }{ }^{2} \\
\text { of Theoretical }\end{array}$ & $\begin{array}{l}\text { Desorption } 3 \\
\text { Time } \\
\end{array}$ & $\begin{array}{c}\text { Time to } 6 \\
90 \% \text { of } \\
\text { Desorption }\end{array}$ \\
\hline $1 / 30$ & 10.40 & 1794 & 140 & 82 \\
\hline $1 / 31$ & 6.85 & 134 & 168 & 132 \\
\hline $2 / 2$ & 5.64 & 115 & 183 & 140 \\
\hline $2 / 7$ & 4.30 & 88 & 47 & 28 \\
\hline $2 / 10$ & 6.40 & 1214 & 81 & 47 \\
\hline $2 / 14$ & 6.80 & $155^{4}$ & 119 & 36 \\
\hline $2 / 18$ & 5.15 & 123 & 79 & 52 \\
\hline $2 / 24$ & 6.00 & 140 & 120 & 55 \\
\hline $3 / 1$ & 6.15 & $154^{5}$ & 87 & 56 \\
\hline $3 / 6$ & 5.50 & 131 & 100 & 80 \\
\hline $3 / 11$ & 1.64 & 51 & 120 & 59 \\
\hline $3 / 12$ & 4.74 & $296^{5}$ & 123 & 80 \\
\hline $3 / 13$ & 4.75 & 151 & 120 & 76 \\
\hline \multirow[t]{2}{*}{$3 / 14$} & 5.06 & 144 & 130 & 63 \\
\hline & Average & 141 & 116 & 70 \\
\hline
\end{tabular}

\footnotetext{
${ }^{1}$ Desorbed water as measured with a graded cylinder.

2 Percent of measured water to that determined by pressure and temperature measurements and zeolite manufacturer's data.

${ }^{3}$ Time in minutes to reach the desorption.

${ }^{4}$ Long vacuum pumping the day before the test.

${ }^{5}$ Long vacuum pumping the night before the test.

${ }^{5}$ Time in minutes to reach 90 percent of final desorption.
} 


\section{CALCULATED PERFORMANCE}

Table 2 shows the projected performance and actual data from tests performed on January 30, 1984, and March 14, 1984. The January 30 data run was preceded by a lengthy purging operation. This data may indicate that when the zeolite is thoroughly purged of any undesirable gases, the actual performance can significantly exceed the projected performance. Although the March 14 run had a very short purging operation, the results are still in line with the differential temperatures and exceed the projected performance values. The ZCAT facility has some brass fittings which are likely to outgas under the test conditions of pressure and temperature. Eliminating such materials should lessen the need for long periods of vacuum pumping prior to the test runs.

The calculated heat flows for an idealized cycle based on six pounds of cycling water are shown in Figures 7 through 10. This cycle is shown on the isobar plots in Figure 11. Figure 7 shows 7775 Btu for desorption of water and 6891 Btu for heating the residual water, zeolite, copper, and fiberglass tank (point A to point B on Figure 11). Figure 8 shows 1902 Btu for heating the system mass while the internal temperature increases from $56^{\circ} \mathrm{F}$ to $82.7^{\circ} \mathrm{F}$ and the internal pressure increases from 0.0886 psia to 0.222 psia (point $D$ to point $A$ on Figure 11). Figure 9 shows 7884 Btu of cooling to adsorb six pounds of vapor and 6195 Btu of cooling to cool the system mass (point $C$ to $D$ on Figure 11). Figure 10 shows 2161 Btu of cooling to cool the system and drop the pressure (point $B$ to point $C$ on Figure 11). Heating and cooling the mass of the materials in the zeolite tank seriously affects the efficiency of operation. For this test facility, about one-half the energy is used for sensible heating and cooling and does not contribute to performance.

The zeolite is the compressor-condenser of the zeolite chill-augmentated system with a standard heat pump. It was calculated that 328.9 Btu of solar heat (Btu in) and 445.4 Btu of evaporative cooling (Btu out) would cycle the solar zeolite chill-augmentated system so that it could furnish 144 Btu of $32^{\circ} \mathrm{F}$ cooling (see Table 2). This cooling was calculated to use 81.1 Btu of electrical energy, but this could be 


\section{TABLE 2. Summary of Energy Flow}

\begin{tabular}{|c|c|c|c|}
\hline & Projected & $\begin{array}{l}\text { Jan. } 30,1984 \\
\text { Test } \\
\end{array}$ & $\begin{array}{c}\text { March } 14,1984 \\
\text { Test } \\
\end{array}$ \\
\hline Sublimation/evaporation & $6 \mathrm{lbs} / \mathrm{day}$ & $10.4^{1 / 5} / 8^{2}$ & $5.06^{1 / 3.5^{2}}$ \\
\hline Freezing capacity & $50.4 \mathrm{lbs} / \mathrm{day}$ & $87.4 \mathrm{lbs} /$ day & $42.5 \mathrm{lbs} /$ day \\
\hline Solar energy required & $16,577 \mathrm{Btu} / \mathrm{day}$ & $12,621 \mathrm{Btu} /$ day & $18,215 \mathrm{Btu} / \mathrm{day}$ \\
\hline Cooling required & $22,447 \mathrm{Btu} / \mathrm{day}$ & & \\
\hline Solar energy/lb of ice & $328.9 \mathrm{Btu} / 1 \mathrm{~b}$ & $144.4 \mathrm{Btu} / 1 \mathrm{~b}$ & $428.6 \mathrm{Btu} / 1 \mathrm{~b}$ \\
\hline $\begin{array}{l}\text { Water chilling/Tb of } \\
\text { ice }\end{array}$ & $445.4 \mathrm{Btu} / 1 \mathrm{~b}$ & & \\
\hline $\begin{array}{l}\text { Hot water temperature } \\
\text { minus cooling water } \\
\text { temperature }\end{array}$ & $124^{\circ} \mathrm{F}$ & $108^{\circ} \mathrm{F}$ & $105^{\circ} \mathrm{F}$ \\
\hline $\begin{array}{l}\text { Cooling water temperatur } \\
\text { minus ice tank water } \\
\text { temperature }\end{array}$ & $24^{\circ} \mathrm{F}$ & $-4^{\circ} \mathrm{F}$ & $18^{\circ} \mathrm{F}$ \\
\hline $\begin{array}{l}\text { Solar Coefficient of } \\
\text { Performance }\end{array}$ & 0.44 & 0.99 & 0.33 \\
\hline
\end{tabular}

\footnotetext{
${ }^{1}$ Based on measurement of water desorbed.

${ }^{2}$ Based on temperature and pressure parameters and zeolite manufacturers technical data.
}

substantialiy reduced by optimizing the solar thermal evaporative water chiller systems and the electricalty driven pumps and blower.

\section{SYSTEMS CHECKOUT}

Zeolite Tube

Initially, single tube tests were run to verify design and operation. A single zeolite tube was connected to a glass beaker by copper tubing. A 


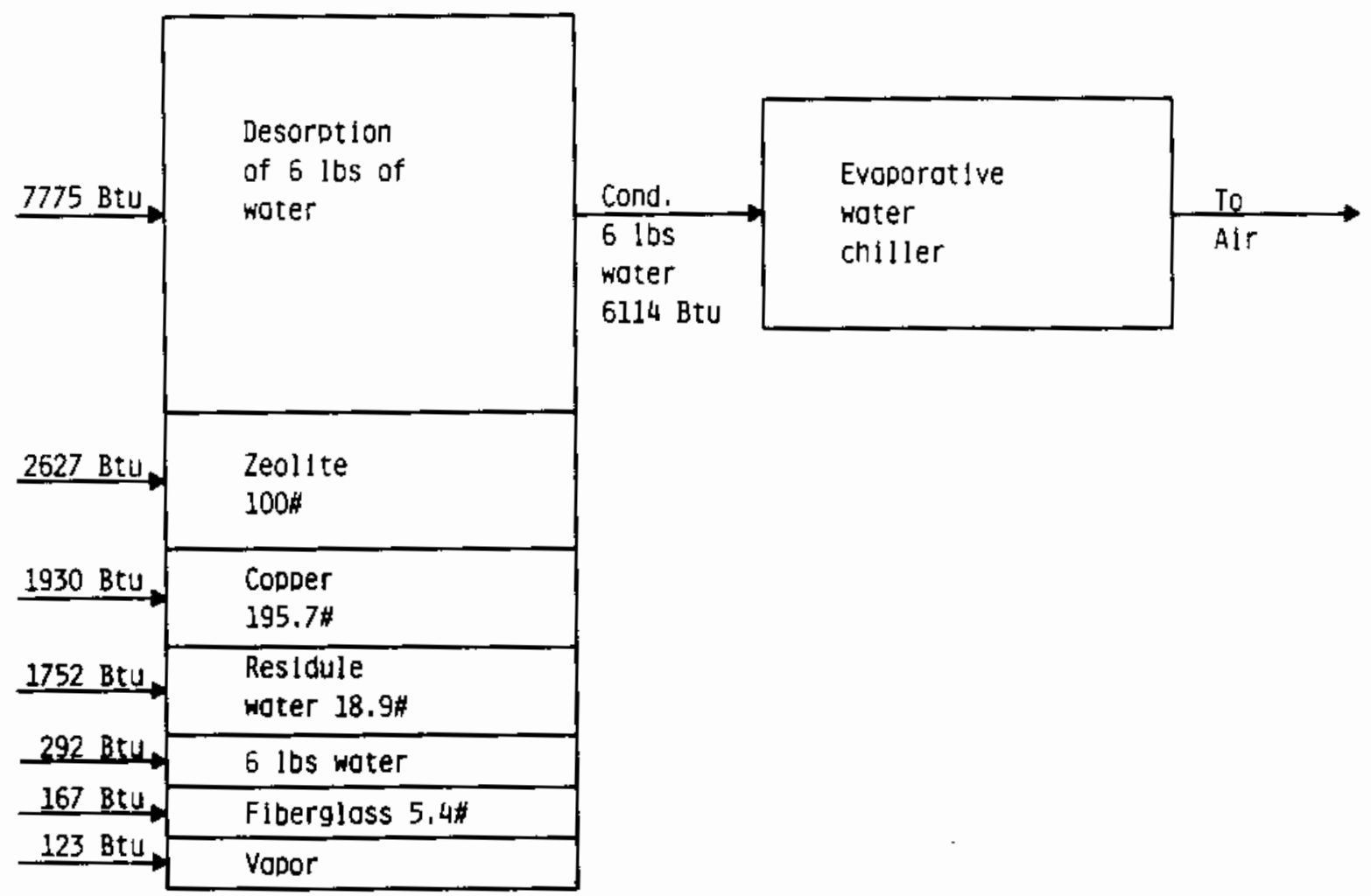

FIGURE 7. Solar Day Heat Flow $82.7^{\circ} \mathrm{F}$ to $180^{\circ} \mathrm{F}$

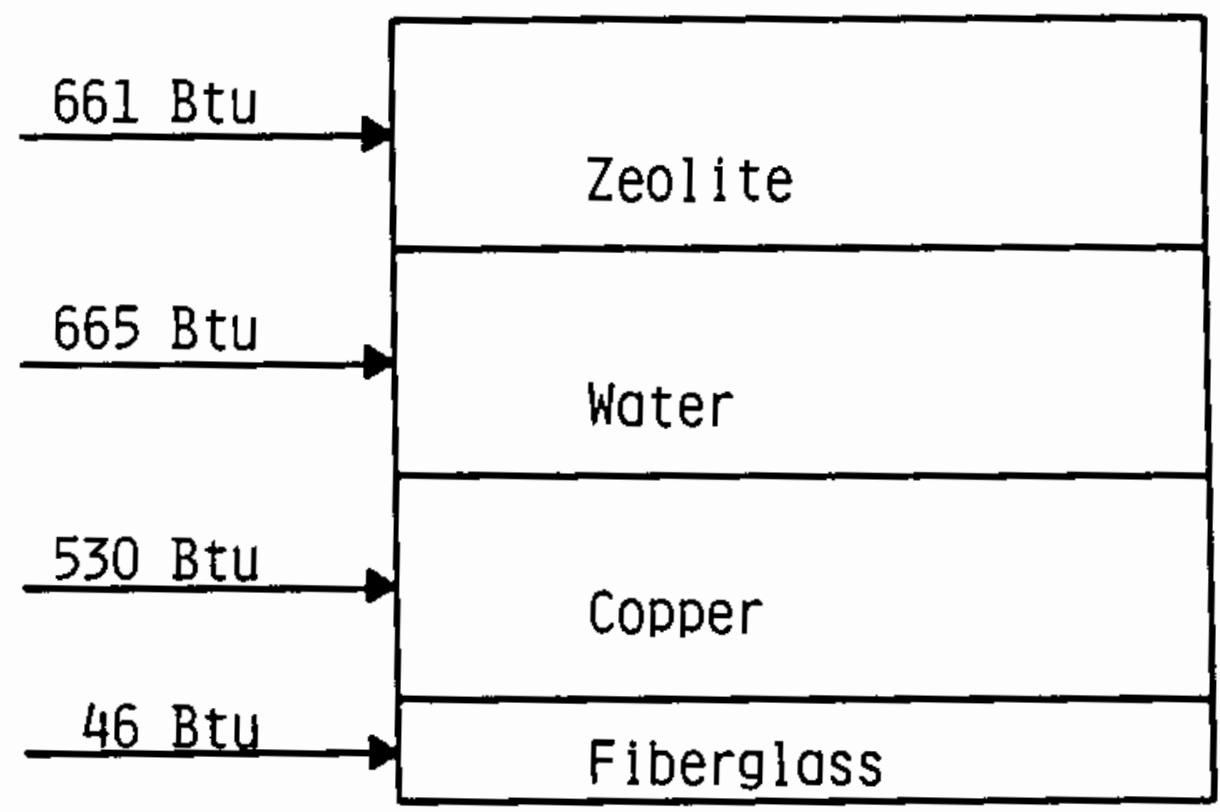

FIGURE 8. Constant Moisture, $56^{\circ} \mathrm{F}$ to $82.7^{\circ} \mathrm{F}, 0.887$ psia to 0.222 psia 


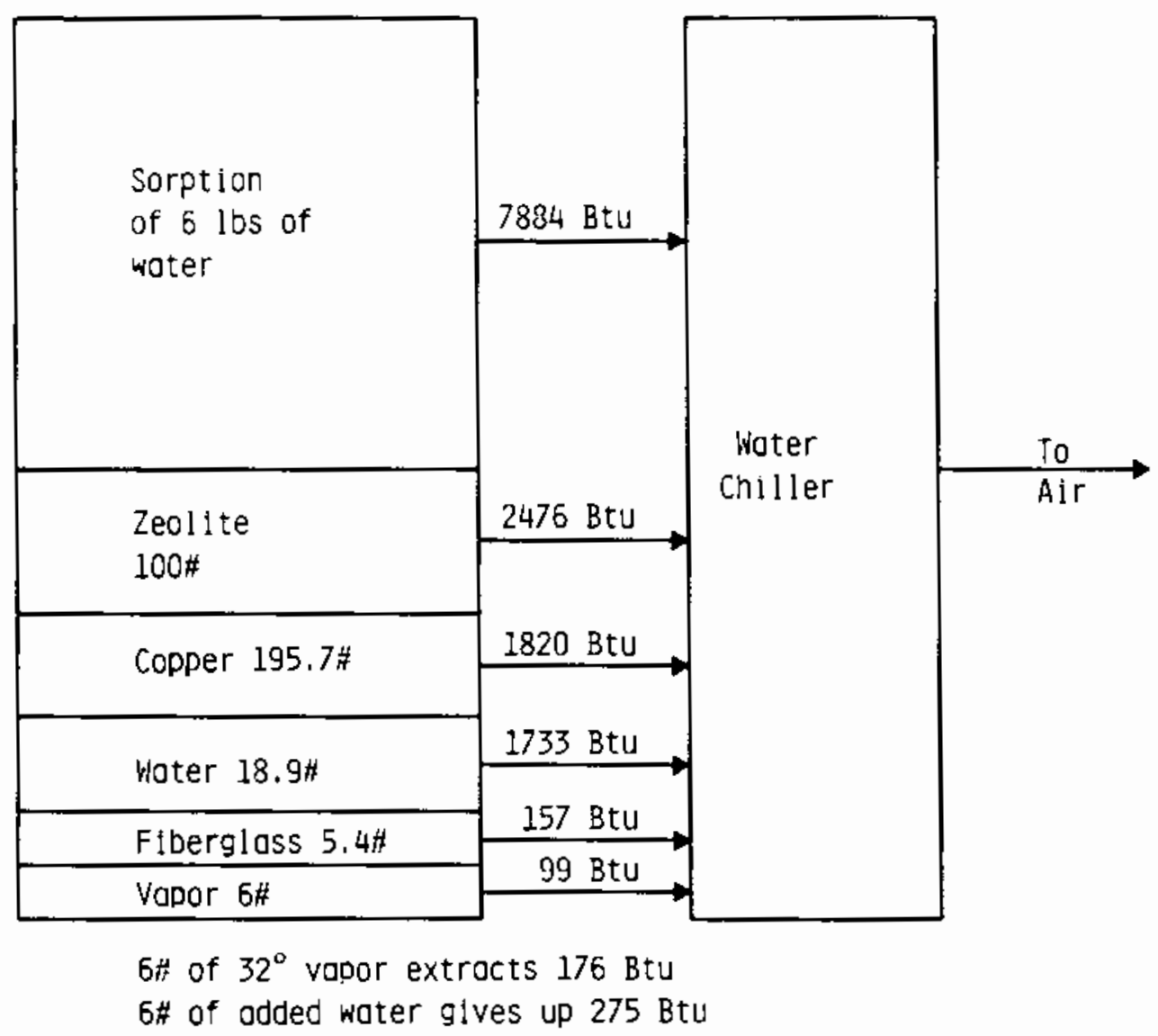

FIGURE 9. Nocturnal Heat Flow $147.7^{\circ} \mathrm{F}$ to $56^{\circ} \mathrm{F}$

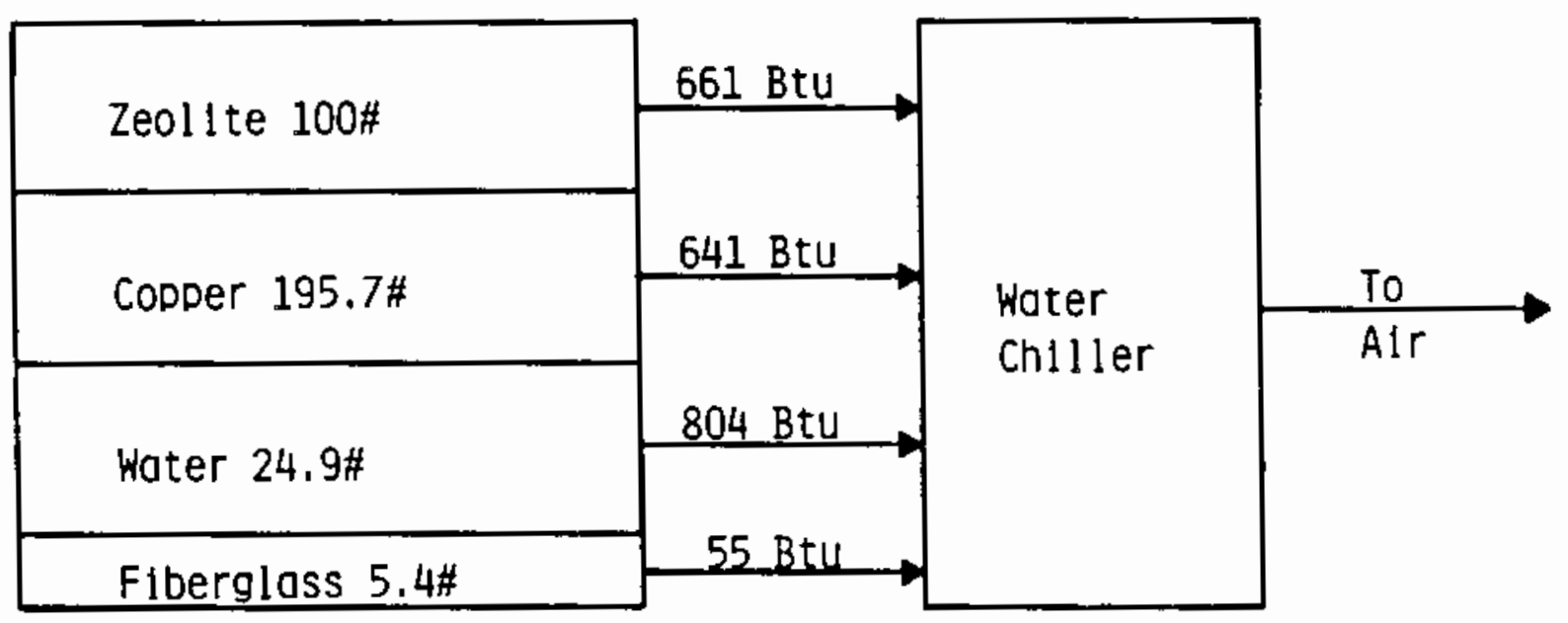

FIGURE 10. Constant Moisture, $180^{\circ} \mathrm{F}$ to $147.7^{\circ} \mathrm{F}, 0.22$ psia to 0.0887 psia 


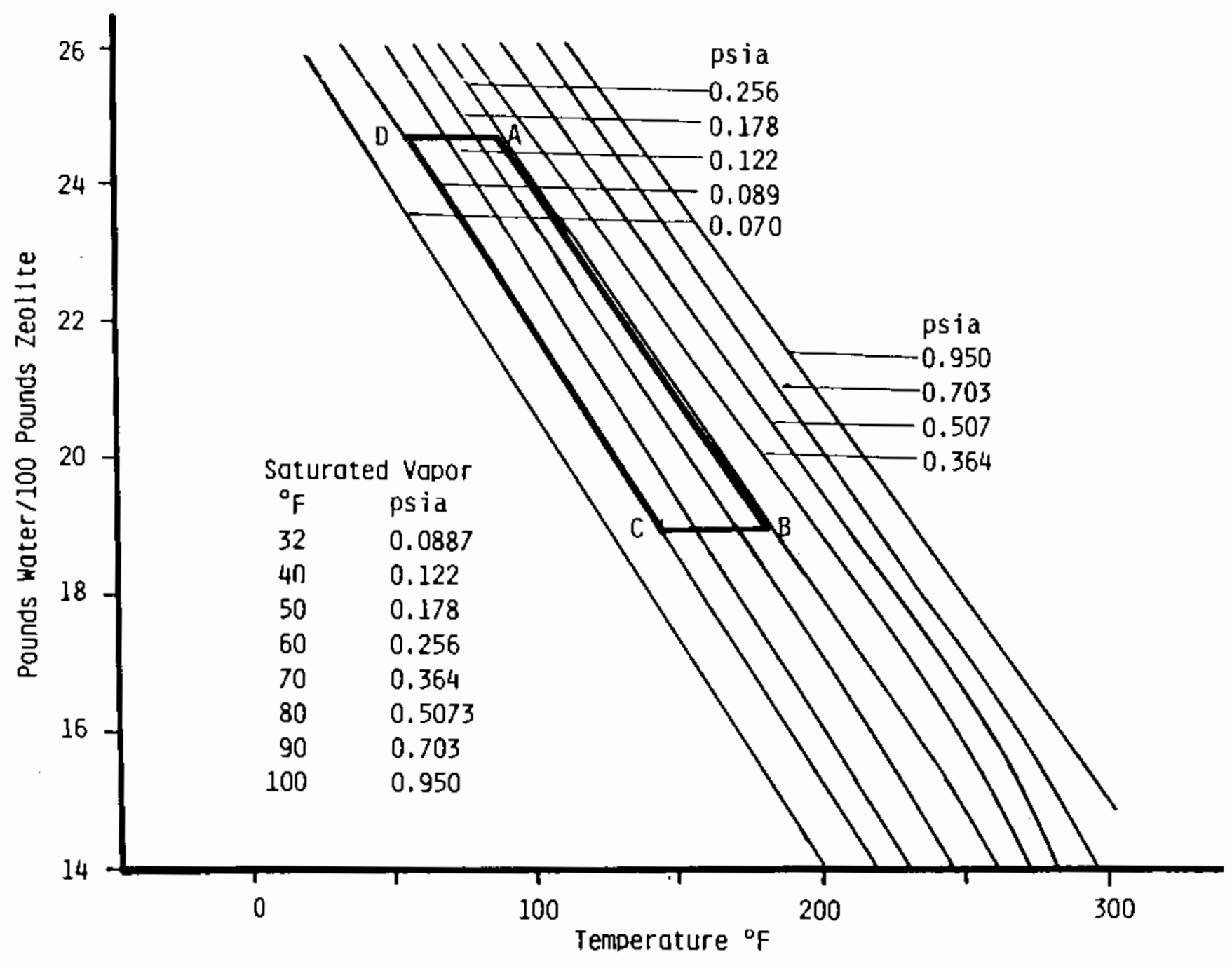

Figure 11. Molecular Sieve 13X Isobars 
vacuum pump was connected to the beaker via a vacuum valve and tubing. The zeolite tube and beaker assembly was pumped to less than 0.4 torr pressure and the valve closed. The zeolite tube was heated by means of heat lamps while the beaker remained cool. Vapor was desorbed from the zeolite, raising the internal pressure, and condensed in the beaker.

Then the lamps were turned off, and the zeolite tube was allowed to cool. As the zeolite tube cooled, it adsorbed the vapor in the systen, causing the pressure to drop. As the pressure dropped to that of boiling at the temperature of the condensate, the condensate began to vaporize and release heat. The temperature of the zeolite and the internal system pressure dropped until the remaining condensate froze.

While not a precision test, the single tube processed 50 cubic centimeters of water when cycled between $75^{\circ} \mathrm{F}$ and $300^{\circ} \mathrm{F}$. Ice was formed and sublimated in the beaker during the zeolite cooling. Since at ambient temperature the zeolite was well below saturation temperature, the water processed was less than it would have been at full saturation.

Each zeofite tube assembly was flushed with distilled water before and after filling with zeolite and vacuum tested, but only the first assembly was run through a series of sorption-desorption cycles.

\section{Manifold-Condenser}

The manifold-condenser section, the most complex subassembly to construct, was prepared for vacuum testing by soldering caps on a11 64 of the 1/2-inch open ends and the open 5 -inch end blocked with a brass plate and gasket. The brass plate had a pipe brazed in that was connected to the vacuum pump. The section was then pumped down to 0.3 torr and monitored for leaks. Leaks were found along the top of the 5-inch cap. Apparently, in cutting the 0.625 -inch diameter holes, small cracks were formed which were too small to see. The manifold was too massive to allow good brazing, but repairs using a combination of sand blasting and soldering were successfut and subsequent vacuum testing showed no leaks. 
Condensate Receiver

The condensate receiver, the 5 -inch by 5 -inch by 3 -inch tee, and the 3-inch vacuum valve were tested for air leaks as a unit with a brass plate and gasket blocking the open end. This section showed no leaks during these tests. In later tests, leaks were found in the bellows part of the vacuum valve and in the gasket around the condensate view window. It is not known when these failures occurred.

The condensate receiver is mounted under the manifold and below the bench. Water circulating through the condenser-manifold tank does not cool the condensate receiver. The condensate receiver should be kept cold to keep condensate from reevaporating. For cooling, four turns of $3 / 8-i$ nch $O D$ copper tubing with a manifold at each end were installed to use chilled water being pumped to the evaporative water chiller sprays.

\section{Ice Tank}

The ice tank was constructed by $T$ and $R$ Mechanical Contractors, Inc., of El Paso, using a 12-inch diameter stainless steel pipe furnished by the New Mexico Solar Energy Institute. It was pumped down to 0.5 torr and the valves closed. It appeared to hold this vacuum indefinitely.

\section{SYSTEMS TESTING}

A vacuum pump was attached to the 1 -inch vacuum valve on the lower part of the manifold. A zeolite water trap, fabricated from 5-inch copper pipe, was inserted between the vacuum valve and the vacuum pump. Pumping was performed in relatively short runs as water desorbed out of the zeolite in the ZCAT facility saturated the drying zeolite in the water trap and infiltrated the pump oil. The sequence was to pump a while, change or dry the zeolite in the water trap, and then pump some more. Several weeks were used to pump the vacuum to a low pressure, turn off the pump, and watch for pressure drift. The daily temperature cycling also caused vacuum pressure cycling so an extended period was required to determine whether leaks were present.

Systems testing for air leaks was performed with a Bell and Howell helium mass spectrometer leak detector borrowed from the Physics Department 
at New Mexico State University. Major leaks were found in the stainless steel bellows, part of the 3 -inch vacuum valve. A copper 3 -inch bellows was purchased and instatled.

Smatl leaks were difficuit to determine or find. The leak detector had to be carefully adjusted to ensure enough sensitivity to show the leaks. Also during this period, the mechanical pump motor and the diffusion pump in the leak detector fajled and were repajred.

Because the unsupported silicone tubes tended to collapse under negative pressure, the zeolite tubes were lowered so that the thermal breaks were each less than 0.5 inches. There was concern that leaks could occur where the silicone tubes were clamped around the 1/2-inch copper tubes.

Small leaks were found along the condensate receiver window and the gasket was replaced with an 0-ring. Further vacuun testing did not reveal any more leaks.

Late afternoon on September 21 the pressure reading was 0.85 torr. The system had been dried and pumped for one month. A 5-gallon jug of distilled water was connected through a $1 / 2$-inch vacuum valve to the bottom of the ice tank. This was done in a manner to minimize any air entering the ice tank. When the 3 -inch vacuum valve was opened, a continuous path was created from inside the ice tank to the zeolite. The vacuum valve was then just cracked open. The water passing through the valve immediately vaporized or froze into snow. The vapors passed through the system and were adsorbed by the zeolite. Loud noise from the vapor indicated a very high flow rate. The water was then allowed to enter at a higher rate and spread out over the bottom of the ice tank. The water boiled at such a high rate that it splashed over the entire inside of the 26.5-cubic foot ice tank. Part of the water froze, part remained, and part was adsorbed into the zeolite. Twelve hours later there was still ice in the ice tank a though the tank was not insulated.

A scaffold was constructed over the zeolite-condenser-manifold system, and $a$ block and tackle was installed at the top of the scaffold. The system was lifted and the bench and other items were moved from the area. The wheeled scaffold was then rolled to the staimell leading down from the 
roof. Next, the fiberglass tank was pushed up onto the system from inside the stairwel1. The system was then returned to the test position; the bench and other test items were placed back into position. The system was lowered onto the bench and reconnected to the rest of the ZCAT facility.

The system was then pumped down to 1.8 torr, all vacuum valves closed, and the pump turned off. During the next three weeks the daity pressure cycling was monitored while the plumbing between the hot water and cold water systems was connected to the zeolitercondenser tank. While the vacuum system showed no leaks, the plumbing connections to the fiberglass tanks were troublesome. Apparently, poor epoxy had been procured and the joints were not holding. A different type of fiberglass resin was obtained and the connections were redone.

\section{TEST AND ANALYSIS}

The evaporative water chilling testing was performed as part of the New Mexico Energy Research and Development Institute (NMERDI) Project 2-71-4224 (Redman 1984). Performance details are given in the final project report to that institute. Copies of that report will be made available upon request.

Other than the magnitude of heat inserted into the zeolite tank, the hot water system was not evaluated. The performance of the solar pane] used is typical of the products of many companies. It was manufactured in Las Cruces by Squires Laboratories-American Products Division.

The 4500-watt, 80-gailon electric water heater, manufactured by the Bradford-white Corporation, was used as a solar water heating system backup heater. Its performance was not evaluated.

Systems testing of the zeolite heat pumping system was initiated on January 30 after extensive testing to assure that there were no air leaks, that the hot and cold water systems were suitable for the tests, and that the zeolite was clean (no gas or other materials blocking the pores). Seventeen test runs were made, critical temperatures were plotted, adsorption and desorption end points were plotted on zeolite isobars, and desorption versus time plots were drawn. Summaries of the 17 tests runs are enclosed in Appendix A. Data were reduced and, along with the above 
plots, are enclosed in Appendix B. Calibration curves and computer programs are enclosed in Appendix C. All data test runs used 20-minute temperature logging interva1s, except for the March 14 run, which was logged at 5-minute intervals. In each isobar plot, points are furnished for the water content in the zeolite at the end of adsorption (points a and b) and desorption (points $c$ and $d$ ). The isobars were extracted from data published by Linde, a Division of Union Carbide. A chart is included to give saturated pressure for eight different temperatures. A chart is also included giving the zeolite water content based on:

a. Ice tank temperature and zeolite temperature at the end of adsorption

b. System pressure and zeolite temperature at the end of adsorption

c. System pressure and zeolite temperature at the end of desorption

d. Condensate receiver temperature and zeolite temperature at the end of desorption

During the adsorption phase, the vapor pressure in the ice tank, and therefore, the entire sealed system, was influenced by the temperature of the water surface in the ice tank. The temperature of the vapor evaporating from the water surface was a measure of the surface temperature after the initial transient condition. Opening the 3 -inch vacuum valve when the zeolite is dry and cool causes a very sudden adsorption of water vapor. This causes an equally fast pressure drop and violent boiling. The pressure drops well below saturation pressure for the temperature of the water. As the boiling continues and the zeolite adsorbs the vapor, the pressure rises, the boiling slows and a stable condition is approached. It is as the system approaches stabilization that the vapor stays at the temperature of the water from which it evaporates. This water temperature was used to obtain saturation pressure from steam charts. These saturation pressures and the temperature measurements of the water cooling the zeolite were used to locate end adsorption points on the isobars. Another point was obtained by means of direct pressure measurements and the above same temperatures of the zeolite cooling water. The assumption here is that as the temperature of the water exiting the zeolite tank is changed very 
little from the temperature of the water entering the tank the zeolite is very close to the temperature of the water.

At the end of desorption phases, the water temperature in the condensate receiver was considered to be close to the temperature of the vapor saturation pressure. The temperature of the condensate was the primary control over the water temperature in the condensate receiver. There was insulation around the receiver and a cooling water coil to minimize any ambient air heating. These were precautions to assure that the receiver was a passive device (that is, that no water would evaporate or vapor condense in the receiver). In this quiet state the vapor pressure was the saturation pressure for the specific temperature. This temperature was then referenced to the saturation line in steam charts and the saturation pressure obtained. The temperature measurements of the hot water flowing through the zeolite tank were used to obtain measures of the zeolite temperature. These pressures and temperatures plotted on zeolite isobars furnished measures of water content in the zeolite. Other points were plotted on the isobars by direct measurements of pressure and temperatures.

The two means of obtaining points for the isobar plots should coincide and did, very closely, for the ends of the adsorption phases. At the end of the desorption phases, the two point plots were typically different by about one pound of water content in the zeolite.

The March 14 data run is used as a specific example of system performance. The March 14 data run can be called an average data run. That is, the measured water processed by the system divided by that theoretically processed was 1.4. The average for 14 data runs was 1.4. The March 14 results were, therefore, not as good as some and better than others. The March 14 data was logged at 5-minute intervals instead of 20-minute intervals like the other data runs, therefore, analysis was easier to perform. All test runs are summarized in Appendix $A$ and the data listings and plots are in Appendix B.

The initial conditions of the March 14 test were 


$\begin{array}{ll}\text { Zeolite tank } & \\ \text { Temperature: } & 83.4^{\circ} \mathrm{F} \\ \text { Water in tank: } & \text { empty } \\ \text { Condenser tank } & \\ \text { Temperature: } & 66.8^{\circ} \mathrm{F} \\ \text { Water in tank: } & \mathrm{full} \\ \text { Circulation rate: } & 0 \mathrm{gpm} \\ \text { Ice tank } & \\ \text { 3-inch vacuum valve: } & \mathrm{closed} \\ \text { Water in tank: } & 220 \mathrm{lbs} \\ \text { Temperature } & 52.2^{\circ} \mathrm{F}\end{array}$

The zeolite isobar plots (see Figure 12) show the zeolite water content at the end of the adsorption phase to be 24.2 pounds using pressure gauge data. At the end of the desorption phase the water content was 20.7 pounds using pressure gauge data. Theoretical water desorption was 3.5 pounds. The measured water desorbed was 5.06 pounds.

At the beginning of the test run, the system was vacuum pumped for 10 minutes. At that point, the pump was turned off, and the oil was changed. The system was then pumped for 8 more minutes. The purpose of this pumping was to purge any "poison" in the zeolites (remove any gas from the zeolites). The data show the system warming caused by the sun shining on the evaporative water chiller system, the zeolite-condenser tank, and the ice tank. At the end of a 30-minute period the conditions of the system were
Zeolite tank
Temperature:
83. $5^{\circ} \mathrm{F}$
Water in tank:
empty
Condenser tank
Temperature:
$76.0^{\circ} \mathrm{F}$
Water in tank:
full
Circulation rate:
0 gpm 
Date: March 14, 1984
a 25.2 1bs/100 Ibs
b $24.21 \mathrm{bs} / 100$ 1bs
c 20.7 lbs/100 lbs
d 21.2 lbs/100 lbs
$b-c=3.51 \mathrm{bs}$
$\mathrm{a}-\mathrm{d}=4.0 \mathrm{lbs}$
measured 5.06 lbs

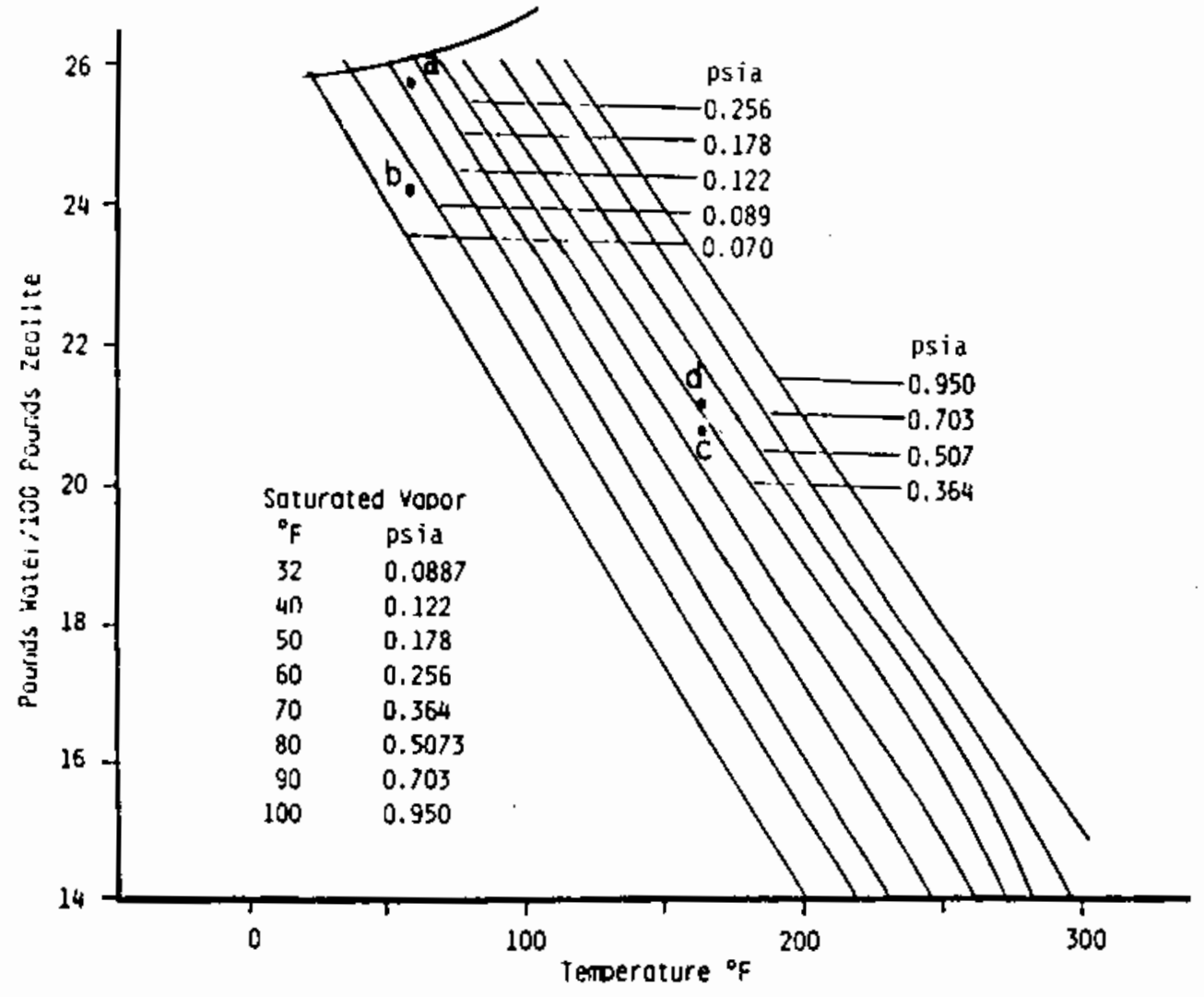

Figure 12. Zeolite Isobars 
Ice tank

$$
\begin{array}{ll}
3 \text {-inch vacuum valve: } & \text { closed } \\
\text { Water in tank } & 220 \text { lbs } \\
\text { Temperature } & 53.4^{\circ} \mathrm{F}
\end{array}
$$

During the first 30 minutes of the March 14 test run, there was no test facility activity other than vacuum pumping. The zeolite tank was empty of water and the water in the condenser tank was not circulating. The vacuum pump was run 18 minutes to purge the system. The 3-inch vacuum valve was closed during this period. During this period, the sun was in a good position for heating the tanks even though there were single layers of a] uminum-covered, 3-inch insulation batts on the zeolite and condenser tanks and two layers on the ice tank. The 3-inch vacuum valve and related piping were not insulated. A $9.2^{\circ} \mathrm{F}$ condenser tenperature rise was, therefore, attributed to solar. The early morning sun was radiating the side of the tank. The condenser tank has a capacity of 4.9 cubic feet; 0.49 cubic feet is occupied by copper pipes, 0.07 cubic feet by iron, and 0.17 cubic feet by rubber. This leaves 4.2 cubic feet for the water. Most of the sensible heat was in the 4.2 cubjc feet (262 pounds) of water. Sensible energy change during the 30-minute preparation phase of the March 14 test run was $262 \times 9.2=2410$ Btu assuming that the entire tank was heated at the same rate. This heat gain cannot be attributed to solar radiation, since the tank was insulated with aluminum covered batting. There is a strong likelihood that water was warmed on the solar side and under the effect of gravity flowed to the top where the thermocouple was located. The zeolite tank thermocouple was in air about 6 inches above the condenser tank thermocouple and showed no temperature change.

The following temperature data are plotted in Figure 13 and the manually recorded data are tabulated in Figure 13 for the adsorption period:

Zeorite input and output water

Condenser mix ( 0 water flow in condenser tank) 
Vacuum punping start Vacuum pumping stop Vacuum pumping start Open 3 inch valve, point a Close 3 inch valve, point $b$ Vacuun pumping stop Start z-tank filling, point $c$ 0855 full of cold water, point d 0904 Hechanical vacuun gauge

stayed below 0 reading from 0820 to 0904 and generally increased to the 0 reading by 1319 . Zero reading was calibrated to be 3.9 torr. Calibration scaling was: reading $\times 3.4 \div 4+3.9$ Open 3 inch valve

Start 2-tank drain, point Start 2 -tank filling

$\omega$ Full of hat water, point i Condenser flowing

Drain: 0.568 lbs

Drain: 0.700 los

Drain: 0.700 lbs

Drain: 0.700 los

Orain: 0.700

Orain: 0.700 los

Orain: 0.700 los

Orain: 0.458 los

Drain: 0.286 lbs

Drain: 0.178 lbs

Drain: 0178 los

Measure of total: 5.06

Adsorption:

cold water flow: $3.5 \mathrm{gpm}$ oesorption:

cold water flow: $3.6 \mathrm{gpm}$ hot water flow: $2.8 \mathrm{gpm}$

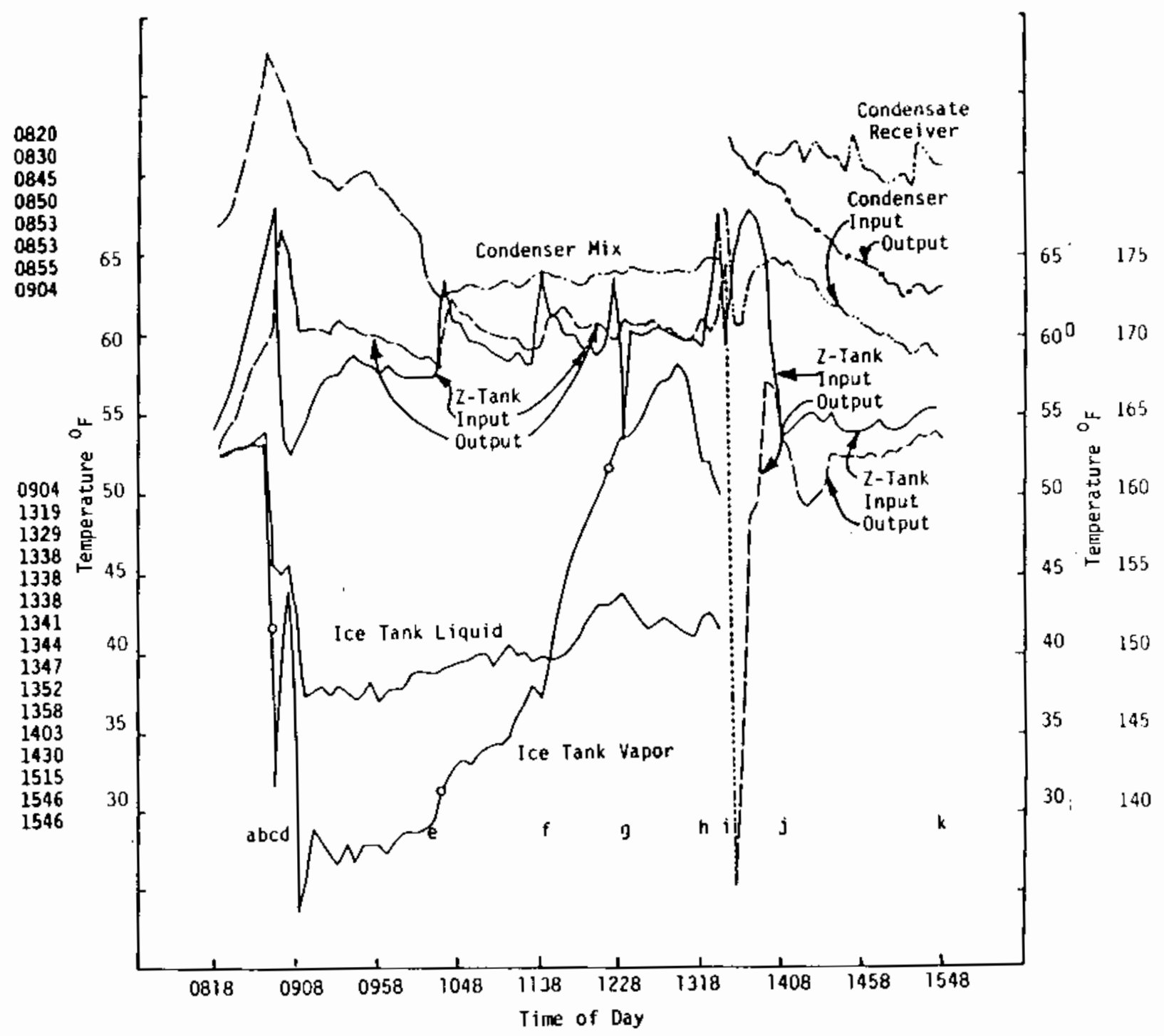

FIGURE 13. Temperatures for March 14 Test Run 
Ice tank water

Ice tank vapor

Because there was no water flow and the temperature transducers are outside the tank, the zeolite tank input and output water temperatures are not significant during the first 30 minutes of system operation. The condenser mix temperature given above is from the condenser mix transducer, which was centered inside the tank about 3 inches from the condenser tank top. The temperature transducers, zeolite mix and condenser mix, are placed to measure water temperatures prior to any infiltration of water across the divider between the zeolite tank and the condenser tank.

At test initiation plus 30 minutes $(T+30$, see point a Figure 13$)$, the 3-inch vacuum valve was opened. The resultant vapor flow could not be directly measured. Failure of the pirani gauge and dependence on the mechanical pressure gauge made it difficult to determine the pressures below 4 torr and the amount of water evaporated could not be measured. The temperature of the bottom of the ice tank near the vapor exit pipe dropped $9^{\circ} \mathrm{F}$ during the 3 minutes the 3 -inch valve was opened and the vacuum pump was on. The valve was closed and the pump was turned off and the 1-inch valve in the pump line closed. The 3 -inch vacuum valve was again opened and the temperature at the bottom of the ice tank dropped another $8.5^{\circ} \mathrm{F}$ within 10 minutes. The temperature leveled off at the end of the second drop at $37.8^{\circ} \mathrm{F}$. The ice tank was about 30 percent full of water at the start of the March 14 test. During the few minutes after opening the 3-inch valve vapor appeared to form at all levels of the water and water splashed over the entire inside of the tank. There is a strong likelihood that this violent boiling kept all the water at the same but rapidly dropping temperature.

At the end of the March 13 test run, there was about 21.2 pounds of water in the zeolite. The vacuum pumping on May 14 could not have lowered the water content much as the March 13 zeolite desorption temperature ended at $156^{\circ} \mathrm{F}$ and the March 14 zeolite temperature during test run initiation was about $40^{\circ} \mathrm{F}$ (ambient air temperature early on March 14 was $36^{\circ} \mathrm{F}$ ). It seems reasonable that most of the vapor released from the water during the 3 minutes the 3 -inch valve was open and the vacuum pump was on, went to the 
zeolite since the zeolite adsorption pumping is far greater than that of the mechanical punp. All of the vapor released from the ice tank went to the zeolite during the 10 minutes following the second opening of the 3-inch valve.

During the 25 minutes after the first 3 -inch valve opening, the ice tank water dropped a total of $16.5^{\circ} \mathrm{F}$ (there appeared to be a $1^{\circ} \mathrm{F}$ rise just before the second opening). Due to the violent boiling along the length of the ice tank, all the water quickly reached a common temperature (the hottest water boiled the most lowering its temperature to the average). The amount of water in the ice tank was not directly measured but from the level it was calculated to be 220 pounds and with the mass of the steel tank the sensible heat capacity was $280 \mathrm{Btu} /{ }^{\circ} \mathrm{F}$. The loss of heat from the tank must have gone with the vapor. Therefore, $280 \times 16.5=4620$ Btu went into vapor. At an average water temperature during this period of $45^{\circ} \mathrm{F}$, the 4620 Btu would evaporate 4.3 pounds of water. As noted above, practically all of this water went to the zeolite even though the pump was on for 3 minutes. The adsorption was, therefore, practically finished within 25 minutes including the 11 minutes between the two openings of the 3-inch valve. The water in the zeolite just prior to the March 14 test run (21. 2 pounds) plus the 4.3 pounds is 25.5 pounds which is within 0.5 pounds of zeolite saturation at the low pressure observed. The zeolite then almost went into saturation during the first 13 minutes that the 3 -inch vacuum valve was open. The adsorption of 4.3 pounds of water would raise the temperature of the zeolite tank filled with water by $79^{\circ} \mathrm{F}$ assuming a sensible heat factor of $70.8 \mathrm{Btu} /{ }^{\circ} \mathrm{F}$ and adsorption of $1300 \mathrm{Btu} /$ pound. since the cooling water was flowing through the filled zeolite tank when the 3-inch valve was opened the second time the high heat dissipation shows up as heat added to the water. The cooling water, flowing at 29.2 pounds/minute, had an initial temperature increase through the tank of $15^{\circ} \mathrm{F}$ which removed the heat at $438 \mathrm{Btu} / \mathrm{minute}$. The heat removal rate dropped as the zeolite temperature dropped and it required over 30 minutes to bring the temperature of the zeolite down to near that of the cooling water. The cooling by the water was complicated by further adsorption and further heating of the zeolite. 
For a period of 220 minutes, there appeared to be some evaporation. Average measured temperature gain of the cooling water over this period was $2.3^{\circ} \mathrm{F}$, and water flow rate was 3.5 gallons per minute. After adsorption was well stabilized, the ice tank water was at $42^{\circ} \mathrm{F}$, indicating an internal system pressure of 0.132 psia and 25.6 pounds of water in the zeolite. There were three operational glitches at points $e, f$, and $g$, shown on Figure 13, and some solar heat was added, making it difficult to develop a good sensible heat and adsorption heat relationship. The glitches were due to adding tap water to the cooling water drainback tank.

The temperature of the ice tank vapor was sampled at the ice tank top next to the 3 -inch exit pipe. Because the 3 -inch pipe and valve were not insulated, heat from the sun and the ambient air heated the pipe and, therefore, the vapor and the water below. As the water warmed, there was a small amount of evaporation which cooled the water keeping the water at about $37.5^{\circ} \mathrm{F}$ for 60 minutes. After that, there was so little activity in the system that the temperatures around the ice tank appeared to drift with solar gain. As the ice tank water and vapor temperatures approached $40^{\circ} \mathrm{F}$, the sun began to shine on the 3-inch piping, causing a large rise in vapor temperature and some rise in water temperature. As the sun passed on, the vapor temperature dropped again. This anomaly was not noted until too late to correct for it by adding more insulation. The rise in vapor pressure should not have affected the test results, but the related rise of about $2^{\circ} \mathrm{F}$ in water temperature may have had a small impact.

At $T+300$ minutes, the cooling water was drained from the zeolite tank and replaced with hot water. This procedure took about 20 minutes and was complete by $T+320$ minutes; point $i$, Figure 13 . The dashed 1 ines in the $Z$-tank (zeolite tank) input and output curves show a scale change to the high temperature scale.

The ice tank temperature plots were terminated at the end of the adsorption period as the 3-inch valve was closed and the ice tank was sealed from the rest of the system. The condensate receiver temperature plot was initiated at start of desorption along with the condenser tank input and output temperature plots. Cooling water was pumped through the 
condenser tank during desorption, making the input and output temperature measurements valid.

The Z-tank input temperature changed from $59.3^{\circ} \mathrm{F}$ at $T+300$ minutes to $175^{\circ} \mathrm{F}$ at $\mathrm{T}+320$ minutes. The output temperature changed from $61.1^{\circ} \mathrm{F}$ to $124^{\circ} \mathrm{F}$ over the same period. The zeolite tank temperature readings are given in Table 3 for the critical period from $T+320$ to $T+345$ minutes, points $i$ to point $j$ on Figure 13 .

The temperature of the hot water was about $180^{\circ} \mathrm{F}$ at the initiation of the desorption phase, dropped to $163.5^{\circ} \mathrm{F}$ within 30 minutes, and recovered to $165.5^{\circ} \mathrm{F}$ by 25 minutes. This shows the need for a large reservoir of hot water.

During the period from $T+320$ to $T+345$, Table 3 , the $Z$-tank heating water flow rate was 2.8 gallons per minute. Based on this flow rate and the temperature changes, the heat input was calculated and listed in Table 3. After the initial 25-minute period, 5236 Btu were added for a total of 17,403 Btu.

The condenser tank temperature readings are given in Table 4 for the critical period from $T+320$ to $T+345$ minutes, point $i$ to point $j$ on Figure 33 . During the critical period, 5349 Btu were removed in the condenser. Figure 14, "Desorption Response," shows that during this period 4.5 pounds of water was desorbed, condensed, and removed from the condensate receiver. Condensation required about $4725 \mathrm{Btu}$. There was also an average of about $1^{\circ} \mathrm{F}$ of cooling of the condenser during this period. The desorption was 82.6 percent complete in 25 minutes.

The solid line in Figure 14 is a plot of the condensate drained from the condensate receiver with respect to time. Immediately before the condensate was drained, the test operators recorded time and the condensate level as viewed through the condensate receiver window. often early in desorption, the level rose above the top of the window. When this occurred. the precise position of the level was not known. The operator-recorded data is tabulated on Figure 13 for the March 14 test run. Figure $\mathrm{C}-2$ is the calibration for these points. For example, water volume at level 10 of $\mathrm{C}-2$ is 258 cubic centimeters. The circled points are the condensate as measured by graduated cylinder. There was a 5/16-inch copper 
TABLE 3. Zeolite Tank Temperature and Heat Input Data, March 14, 1984

\begin{tabular}{|c|c|c|c|c|}
\hline $\begin{array}{l}\text { Time } \\
\text { Minutes }\end{array}$ & $\begin{array}{l}\text { Input } \\
{ }^{\circ} \mathrm{F} \\
\end{array}$ & $\begin{array}{c}\text { Output } \\
{ }^{\circ} \mathrm{F} \\
\end{array}$ & $\begin{array}{c}\text { Differential } \\
{ }^{\circ} \mathrm{F}\end{array}$ & $\begin{array}{l}\text { Heat } \\
\text { Input } \\
\text { Btu }\end{array}$ \\
\hline$T+320$ & 175 & 124 & 51.0 & \multirow{3}{*}{$\begin{array}{r}-4,951 \\
-3,117\end{array}$} \\
\hline$T+325$ & 177.1 & 143.4 & 33.7 & \\
\hline$T+330$ & 177.9 & 158.3 & 19.6 & \\
\hline$T+335$ & 177.1 & 159.6 & $17.5 \mid$ & 2,172 \\
\hline$T+340$ & 174.6 & 167.1 & $7.5\}$ & \multirow{2}{*}{$\begin{array}{r}1,460 \\
467\end{array}$} \\
\hline$T+345$ & 167.1 & 166.7 & 0.4 & \\
\hline & & Total & & 12,167 \\
\hline
\end{tabular}

TABLE 4. Condenser Tank Temperature and Heat Remova 1 Data, March 14, 1984

\begin{tabular}{ccccr} 
Time & $\begin{array}{c}\text { Input } \\
\text { Minutes }\end{array}$ & $\begin{array}{c}\text { Output } \\
{ }^{\circ} \mathrm{F}\end{array}$ & $\frac{{ }^{\circ} \mathrm{F}}{\text { Differential }}$ & $\begin{array}{c}\text { Heat } \\
\text { Removed }\end{array}$ \\
\hline $\mathrm{T}+320$ & 60.6 & 71.7 & ${ }^{\circ} \mathrm{F}$ & $\frac{11.1}{\text { Btu }}$ \\
$\mathrm{T}+325$ & 60.6 & 71.3 & 10.7 & 1,591 \\
$T+330$ & 63.4 & 70.4 & 7.0 & 1,292 \\
$T+335$ & 64.3 & 70.2 & 5.9 & 941 \\
$T+340$ & 64.4 & 69.7 & 5.3 & 708 \\
$T+345$ & 65.0 & 69.4 & 4.4 & 5,349
\end{tabular}




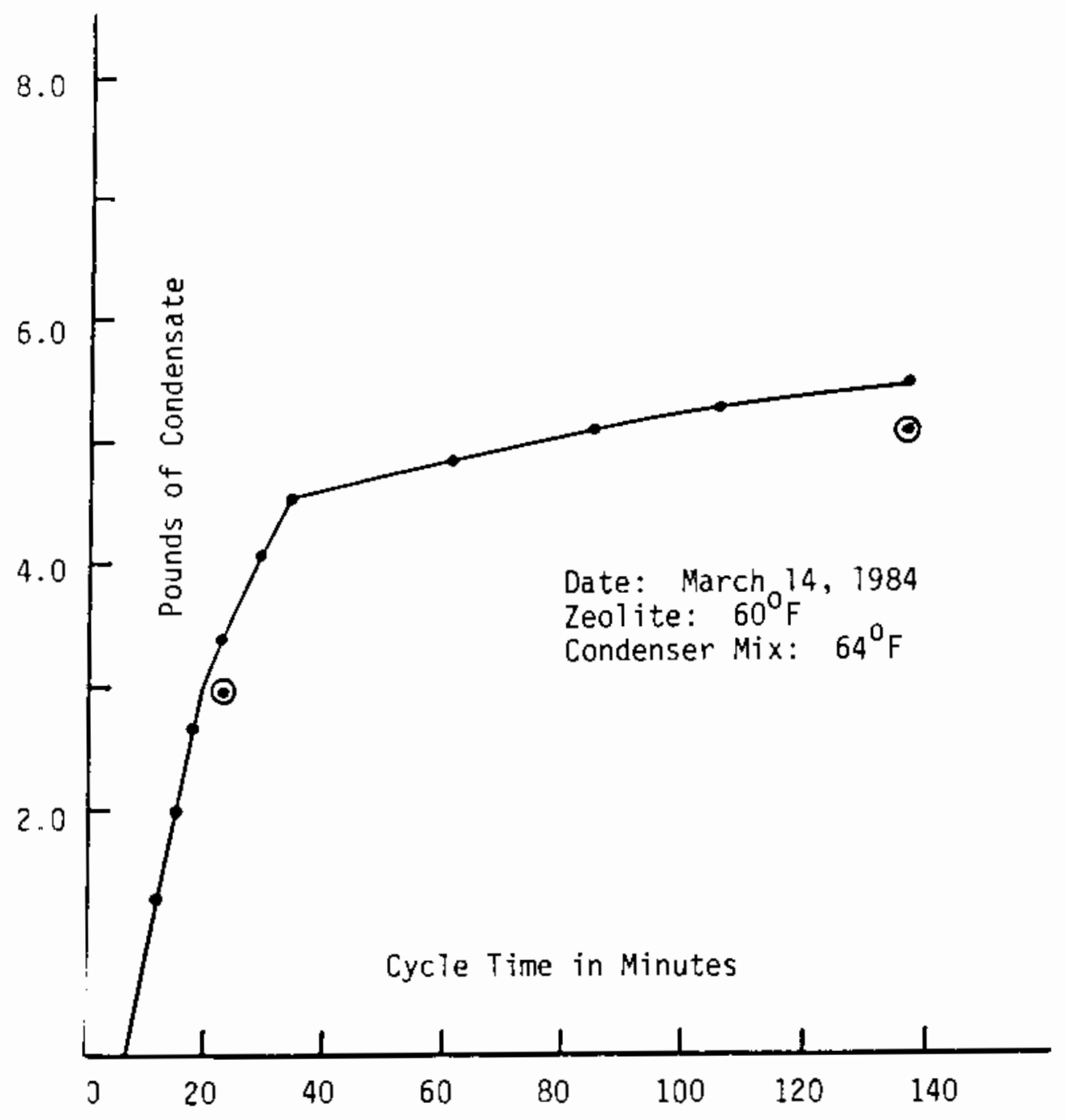

FIGURE 14. Desorption Response

line to drain the condensate receiver. Near the drain point there was a vacuum valve. After the vacuum valve, the drain line continued for about 2 feet to a gallon glass jug via a sealing stopper. There was a second vacuum valve between the jug and the pump. Prior to draining any condensate, the vacuum pump was used to evacuate air from the gallon jug. Both of the 5/16-inch valves were then closed. Periodically the test operator recorded the condensate level and the time, and opened the 5/16-inch valve next to the condensate receiver. The condensate ran into 
the jug without allowing any air to enter the system. During the March 14 test run, the water collected in the jug was twice poured into a graduated liter cylinder for measurement. It was initially planned to use a peristaltic pump for this purpose. It did not work. Or. Liefeld of the Physics Department suggested the jug approach and it worked very wel1. The condenser mix temperature was close to $64^{\circ} \mathrm{F}$ during the desorption period. It is given in Table B-15 but was not plotted on Figure 13. During desorption, it started at $63.9^{\circ} \mathrm{F}$, went up to $68.5^{\circ} \mathrm{F}$ and at the end had dropped to $59.5^{\circ} \mathrm{F}$.

Figure 12 presented earlier in this section, gives the zeolite isobars and end points for adsorption and desorption. Points $a$ and $b$ are based on the final adsorption phase zeolite temperature of $60^{\circ} \mathrm{F}$. Point a is aiso based on the ice tank water temperature $\left(41.5^{\circ} \mathrm{F}\right)$. Point $b$ is also based on the pressure gauge measurement (less than 3.9 torr, 0.075 psia) (this pressure is discussed farther below). The ice tank water temperature was cycling about the $42^{\circ} \mathrm{F}$ level and saturation pressure was, therefore, indicated to be 0.132 psia. Point a is a plot of $60^{\circ} \mathrm{F}$ and 0.132 psia, which gives a water reading of 25.2 pounds. An estimated 0.082 psia was plotted on the $60^{\circ} \mathrm{F}$ line, giving 24.2 pounds of water, point $b$ on Figure 12. Points $c$ and $d$ are based on the final desorption phase zeolite temperature of $164.5^{\circ} \mathrm{F}$, a mechanical gauge reading of 14.5 torr (point $c$ ), and a condensate receiver temperature of $71^{\circ} \mathrm{F}$ (point d). The calibrated pressure reading was 16.22 torr (0.314 psia). Point c of Figure 12 shows that the zeoljte should contain 20.7 pounds of water at $164.5^{\circ} \mathrm{F}$ and 0.314 psia at thermal balance. The saturation vapor pressure at $71^{\circ} \mathrm{F}$ condensate receiver temperature is 0.3763 psia. At $164.5^{\circ} \mathrm{F}$, this plots at point $d$, which is 21.2 pounds of water. Points $d$ and $c$ differ by 0.5 pounds. Point $b$ to point $c$ gives a change in water in the zeolite of 3.5 pounds; point a to point d gives 4.4 pounds. During desorption, 5.06 pounds of water were drained from the system.

The pirani gauge used a hot wire for measuring pressure and did not prove satisfactory. Five of the sensors were procurred as they failed so often and in December 1983 the electronics failed. The mechanical pressure gauge was then substituted for the pirani. Figure $c-3$ gives the 
calibration points and best straight line plot. The line follows the equation: corrected value equals $3.9+3.4 / 4 \times$ reading. The 15 points were obtained by bringing water in the condensate receiver just to the vaporization temperature, measuring the temperature of the receiver close to the water line, and obtaining the saturation pressure from the steam charts. Fifteen different temperatures were obtained and, thereby, 15 pressure points. Tests run on January 31, February 2, February 28, and March 6 all had ice in the ice tank so when vaporization reached a very low level during adsorption, the presssure had to be very close to 0.0887 psia. These points confirm the calibration down to 0.0887 psia (4.6 torr). At the end of the March 14 test run adsorption phase, the pressure gauge indicated below 0.075 psia. However, since the gauge readings did not have much significance below 0.0887 psia and there was no ice in the tank at the end of adsorption it is reasonable to believe that the pressure was very little below 0.0887 psia. A pressure of 0.082 psia is not an exact figure, but is as close as could be estimated for the end of the adsorption phase.

The large $\Delta T$ early in a desorption between the vapor and the bottom of the ice tank illustrates a limitation to the speed of system response. For about 70 minutes, the vapor was below $32^{\circ} \mathrm{F}$. Boiling sometimes appeared to be from the bottom of the ice tank as at times water errupted and splashed over the inside of the tank.

A hey instrument that was not available for this project was a vapor flowmeter. At the time of the proposal, none could be found to measure bidirectional flow of vapor down to 0.05-psia pressures. Therefore it is not directly known when adsorption and desorption reached zero. At $T+204$ minutes the ice tank vapor temperature and the temperature at the bottom of the ice tank were equal, indicating that there was no $\Delta T$ vertically through the water. The vapor flow must have been close to zero at that point. This is 159 minutes after the vacuum valve was opened.

Table 5 summarizes all the test runs. Detailed data for these runs are in Appendix A. Apparently zeolite "poisoning" was a severe problem in runs made on February 2, 7, and 28, and March 11, 1984, as water processed was very low. Poisoning is analogous to decreasing the amount of zeolite in the system. That is, the water vapor does not have access to many of 
the pores in the zeolite. The three runs made consecutively on February 28 were unsatisfactory in that very little water was processed when the adsorption and desorption were run in 1-hour phases. Referring to Figure 14, which uses March 14 data, the desorption should be 83 percent complete by the end of 25 minutes; thus a 60-minute run should be close to 90 percent complete. This indicates that desorption times for the February 2, 28, and March 11 tests should not have had a significant impact on the amount of water processed. More testing of the nature of the February 28 test runs needs to be performed since muttiple cycles per day can greatly increase the value of the system.

Table 5 furnishes differential temperatures between the hot water and the cooling water and between the hot water and the condensate. These differences were taken toward the end of the desorption periods when desorption was nearly complete and temperatures and pressures were assumed to be comparatively steady. The desorption of water from the zeolite is a direct function of the zeolite temperature and an inverse function of pressure. Maximum desorption requires a high temperature and a low pressure. The hot water sets the temperature of the zeolite. The cooling water causes the desorbed vapor to condense and, thereby, the pressure is kept low. The cooler the water, the lower was the pressure. A large differential is, therefore, desired to maximize the zeolite drying. The condensate receiver temperature and its relationship to the other temperatures is important in that if it becomes too high, there would be a tendency for the condensate to reevaporate.

Desorption typically occurred very fast during the first 30 minutes and then slowed. During the testing, the operators watched the condensate receiver water Tevel. When it appeared that condensation had finished, the operators terminated the tests. As shown $n$ Table 2, the desorption time averaged 116 minutes but was as fast as 47 minutes and as slow as 183 minutes. One factor of desorption which has not yet been analyzed is that in many cases, after desorption appeared to be finished and the hot water was draining, additional condensate would run into the receiver.

once the ZCAT facility was found to be free of air leaks and PVC plumbing was properly attached to the fiberglass tanks, the primary 
TABLE 5. Test Summary

\begin{tabular}{|c|c|c|c|c|c|c|c|c|c|c|c|c|}
\hline & & & & & & & $\mathrm{Hot} / 5$ & Hot ${ }^{6}$ & & & & \\
\hline & & & & & & & Cold & Water/ & & Vacuum & Ice $\tan k^{8}$ & Ice $\operatorname{tank}^{9}$ \\
\hline & Hot Water 1 & & ure & & & Condensate ${ }^{4}$ & Water & Receiver & Desorption 7 & Pump & Vapor & Water \\
\hline & Temperature & Adsorp & sorption & & & Receiver & $\Delta$ & $\Delta T$ & Time & Time & Low/high & Low/high \\
\hline Date & ${ }^{\circ} \mathrm{F}$ & ${ }^{\circ} \mathrm{F}$ & ${ }^{\circ} \mathrm{F}$ & Measured & retical & ${ }^{\circ} \mathrm{F}$ & ${ }^{\circ} \mathrm{F}$ & ${ }^{o} \mathrm{~F}$ & Minutes & Minutes & ${ }^{\circ} \mathrm{F}$ & ${ }^{\circ} \mathrm{F}$ \\
\hline $1 / 30 / 84$ & 163 & 43 & 51 & 10.4 & 5.8 & 52 & 112 & 111 & 141 & $30^{10}$ & $49 / 53$ & $48 / 48$ \\
\hline $1 / 31 / 84$ & 162 & 47 & 53 & 6.85 & 5.1 & 61 & 109 & 110 & 173 & 29 & $38 / 58$ & $36 / 42$ \\
\hline $2 / 2 / 84$ & 164 & 50 & 55 & 5.64 & 4.9 & 61 & 103 & 103 & 193 & 56 & $33 / 63$ & $37 / 44$ \\
\hline $2 / 7 / 84$ & 165 & 54 & 63 & 4.3 & 4.9 & 62 & 102 & 103 & 52 & 0 & $36 / 54$ & $39 / 57$ \\
\hline $2 / 10 / 84$ & 167 & 55 & 67 & 6.4 & 5.3 & 69 & 100 & 98 & 81 & 0 & $45 / 56$ & $49 / 59$ \\
\hline $2 / 14 / 84$ & 164 & 53 & 65 & 6.8 & 4.4 & 68 & 98 & 96 & 119 & $30^{10}$ & $38 / 56$ & $41 / 57$ \\
\hline $2 / 18 / 84$ & 152 & 49 & 57 & 5.2 & 4.2 & 60 & 95 & 92 & 79 & 30 & $39 / 56$ & $43 / 53$ \\
\hline $2 / 24 / 84$ & 158 & 50 & 62 & 6.0 & 4.3 & 66 & 96 & 92 & 120 & $27^{10}$ & $46 / 55$ & $51 / 57$ \\
\hline $2 / 28 / 84$ & 160 & 47 & 49 & 0.8 & & 52 & 111 & 108 & 66 & 60 & $49 / 54$ & $40 / 47$ \\
\hline & 153 & 57 & 55 & 1.2 & & 57 & 98 & 96 & 61 & 0 & $53 / 58$ & $43 / 55$ \\
\hline & 149 & 55 & 51 & 1.4 & & 54 & 98 & 95 & 52 & 0 & $51 / 63$ & $43 / 58$ \\
\hline $3 / 1 / 84$ & 151 & 57 & 59 & 6.2 & 4.0 & 64 & 92 & 87 & 89 & $45^{10}$ & $59 / 62$ & $63 / 64$ \\
\hline $3 / 6 / 84$ & 146 & 43 & 49 & 5.5 & & 50 & 97 & 96 & 106 & 38 & $25 / 54$ & $33 / 40$ \\
\hline $3 / 11 / 84$ & 139 & 54 & 54 & 1.6 & 3.2 & 67 & 85 & 72 & 120 & 10 & $42 / 52$ & $47 / 51$ \\
\hline $3 / 12 / 84$ & 132 & 55 & 56 & 4.7 & 1.6 & 66 & 76 & 66 & 120 & $32^{10}$ & $29 / 41$ & $41 / 45$ \\
\hline $3 / 13 / 84$ & 157 & 55 & 60 & 4.7 & 3.1 & 70 & 97 & 87 & 130 & 46 & $29 / 42$ & $38 / 41$ \\
\hline $3 / 14 / 84$ & 159 & 68 & 63 & 5.1 & 3.6 & 72 & 96 & 87 & 137 & 18 & $24 / 58$ & $37 / 44$ \\
\hline
\end{tabular}




\section{Table 5 Notes}

1. Temperature just before the end of desorption; thermocouple 02 .

2. Temperatures just before the end of adsorption and desorption. Adsorption is from thermocouple 02 . Desorption is from thermocouple 17 except for March 11, 12, 13, and 14 which are from thermocouple 00.

3. Water processed was measured using a graduated cylinder and estimated using the zeolite isobar plots.

4. Temperature just before the end of desorption; thermocouple 06 .

5. Column 1 minus column 3 .

6. Column 1 minus column 6 .

7. Time the system was in the desorption phase. It was terminated when the test operators saw no additional water entering the condensate receiver.

8. Thermocouple 20 data during adsorption.

9. Thermocouple 19 data during adsorption.

10. Eight hour vacuum pumping before the test. The minutes of pumping given in this column for each date were done the morning of the test and typically included opening the 3 -inch vacuum valve for a short period. 
operational problems involved water flow adjustments and water pumps. The hot and cold water flows had to be adjusted carefuliy and were sometimes readjusted both to keep hot and cold water from mixing at the condenser tank-zeolite tank interface and to keep the zeolite tank full but not overflowing. The general design of the zeolite, condenser, and manifold sections was adequate. However, the sections should be installed in a manner that allows some differential pressurization of the two tank sections without mixing hot and cold water and without overflowing the zeolite tank.

The system to freeze water in the ice tank by means of nocturnal radiation was completed but not tested.

\section{Electrical Analysis}

Electrical input (January 30, 1984)

$\begin{array}{ll}\text { Cooling water flow rate } & 3.3 \mathrm{gpm} \\ \text { Spray water flow rate } & 0.5 \mathrm{gpm} \\ \text { Hot water flow rate } & 3.0 \mathrm{gpm} \\ \text { Air flow rate } & 485 \mathrm{cfm} \\ \text { Adsorption phase } & 250 \text { minutes } \\ \text { Desorption phase } & 119 \text { minutes }\end{array}$

From pump manufacturer's literature Cooling water pressure rise 8 feet Spray water pressure rise 27 feet Hot water pressure rise 12 feet

Adsorption phase energy (water pumps):

$3.3 \mathrm{gpm} \times 8.34 \mathrm{ib} / \mathrm{gal} \times 8 \mathrm{ft} \times 0.0012 \mathrm{~B} 54 \mathrm{Btu} / \mathrm{ft}$ lb per min $\times 250 \mathrm{~min}+0.5$ $\times 8.34 \times 27 \times 0.0012854 \times 250=70.75+36.18=106.93 \mathrm{Btu}$.

Desorption phase energy (water pumps):

$119 \div 250 \times 106.93+3 \times 8.34 \times 12 \times 0.0012 B 54 \times 119=50.90+45.93=$ $96.83 \mathrm{Btu}$. 
Total fan energy:

$485 \mathrm{ft}^{3} / \mathrm{min} \times 0.0648 \mathrm{lb} / \mathrm{ft}^{3} \times 0.167 \mathrm{ft}$ (water) $\times 62.4 \mathrm{lb} / \mathrm{ft}^{3}$ (water) $\div$ $0.0648 \mathrm{lb} / \mathrm{ft}^{3}$ (air) $\times 0.0012854 \mathrm{Btu} / \mathrm{ft}$ lb per min $x(250+119)=2,397$ Btu.

Total electrical energy $=106.93+96.83+2,397=2,602$ Btu (rounded off)

Energy pumped from the $48^{\circ} \mathrm{F}$ ice tank water was:

$10.4 \mathrm{lb}$ (vaporized) $\times 1,066.4 \mathrm{Btu} / \mathrm{lb}=11,091 \mathrm{Btu}$. $\operatorname{COP}=11,091 / 2,602=4.3$ (electrical)

The fan efficiency was 40 percent and the pump efficiencies were about 6 percent. The pump efficiencies can be boosted to 60 percent by use of better pumps, but pump energy is only 7.8 percent of the total electrical energy Jsed. A big improvement would come by decreasing the static air impedance through the evaporative water chiller. If this is done by using two heat exchangers, instead of one, the energy requirement drops to 50 precent of present use. This would increase the electrical cop to 8.6. 


\section{PROPERTIES OF ZEOLITES FOR ADSORPTION REFRIGERATION SYSTEMS}

The principal uses for natural or synthetic zeolites and molecular sieves are for ion exchange and as substrates for heterogeneous catalys is (typically gas phase cracking of petroleum hydrocarbons). A secondary use has been as desiccants, but in the latter applications silica gel and activated alumina have been preferred because of their lower cost. Typical costs are 5 to 8 cents per pound for silica ge 1 and 15 to 18 cents per pound for activated alumina in carload lots versus about $\$ 2.09$ per pound in carload lots for the Linde $13 \mathrm{X}$ molecular sieve used in the experimental test equipment at the New Mexico Solar Energy Institute. The Linde $13 \mathrm{X}$ has a tailored, controlled structure. It is a sodalite-type structure in which the $\mathrm{SiO}_{4}$ and $\mathrm{AlO}_{4}$ tetrahedral groups link to form truncated octahedra having six square faces and eight hexagonal faces. This structure has very low density and is capable of containing about 28 to 30 weight percent of water ( 0.17 to $0.2 \mathrm{ft}^{3}$ of $\mathrm{H}_{2} \mathrm{O}(l)$ per bulk $\mathrm{ft}^{3}$ adsorbent) at a water vapor pressure of about 17.5 torr (about 0.34 psia, the saturation pressure of water at $68^{\circ} \mathrm{F}$ ). It will hold up to $35-40$ weight percent of water when saturated by immersion.

The constraints on the temperature cycling of the adsorbent using evaporatively cooled water and a flat-plate solar energy collector under ambient summer conditions in Las Cruces are about $65-70^{\circ} \mathrm{F}\left(18-21^{\circ} \mathrm{C}\right)$ minimum to $200-205^{\circ} \mathrm{F}\left(93-96^{\circ} \mathrm{C}\right)$ maximum, which give about a 6 -pound change in water content per 100 pounds of zeolite on top of 19 pounds of preadsorbed ("dead") water on the oxide substrate when making ice. A siightly greater change, 6- to 7-pounds in water content per 100 pounds of zeolite occurs when making $50^{\circ} \mathrm{F}$ cool water. The expected amounts and ranges of water adsorption are based on isotherms supplied by Union Carbide Corporation, manufacturer of Linde $13 x$.

The $X$-type molecular sieves have, as a class, the greatest gross water adsorption capacity. The natural faujasites and $Y$-type molecular sieves have structures very similar to $x$-type, and may, on the basis of cost comparisons, be candidates for direct substitution for the Linde $13 x$ $(x$-type) selected for the demonstration system. 
Faujasite-type zeolites, which are topologically similar to the $X$ and $Y$ type synthetic zeolites, have a high and fairly uniform energy of adsorption after the first two layers of water have been adsorbed. About 50 percent of the crystal volume in the dehydrated state is voids. The theoretical pore diameter is 8 to 10 angstroms, compared to a dynamically effective average $\mathrm{H}_{2} \mathrm{O}$ molecular diameter of 3.9 angstroms. The molecular sieve chosen for the demonstration unit, Linde 13X, operates in the water vapor pressure range of 4 to $10 \mathrm{mmHg}$.

The open, definite, structures of the crystalline molecular sieves such as Linde $13 X$ are advantageous and worth the cost compared to silica gel or activated alumina in gas phase catalysis of reactions involving large molecules. However, it is worth evaluating whether or not the simpler service for water adsorption requires the added control and cost of such a "tailored," crystalline structure. For simple water adsorption, detailed structural specifics hardly matter as long as the pores will admit the relatively small water molecule. Adsorption of water by aluminosilicates will be structure sensitive, varying as the average diameter of a water-containing pore is changed. However, adsorption will not show as great a structural sensitivity as chemically active catalytic centers typically show toward structural changes.

The vapor pressure of adsorbed water on the surface of a porous solid depends on two main properties: the intrinsic energy of surface adsorption and the diameter of the pores in which the water is adsorbed. The effect of the intrinsic energy (enthalpy) of adsorption on vapor pressure is described by the Clausius-Clapyron equation where $\Delta H^{\text {vap }}$ of bulk liquid is replaced by $\Delta \underline{H}^{\text {des }}$, the heat of desorption from the surface:

$d\left(\ln p^{\text {des }}\right) / d T \cong \Delta H^{\text {des }} / R T$

for low pressures, in the range of practical interest for refrigerative adsorption applications. The integrated form of this equation, assuming $\Delta H^{\text {des }}$ is not a function of temperature, is 


$$
\text { In }\left[P^{\text {des }}\left(T_{2}\right) / P^{\text {des }}\left(T_{1}\right)\right]=\left[-\Delta \underline{H}^{\text {des }} / R\right]\left[1 / T_{2}-1 / T_{1}\right] \text {. }
$$

Since $\Delta \underline{H}^{\text {des }}$ is a function of $T$, the foregoing equation is only approximately valid, but is satisfactory for engineering calculations when:

(1) $T_{1}$ and $T_{2}$ are not "too far" apart,

(2) $T_{c}>\sim 1.3 \times\left(T_{1}\right.$ or $\left.T_{2}\right)$, whichever of $T_{1}$ and $T_{2}$ is higher, where $T_{c}$ is the critical temperature of the fluid being adsorbed,

(3) $\underline{V}_{\text {vapor }}$ per unit mass (mola) $>\underline{V}_{\text {liquid }}$ per unit mass (mole), and (4) the vapor behaves nearly like an ideal gas.

When all these criteria are met, the foregoing equation can be solved for $\left(\Delta \underline{H}^{\text {des }}\right)$ :

$$
\left(\Delta \underline{H}^{\text {des }}\right) \simeq-R\left\{\ln \left[P^{\text {des }}\left(T_{2}\right) / P^{\text {des }}\left(T_{1}\right)\right]\right\} /\left(1 / T_{2}-1 / T_{1}\right)
$$

where $R=$ the gas constant.

The temperature to which $\left(\Delta \underline{H}^{\text {des }}\right)$ is referred specifically is

$$
T_{\text {Avg }}=\left[\left(1 / T_{2}+1 / T_{1}\right) / 2\right]^{-1} \text { if } \Delta H^{\text {des }} \text { varies linearly versus }(1 / T) \text {. }
$$

The following data are given in manufacturer's literature (Union Carbide Corporation) for adsorption of water vapor on Linde I3X molecular sieve adsorbent.

At $T_{1}=273.2^{\circ} \mathrm{K}\left(32^{\circ} \mathrm{F}\right), P_{1}{ }^{\text {ads }}=281 \times 10^{-5} \mathrm{~g} / \mathrm{cm}^{2}\left(4.00 \times 10^{-5} \mathrm{psia}\right)$

At $T_{2}=294.1^{\circ} \mathrm{K}\left(69.8^{\circ} \mathrm{F}\right), P_{2}{ }^{\text {ads }}=169 \times 10^{-4} \mathrm{~g} / \mathrm{cm}^{2}\left(2.40 \times 10^{-4} \mathrm{psia}\right)$

At $T_{3}=338.8^{\circ} \mathrm{K}\left(150.1^{\circ} \mathrm{F}\right), \mathrm{P}_{3}^{\text {ads }}=365.6 \times 10^{-3} \mathrm{~g} / \mathrm{cm}^{2}\left(5.20 \times 10^{-3} \mathrm{psja}\right)$

At $\mathrm{T}_{4}=360.9^{\circ} \mathrm{K}\left(190^{\circ} \mathrm{F}\right), P_{4}^{\text {ads }}=1.16 \times \mathrm{g} / \mathrm{cm}^{2}\left(1.65 \times 10^{-2} \mathrm{psia}\right)$ 
These temperatures cover the adsorbent operating range in the chill generation equipment.

The form of the Clapyron equation is general and applies to any phase-change type process, including vapor-solid (sublimation), liquid-solid (freezing), and vapor-adsorbate (adsorption) so long as the substance whose phase is changing is a single pure substance.

Therefore $\left(\Delta \underline{H}^{\text {des }}\right)$ at $T_{\text {Avg }} \simeq R T_{A v g}^{2}\left[\ln \mathrm{P}^{\text {ads }}\left(T_{2}\right)-\ln \mathrm{p}^{\text {ads }}\left(T_{1}\right)\right] /\left(T_{2}-T_{1}\right)$ $\left(T_{1,2}\right)_{\text {Avg }}=[(1 / 294.1+1 / 273.2) / 2]^{-1}=283.27^{\circ} \mathrm{K}\left(50.2^{\circ} \mathrm{F}\right) ;\left(T_{2}-T_{1}\right)$ $=20.9^{\circ} \mathrm{K}$

$\left(T_{2,3}\right)_{A v g}=[(1 / 338.8+1 / 294.1) / 2]^{-1}=314.87^{\circ} \mathrm{K}\left(107.1^{\circ} \mathrm{F}\right) ;\left(T_{3}-T_{2}\right)$ $=44.7^{\circ} \mathrm{K}$

$\left(T_{3,4}\right)_{A V g}=[(1 / 360.9+1 / 338.8) / 2]^{-1}=349.50^{\circ} \mathrm{K}\left(169.4^{\circ} \mathrm{F}\right) ;\left(T_{4}-T_{3}\right)$ $=22.1^{\circ} \mathrm{K}$

$\left(\Delta_{H_{2} 0}^{\text {des }}\right) 283.27^{\circ} \mathrm{K} \simeq 1.987\left[\ln 169 \times 10^{-4}-\ln 281 \times 10^{-5}\right](283.27)^{2} / 20.9$ $=13686.9 \mathrm{cal} / \mathrm{g}-\mathrm{mole} \mathrm{H}_{2} \mathrm{O}$ $\left(\Delta \underline{H}_{H_{2} O}^{\text {des }}\right) 314.87^{\circ} \mathrm{K} \simeq 1.987\left[\ln 365.6 \times 10^{-3}-1 \mathrm{n} 169 \times 10^{-4}\right](314.87)^{2} / 44.7$ $=13548.4 \mathrm{cal} / \mathrm{g}-$ mole $\mathrm{H}_{2} \mathrm{O}$ $\left(\Delta \mathrm{H}_{\mathrm{H}_{2} \mathrm{O}}^{\text {des }}\right) 349.50^{\circ} \mathrm{K} \simeq 1.987\left[\ln 1.16-\ln 365.6 \times 10^{-3}\right](349.50)^{2} / 22.1$ $=12680.7 \mathrm{cal} / \mathrm{g}-\mathrm{mole} \mathrm{H}_{2} \mathrm{O}$

At the foregoing temperatures, the enthalpy of vaporization of bulk water is

$T^{\circ} \mathrm{F}$

$\overline{50.2} \Delta \hat{\mathrm{H}}^{\text {vap }}=1065.346-[0.2 / 10](5.7076)=1065.232 \simeq 1065.2 \mathrm{Btu} / \mathrm{Ib}$ $=10,664 \mathrm{cal} / \mathrm{g}-\mathrm{mole}$ 


$$
\text { 107.I } \begin{aligned}
\Delta \hat{A}^{\text {vap }} & =1037.161-[7.1 / 10](5781)=1033.056 \simeq 1033.1 \mathrm{Btu} / \mathrm{lb} \\
& =10,342 \mathrm{cal} / \mathrm{g}-\mathrm{mole}
\end{aligned}
$$

$169.4 \Delta \hat{H}^{\text {vap }}=1002.24-[9.4 / 10](6.01)=996.591 \simeq 996.6 \mathrm{Btu} / 1 \mathrm{~b}$

$$
=9,977 \mathrm{cal} / \mathrm{g}-\text { mole. }
$$

Compare $\Delta H^{\text {des }}$ versus $\left(\Delta H^{\text {vap}}\right.$ ) for $\mathrm{H}_{2} \mathrm{O}$ at the same temperature:

$\Delta \mathrm{H}_{\mathrm{H}_{2} \mathrm{O}} \mathrm{O} \quad \Delta \mathrm{H}_{\mathrm{H}_{2} \mathrm{O}}$

$T^{\circ} \mathrm{K}$

283.2

314.9

349.5

\section{cal/g-mole cal/g-mole}

13,687

13,548

12,681
10,664

10,342

9,977
Difference

cal/g-mole

3,023

3,206

2,704

\section{\% Differencegap
based on $\Delta H^{\circ}$}

28.3

31.0

27.1

Since the original data are probably not better than 3 significant figures, and the temperature intervals are fairly large, it is appropriate to round the results:

$\underline{T^{\circ} \mathbf{K}}$

283

315

350

$$
\underline{\Delta H_{-} \mathrm{O}} \text { des cal/g-mole }
$$

13,700

13,500

12,700

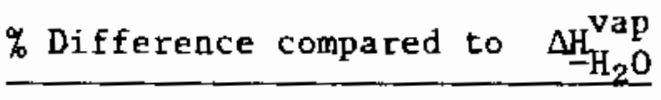

$30 \%$

$30 \%$

$30 \%$

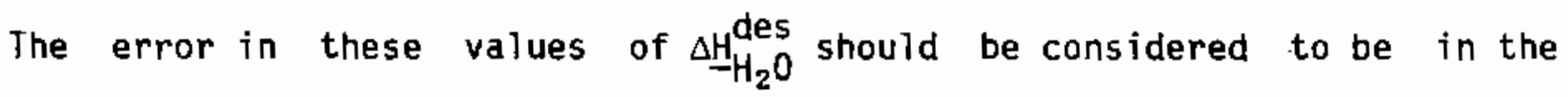
vicinity of \pm 3 percent, if the manufacturer's data are good to the readability of the adsorption isotherm graphs which were supplied. The effect of pore diameter on vapor pressure is 


$$
\left(P V P / P_{f}^{V P}\right)=\exp \left[2 \gamma \underline{w}_{w a t e r} / r R T\right]
$$

where $P_{f}^{V P}$ is the ordinary bulk liquid vapor pressure

$$
\begin{aligned}
& v_{\text {water }} \text { is the voiume of water } \\
& r \text { is pore radius } \\
& \gamma \text { is surface tension }
\end{aligned}
$$

Since the pore size in Linde $13 \mathrm{X}$ molecular sieve is about $1 \times 10^{-7} \mathrm{~cm}$ diameter at about $40^{\circ} \mathrm{C}$, the vapor pressure of water inside the pores will be about 86 percent of the ordinary vapor pressure of bulk liquid. Some of the 19 pounds of "dead" water per 100 pounds of Linde $13 \mathrm{X}$ is due to lowering of vapor pressure by pore-capillarity. If the pore size could be increased enough to make the capillarity effect negligible, about 2 to 3 pounds of the 19 pounds of "dead" water could be eliminated.

"Dead" water harms the thermal efficiency and capital costs of the system by having to be heated up and cooled down during each desorption-adsorption cycle without contributing to process performance other than adjusting the water vapor pressure over the adsorbent to the operating value set by the temperature limits on equipment operability. Since the specific heat of bulk water is $18 \mathrm{tu} / 1 \mathrm{~b}{ }^{\circ} \mathrm{F}\left(1 \mathrm{cal} / \mathrm{g}{ }^{\circ} \mathrm{C}\right.$ ) versus about $\mathrm{C} .2 \mathrm{Btu} /$ pound ${ }^{\circ} \mathrm{F}$ for the solid dry adsorbent, the 19 pounds of adsorbed "dead" water contributes aimost as much useless thermal inertia to the system as the solid adsorbent itself. The adsorbed water should have somewhat less specific heat than free bulk water since some degrees of freedom of motion have been lost. The first layer of water will be chemically reacted to immobile surface hydroxyl, losing all degrees of freedom except vibration. The next layer of water molecules, which is the first layer of hydrogen-bonded water, will lose one translational degree of freedom. Layers beyond the first will possess all degrees of freedom although to a variably restricted extent. The linearity of the adsorption isobars versus temperature down to 8 pounds water per 100 pounds zeolite suggests that the first hydrogen-bonded water layer on the surface 
hydroxyls is completed at somewhat less than 8 pounds water per 100 pounds adsorbent.

As long as the adsorbent has surface hydroxyls on an aluminosilicate surface, it is unlikely that the $\left(\Delta^{\text {des }}-\Delta_{-H^{2}}^{v a}\right)$ will drop below about 20 $\mathrm{kca} 1 / \mathrm{g}$ mole for the first 3 to 4 pounds of water absorbed per 100 pounds of zeolite. The difference is unlikely to drop below about $7 \mathrm{kcal} / \mathrm{g}$ mole for the first 6 to 7 pounds per 100 pounds. Thus, if the "dead" water content of molecular sieve-type adsorbents is to be dropped by more than 10 to 15 percent, it will be necessary to chemically modify the adsorbent surface, to make it act more like a compound containing weakly incorporated water of hydration, like an immobilized clathrate water compound instead of a high-energy chemisorption surface compound. Many alum-type compounds contain 12 waters of hydration with 6 waters chemically coordinated to the $\mathrm{Al}^{3+}$ ion with strong forces and 6 ions trapped in lattice cavities by weak forces. The incorporation of alumina in an insolubilizing silica lattice and then reacting the alumina with $\mathrm{SO}^{3}$ or $\mathrm{H}_{2} \mathrm{SO}^{4}$ vapor, to make a surface alum compound, offers a possible approach to increasing the proportion of water utilized in the absorption-desorption cycle beyond the current 20 to 25 percent of total adsorbed water.

The randomly structured permutites, while easier and cheaper to prepare than crystalline zeolites, are not as well characterized in the literature and their inherently indefinite structure make them less attractive for rigorous scientific study. For engineering use as water adsorbents (rather than for ion exchange, catalysis, or molecular sieving type separations) the structural indeterminacy could represent a minor drawback that might be worthwhile in view of the potential savings of cost and volume. The cost of the adsorbent is a secondary factor in small installations such as the current test system, but it will have more importance as the size of the equipment increases. The costs of tanks and bulk fluid handling equipment tend to grow as the $2 / 3$ to $3 / 4$ power of size or capacity, whereas the adsorbent inventory will grow linearly (first power) with respect to capacity.

The permutite-amorphous type desiccants should be evaluated for suitability of substitution for synthetic zeolite Linde $13 X$. A set of five 
aluminosilicate samples of the permutite type (amorphous rather than crystalline aluminum silicates) were made for adsorption isotherm testing, first by titrating sodium silicate solution with aluminum sulfate solution with the desired Si/Al ratio and then with sufficient sulfuric acid or sodium hydroxide to achieve neutrality. Samples of 0 percent $\mathrm{Al}_{2} \mathrm{O}_{3}-100$ percent SiO, 25 percent $\mathrm{Al}_{2} \mathrm{O}_{3}$ - 75 percent $\mathrm{SiO}_{2}, 50$ percent $\mathrm{Al}_{2} \mathrm{O}_{3}-50$ percent $\mathrm{SiO}_{3}, 75$ percent $\mathrm{Al}_{2} \mathrm{O}_{3}-25$ percent $\mathrm{SiO}_{2}$ and 100 percent $\mathrm{Al}_{2} \mathrm{O}_{3}-0$ percent $\mathrm{SiO}_{3}$ (mole percent) were prepared.

Aqueous coprecipitation of mixtures of soluble silicate and soluble aluminum salts at temperatures between $0^{\circ} \mathrm{C}$ and $100^{\circ} \mathrm{C}$, followed by washing and drying to gel-flake produces permutite-type zeolites having amorphous to partialiy crystalline character. While their technical suitability for chill-adsorption application (compared to the highly controlled fully crystallized faujasite-type and X-type zeolites) is not certain, they are cheaper and can be made with less internal voidage.

Difficulty with adsorption apparatus leakage, breakage, and spare parts procurement prevented attaining satisfactory data in time for this report, but the experimental work is continuing and experimental results will be available later. When the adsorption isotherms of these samples are reproducibly well characterized, the $\mathrm{Al}_{2} \mathrm{O}_{3}$ bearing samples will be sulfated and the adsorption characteristics remeasured. Silica gel is includeif in the samples as a reference-control material and because it is the cheapest water adsorbent in wide use.

Li ide $13 \mathrm{X}$ pellets have a settled bulk density of 38 pounds per cubic feet when dry and a dry pellet density of about 57 pounds per cubic feet. Pure alumina and silica have close-packed crystal densities of 250 pounds per cubic foot and about 138 pounds per cubic foot, respectively, with a mole ratio of about $1.2\left(\mathrm{SiO}_{2} / \mathrm{NaAlO}_{2}\right)$. The density of the solid atomic framework, in a close-packed atom-ion sense, should be roughly 184 pounds per cubic foot, giving a solid volume for 57 pounds of about $1 / 3$ cubic foot. When the absorbent is being operated in its normal adsorbed water range of 19 to 26 pounds of water per cubic foot, about 0.3 to 0.4 cubic foot of adsorbed water is involved, which leaves about an additional $1 / 3$ of the volume inside the pellets as empty space, probably associated with 
microscopic porosity between molecular sieve individual crystals in the pellets. For small, mobile molecules such as water, unlike bulky hydrocarbon molecules, this pore space increases equipment size costs without much advantage. The capillary action of fine pores toward adsorbed water and the strong forces of chemisorption of water make the high porosity pellet structure less necessary for rapid transport than in gas phase hydrocarbon catalysis. All-gel particles of the permutite type are likely to be a preferred form of adsorbent, both because of the low cost of fabrication compared to the crystalline zeolites and the decreased size (capital cost) of the adsorbent containment equipment. Since pellet packing fraction is not a function of pellet diameter in most ranges of typical adsorbent particle sizes, the change to all-gel pellets lacking the granular pore structure of Linde $13 \mathrm{X}$ pellets has potential for reducing the number or size of adsorption tubes required at a fixed capacity by $1 / 4$ to 1/3. The low cost permutites and the pure and chemically modified silica gels both seem to be worthwhile candidates for exploration to bring down capital costs. Silica gel desiccants having adsorption capacities up to 30 pounds of water per 100 pounds of gel are commercially available.

About 35 to 40 different arrangements of the fundamental aluminosilicate zeolite-type structures are characterized in the current literature. The number of theoretically possible distinguishable zeolite structures is indefinitely large, depending on how small a variation over what repeating unit distance is considered significant. The most significant aspect of the structurally tailored crystaliine-compound type zeolites and molecular sieves is the high cost of exerting the kind of process control needed to fabricate their precise structures for gas phase catalysis, compared to making amorphous ge1s of silica, alumina, and the permutite aluminosilicates.

Another current practical problem with the commercial molecular sieves is that their available forms are fine powders or porous, catalyst-type granular pellets rather than gel shards or beads, leading to about $2 / 3$ of the adsorbent total volume being empty space. This empty space promotes rapid vapor transport and equilibration, but it should be possible to modify the catalyst pore structure so that, for small penalties on transfer 
rates and equilibration times, significant savings of adsorbent volume, on the order of $1 / 3$ of the volume now required, can be obtained by the inorganic: gel technology developed initially for fabricating ceramic nuclear fuels ("sol-gel" technology).

Adsurbent packing has further potential for improvement by more than $1 / 3$, when particles are of two distinct sizes, the smaller being about $1 / 3$ to $1 / 4$ the diameter of the larger. The tradeoff is, again, capital cost savings versus vapor flow rates and equilibration time penalties.

The directions of research in the adsorbent character which seem likely to be fruitful are to reduce the volume of "dead" water adsorbed by chemically modifying the surface to make the first and second water layers more lousely bound and more participative in the desorption-adsorption cycle. A second approach would be to adapt the physical pore structure of the catalyst for efficient space utitization in the adsorption tubes. In stationary applications, the weight of adsorbent required to provide a certain volumetric adsorbent-desorbent cycling capacity is less important than either the volume of adsorbent or the amount of "dead" water it contains. If one pound of "dead" water can be eliminated, up to 5 pounds of added dry aluminosilicate solids weight can be added before the thermal efficiency loss is equivalent to that of the water eliminated.

The following data was extracted from curves given in Dr. D. I. Tchernev's report "Solar Energy Applications of Natural Zeolites."

Silica Gel

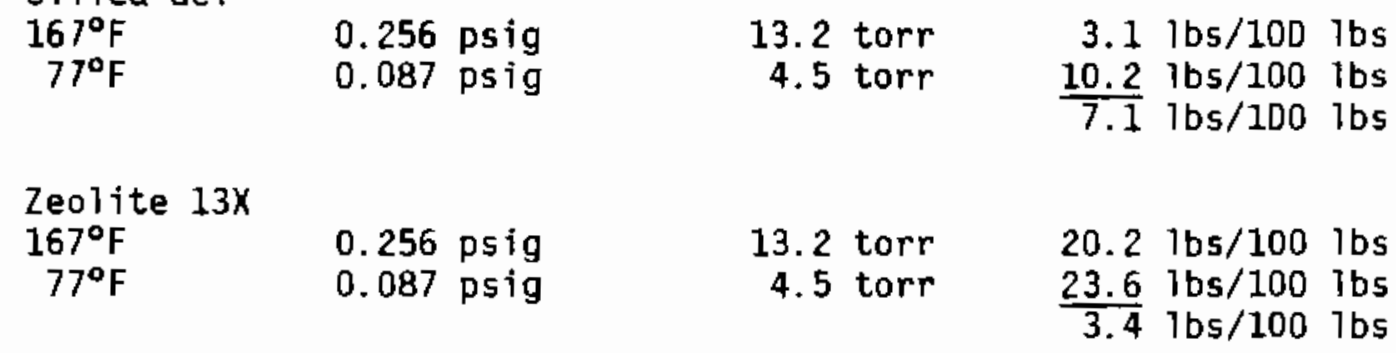

This example shows that even though zeolite $13 x$ holds much more water, the silica gel cycles more water and keeps less dead water. 
The Chemical Engineering Department of New Mexico State University is continuing a program of investigation of adsorbers. A gaijon of montmarilionite was recently received from Multiform Desiccants, Inc., Multiform casts desiccants into many different forms including hollow cylinders. Far example, cylinders 48 inches long by 1.5 inches in diameter with a $0.5-i n c h$ concentric hole lengthwise could alleviate the weight and complexity of the inner structure of the zeolite tubes in the ZCAT facility.

This program for continued investigation is to

1. Develop a bibijography of literature relevant to the adsarption isotherms and heats of adsorption of zeolites in relation to heating - cooling system design.

2. Experimentally prepare representative permutite-type zeolite samples and measure their adsorption isotherms in the $0^{\circ}-100^{\circ} \mathrm{C}$ range.

3. Compare the properties of Linde $13 \mathrm{X}$ with those of the permutite-type zeolites and evaluate their potential for cast savings in the type of application being investigated.

\section{REFERENCES}

Redman, C. M. 1984. Test and Evaluation of Evaporative Water Chilling. Final Repart. NMERDI Project 2-71-4224. New Mexico Energy Research and Development Institute Information Center, Santa Fe, NM.

Tchernev, D. I. "Solar Energy Applications of Natural Zeolites." (Report received from Dr. Tchernev in private communication. Report not dated and does not show name of publication.)

Union Carbide Corporation furnished test curves which were not dated. 


\section{APPENDIX A}

SUMMARY OF TEST RUNS 


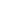




\begin{tabular}{|c|}
\hline $\begin{array}{l}\qquad \begin{array}{l}\text { Test Run 1: To determine the chill } \\
\text { generation, and operational characteristics of the zeolite chill } \\
\text { augmented test facility. }\end{array}\end{array}$ \\
\hline 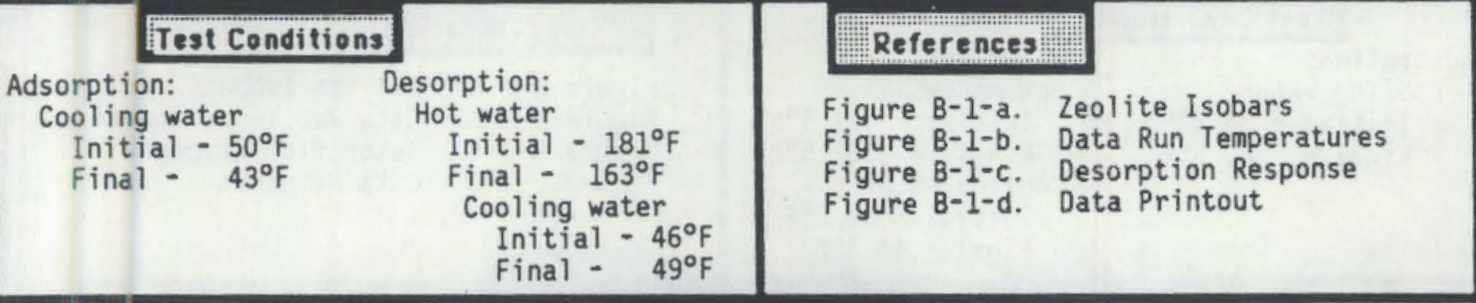 \\
\hline $\begin{array}{lc} & \text { Key Results: } \\
\text { Actual water processed: } & 10.4 \text { pounds } \\
\text { Cooling: } & 11,086 \mathrm{Btu} / \mathrm{cycle} \\
\text { Theoretic water processed: } & 5.8 \text { pounds } \\
\text { Cooling: } & 6183 \mathrm{Btu} / \mathrm{cycle} \\
\text { Actual/theoretical: } & 1.79 \\
\text { Time for } 90 \% \text { desorption: } & 82 \text { minutes }\end{array}$ \\
\hline $\begin{array}{l}\text { The first } 267 \text { minutes of the test run were used for zeolite adsorption of water. Some data } \\
\text { logger problems caused loss of the temperature data during first } 27 \text { minutes and } 160 \text { minutes } \\
\text { during the middle of the adsorption phase. Based on pressure gauge reading, the zeolite had } \\
26.6 \text { pounds of water and based on the temperature of the ice tank water, the zeolite had } \\
26.7 \text { pounds of water at the end of adsorption. } \\
\text { Evaporatively chilled water cooled the zeolite during the adsorption phase. Hot water } \\
\text { replaced the chilled water circulating through the zeolite tank at } 267 \text { minutes to start the } \\
\text { desorption phase. The } 3-i n c h \text { vacuum valve was closed during this phase and condensate } \\
\text { drained into the condensate receiver. } \\
\text { Figure } 8-1-c \text { shows the condensate collection versus time after initiation of desorption. } \\
\text { The curve is based on reading the levels of condensate at the times it was drained from the } \\
\text { receiver into the gallon jug. The last point is by measure using a graduated liter measure. } \\
\text { Using the pressure gauge reading and zeolite temperature, desorption left } 20.8 \text { pounds of } \\
\text { water in the zeolite and based on the temperature of the condensate receiver and zeolite } \\
\text { temperature, there were l9.8 pounds. Using the temperature and pressure data and the } \\
\text { zeolite isobars, the desorption was } 5.8 \text { pounds of water. The actual measured value was } 10.4 \\
\text { pounds or } 179 \text { percent of that derived using the zeolite manufacturer's data. } \\
\text { The condenser input/output temperature change followed the desorption response curve for the } \\
\text { first } 100 \text { minutes of desorption and then the differential temperature reversed. This } \\
\text { anomaly was caused by hot water in the zeolite tank flowing across the barrier into the } \\
\text { condenser tank and only affected the top few inches of the condenser. } \\
\text { The January } 30 \text { test run was preceded by an } 8 \text {-hour vacuum pumping period. }\end{array}$ \\
\hline
\end{tabular}




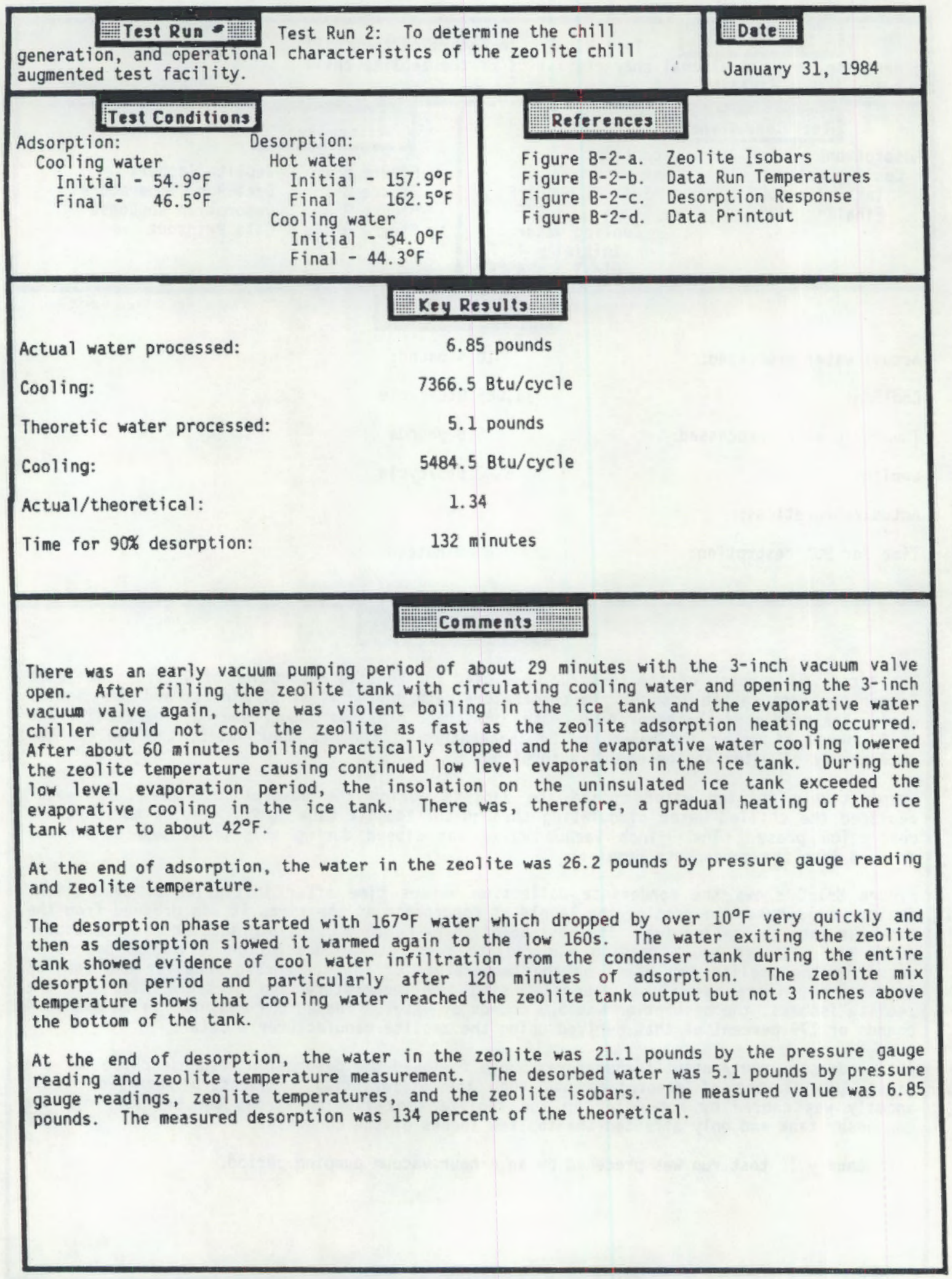




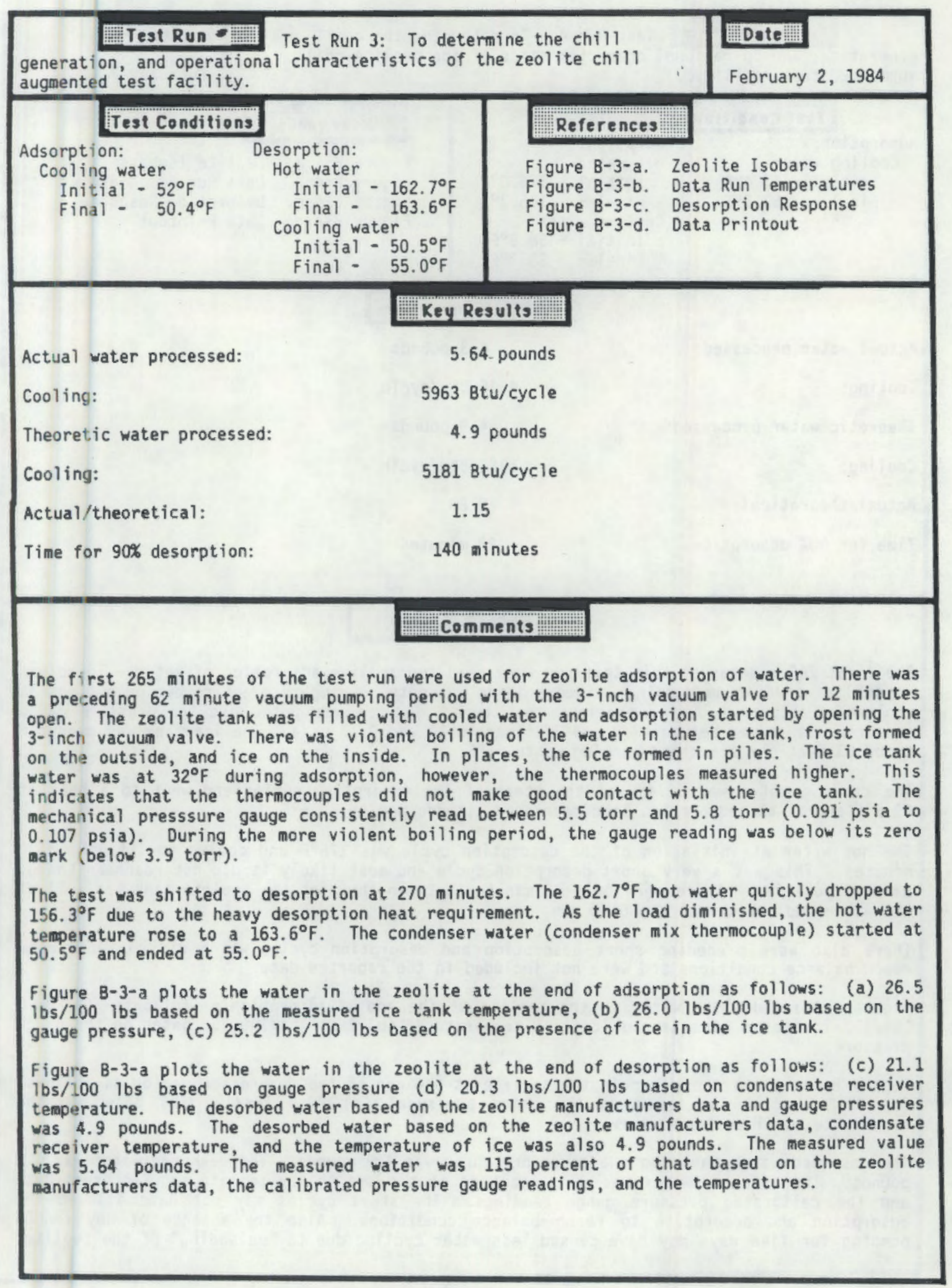




\begin{tabular}{|c|}
\hline 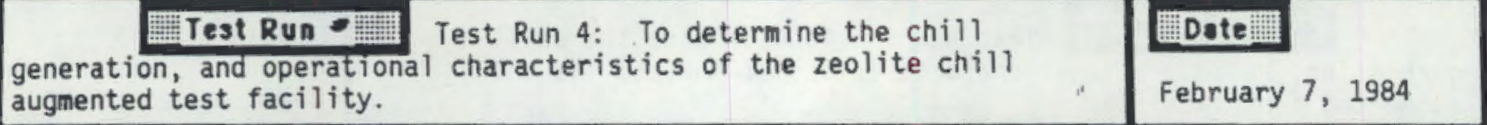 \\
\hline 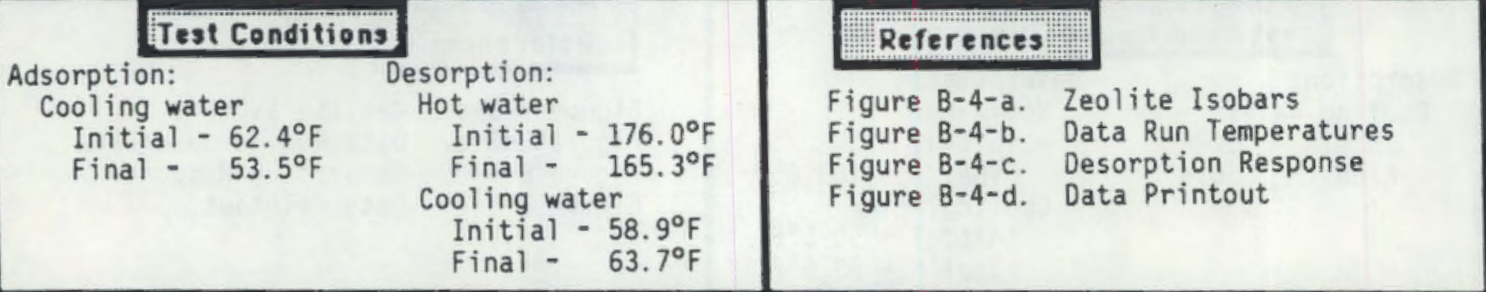 \\
\hline $\begin{array}{lc} & \text { Key Results } \\
\text { Actual water processed: } & 4.3 \text { pounds } \\
\text { Cooling: } & 45468 \text { tu/cycle } \\
\text { Theoretic water processed: } & 4.9 \text { pounds } \\
\text { Cooling: } & 51818 \mathrm{tu} / \text { cycle } \\
\text { Actual/theoretical: } & 0.88 \\
\text { Time for 90\% desorption: } & 28 \text { minutes }\end{array}$ \\
\hline $\begin{array}{l}\text { The first } 240 \text { minutes of this test run were used for zeolite adsorption of water. There was } \\
\text { no preliminary vacuum pumping. Some boiling was noted during this entire period but not as } \\
\text { violent as occurred during previous test runs. No ice was noted and the pressure gauge } \\
\text { measurements stayed between } 7.2 \text { and } 8.8 \text { torr }(0.14 \text { and } 0.17 \text { psia. The ice tank was measured } \\
\text { to be } 53^{\circ} \mathrm{F} \text { at the start and warming up to } 57^{\circ} \mathrm{F} \text {. } \\
\text { The cooling water was } 62.4^{\circ} \mathrm{F} \text { at the start of the adsorption period and went to a peak of } \\
63.5^{\circ} \mathrm{F} \text { and as the adsorption load decreased, it dropped to } 53.5^{\circ} \mathrm{F} \text {. } \\
\text { The hot water at initiation of the desorption cycle was } 176^{\circ} \mathrm{F} \text { and cooled to } 165.3^{\circ} \mathrm{F} \text { in } 20 \\
\text { minutes. This was a very short desorption cycle and most likely it did not reach an energy } \\
\text { balance position. There were only } 46 \text { minutes between the time the zeolite tank was full of } \\
\text { hot water and the end of the test run. } \\
\text { There also were preceding short adsorption and desorption cycles which did not appear to } \\
\text { reach balance conditions and were not included in the reported data. } \\
\text { Figure B-4-a plots the water in the zeolite at the end of adsorption as follows: (a) } 26.6 \\
\text { los/100 } 1 \text { bs based on measured ice tank temperature, (b) } 26.1 \text { lbs/100 lbs based on the gauge } \\
\text { pressure. } \\
\text { Figure } 8-4-a \text { plots the water in the zeolite at the end of the desorption period as follaws, } \\
\text { (c) } 21.2 \text { lbs/loo lbs based on the gauge pressure, (d) } 20.4 \text { los/100 lbs based on the } \\
\text { condensate receiver temperature. } \\
\text { The desorbed water based on the gauge pressures was } 4.9 \text { pounds. The measured water was } 4.3 \\
\text { pounds. The measured water was } 88 \text { percent of that based on the zeolite manufacturers data } \\
\text { and the calibrated pressure gauge readings. The short cycles may not have allawed the } \\
\text { adsorption and desorption to reach balance conditions. Also the absence of any vacuum } \\
\text { pumping for five days may have caused less water cycling due to "poisoning" of the zeolite. }\end{array}$ \\
\hline
\end{tabular}




\begin{tabular}{|c|}
\hline 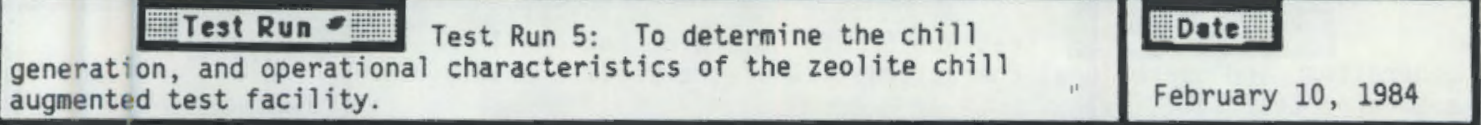 \\
\hline 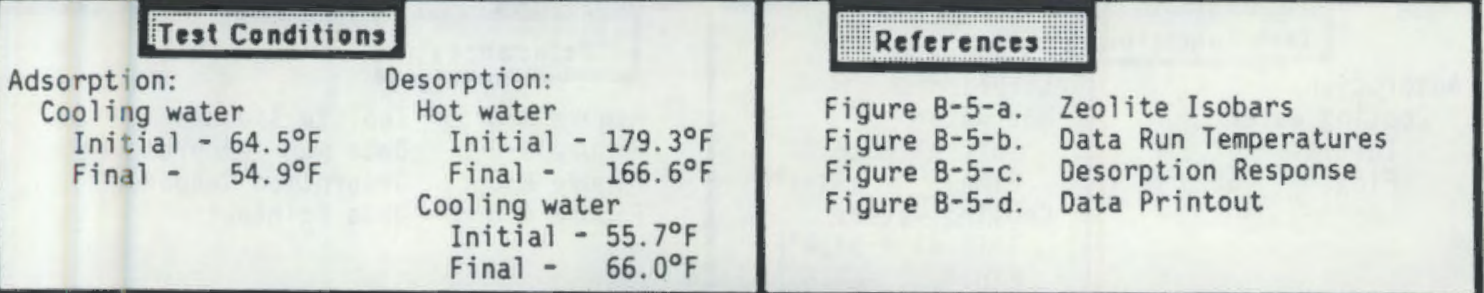 \\
\hline $\begin{array}{lc} & \text { Key Results: } \\
\text { Actual water processed: } & 6.4 \text { pounds } \\
\text { Cooling: } & 6825 \mathrm{Btu} / \mathrm{cycle} \\
\text { Theoretic water processed: } & 5.3 \text { pounds } \\
\text { Cooling: } & 5652 \mathrm{Btu} / \mathrm{cycle} \\
\text { Actual/theoretical: } & 1.21 \\
\text { Time for } 90 \% \text { desorption: } & 47 \text { minutes }\end{array}$ \\
\hline 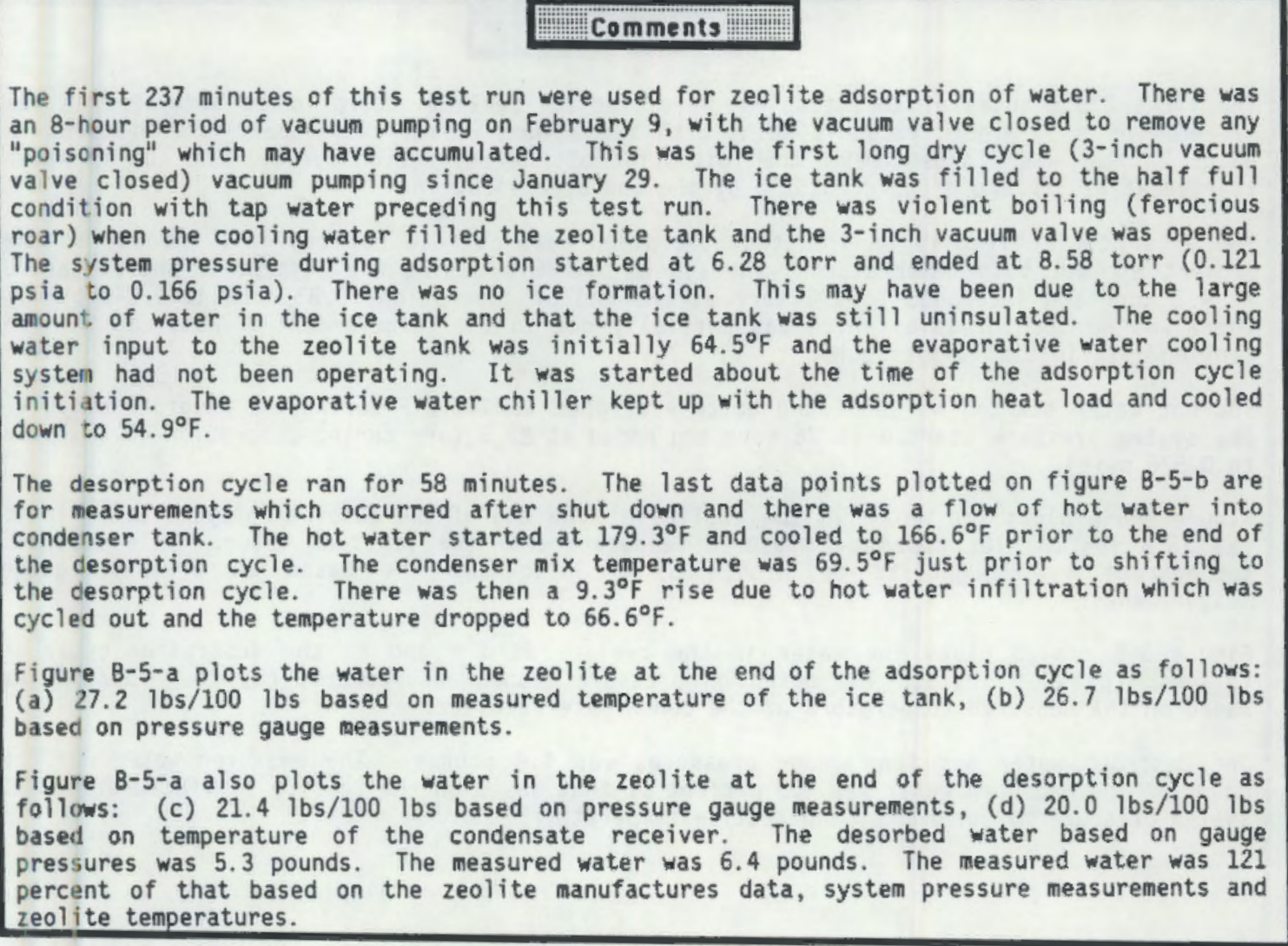 \\
\hline
\end{tabular}




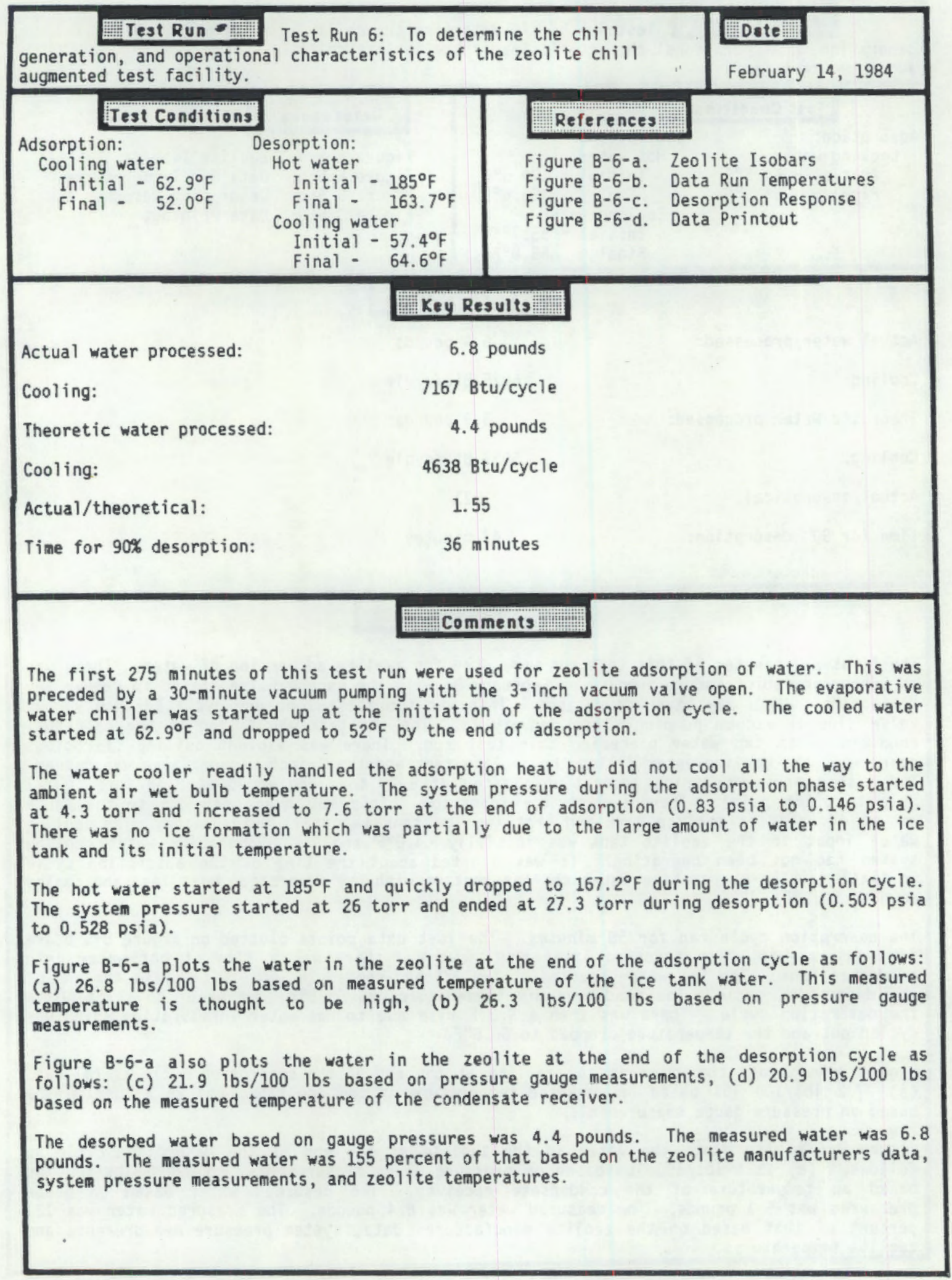

A. 8 


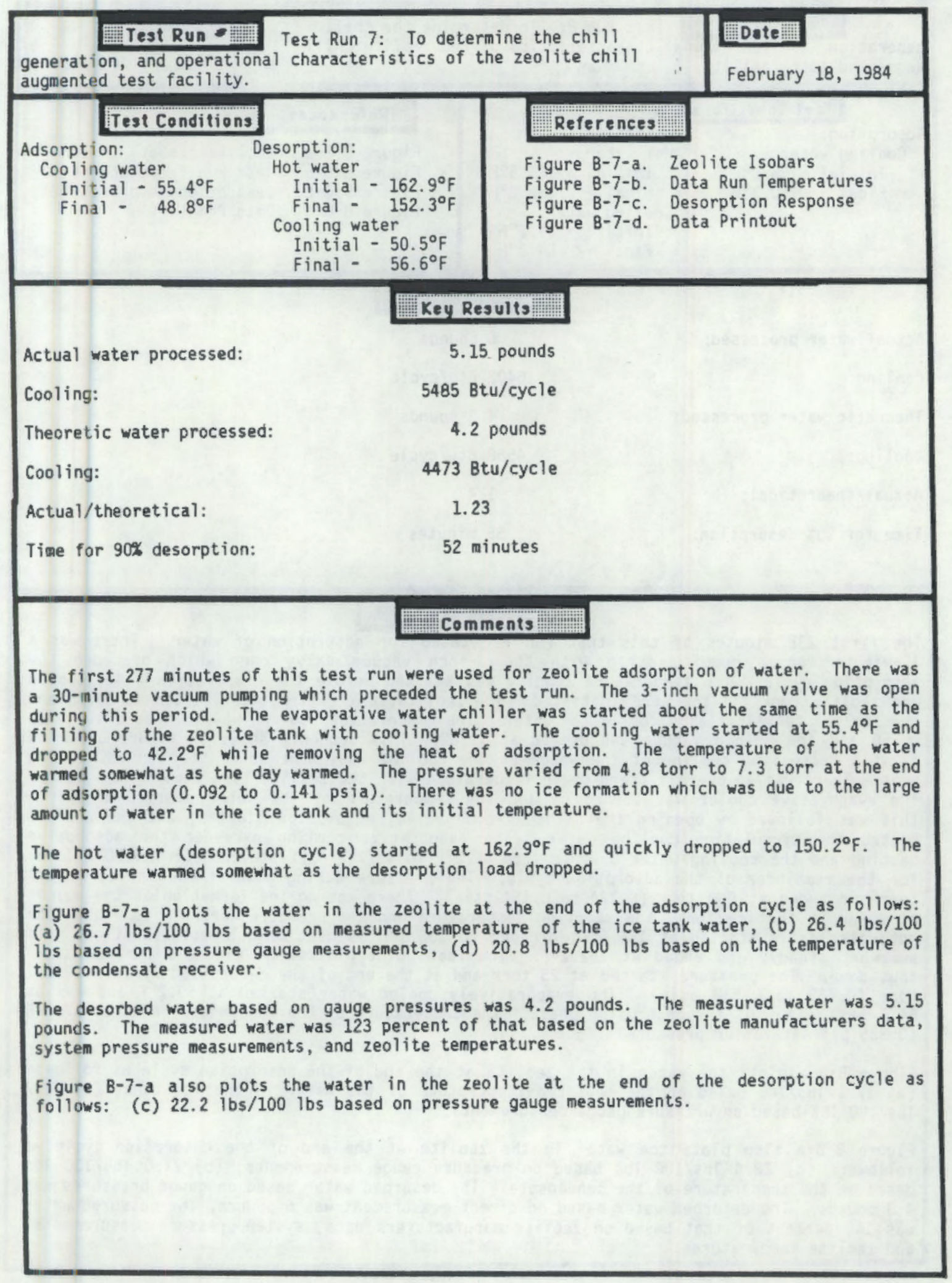




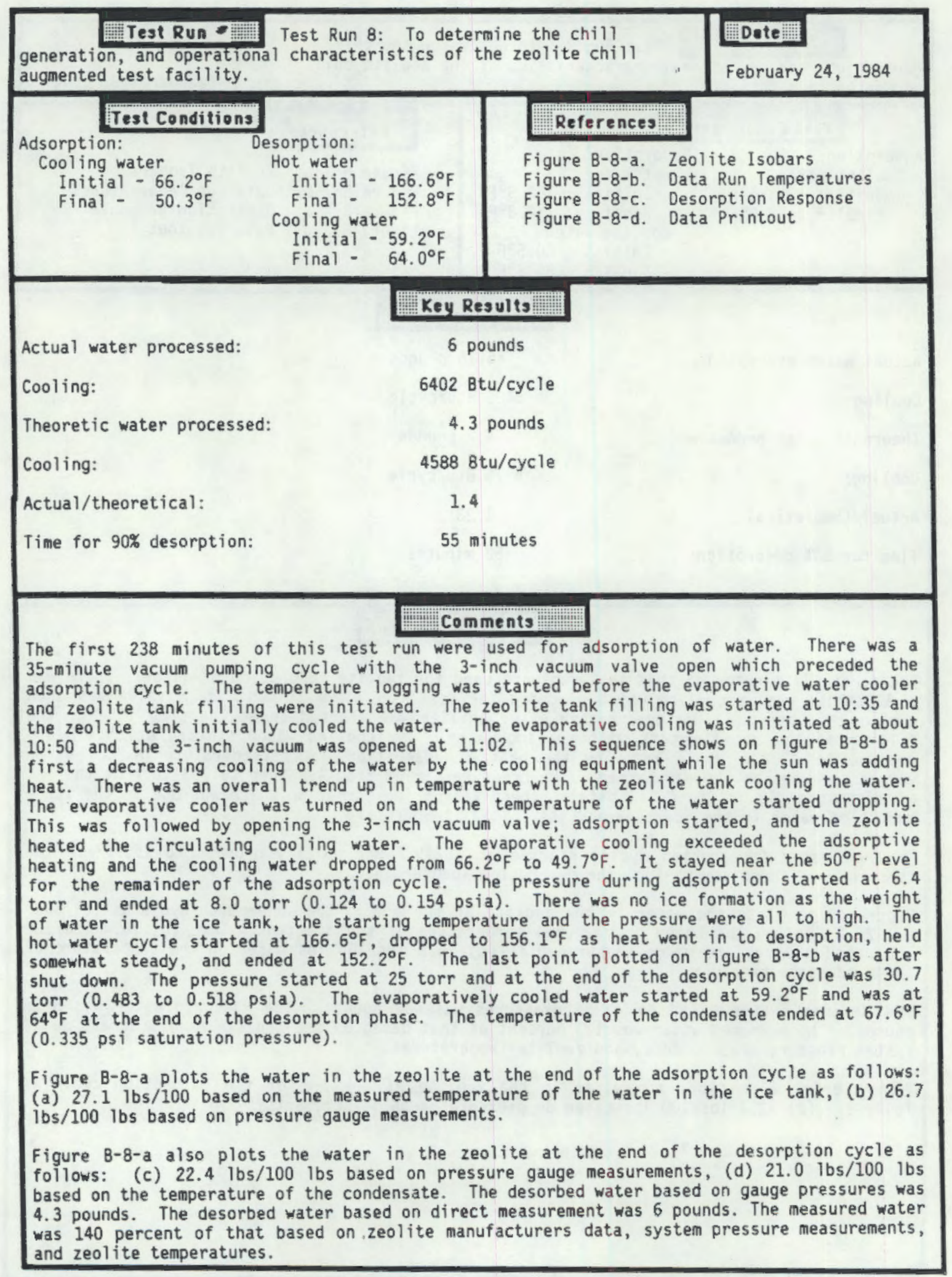




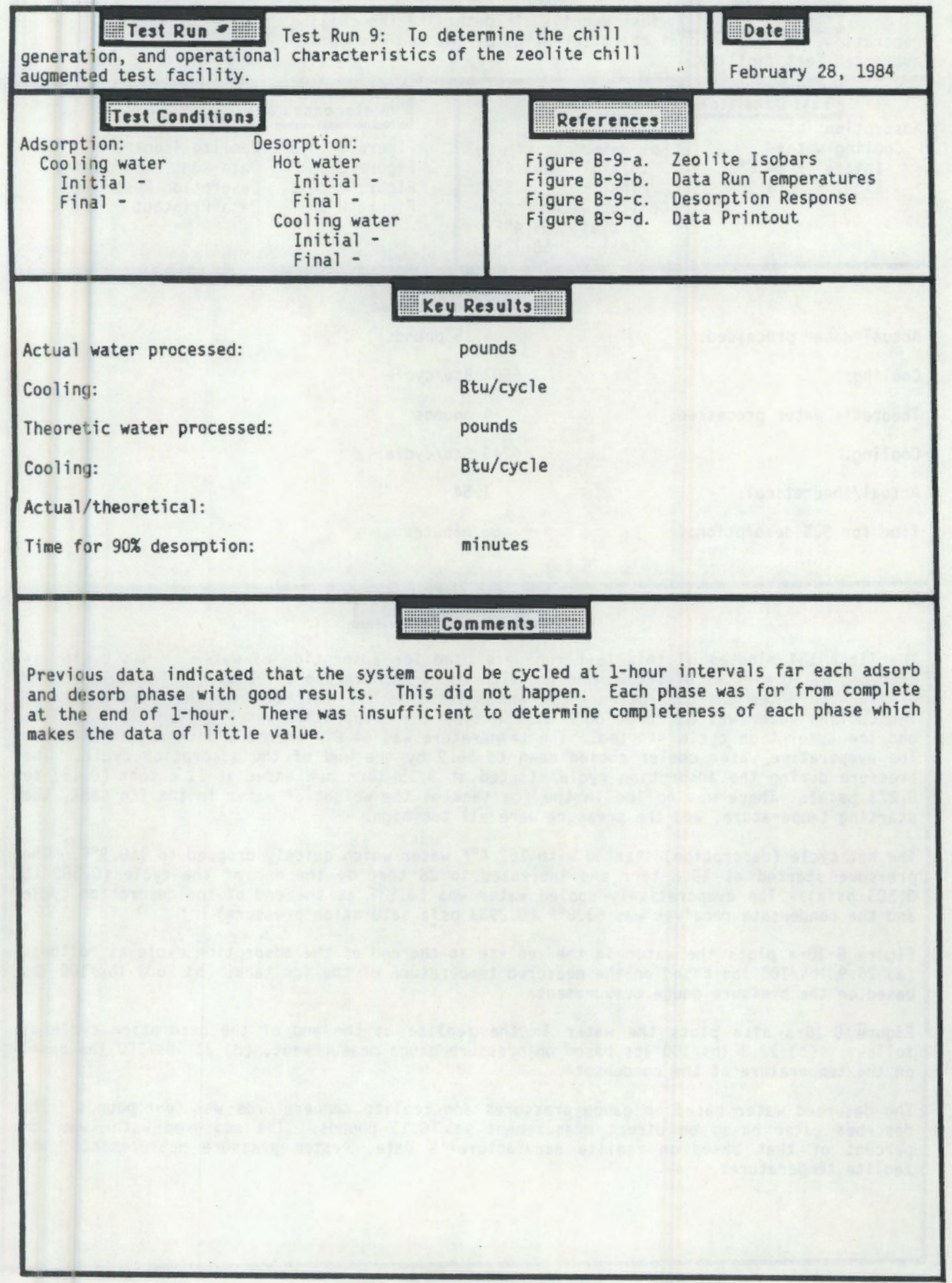

A. 11 


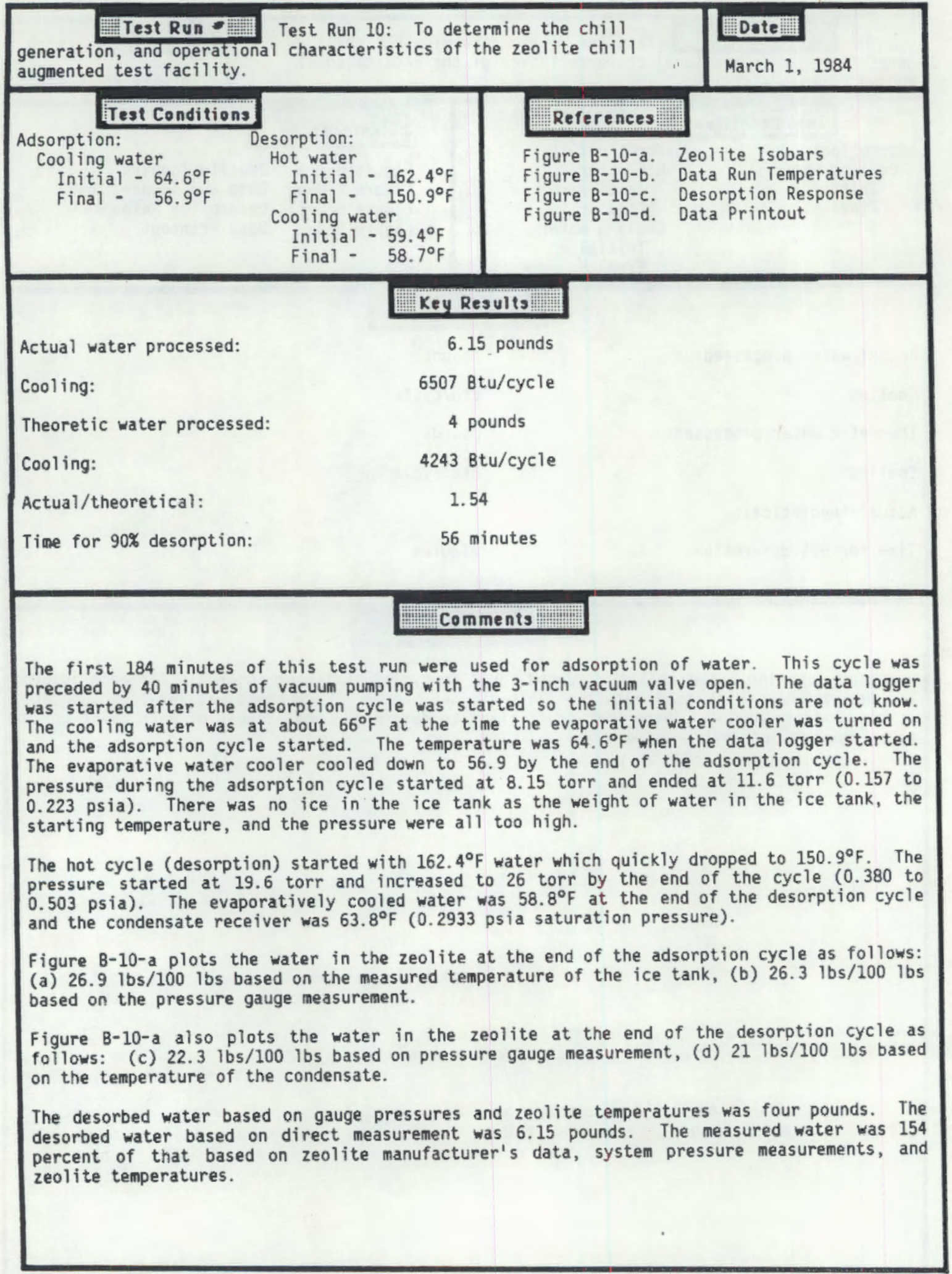




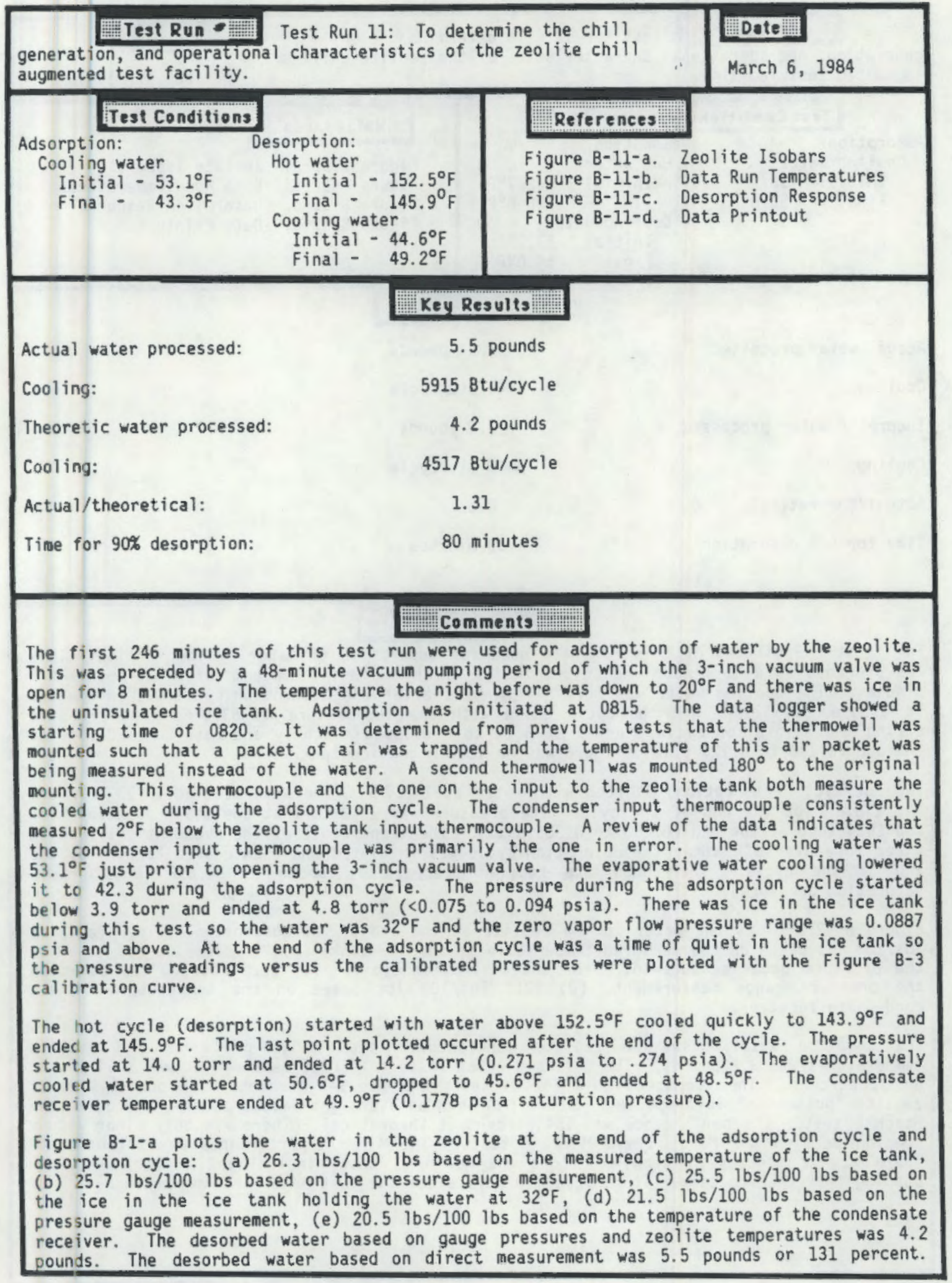




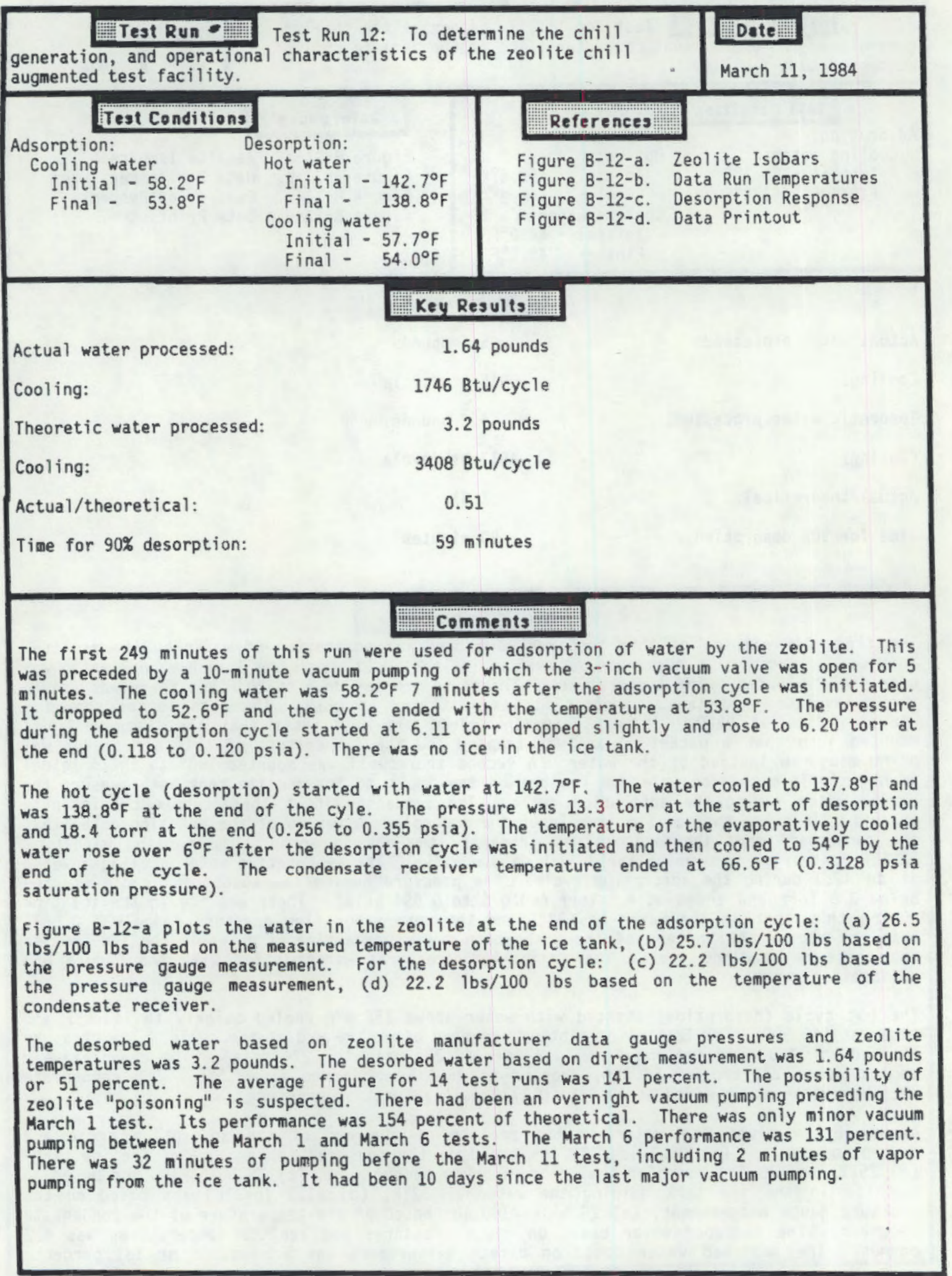




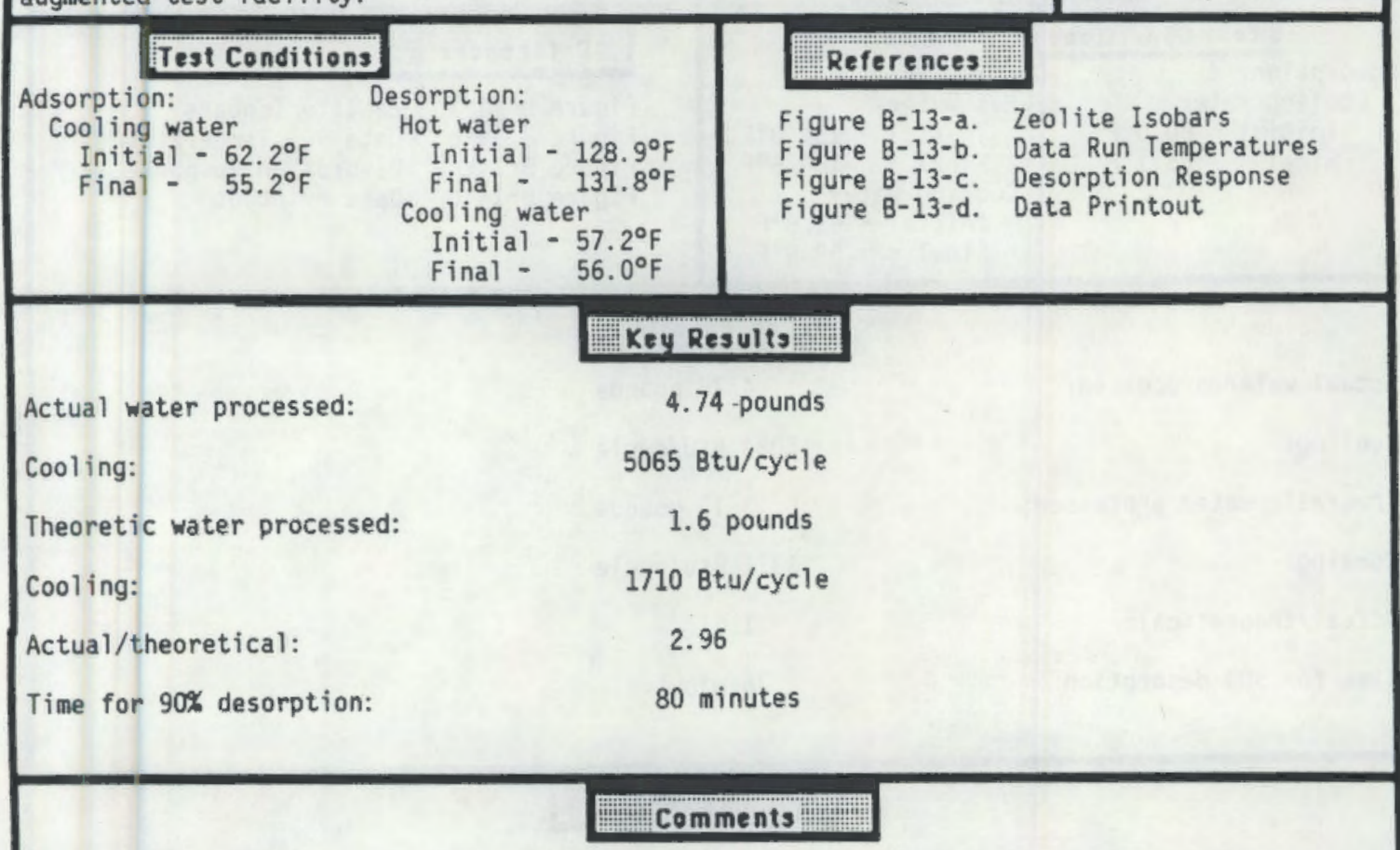

The first 255 minutes of this test run were used for adsorption of water by the zeolite. This was preceded by a 32-minute vacuum pumping the morning of the test and a long vacuum pumping during the previous night. The cooling water was $62.2^{\circ} \mathrm{F} 18$ minutes after test initiation, dropped to $54.5^{\circ} \mathrm{F}$, and rose to $55.2^{\circ} \mathrm{F}$ at the end of the adsorption cycle. The pressure during the adsorption cycle was below the zero of the mechanical pressure gauge until the end when it rose to 4.5 torr $(0.0886 \mathrm{psia})$. There was no ice noted in the tank. The ice tank was in the low $40^{\circ} \mathrm{F}$ range which precluded any freezing $(0.142$ psia saturation pressure).

The hot cycle (desorption) started with water at $128.9^{\circ} \mathrm{F}$, which quickly dropped to $124.5^{\circ} \mathrm{F}$, and then rose gradually to $131.8^{\circ} \mathrm{F}$. The pressure during desorption started at 14.5 torr and finished at 19.2 torr $(0.280$ to $0.371 \mathrm{psia})$. The temperature of the evaporatively cooled water started at $57.2^{\circ} \mathrm{F}$, rose to $60.2^{\circ} \mathrm{F}$ during heavy condensation, and dropped to $56^{\circ} \mathrm{F}$ by the end of the test run. The condensate receiver temperature was $66^{\circ} \mathrm{F}(0.317$ psia saturation pressure) at the end of the desorption.

Figure 8-13-a plots the water in the zeolite at the end of the adsorption cycle as follows: (a) $26.0 \mathrm{lbs} / 100$ ibs based on the measured temperature of the ice tank, (b) $23.01 \mathrm{bs} / 100 \mathrm{lbs}$ based on the pressure gauge measurements.

Figure B-13-a also plots the water in the zeolite at the end of the desorption cycle as follows: (c) $23.0 \mathrm{lbs} / 100$ lbs based on the pressure gauge measurement, (d) $22.7 \mathrm{lbs} / 1001 \mathrm{bs}$ based on the temperature of the condensate receiver.

The desorbed water based on the zeolite manufacture data, gauge pressures, and zeolite temperatures was 1.6 pounds. The desorbed water based on direct measurement was 4.74 pounds. The measured water was 296 percent of that based on zeolite manufacturers data, systen pressure measurements, and the zeolite temperature measurements. 


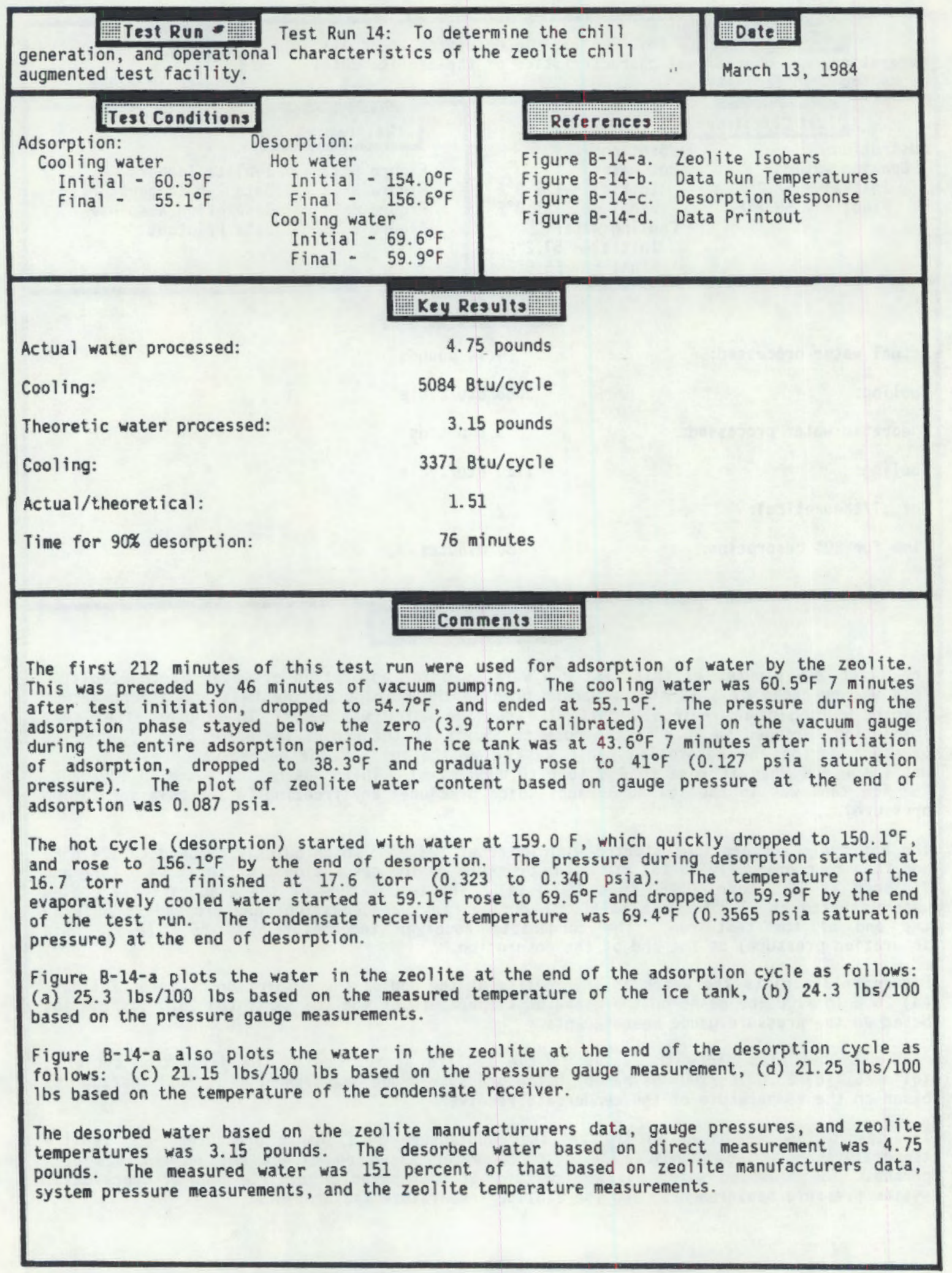




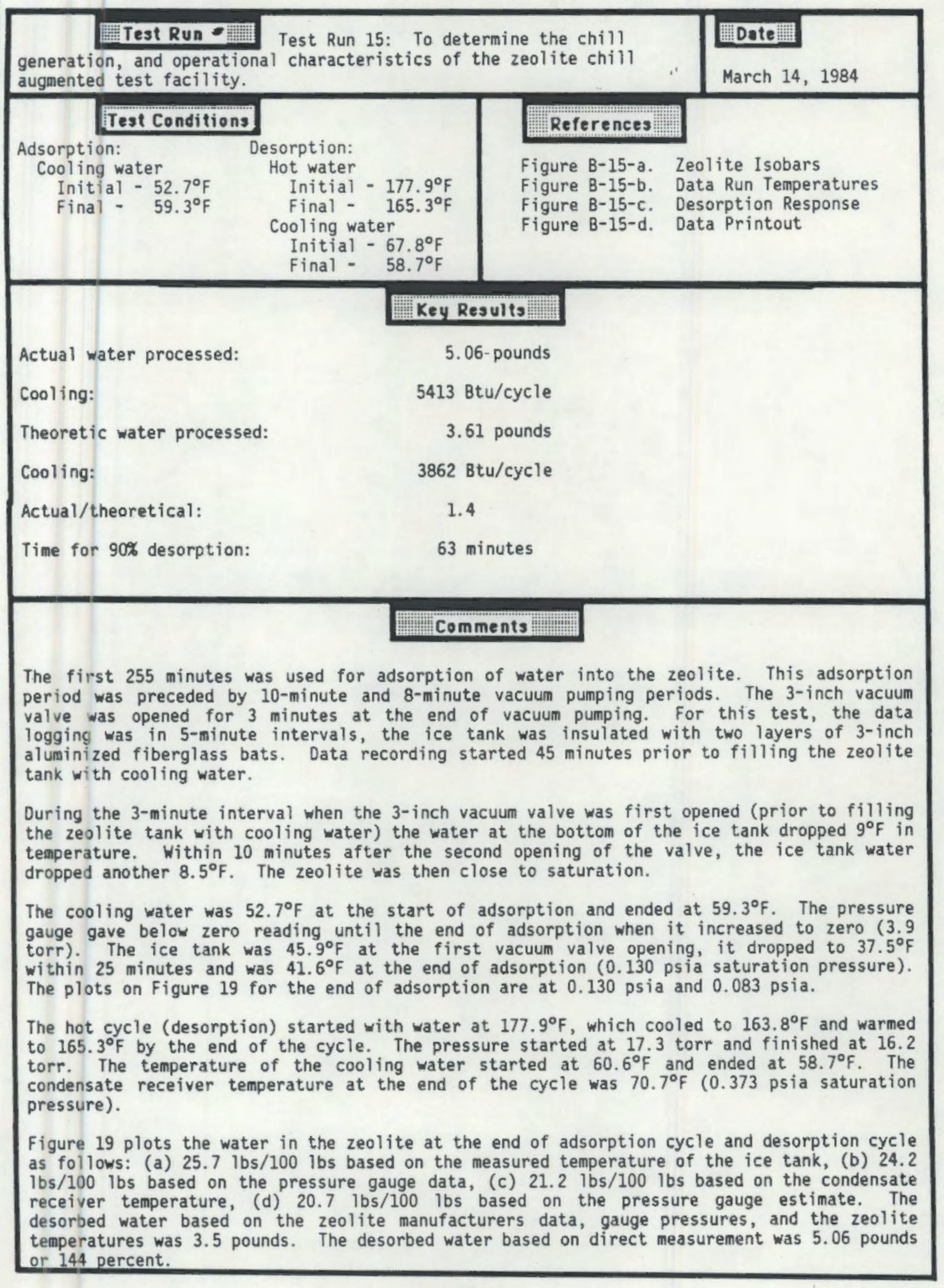


APPENDIX B

EXHIBIT OF DATA FROM TEST RUNS 



\section{EXHIBIT OF DATA FROM TEST RUNS}

\section{Description of figures}

\section{Zeolite Isobars}

The isobars were extracted from data pub 7 ished by Linde, a Division of Union Carbide. A chart is included to give saturated pressures for eight different temperatures. A chart is also included giving the zeolite water content based on:

a. Ice tank temperature and zeolite temperature at the end of adsorption

b. System pressure and zeolite temperature at the end of adsorption

c. System pressure and zeolite temperature at the end of desorption

d. Condensate receiver temperature and zeolite temperature at the end of desorption

\section{Data Run}

These are plots of the temperature data logged during the test runs and a summary of the hand recorded data.

\section{Desorption Response}

These are plots of the levels of condensate drained from the condensate receiver (see figure $\mathrm{c}-2$ ) versus time of the draining. There are also one or two points (circled points) plotted for each showing the actual measurements of the condensate by means of a graduated cylinder.

\section{Data Printout}

This printouts give the calibrated temperature data for both hot (desorption) and cold (adsorption) cycles as follows:

Time of measurements

\section{Condenser:}

$$
\begin{aligned}
& \text { in, channel } 00 \\
& \text { out, channel } 01 \\
& \text { mix, channel } 17
\end{aligned}
$$


Z-tank:

in, channel 02

out, channel 03

mix, channel 18

Condensate Receiver:

1. CI, input cooling water around the receiver, channel 04

2. CO, output cooling water around the receiver, channel 05 (channels 04 and 00 are nominally the same temperature)

3. SUR, temperature of condensate, channel 06

4. BR, bottom right on ice tank, channel 19

5. TR, top right on ice tank, channel 20 
Date: January 30,1984

a $26.7 \mathrm{lbs} / 100 \mathrm{lbs}$

b $26.6 \mathrm{lbs} / 100 \mathrm{lbs}$

c $20.8 \mathrm{lbs} / 100 \mathrm{lbs}$

d $19.8 \mathrm{lbs} / 100 \mathrm{lbs}$

$\mathrm{b}-\mathrm{c}=5.8 \mathrm{lbs}$

$\mathrm{a}-\mathrm{d}=6.9 \mathrm{lbs}$

measured 10.4 1bs

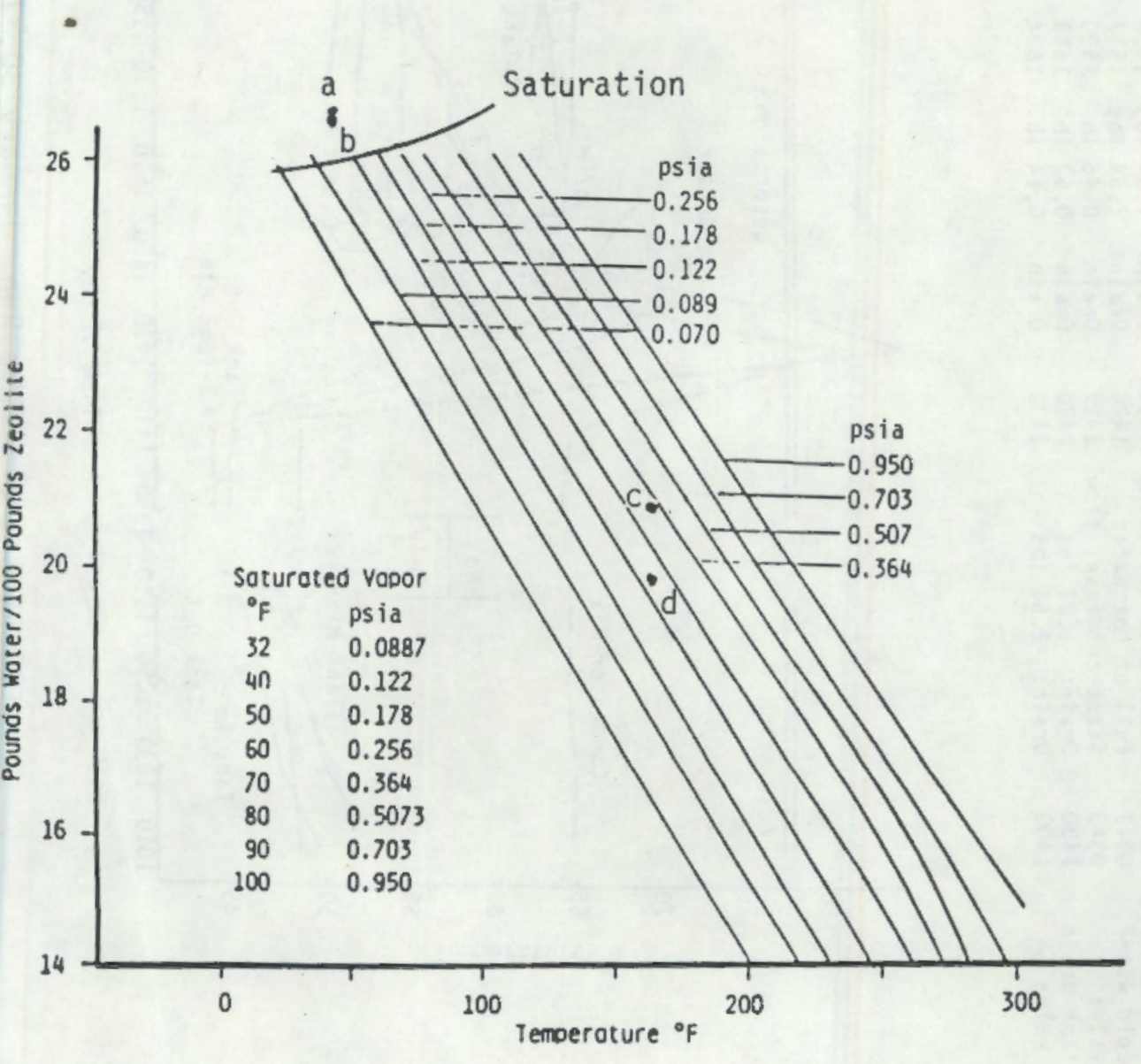

FIGURE B-1-a. Zeolite Isobars

B. 5 


\begin{tabular}{|c|c|c|c|c|c|c|c|}
\hline $\begin{array}{l}\text { Start } 2 \text {-tank filling } \\
\text { Full of cold water } \\
\text { Open } 3^{\circ} \text { valve } \\
\text { Start } 2 \text {-tank drain } \\
\text { Close } 3^{\circ} \text { valve }\end{array}$ & $\begin{array}{l}0935 \\
0943 \\
0943 \\
1400 \\
1400\end{array}$ & $\begin{array}{l}\text { Start } 2 \text {-tank fllling } \\
\text { Full of hot water } \\
\text { Start condenser flow } \\
\text { Orain: } 2.22 \text { los } \\
\text { Orain: } 2.68 \text { ibs }\end{array}$ & $\begin{array}{l}1410 \\
1420 \\
1427 \\
1420 \\
1432\end{array}$ & $\begin{array}{l}\text { Orain: } \\
\text { Orain: } \\
\text { Orain: } \\
\text { Orain } \\
\text { Orain: }\end{array}$ & $\begin{array}{l}1.34 \mathrm{lbs} \\
2.64 \mathrm{ibs} \\
0.46 \mathrm{10} \\
0.57 \mathrm{10} \\
0.14 \mathrm{1b}\end{array}$ & $\begin{array}{l}1438 \\
1517 \\
1530 \\
1613 \\
1624\end{array}$ & $\begin{array}{l}\text { Orain: } 0.23 \text { ib } 1632 \\
\text { Measured: } 10.4 \text { los } 1632 \\
\text { Adsorption: cold water flow. } 3.3 \mathrm{gmm} \\
\text { Desorption: cold water flow. } 3.5 \mathrm{gmm} \\
\text { hot weter flow. } 3 \mathrm{ggm}\end{array}$ \\
\hline
\end{tabular}

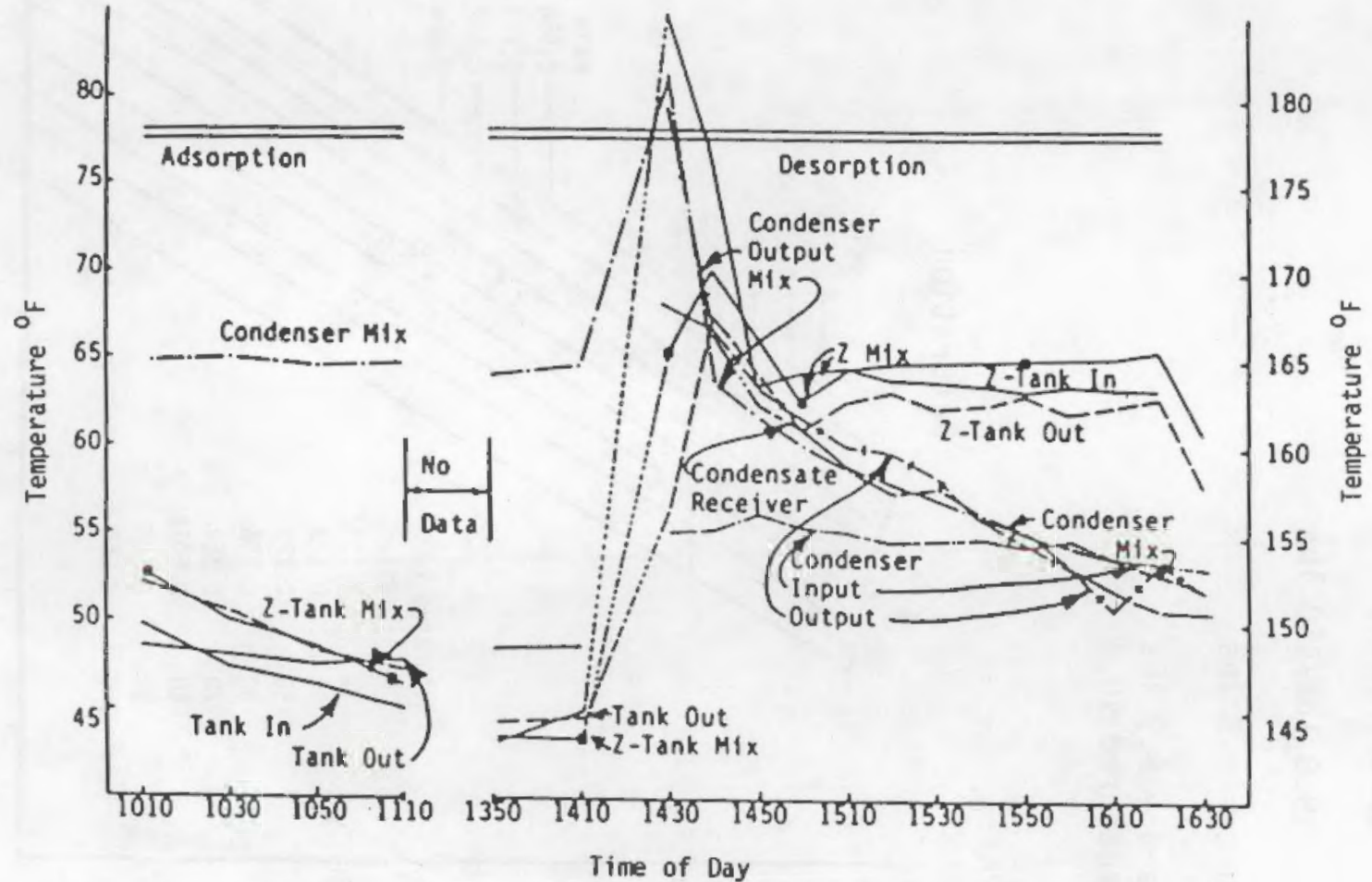

FIGURE B-1-b. Data Run, January 30, 1984 


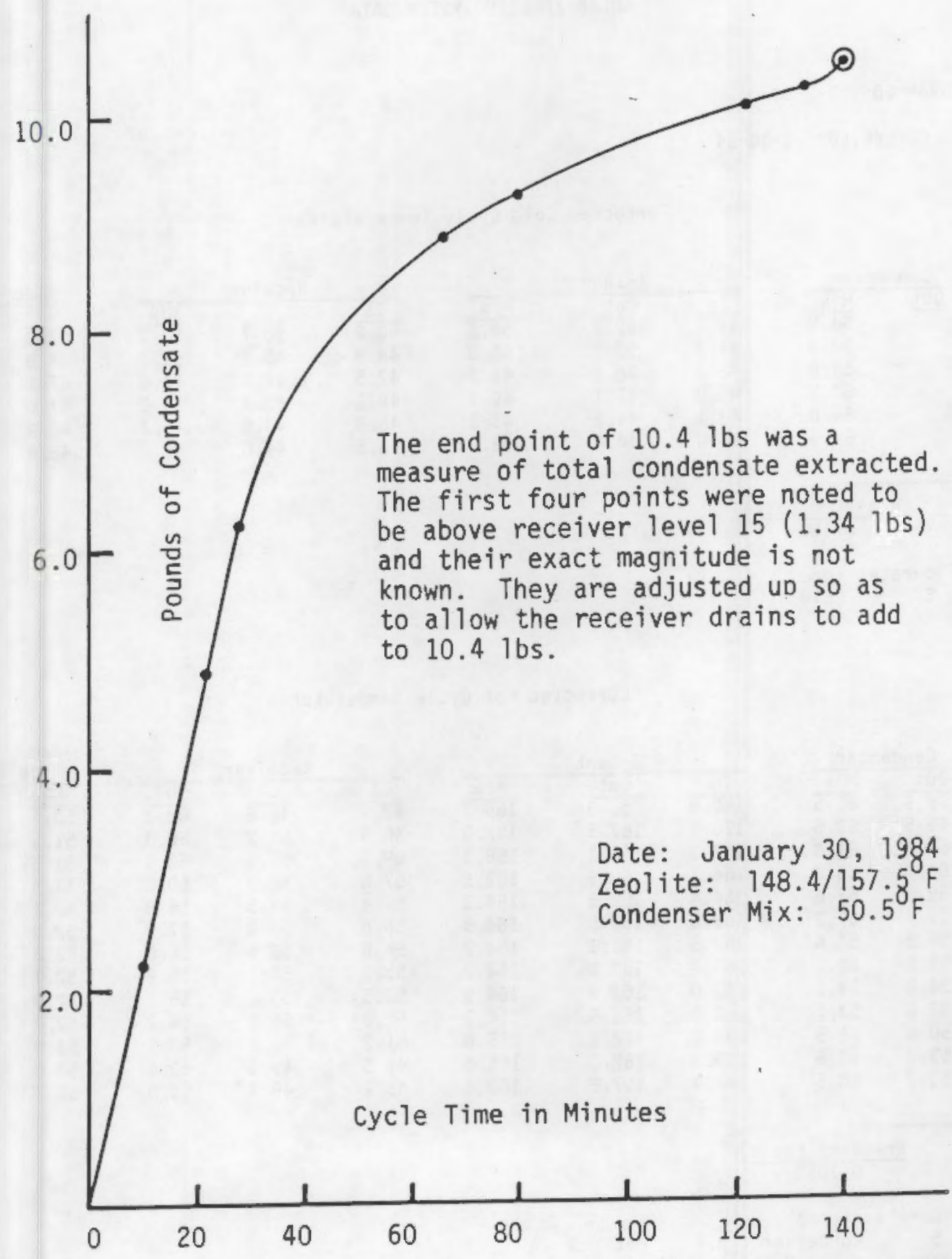

FIGURE B-1-C. Desorption Response

B.7 
DATE PROGRAMMED: $\quad 3-2-84$

DATE DATA COLLECTED: $1-30-84$

Corrected Cold Cycle Temperatures

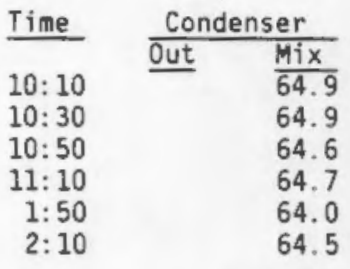

\begin{tabular}{ccc}
\multicolumn{3}{c}{ Z-Tank } \\
\hline In & Out & Mix \\
49.7 & $\frac{52.2}{52.8}$ \\
47.2 & 50.3 & 50.0 \\
46.3 & 48.2 & 48.2 \\
45.0 & 47.1 & 46.3 \\
43.1 & 44.1 & 43.3 \\
45.0 & 44.4 & 43.2
\end{tabular}

\begin{tabular}{|c|c|c|}
\hline & & \\
\hline$\frac{\mathrm{Cl}}{50.8}$ & $\frac{\mathrm{CO}}{50.7}$ & $\frac{\text { SUR }}{50.0}$ \\
\hline 48.4 & 48,1 & 51.3 \\
\hline 47.5 & 47.0 & 51.0 \\
\hline 46. & 45.7 & \\
\hline 43. & 43.8 & 9. \\
\hline 43.6 & 44.0 & 49.0 \\
\hline
\end{tabular}

\begin{tabular}{cc} 
ICe & Tank \\
\hline$\frac{B R}{47.9}$ & $\frac{T R}{49.1}$ \\
48.0 & 49.8 \\
47.5 & 49.3 \\
47.6 & 47.2 \\
48.4 & 46.6 \\
48.4 & 52.5
\end{tabular}

$\frac{\text { Time }}{2: 02} \quad \frac{\text { Pressure (psia) }}{0.1864}$

Average Flowrates (gpm)

Spray: 0.5 Cold:

3. 3

Corrected Hot Cycle Temperatures

\begin{tabular}{|c|c|c|c|c|c|}
\hline \multirow[t]{2}{*}{ Time } & \multicolumn{2}{|c|}{ Condenser } & \multicolumn{3}{|c|}{$Z-\operatorname{Tan} k$} \\
\hline & Dut & Mix & In & out & Mix \\
\hline $2: 30$ & $\overline{79.5}$ & $\overline{81.5}$ & $\overline{180.9}$ & $\overline{156.3}$ & $\overline{165.2}$ \\
\hline $2: 40$ & 66.5 & 63.5 & 176.5 & 167.5 & 172.0 \\
\hline $2: 50$ & 63.6 & 61.4 & 163.3 & 164.4 & 166.1 \\
\hline $3: 00$ & 61.3 & 60.0 & 164.1 & 160.9 & 162.5 \\
\hline $3: 10$ & 59.8 & 58.6 & 164.4 & 162.5 & 164.3 \\
\hline $3: 20$ & 59.7 & 57.2 & 163.6 & 163.0 & 164.8 \\
\hline $3: 30$ & 58.1 & 57.6 & 163.5 & 162.1 & 164.7 \\
\hline $3: 40$ & 55.8 & 56.1 & 163.4 & 162.0 & 164.7 \\
\hline $3: 50$ & 54.5 & 54.2 & 163.0 & 162.9 & 164.9 \\
\hline 4:00 & 52.6 & 53.1 & 163.3 & 161.9 & 164.9 \\
\hline $4: 10$ & 50.6 & 51.5 & 163.2 & 162.2 & 165.0 \\
\hline $4: 20$ & 53.3 & 50.6 & 163.2 & 162.6 & 165.4 \\
\hline $4: 30$ & 51.7 & 50.5 & 148.4 & 157.5 & 160.4 \\
\hline
\end{tabular}

\begin{tabular}{ccc}
\multicolumn{3}{c}{ Receiver } \\
\hline$\frac{C 1}{47.7}$ & $\frac{C O}{46.8}$ & $\frac{\text { SUR }}{68.1}$ \\
56.5 & 59.2 & 66.3 \\
59.3 & 59.6 & 62.1 \\
57.8 & 58.3 & 60.0 \\
57.4 & 57.5 & 58.8 \\
56.6 & 56.8 & 57.9 \\
56.6 & 56.4 & 56.9 \\
55.1 & 54.1 & 55.9 \\
53.5 & 53.2 & 55.2 \\
52.0 & 51.9 & 54.2 \\
51.2 & 50.6 & 53.5 \\
49.5 & 49.5 & 52.6 \\
49.2 & 49.7 & 51.5
\end{tabular}

\begin{tabular}{|c|c|}
\hline$\frac{\text { ICE }}{\mathrm{BR}}$ & $\frac{m}{T R}$ \\
\hline$\frac{51}{50.2}$ & $\frac{1 n}{54.2}$ \\
\hline 51.5 & 54.8 \\
\hline 51.5 & 55.2 \\
\hline 51.5 & 54.9 \\
\hline 52.1 & 55.2 \\
\hline 52.2 & 55.1 \\
\hline 52.8 & 55.2 \\
\hline 52.7 & .7 \\
\hline 52.9 & 5.2 \\
\hline 52.7 & 55.2 \\
\hline 53.0 & 54.8 \\
\hline 52.8 & 4.1 \\
\hline 52.7 & \\
\hline
\end{tabular}

$\frac{\text { Time }}{\frac{\text { Pressure (psia) }}{2: 37}}$

Average Flowrates (gpm)

Spray: 0.5 Condenser: 3.4 Hot: 3

Total condensate removed this hot cycle (lbs):

10.417

FIGURE B-1-d. Data Printout 
Date: January 31, 1984

a $26.3 \mathrm{lbs} / 100 \mathrm{lbs}$

b $26.2 \mathrm{lbs} / 100 \mathrm{lbs}$

c $21.1 \mathrm{lbs} / 100 \mathrm{lbs}$

d $19.7 \mathrm{lbs} / 100 \mathrm{lbs}$

e $25.3 \mathrm{lbs} / 100$ lbs based on ice in tank

$\mathrm{b}-\mathrm{c}=5.1 \mathrm{lbs}$

$\mathrm{a}-\mathrm{d}=6.6 \mathrm{lbs}$

measured 6.85 lbs

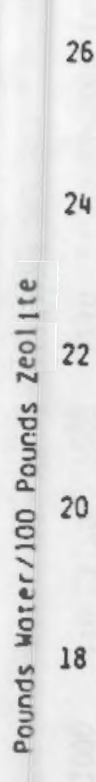

26

1

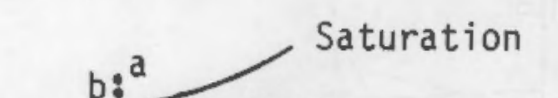

24

$-$

22

20

(1) 
Start Z-tank fllling

Full of cold water

Open 3" valve

Start 2 -tank drain

Start 2-tank flliling
0845

0913

0913

1406

1417

$\begin{array}{ll}\text { Full of hot water } & 1427 \\ \text { Orain: } 1 \text { io } & 1427 \\ \text { Orain: } 1.77 \text { los } & 1431 \\ \text { Orain: } 1.77 \text { ibs } & 1440 \\ \text { Orain: } 1.7 \text { ibs } & 1500\end{array}$

Mesured: 6.85 los

Orain 2-tank fill with cold 1715

Adsorption: cold water flow, 3.35

Desorption: cold water flow. $3.5 \mathrm{gpm}$

Desorption: cold water flon, $3.5 \mathrm{gpm}$ hot water flow, $3.1 \mathrm{gpm}$

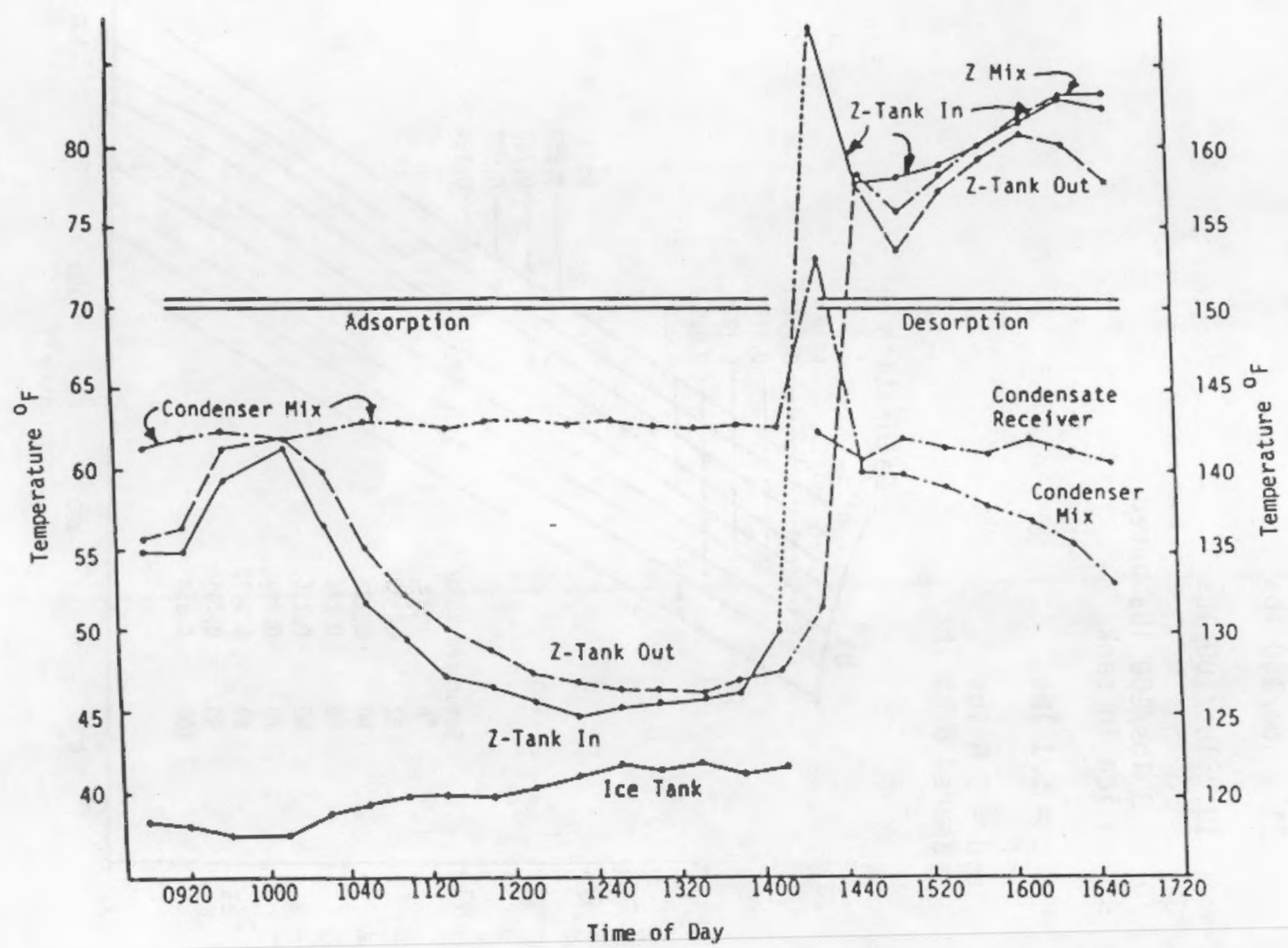

FIGURE B-2-b. Data Run, January 31, 1984 


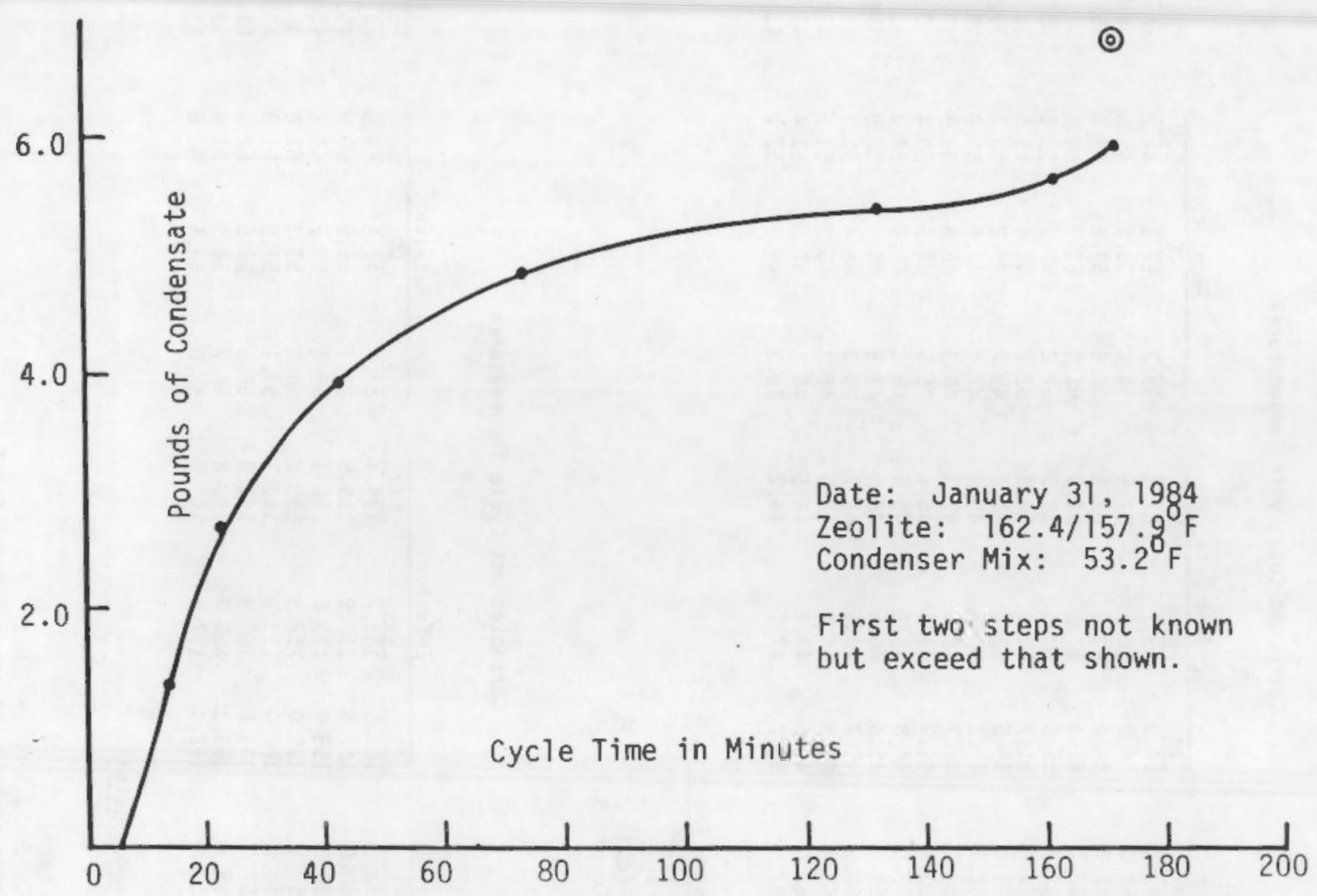

FIGURE B-2-C. Desorption Response 
DATE PROGRAMMED: $\quad 3-2-84$

DATE DATA COLLECTED: $1-31-84$

Corrected Cold Cycie Temperatures

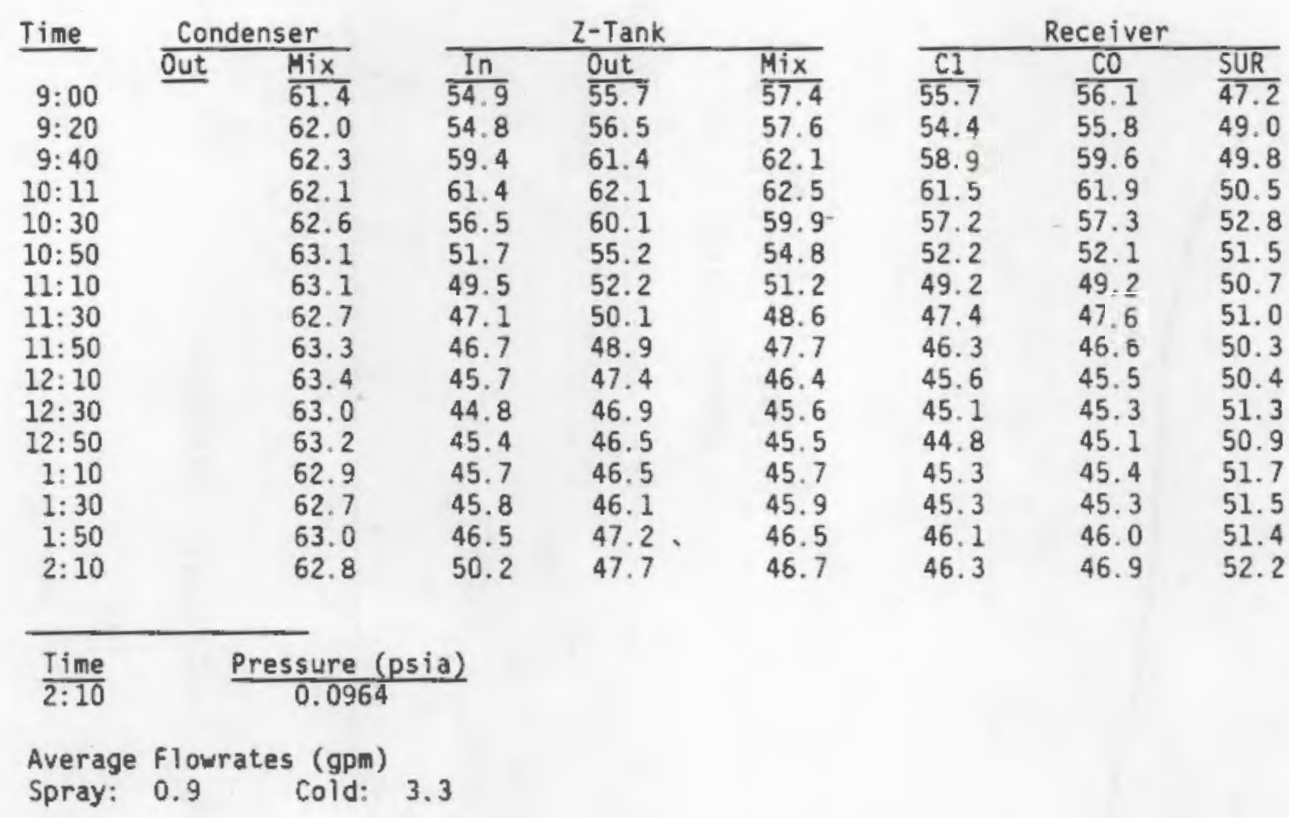

Corrected Hot Cycle Temperatures

\begin{tabular}{clr} 
Time & \multicolumn{2}{c}{ Condenser } \\
\cline { 3 - 3 } $2: 30$ & $\frac{\text { 0ut }}{61.9}$ & $\frac{\text { Mix }}{73.1}$ \\
$2: 50$ & 70.4 & 60.0 \\
$3: 10$ & 61.1 & 59.8 \\
$3: 30$ & 60.7 & 59.1 \\
$3: 50$ & 59.1 & 58.0 \\
$4: 10$ & 57.9 & 57.0 \\
$4: 30$ & 55.8 & 55.7 \\
$4: 50$ & 53.7 & 53.2
\end{tabular}

\begin{tabular}{|c|c|c|}
\hline & $Z$-Tank & \\
\hline$\frac{\text { In }}{1675}$ & $\frac{\text { Out }}{137.7}$ & $\frac{\text { Mix }}{139 \sqrt{4}}$ \\
\hline 167.5 & & \\
\hline 157.9 & 157.9 & 158.5 \\
\hline 158.2 & 153.6 & 156.1 \\
\hline 159.0 & 157.3 & 158.2 \\
\hline 160.0 & 159.4 & 160.1 \\
\hline 161.6 & 160.8 & 161.9 \\
\hline 163.1 & 160.2 & 162.8 \\
\hline 162.4 & 157.9 & 163.4 \\
\hline
\end{tabular}

\begin{tabular}{ccc}
\multicolumn{3}{c}{ Receiver } \\
\hline$\frac{C 1}{47.9}$ & $\frac{C 0}{47.8}$ & $\frac{\text { SUR }}{62.5}$ \\
54.1 & 55.9 & 60.8 \\
59.6 & 59.7 & 62.1 \\
58.1 & 58.3 & 61.6 \\
57.1 & 57.8 & 61.3 \\
56.5 & 56.5 & 62.1 \\
54.7 & 54.9 & 61.4 \\
53.0 & 52.6 & 60.6
\end{tabular}

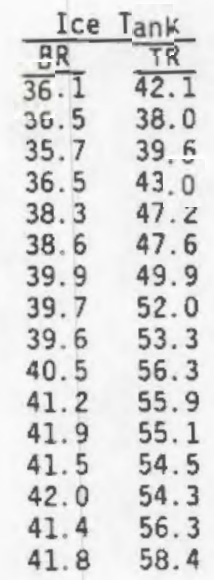

$\frac{\text { Time }}{3: 30} \quad \frac{\text { Pressure (psia) }}{0.1647}$

Average Flowrates (ggm)

Spray: 0.9 Cold: 3.5 Hot: 3.1

Total condensate removed this hot cycle (1bs): 6.853

FIGURE B-2-d. Data Printout 
Date: February 2, 1984

a $26.5 \mathrm{lbs} / 100 \mathrm{lbs}$

b $26.0 \mathrm{lbs} / 100 \mathrm{lbs}$

c $21.1 \mathrm{lbs} / 100 \mathrm{lbs}$

d $20.3 \mathrm{Tbs} / 100 \mathrm{Tbs}$

e 25.2 lbs based on ice in the tank

$b-c=4.9$ lbs

$\mathrm{a}-\mathrm{d}=6.2 \mathrm{lbs}$

measured 5.64 ibs

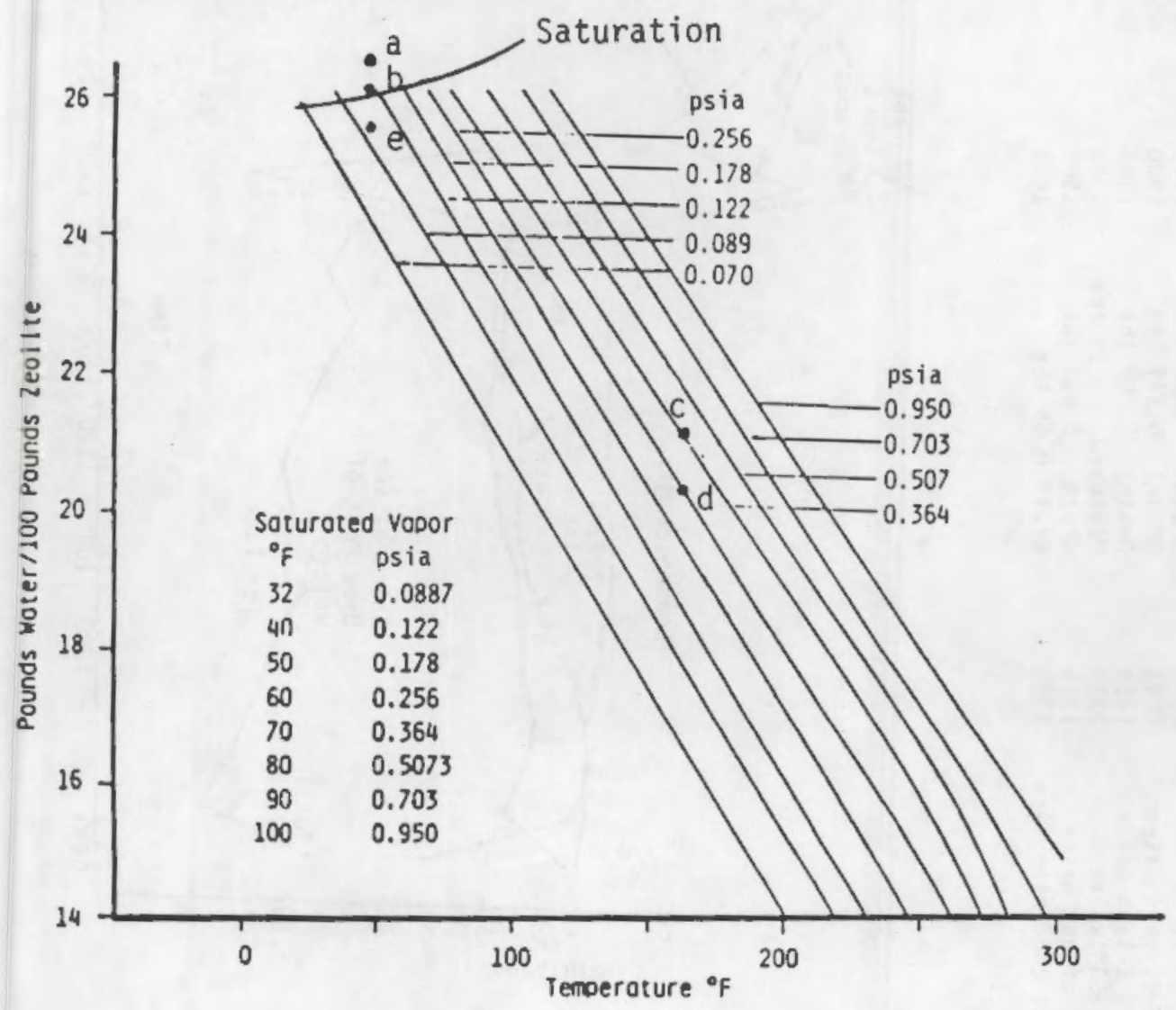

FIGURE B-3-a. Zeolite Isobars 


\begin{tabular}{|c|c|c|c|c|c|}
\hline $\begin{array}{l}\text { Start Z-tank filling } \\
\text { Open } 3^{\text {" valve }} \\
\text { Full of cold water } \\
\text { Start Z-tank drain } \\
\text { Close } 3^{n} \text { valve } \\
\text { Full of hot water } \\
\text { Start condenser flow }\end{array}$ & $\begin{array}{l}0834 \\
0834 \\
0845 \\
1259 \\
1259 \\
1315 \\
1320\end{array}$ & $\begin{array}{l}\text { Orain: } 1 \\
\text { Drain: } 1 \\
\text { Drain: } 0 \\
\text { Orain: } 0 \\
\text { Measured: } \\
\text { Orain: } 0 \\
\text { Drain } 0.5\end{array}$ & $\begin{array}{l}1.342 \text { lbs } \\
1.008 \text { lbs } \\
0.847 \text { lbs } \\
0.360 \text { lbs } \\
04.35 \mathrm{lbs} \\
0.847 \mathrm{lbs} \\
55 \mathrm{lbs}\end{array}$ & $\begin{array}{l}1320 \\
1320 \\
1330 \\
1345 \\
1355 \\
1500 \\
1601\end{array}$ & $\begin{array}{l}\text { Drain: } 0.123 \\
\text { Medsured: } 1.3 \text { los } 1612 \\
\text { Adsorption: cold water flow, } 3.3 \mathrm{gpm} \\
\text { Desorption: cold water flow, } 3.5 \mathrm{gpm} \\
\\
\text { hot water flow, } 3.2 \mathrm{gpm}\end{array}$ \\
\hline
\end{tabular}

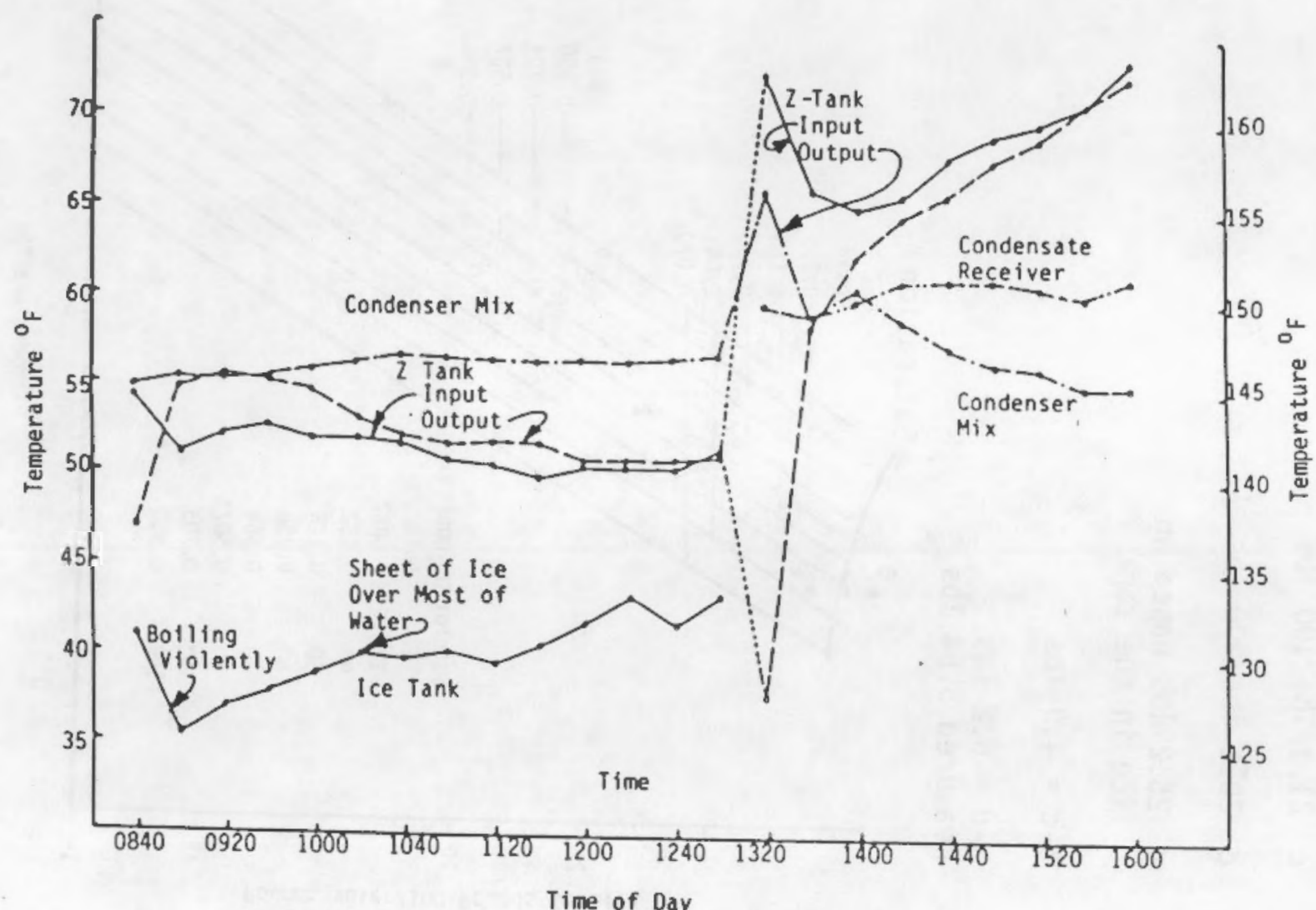

FIGURE B-3-b. Data Run, February 2, 1984 
$\infty$

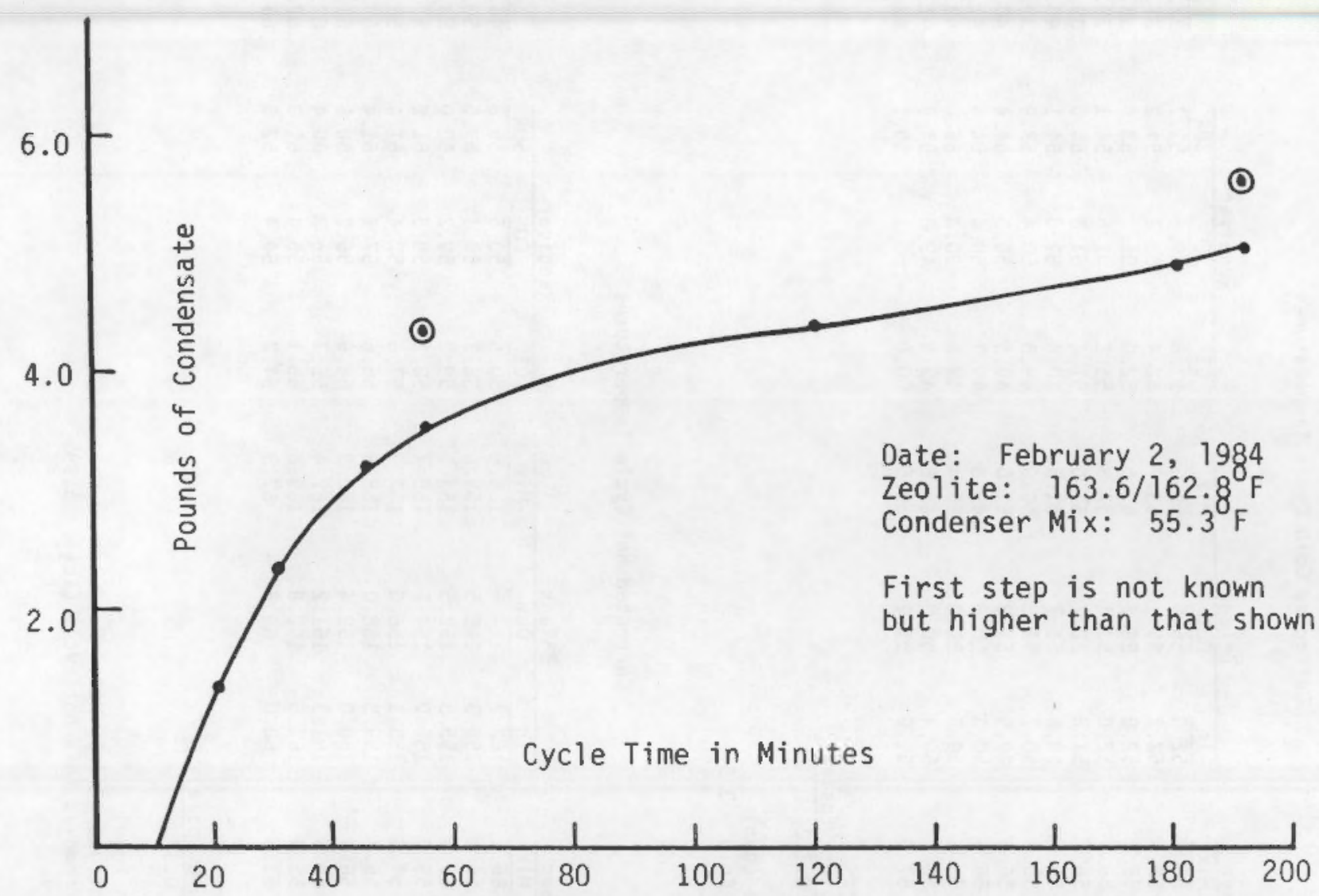

FIGURE B-3-c. Desorption Response 
DATE PROGRAMMED: $\quad 3-5-84$

DATE DATA COLLECTED: $\quad 2-2-84$

Corrected Cold Cycle Temperatures

\begin{tabular}{|c|c|c|c|c|}
\hline Time & Condenser & & Z-Tank & \\
\hline & out $\quad$ Mix & In & Out & Mix \\
\hline $9: 20$ & $\overline{55.3}$ & $\overline{52.0}$ & $\overline{55.6}$ & $\overline{55.6}$ \\
\hline $9: 40$ & 55.6 & 52.7 & 55.1 & 53.7 \\
\hline $10: 00$ & 56.0 & 52.0 & 54.6 & 53.5 \\
\hline $10: 20$ & 56.3 & 52.0 & 53.1 & 52.8 \\
\hline $10: 40$ & 56.7 & 51.8 & 52.2 & 52.0 \\
\hline $11: 00$ & 56.6 & 50.8 & 51.7 & 51.5 \\
\hline $11: 20$ & 56.5 & 50.7 & 51.8 & 50.9 \\
\hline $11: 40$ & 56.5 & 49.9 & 51.8 & 51.0 \\
\hline $12: 00$ & 56.5 & 50.3 & 50.8 & 49.8 \\
\hline $12: 20$ & 56.5 & 50.3 & 51.0 & 50.4 \\
\hline $12: 40$ & 56.7 & 50.4 & 50.9 & 49.6 \\
\hline $1: 00$ & 57.0 & 51.6 & 51.2 & 50.5 \\
\hline
\end{tabular}

\begin{tabular}{ccc}
\multicolumn{3}{c}{ Receiver } \\
\hline$\frac{\text { C1 }}{51.8}$ & $\frac{\text { CO }}{52.8}$ & $\frac{\text { SUR }}{51.7}$ \\
52.4 & 53.2 & 54.2 \\
52.0 & 51.7 & 53.9 \\
51.2 & 51.6 & 54.1 \\
51.1 & 51.3 & 54.0 \\
50.6 & 51.0 & 54.1 \\
49.8 & 50.4 & 53.9 \\
49.5 & 50.5 & 54.4 \\
49.7 & 50.4 & 54.4 \\
49.8 & 50.3 & 55.0 \\
49.8 & 49.8 & 54.9 \\
50.0 & 50.1 & 55.1
\end{tabular}

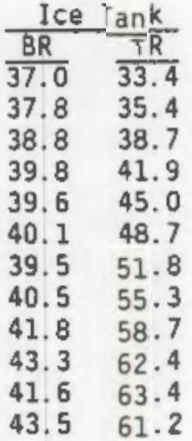

Time
$\begin{aligned} & \text { Pressure (psia) } \\ & 0.112\end{aligned}$
$\begin{array}{ll}\text { Average } & \text { Flowrates (gpm) } \\ \text { Spray: } 0.7 & \text { Cold: } 3.3\end{array}$

Corrected Hot Cycle Temperatures

\begin{tabular}{|c|c|c|}
\hline Time & \multicolumn{2}{|c|}{ Condenser } \\
\hline & out & Mix \\
\hline $1: 20$ & $\overline{64.5}$ & 66.1 \\
\hline $1: 40$ & 67.5 & 59.1 \\
\hline $2: 00$ & 61.1 & 60.6 \\
\hline $2: 20$ & 60.4 & 59.0 \\
\hline $2: 40$ & 60.4 & 7.5 \\
\hline $3: 00$ & 60.4 & 5.7 \\
\hline $3: 20$ & 57.5 & 5. \\
\hline $3: 40$ & 56.7 & \\
\hline $4: 00$ & 55.8 & \\
\hline $4: 20$ & 60.2 & 7 \\
\hline
\end{tabular}

\begin{tabular}{|c|c|c|}
\hline & $z-\operatorname{Tan} k$ & \\
\hline In & out & Mix \\
\hline$\overline{162.7}$ & $\overline{127.6}$ & $\overline{136.9}$ \\
\hline 156.3 & 148.5 & 155.0 \\
\hline 155.3 & 152.5 & 153.1 \\
\hline 156.0 & 154.6 & 155.7 \\
\hline 158.1 & 156.0 & 157.3 \\
\hline 159.3 & 158.0 & 158.8 \\
\hline 160.0 & 159.4 & 160.3 \\
\hline 161.3 & 161.2 & 162.4 \\
\hline 163.6 & 162.8 & 163.6 \\
\hline 60.0 & 69.8 & 67.9 \\
\hline
\end{tabular}

\begin{tabular}{ccc}
\multicolumn{3}{c}{ Receiver } \\
$\frac{C 1}{50.5}$ & $\frac{C O}{50.5}$ & $\frac{\text { SUR }}{59.8}$ \\
58.3 & 59.1 & 59.5 \\
59.3 & 59.2 & 60.0 \\
58.3 & 58.3 & 61.2 \\
57.6 & 57.4 & 61.4 \\
56.6 & 57.1 & 61.4 \\
56.6 & 56.2 & 60.9 \\
55.7 & 55.8 & 60.4 \\
55.1 & 55.4 & 61.3 \\
54.2 & 54.4 & 52.5
\end{tabular}

\begin{tabular}{|c|c|}
\hline$\overline{B R}$ & TR \\
\hline$\overline{46.9}$ & $\overline{59.4}$ \\
\hline 50.2 & 62.4 \\
\hline 53.1 & 65.4 \\
\hline 55.6 & 67.7 \\
\hline 58.0 & 67.4 \\
\hline 59.4 & 69.5 \\
\hline 61. 1 & 69.4 \\
\hline 62.7 & 68.1 \\
\hline 63.9 & 67.4 \\
\hline
\end{tabular}

$\frac{\text { Time }}{4: 12} \quad \frac{\text { Pressure }(p s i a)}{0.37}$

Average Flowrates (gpm)

Spray: 0.55 Condenser: 3.6 Hot: 3

Total condensate removed this hot cycle (1bs): 5.995

FIGURE B-3-d. Data Prinout 
Date: February 7, 1984
a $26.6 \mathrm{lbs} / 100 \mathrm{lbs}$
b $26.1 \mathrm{lbs} / 100 \mathrm{lbs}$
c $21.2 \mathrm{lbs} / 100 \mathrm{lbs}$
d $20.4 \mathrm{lbs} / 100 \mathrm{lbs}$
$\mathrm{b}-\mathrm{c}=4.9 \mathrm{lbs}$
$\mathrm{a}-\mathrm{d}=6.2 \mathrm{lbs}$
measured 4.3 lbs

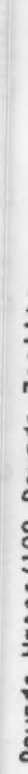

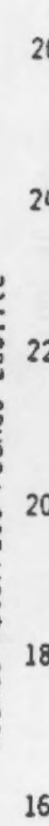

$26-1$

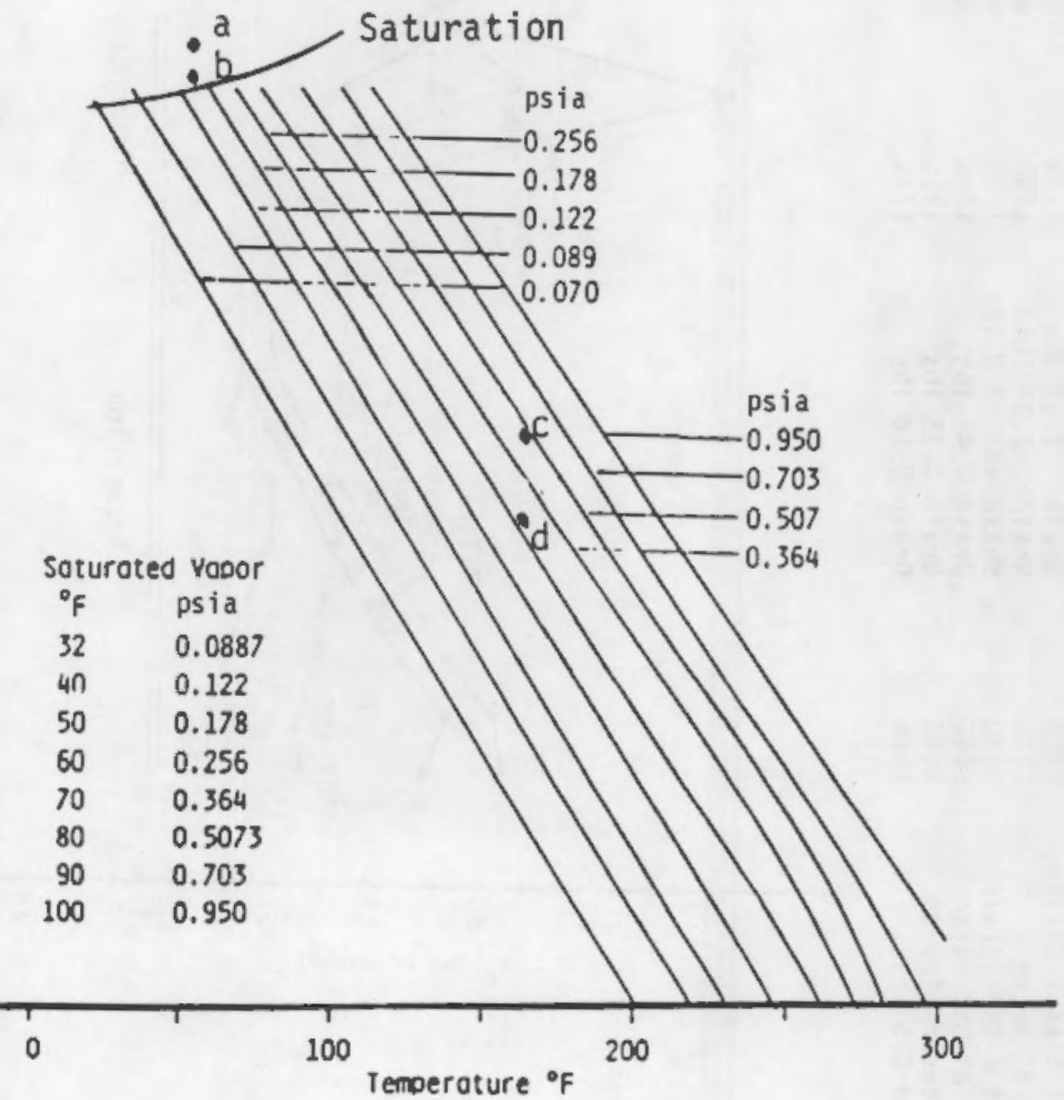

FIGURE B-4-a. Zeolite Isobars 


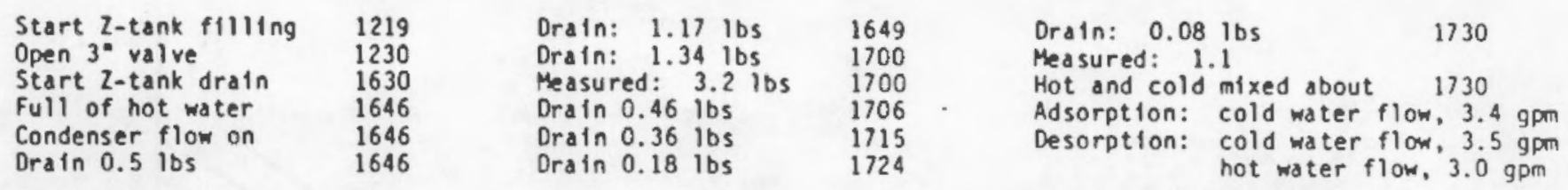

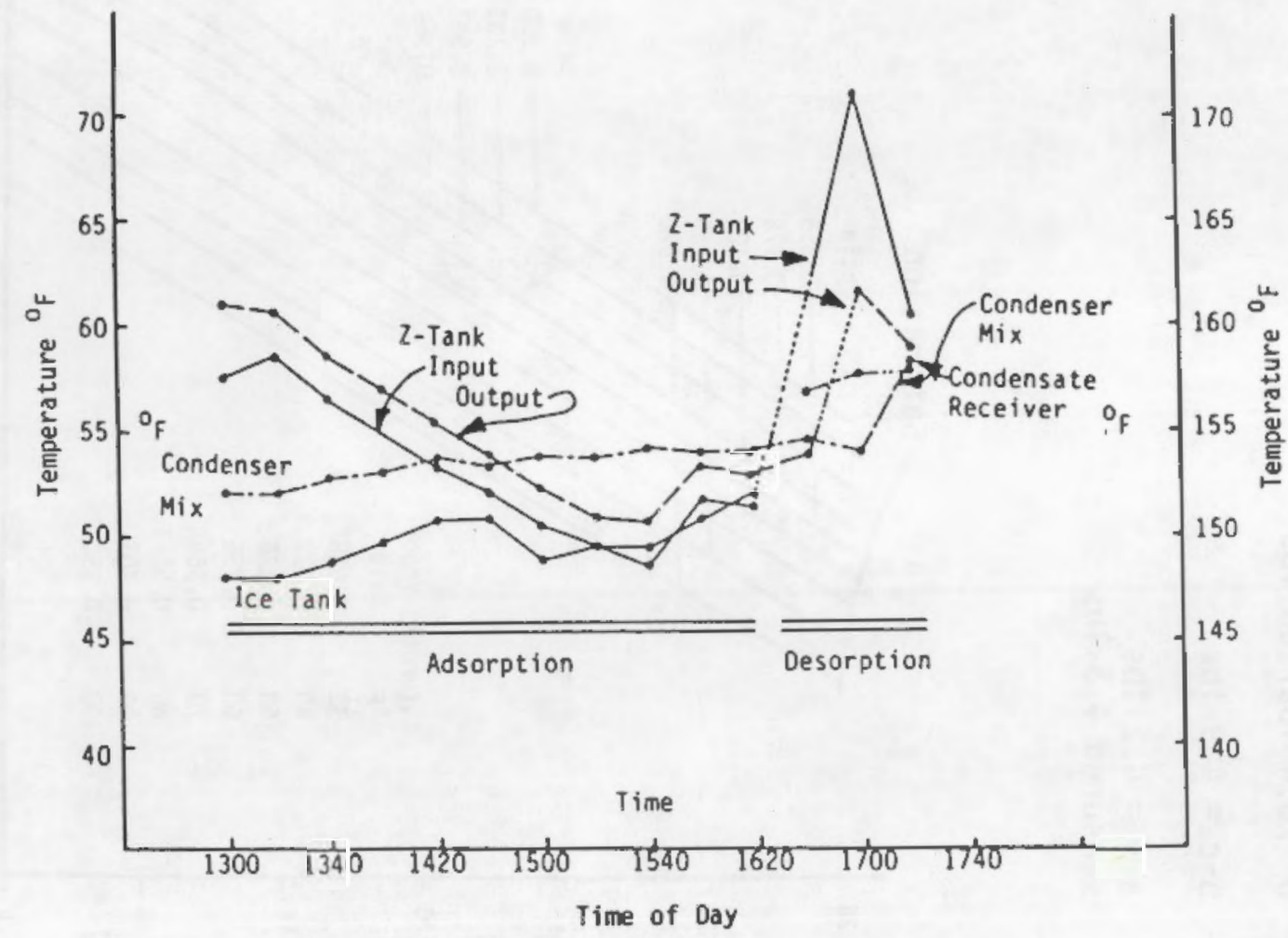

FIGURE B-4-b. Data Run, February 7, 1984 


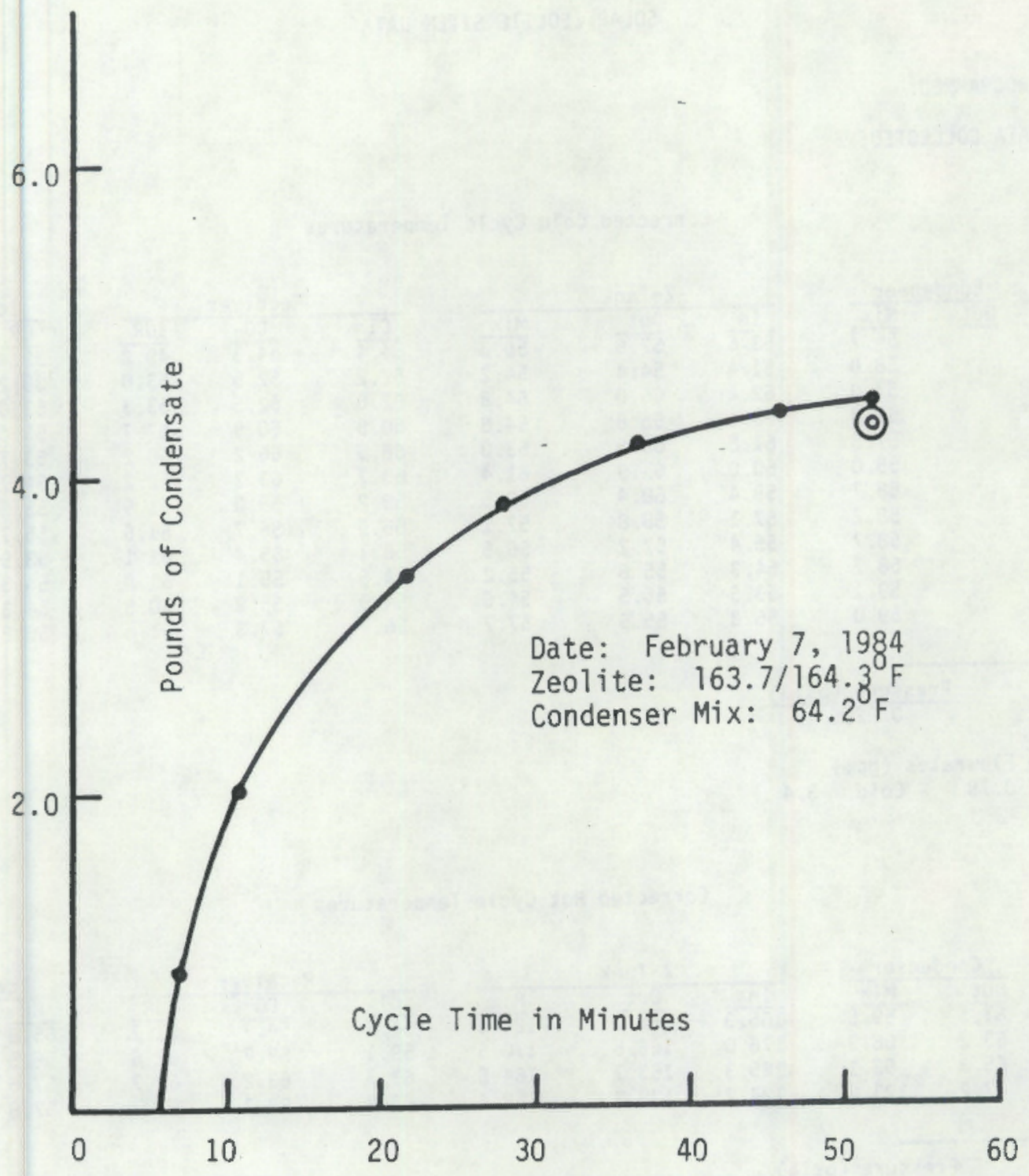

FIGURE B-4-c. Desorption Response 
DATE PROGRAMMED:

DATE DATA COLLECTED:

Corrected Cold Cycle Temperatures

\begin{tabular}{|c|c|c|c|c|c|c|c|c|c|}
\hline Time & Condenser & & $z-\operatorname{Tan} k$ & & & Receiv & & Ice & Tank \\
\hline & Out Mix & In & Out & Mix & $\mathrm{Cl}$ & $\mathrm{CO}$ & SUR & $\overline{B R}$ & TR \\
\hline 9:00 & $\overline{56.7}$ & $\overline{53.6}$ & $\overline{57.8}$ & $\overline{56.3}$ & $\overline{54.4}$ & $\overline{54.3}$ & $\overline{49.2}$ & $\overline{39.4}$ & $\overline{37.6}$ \\
\hline $9: 20$ & 58.0 & 51.4 & 54.4 & 54.2 & 52.2 & 52.5 & 53.0 & 39.2 & 35.8 \\
\hline 1:02 & 57.0 & 62.4 & 66.0 & 64.8 & 62.0 & 62.5 & 53.3 & 53.0 & 50.2 \\
\hline $1: 20$ & 57.0 & 63.5 & 65.6 & 64.8 & 60.5 & 60.9 & 57.7 & 53.0 & 50.2 \\
\hline $1: 40$ & 57.8 & 61.5 & 63.5 & 63.0 & 66.5 & 66.2 & 60.2 & 53.7 & 52.1 \\
\hline $2: 00$ & 58.0 & 60.0 & 61.9 & 61.4 & 63.7 & 63.7 & 62.2 & 54.7 & 51.9 \\
\hline $2: 20$ & 58.7 & 58.4 & 60.4 & 59.5 & 59.2 & 59.0 & 61.9 & 55.6 & 53.2 \\
\hline $2: 40$ & 58.2 & 57.1 & 58.8 & 57.1 & 56.9 & 56.7 & 61.6 & 55.7 & 54.3 \\
\hline $3: 00$ & 58.7 & 55.4 & 57.2 & 56.5 & 56.1 & 55.4 & 61.1 & 53.9 & 52.8 \\
\hline $3: 20$ & 58.7 & 54.3 & 55.8 & 55.2 & 54.6 & 55.1 & 61.0 & 54.3 & 52.0 \\
\hline $3: 40$ & 59.1 & 53.5 & 55.5 & 54.6 & 54.9 & 55.9 & 60.5 & 54.3 & 52.1 \\
\hline $4: 20$ & 59.0 & 56.3 & 55.5 & 57,7 & 56.7 & 57.3 & 61.6 & 56.8 & 54.6 \\
\hline
\end{tabular}

$\frac{\text { Time }}{3: 55} \quad \frac{\text { Pressure (psia) }}{0.2206}$

Average Flowrates (gpm)

Spray: 0.79 Cold: 3.4

Corrected Hot Cycle Temperatures

\begin{tabular}{|c|c|c|}
\hline Time & \multicolumn{2}{|c|}{ Condenser } \\
\hline & out & Mix \\
\hline $4: 40$ & 61.5 & 59.5 \\
\hline $5: 00$ & 63.2 & 58.9 \\
\hline $5: 20$ & 65.3 & 63.1 \\
\hline $5: 40$ & 77.2 & 123.8 \\
\hline
\end{tabular}

\begin{tabular}{|c|c|c|}
\hline & & \\
\hline$\frac{\text { In }}{165.3}$ & $\frac{\text { Out }}{58.7}$ & $\frac{\text { Mix }}{129.3}$ \\
\hline 176.0 & 166.5 & 170.5 \\
\hline 165.3 & 163.7 & 164.6 \\
\hline 127.2 & 128.3 & 158.4 \\
\hline
\end{tabular}

\begin{tabular}{|c|c|c|}
\hline \multicolumn{3}{|c|}{ Receiver } \\
\hline$\frac{C 1}{54.6}$ & $\frac{\mathrm{CO}}{54.7}$ & $\frac{\text { SUR }}{\frac{61.7}{4}}$ \\
\hline 59.1 & 59.7 & 62.6 \\
\hline 63.7 & 63.2 & 62.7 \\
\hline 63.3 & 63.1 & 61.7 \\
\hline
\end{tabular}

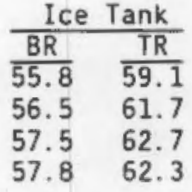

$\frac{\text { Time }}{5: 30} \quad \frac{\text { Pressure (psia) }}{0.6052}$

\section{Average Flowrates (gpm)}

Spray: 0.7 Condenser: 3.5 Hot: 3

Total condensate removed this hot cycle (lbs): 4.29

FIGURE B-4-d. Data Prinout 
Date: February 10, 1984

a $27.2 \mathrm{lbs} / 100 \mathrm{lbs}$

b 26.7 lbs/100 lbs

c $21.4 \mathrm{lbs} / 100 \mathrm{lbs}$

d $20.0 \mathrm{lbs} / 100 \mathrm{lbs}$

$b-c=5.3 \mathrm{lbs}$

$\mathrm{a}-\mathrm{d}=7.2 \mathrm{lbs}$

measured 6.4 lbs

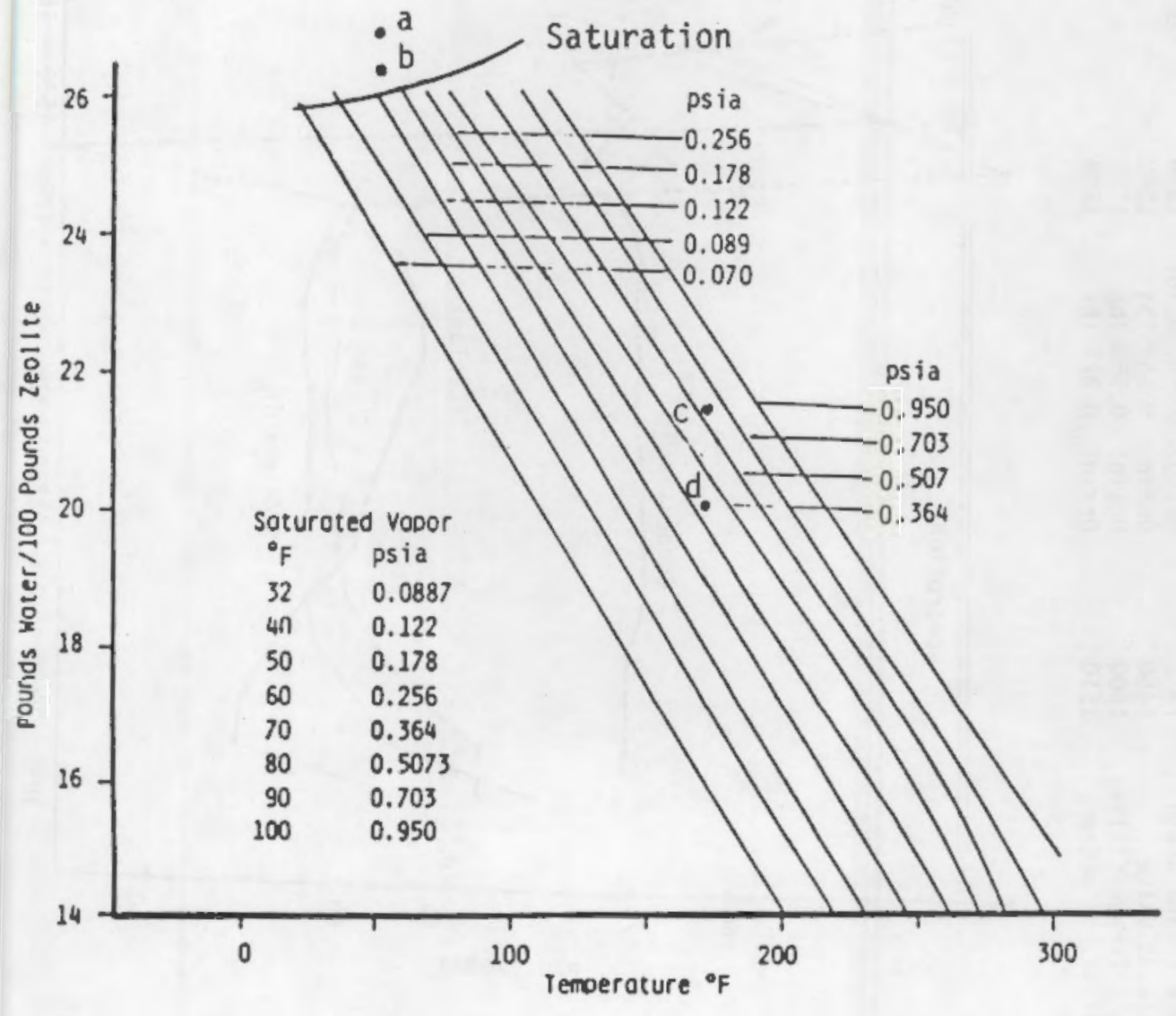

FIGURE B-5-a. Zeolite Isobars 


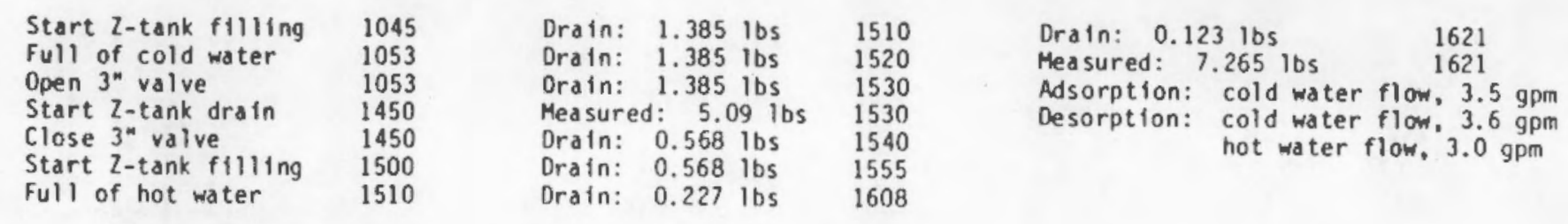

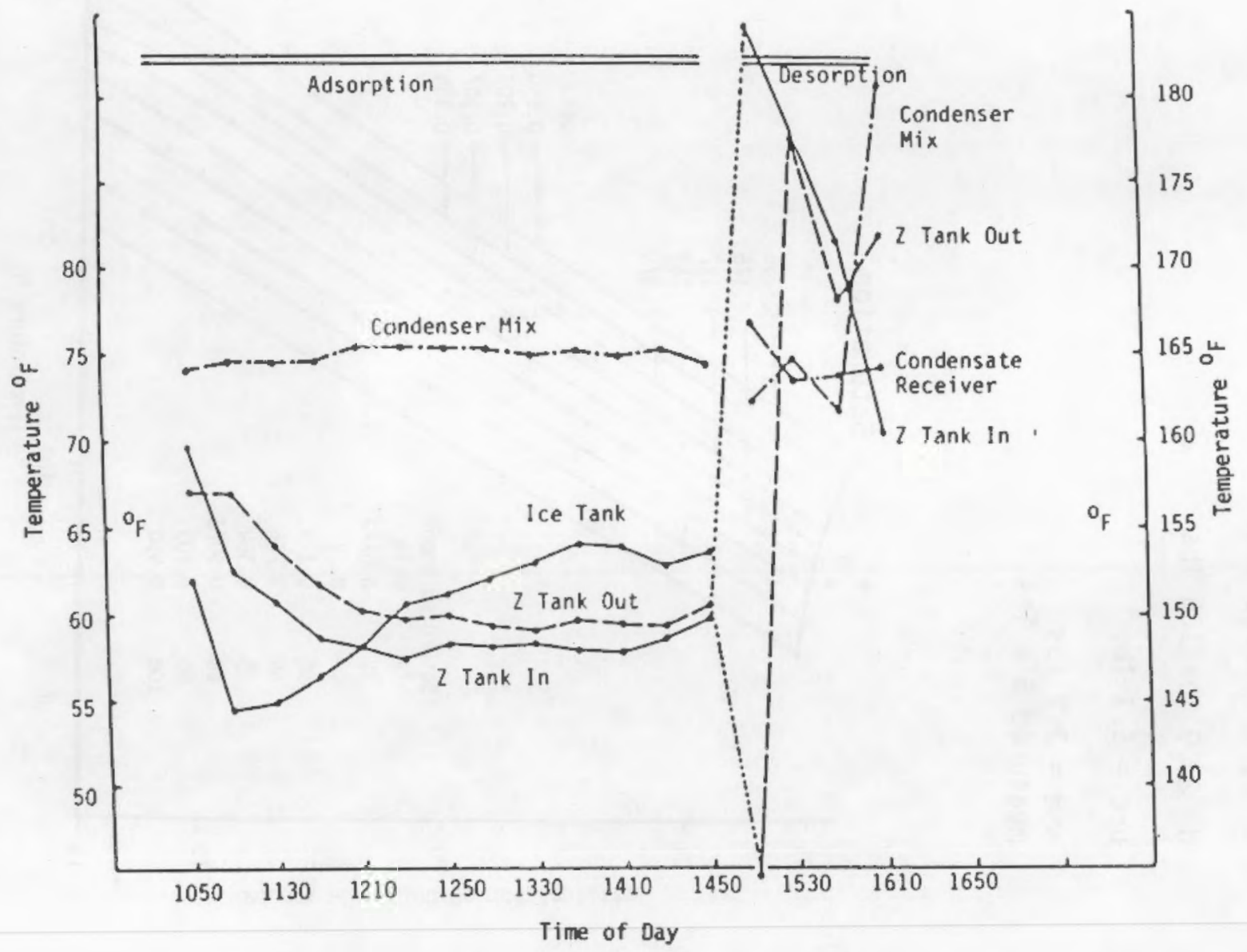

FIGURE B-5-b. Data Run, February 10, 1984 


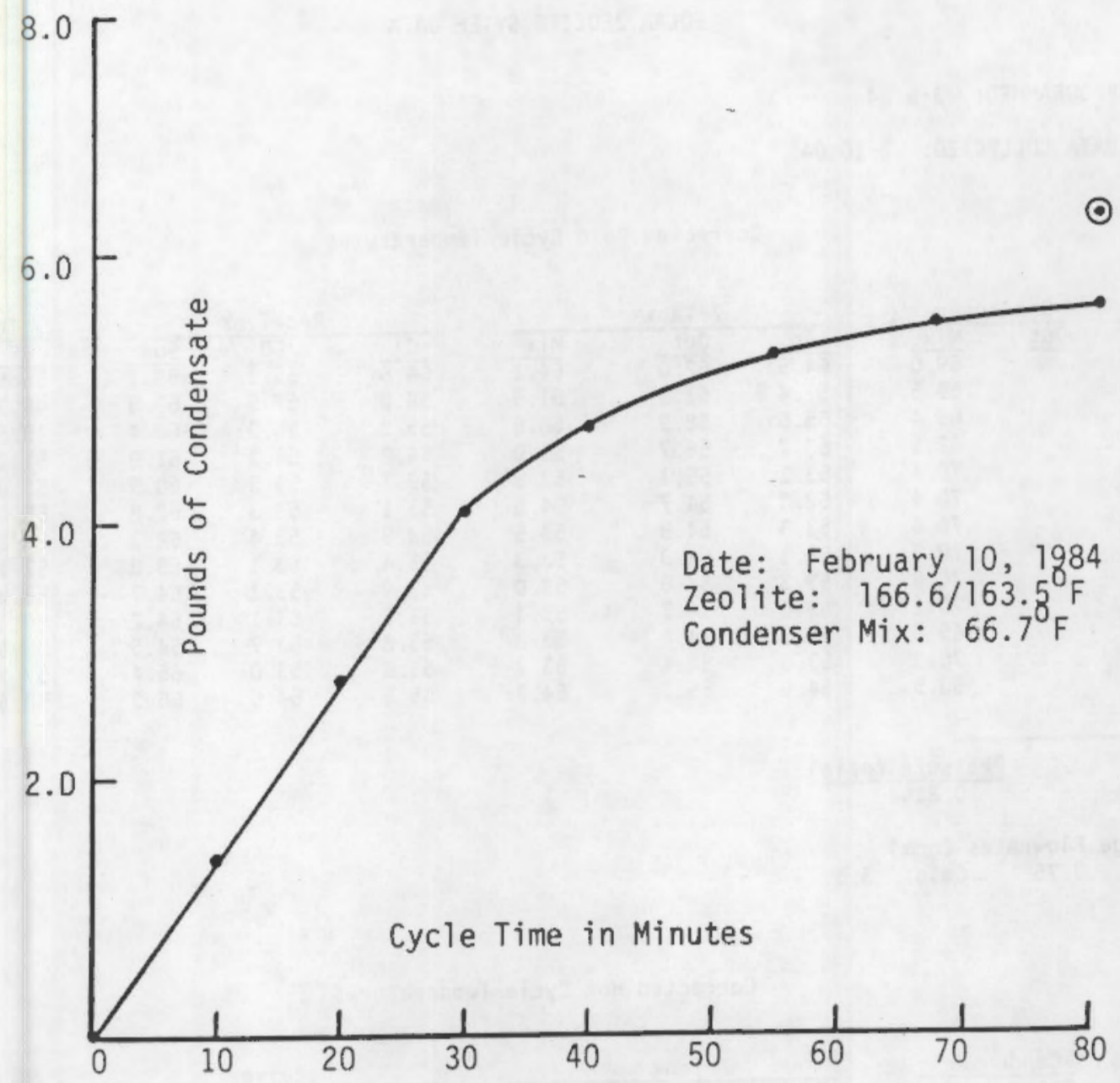

FIGURE B-5-c. Desorption Response 
DATE PROGRAMMED: $\quad 3-6-84$

DATE DATA COLLECTED: $2-10-84$

Corrected Cold Cycle Temperatures

\begin{tabular}{|c|c|}
\hline Time & Con \\
\hline & out \\
\hline $10: 50$ & \\
\hline $11: 10$ & \\
\hline $11: 30$ & \\
\hline $11: 50$ & \\
\hline $12: 10$ & \\
\hline $12: 30$ & \\
\hline $12: 50$ & \\
\hline $1: 10$ & \\
\hline $1: 30$ & \\
\hline $1: 50$ & \\
\hline $2: 10$ & \\
\hline $2: 30$ & \\
\hline $2: 50$ & \\
\hline
\end{tabular}

\begin{tabular}{lll} 
& Z-Tank \\
In & $\frac{\text { Out }}{62.0}$ & $\frac{\text { Mix }}{64.1}$ \\
\hline 6.5 & 61.9 & 61.9 \\
57.4 & 61.9 & 58.6 \\
55.6 & 58.9 & 55.0 \\
53.7 & 56.7 & 53.8 \\
53.1 & 55.1 & 54.5 \\
52.3 & 54.7 & 53.5 \\
53.3 & 54.9 & 53.3 \\
53.1 & 54.3 & 53.0 \\
53.3 & 54.0 & 53.1 \\
53.0 & 54.7 & 53.3 \\
52.9 & 54.5 & 53.7 \\
53.6 & 54.4 & 54.2
\end{tabular}

\begin{tabular}{lcc}
\multicolumn{3}{c}{ Receiver } \\
\hline$\frac{C 1}{64.6}$ & $\frac{C O}{65.1}$ & $\frac{\text { SUR }}{59.1}$ \\
58.0 & 57.9 & 60.5 \\
55.8 & 55.3 & 60.4 \\
54.2 & 54.1 & 61.0 \\
52.7 & 53.3 & 60.9 \\
53.1 & 53.3 & 62.8 \\
53.9 & 53.4 & 62.7 \\
53.4 & 53.1 & 63.8 \\
53.9 & 53.1 & 64.7 \\
53.5 & 53.1 & 64.2 \\
53.8 & 53.7 & 54.5 \\
53.8 & 53.0 & 65.4 \\
55.5 & 54.9 & 66.3
\end{tabular}

\begin{tabular}{|c|c|}
\hline$B R$ & TR \\
\hline 56.9 & 60.3 \\
\hline 49.3 & 44.8 \\
\hline 49.8 & 45.8 \\
\hline 51.3 & 47.0 \\
\hline 53.0 & 49.6 \\
\hline 55.6 & 52.6 \\
\hline 56.2 & 53.3 \\
\hline 57.1 & 54.4 \\
\hline 58.0 & 54.6 \\
\hline $\begin{array}{l}59.1 \\
59\end{array}$ & 55.8 \\
\hline 57.9 & 56.2 \\
\hline 58.6 & 54.7 \\
\hline
\end{tabular}

$\frac{\text { Time }}{2: 50} \quad \frac{\text { Pressure (psia) }}{0.2164}$

Average Flowrates (gpm)

Spray: 0.75 Cold: 3.5

Corrected Hot Cycle Temperatures

\begin{tabular}{ccc} 
Time & \multicolumn{2}{c}{ Condenser } \\
$3: 10$ & $\frac{\text { out }}{67.3}$ & $\frac{\text { Mix }}{78.8}$ \\
$3: 30$ & 69.8 & 66.6 \\
$3: 50$ & 66.8 & 66.7 \\
$4: 10$ & 90.1 & 85.6
\end{tabular}

$\frac{\text { Time }}{4: 05} \quad \frac{\text { Pressure (psia) }}{0.5382}$

Average Flowrates (gpm)

Spray: 0.78 Condenser: 3.7 Hot: 3

Total condensate removed this hot cycle (lbs):

\begin{tabular}{ccc}
\multicolumn{3}{c}{ Receiver } \\
\hline$\frac{\text { CI }}{55.9}$ & $\frac{\text { CO }}{55.5}$ & $\frac{\text { SUR }}{71.8}$ \\
67.5 & 67.7 & 68.6 \\
65.8 & 65.2 & 68.8 \\
66.5 & 66.4 & 69.3
\end{tabular}

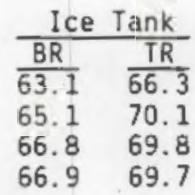

FIGURE B-5-d. Data Prinout 
Date: February 14, 1984

a $26.8 \mathrm{lbs} / 100 \mathrm{lbs}$

b $26.3 \mathrm{lbs} / 100 \mathrm{lbs}$

c $21.9 \mathrm{lbs} / 100 \mathrm{lbs}$

d $20.9 \mathrm{lbs} / 100 \mathrm{lbs}$

$\mathrm{b}-\mathrm{c}=4.4 \mathrm{lbs}$

$\mathrm{a}-\mathrm{d}=5.9 \mathrm{lbs}$

measured 6.8 lbs

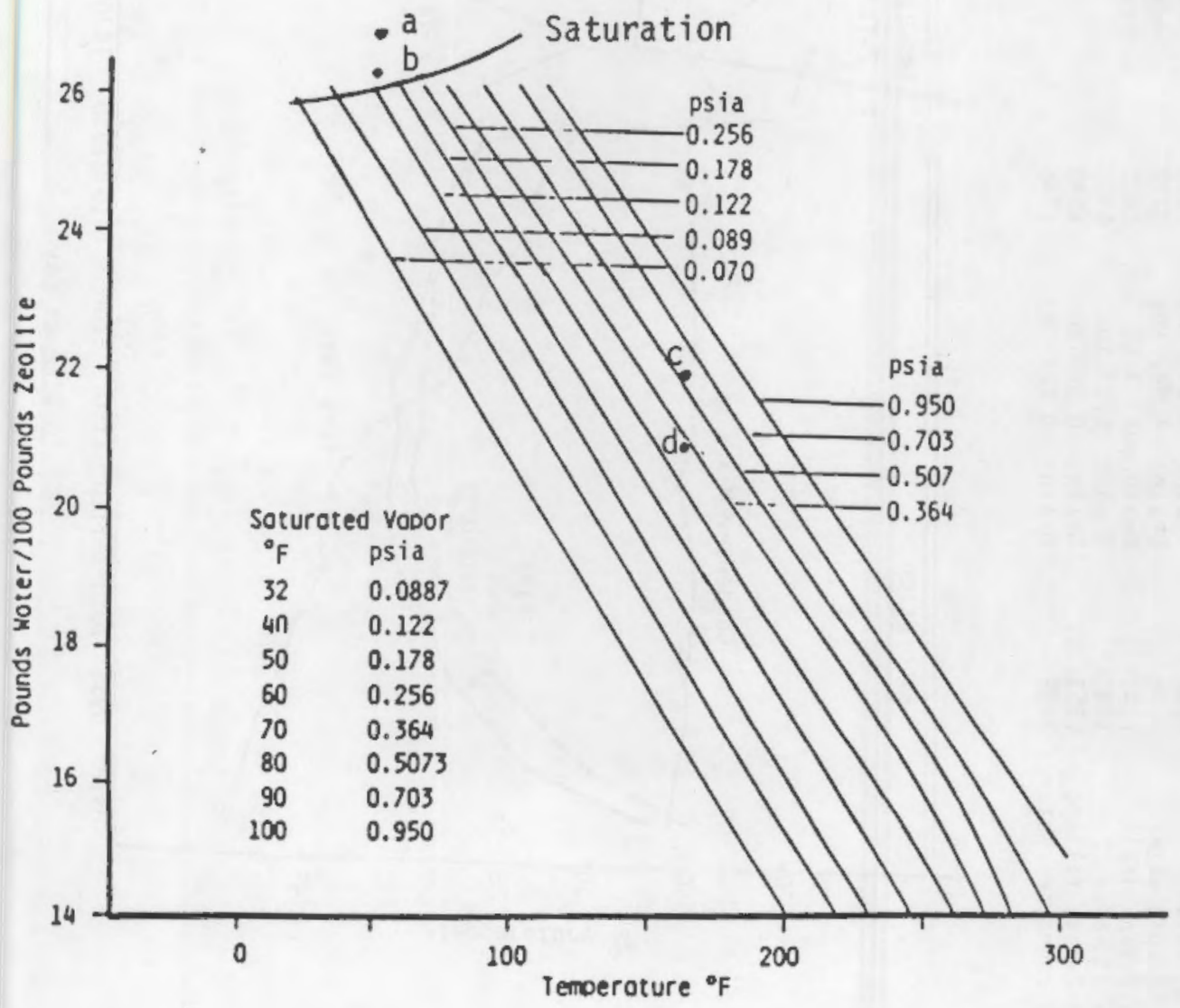

FIGURE B-6-a. Zeolite Isobars 


\begin{tabular}{|c|c|c|c|c|c|}
\hline $\begin{array}{l}\text { Start } 2 \text {-tank filling } \\
\text { Open } 3 \text { " valve } \\
\text { full of cold water } \\
\text { Start } 2 \text {-tank drain } \\
\text { Close } 3 " \text { valve } \\
\text { Start } 2 \text {-tank filling } \\
\text { Start condenser water }\end{array}$ & $\begin{array}{l}0900 \\
0908 \\
0908 \\
1343 \\
1343 \\
1353 \\
1402\end{array}$ & $\begin{array}{l}\text { Orain: } \\
\text { Ordin: } \\
\text { Orain: } \\
\text { Medsured } \\
\text { Orain: } \\
\text { Orain: } \\
\text { Ordin: }\end{array}$ & $\begin{array}{l}1.386 \text { lbs } \\
1.342 \text { ibs } \\
1.342 \text { los } \\
4.65 \text { los } \\
1.17 \text { ibs } \\
0.568 \text { lbs } \\
0.227 \text { ibs }\end{array}$ & $\begin{array}{l}1402 \\
1409 \\
1418 \\
1425 \\
1425 \\
1540 \\
1540\end{array}$ & $\begin{array}{l}\text { Orain: } 0.074 \text { lbs } 1552 \\
\text { Measured: } 2.15 \text { lbs } 1552 \\
\text { Adsorption: cold water flow, } 3.5 \mathrm{gpm} \\
\text { Desorption: cold water flow, } 3.5 \mathrm{gpm} \\
\text { hot water flow, } 3.0 \mathrm{gpm}\end{array}$ \\
\hline
\end{tabular}

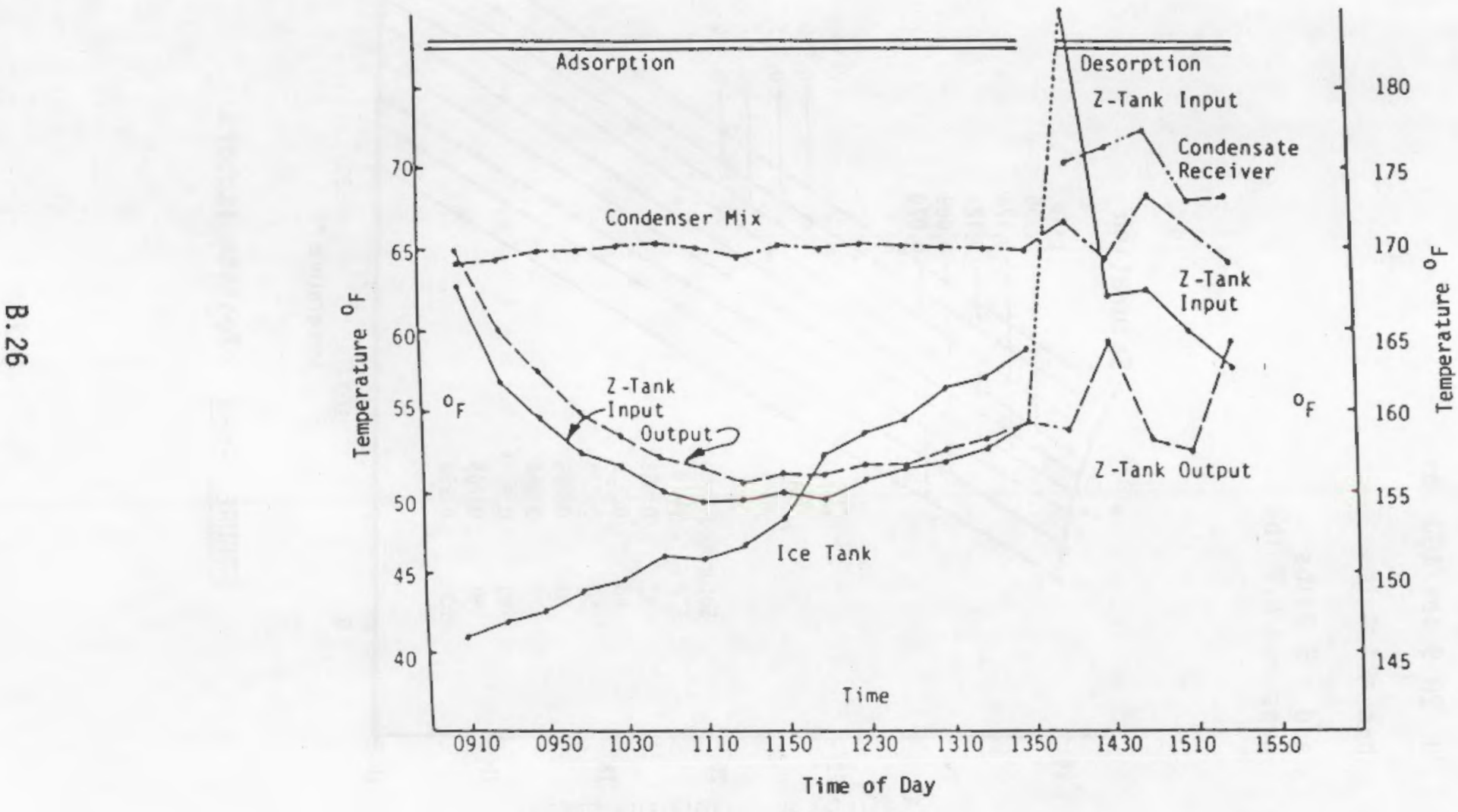

FIGURE B-6-b. Data Run, February 14, 1984 


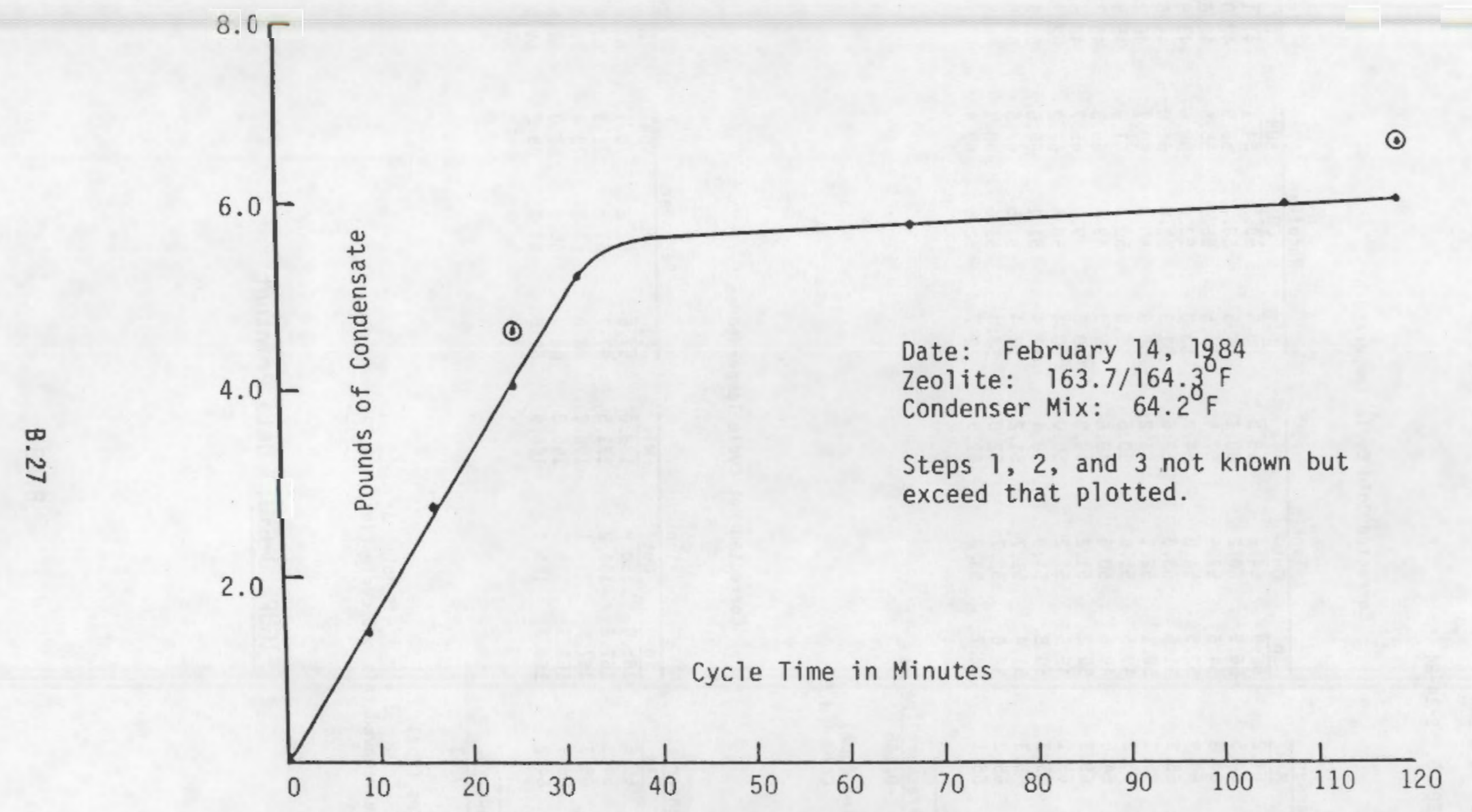

FIGURE B-6-C. Desorption Response 
SOLAR ZEOLITE SYSTEM DATA

DATE PROGRAMMED: $\quad 3-6-84$

DATE DATA COLLECTED: 2-14-84

Corrected Cold Cycle Temperatures

\begin{tabular}{|c|c|c|c|c|c|c|c|c|c|}
\hline Iime & Condenser & \multicolumn{3}{|c|}{$z-\operatorname{Tan} k$} & \multicolumn{3}{|c|}{ Receiver } & \multicolumn{2}{|c|}{ Ice Tank } \\
\hline & Out $\quad$ Mix & In & out & Mix & $\mathrm{Cl}$ & $\mathrm{CO}$ & SUR & $B R$ & TR \\
\hline $9: 10$ & $\overline{64.2}$ & $\overline{62.9}$ & $\overline{64.8}$ & $\overline{65.8}$ & $\overline{58.5}$ & $\overline{60.2}$ & $\overline{54.1}$ & $\overline{41.1}$ & $\overline{45.0}$ \\
\hline $9: 30$ & 64.5 & 56.9 & 60.2 & 60.1 & 57.5 & 58.2 & 56.9 & 42.0 & 37.9 \\
\hline $9: 50$ & 64.8 & 54.6 & 57.5 & 57.5 & 54.5 & 55.1 & 55.5 & 42.6 & 38.9 \\
\hline $10: 10$ & 64.9 & 52.5 & 54.8 & 54.8 & 53.0 & 52.6 & 58.6 & 43.9 & 40.0 \\
\hline $10: 30$ & 65.2 & 51.6 & 53.3 & 52.6 & 51.3 & 51.8 & 61.0 & 44.5 & 42.3 \\
\hline $10: 50$ & 65.3 & 50.1 & 52.1 & 51.2 & 50.5 & 50.8 & 60.7 & 46.2 & 44.0 \\
\hline 11: 10 & 65.2 & 49.5 & 51.6 & 50.5 & 49.5 & 50.0 & 61.9 & 45.9 & 43.4 \\
\hline $11: 30$ & 64.6 & 49.6 & 50.6 & 49.6 & 49.3 & 49.4 & 65.3 & 46.7 & 45.2 \\
\hline $11: 50$ & 65.3 & 50.2 & 51.2 & 49.9 & 49.5 & 49.5 & 65.7 & 48.5 & 46.7 \\
\hline $12: 10$ & 65.1 & 49.6 & 51.2 & 50.0 & 50.4 & 50.4 & 67.2 & 52.3 & 51.1 \\
\hline $12: 30$ & 65.3 & 50.8 & 51.9 & 50.4 & 51.4 & 51.1 & 68.5 & 53.6 & 52.2 \\
\hline $12: 50$ & 65.3 & 51.4 & 51.7 & 51.2 & 52.4 & 51.5 & 67.5 & 54.5 & 54.0 \\
\hline $1: 10$ & 65.2 & 52.0 & 52.7 & 52.0 & 53.4 & 51.6 & 68.3 & 56.5 & 55.8 \\
\hline $1: 30$ & 65.1 & 52.7 & 53.2 & 52.3 & 52.7 & 52.5 & 69.4 & 57.1 & 55.9 \\
\hline
\end{tabular}

\begin{tabular}{ll} 
Time & Pressure (psia) \\
\hline $1: 43$ & 0.146
\end{tabular}

Average Flowrates (gpm)

Spray: 0.75 Cold: 3.5

Corrected Hot Cycle Temperatures

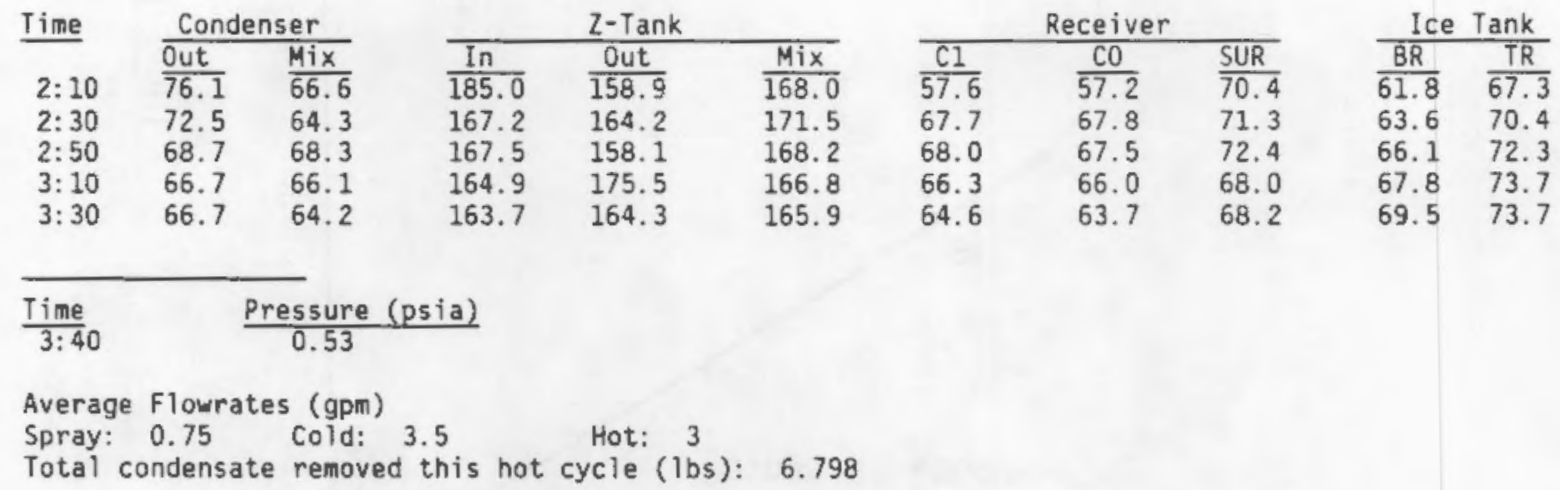

FIGURE B-6-d. Data Printout 
Date: February 18, 1984

a $26.7 \mathrm{lbs} / 100 \mathrm{lbs}$

b $26.4 \mathrm{lbs} / 100 \mathrm{lbs}$

c $22.2 \mathrm{lbs} / 100 \mathrm{lbs}$

d $20.8 \mathrm{lbs} / 100 \mathrm{lbs}$

$\mathrm{b}-\mathrm{c}=4.2 \mathrm{lbs}$

$a-d=5.9$ lbs

measured 5.15 lbs

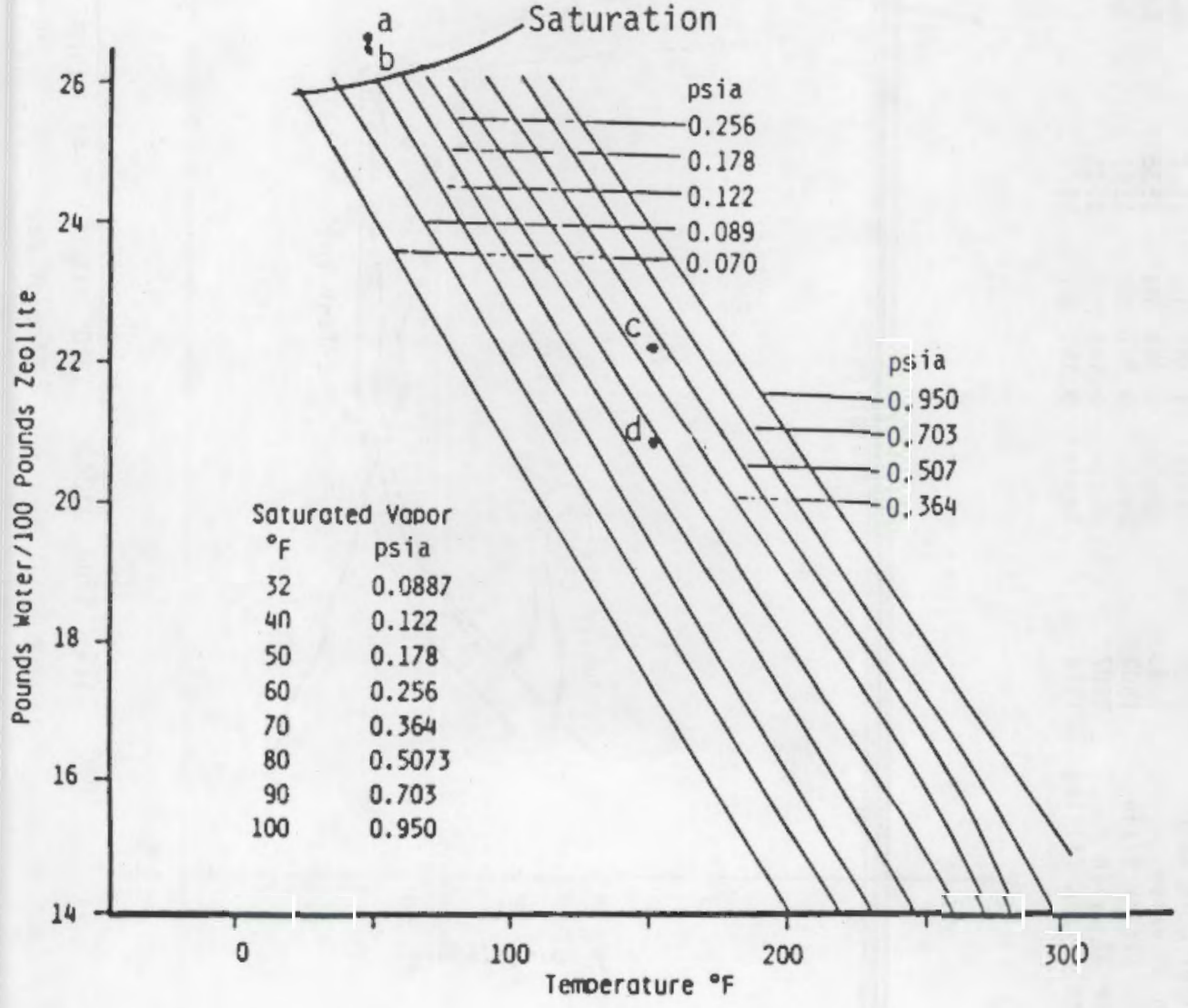

FIGURE B-7-a. Zeolite Isobars 


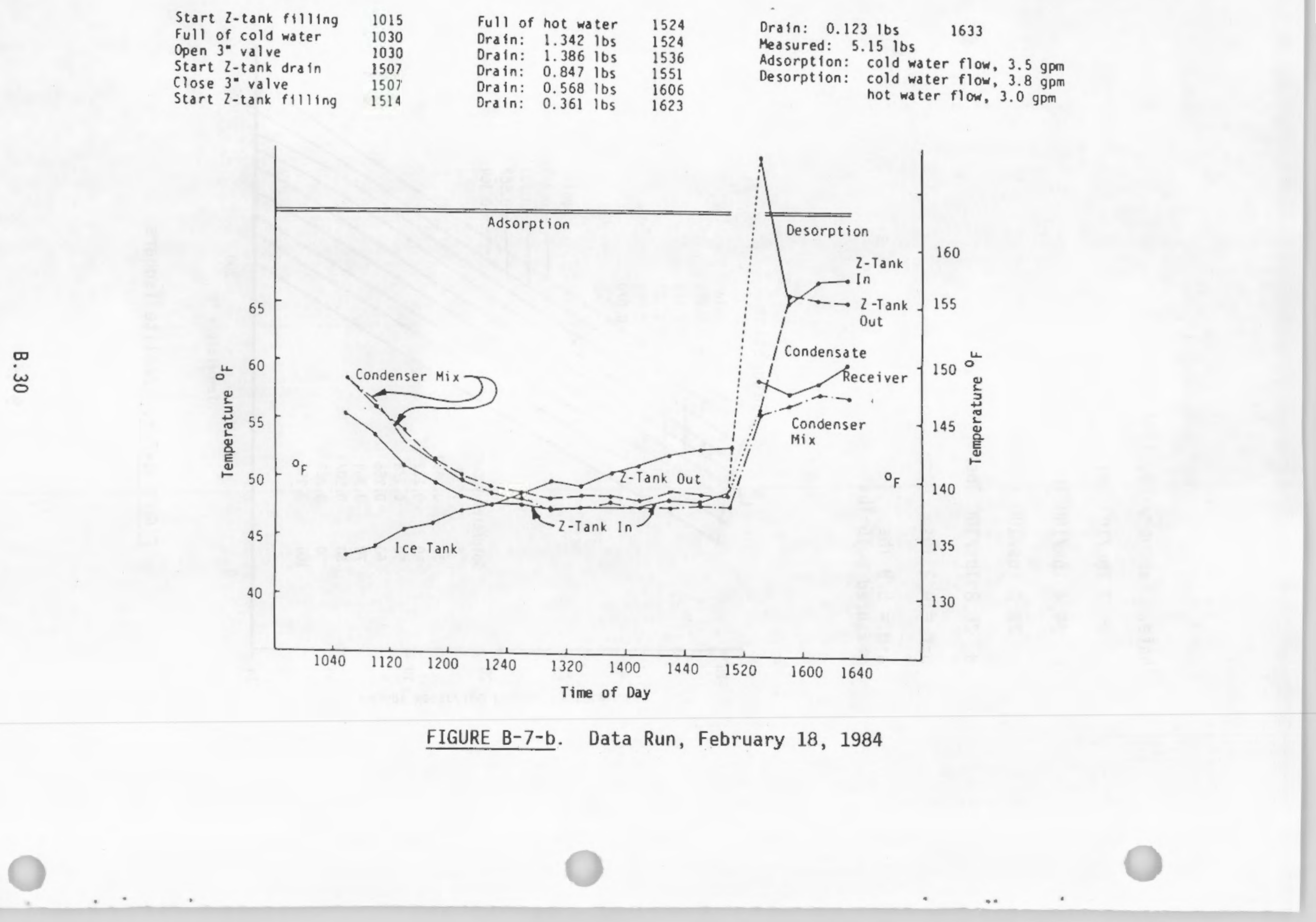




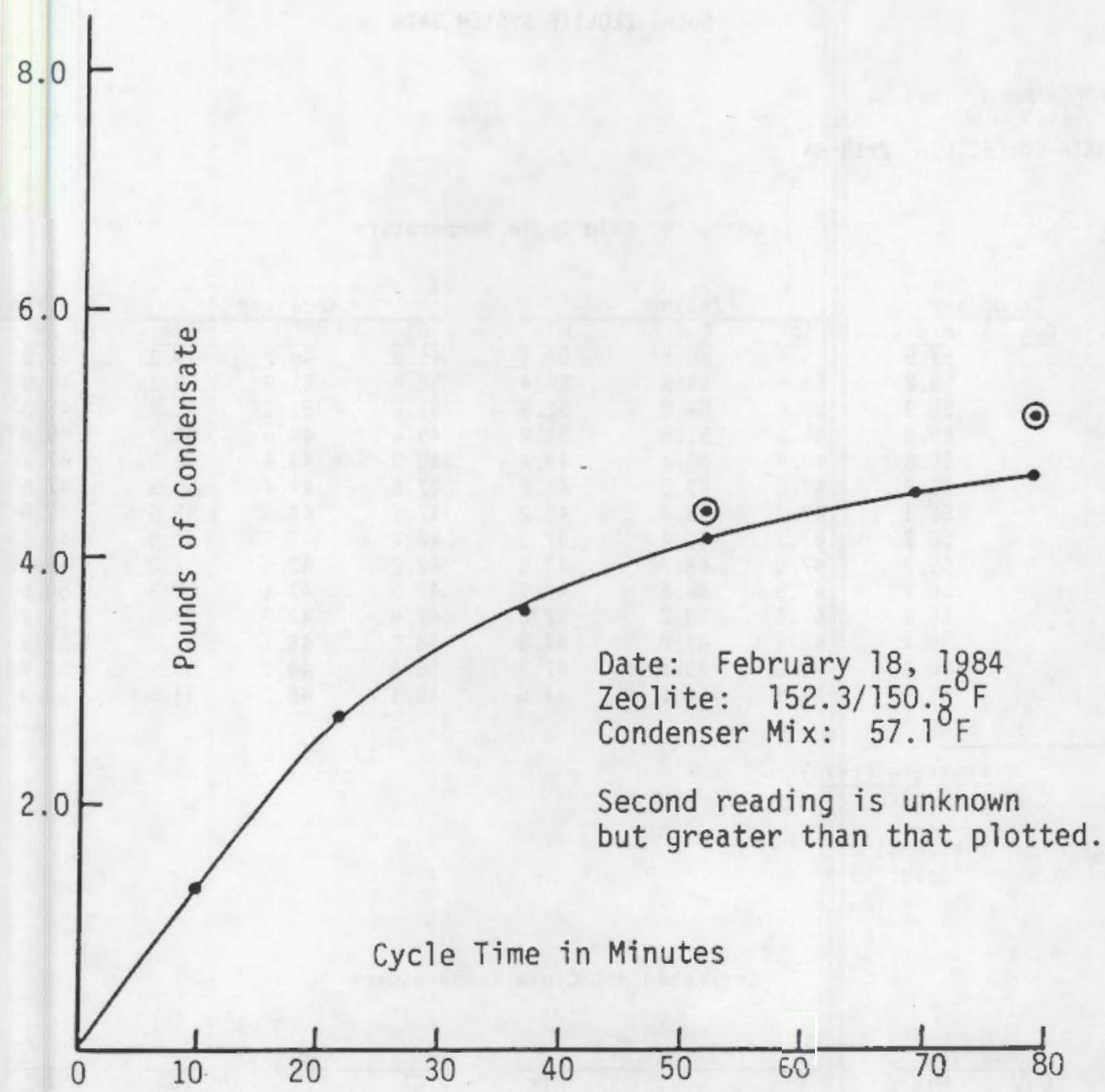

FIGURE B-7-c. Desorption Response 
DATE PROGRAMMED: $\quad 3-5-84$

DATE DATA COLLECTED: $2-18-84$

Corrected Cold Cycle Temperature

\begin{tabular}{|c|c|c|c|c|c|c|c|c|c|}
\hline \multirow{2}{*}{ Time } & Condenser & \multicolumn{3}{|c|}{ Z-Tank } & \multicolumn{3}{|c|}{ Receiver } & \multicolumn{2}{|c|}{ Ice Tank } \\
\hline & Out $\quad$ Mix & In & Out & Mix & C1 & $\mathrm{CO}$ & $\overline{\text { SUR }}$ & BR & TR \\
\hline $10: 50$ & $\overline{53.9}$ & 55.4 & 58.5 & 58.4 & 45.2 & $\overline{46.2}$ & 49.3 & $\overline{43.2}$ & 38.6 \\
\hline $11: 10$ & 55.2 & 53.6 & 55.9 & 56.4 & 50.6 & 51.9 & 50.2 & 43.9 & 39.8 \\
\hline $11: 30$ & 55.3 & 50.8 & 54.0 & 52.9 & 51.0 & 51.1 & 51.0 & 45.3 & 41.1 \\
\hline $11: 50$ & 55.8 & 49.5 & 51.6 & 51.2 & 49.4 & 49.6 & 51.7 & 45.8 & 42.4 \\
\hline $12: 10$ & 55.8 & 48.4 & 50.1 & 49.7 & 49.0 & 48.4 & 50.5 & 47.2 & 44.6 \\
\hline $12: 30$ & 56.3 & 47.6 & 49.3 & 48.6 & 47.6 & 47.4 & 50.9 & 47.6 & 44.5 \\
\hline $12: 50$ & 56.1 & 47.7 & 48.8 & 48.2 & 47.7 & 47.6 & 51.0 & 48.6 & 45.4 \\
\hline $1: 10$ & 56.2 & 47.2 & 48.4 & 47.2 & 47.2 & 47.5 & 50.9 & 49.6 & 45.9 \\
\hline $1: 30$ & 55.9 & 47.5 & 48.7 & 47.6 & 47.2 & 47.5 & 52.0 & 49.4 & 47.1 \\
\hline $1: 50$ & 56.2 & 47.5 & 48.6 & 47.9 & 47.5 & 47.1 & 52.3 & 50.5 & 48.1 \\
\hline $2: 10$ & 56.4 & 47.5 & 48.2 & 47.5 & 47.8 & 47.8 & 52.3 & 51.2 & 48.8 \\
\hline $2: 30$ & 56.4 & 48.2 & 49.0 & 47.5 & 48.5 & 48.1 & 53.2 & 52.1 & 50.4 \\
\hline $2: 50$ & 56.9 & 48.0 & 48.8 & 47.7 & 48.8 & 48.2 & 53.5 & 52.7 & 51.1 \\
\hline $3: 10$ & 56.6 & 48.8 & 48.6 & 47.6 & 49.1 & 48.2 & 54.6 & 52.9 & 55.9 \\
\hline
\end{tabular}

$\frac{\text { Time }}{3: 07} \quad \frac{\text { Pressure (psia) }}{0.1829}$

Average Flowrates (gpm)

Spray: 0.6 Cold: 3.5

Corrected Hot Cycle Temperatures

\begin{tabular}{|c|c|c|c|c|c|}
\hline \multirow{2}{*}{ Time } & \multicolumn{2}{|c|}{ Condenser } & \multicolumn{3}{|c|}{$z-\operatorname{Tan} k$} \\
\hline & out & Mix & In & Out & \\
\hline $3: 30$ & 59.7 & 55.7 & $\overline{162.9}$ & $\overline{141.1}$ & $\overline{148.7}$ \\
\hline & 59.5 & 56.4 & 150.2 & 151.0 & 151.3 \\
\hline & 61.0 & 57.4 & 152.2 & 150.5 & 151.9 \\
\hline & 59.0 & 57.1 & 152.3 & 150.2 & 152.2 \\
\hline
\end{tabular}

\begin{tabular}{|c|c|c|}
\hline \multicolumn{3}{|c|}{ Receiver } \\
\hline $\mathrm{Cl}$ & $\mathrm{CO}$ & SUR \\
\hline$\overline{50.6}$ & $\overline{52.4}$ & 58. \\
\hline 57.4 & 57.2 & 57.4 \\
\hline 57.9 & 57.7 & 58.5 \\
\hline 56.9 & 56.2 & 60.0 \\
\hline
\end{tabular}

\begin{tabular}{cc} 
Ice & Tank \\
\hline$\frac{\text { RR }}{54.6}$ & $\frac{T R}{58.5}$ \\
56.2 & 59.7 \\
56.9 & 60.0 \\
58.0 & 60.7
\end{tabular}

$\frac{\text { Time }}{4: 33} \quad \frac{\text { Pressure (psia) }}{0.4580}$

Average Flowrates (gpm)

Spray: 0.6 Cold: 3.8 Hot: 3

Total condensate removed this hot cycle (lbs): 5.148

FIGURE B-7-d. Data Printout 
Date: February 24, 1984
a 27.1 lbs/100 lbs
b 26.7 lbs/100 lbs
c 22.4 1bs/100 lbs
d $21 \mathrm{lbs} / 100 \mathrm{lbs}$
$\mathrm{b}-\mathrm{c}=4.3 \mathrm{lbs} / 100 \mathrm{ibs}$
$\mathrm{a}-\mathrm{d}=6.1 \mathrm{lbs} / 100 \mathrm{lbs}$
measured 6 lbs

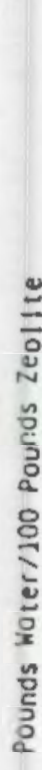

26
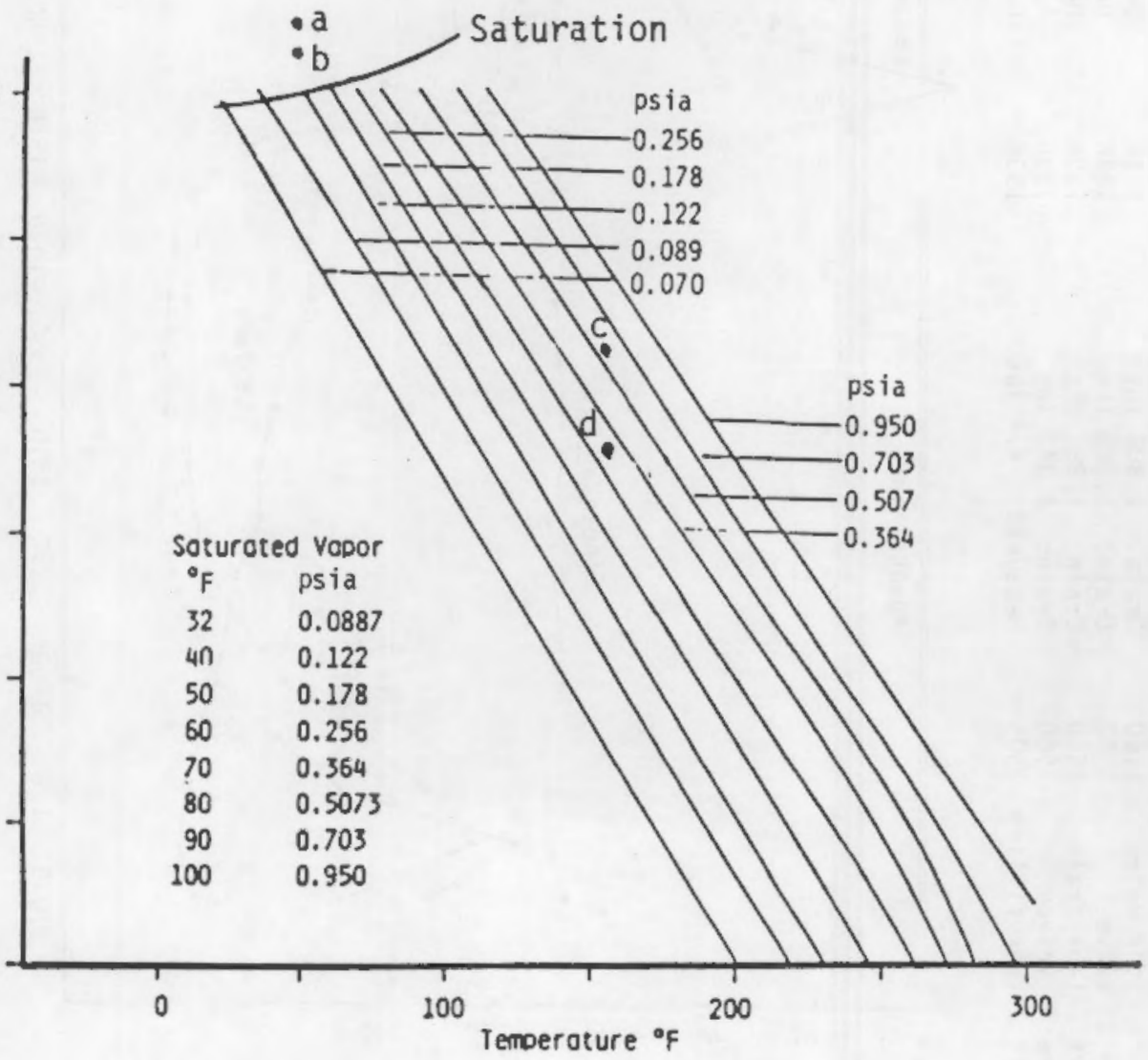

FIGURE B-8-a. Zeolite Isobars 


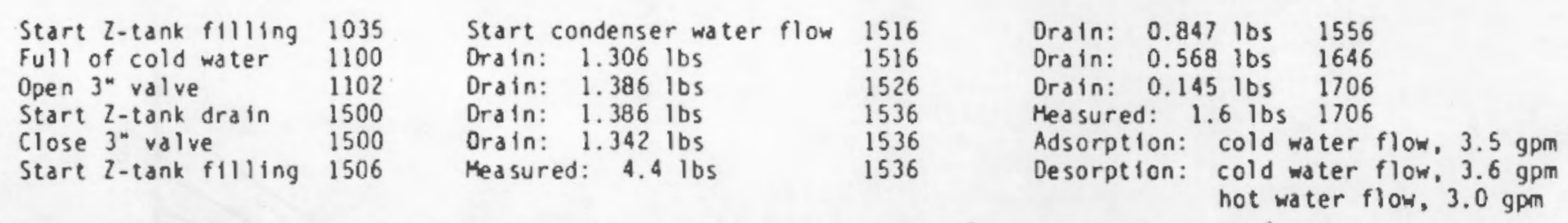

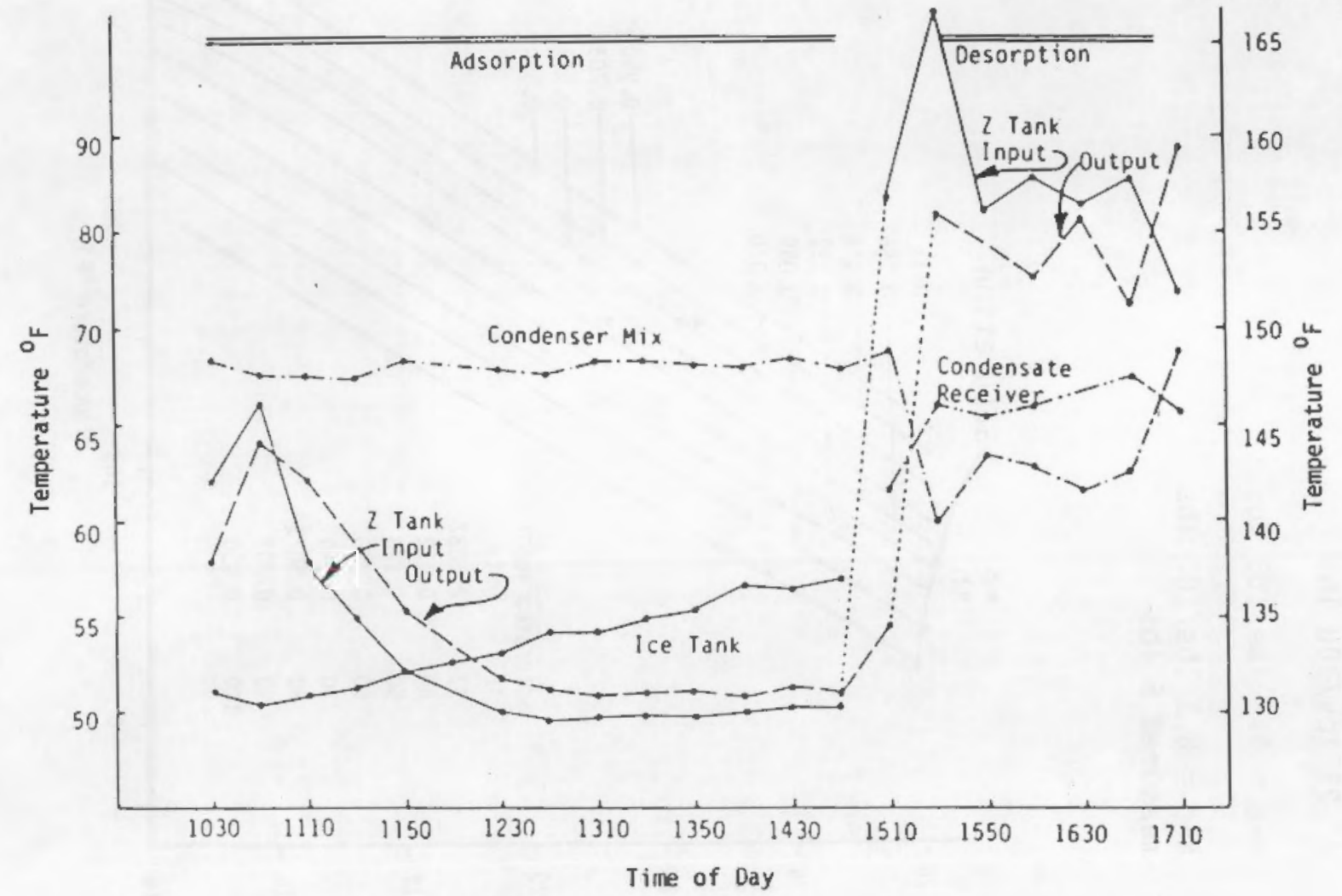

FIGURE B-8-b. Data Run, February 24, 1984 


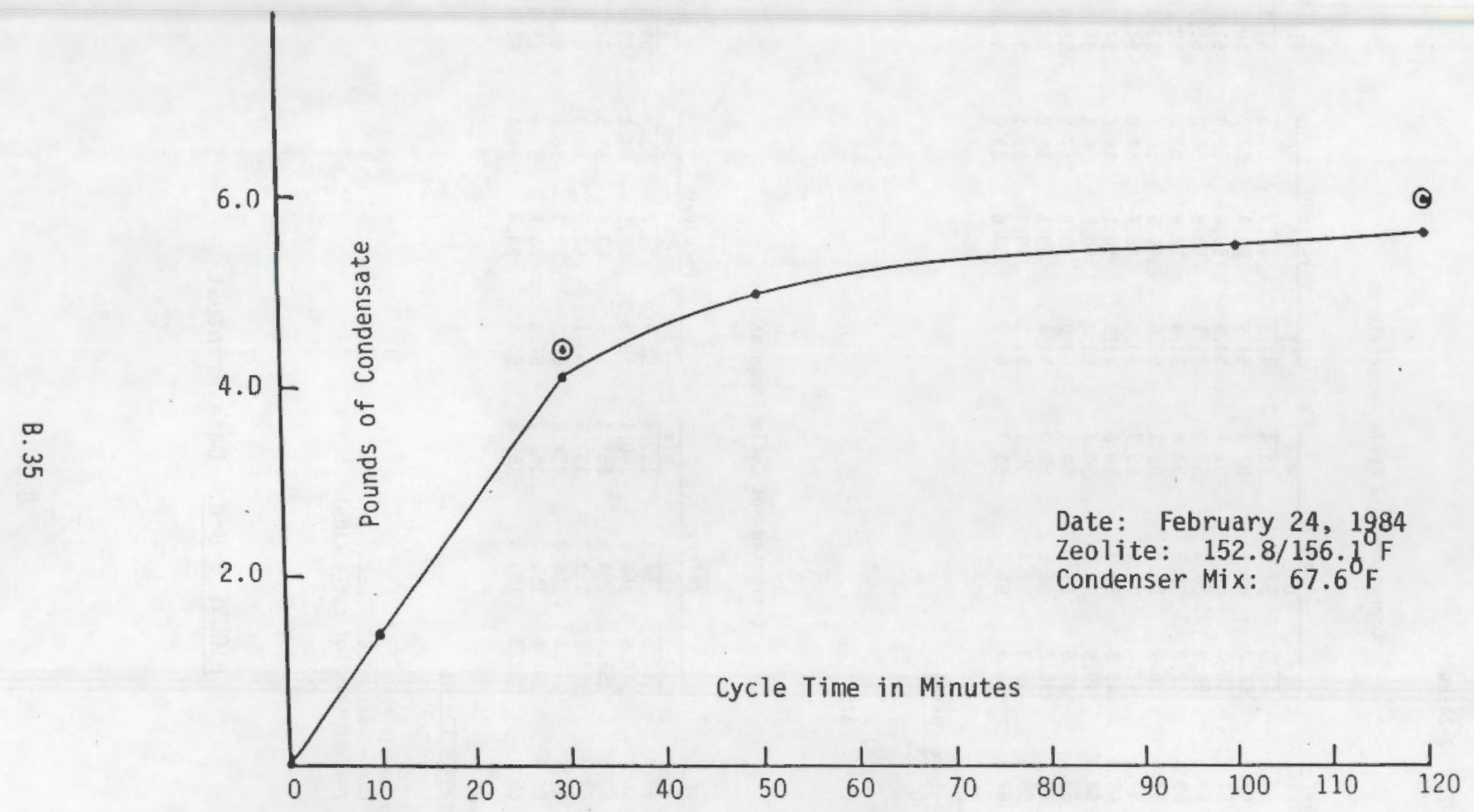

FIGURE B-8-C. Desorption Response 
SOLAR ZEOLITE SYSTEM DATA

DATE PROGRAMMED: 3-5-84

DATE DATA COLLECTED: 2-24-84

Corrected Cold Cycle Temperatures

\begin{tabular}{|c|c|c|c|c|c|c|c|c|c|}
\hline \multirow{2}{*}{ Iime } & Condenser & \multicolumn{3}{|c|}{$z$-Tank } & \multicolumn{3}{|c|}{ Receiver } & \multicolumn{2}{|c|}{ Ice Tank } \\
\hline & out $\quad$ Mix & In & out & Mix & $\overline{\mathrm{Cl}}$ & $\mathrm{CO}$ & SUR & $\mathrm{BR}$ & $T R$ \\
\hline $10: 30$ & $\overline{68.4}$ & 62.0 & $\overline{57.9}$ & $\overline{63.4}$ & $\overline{47.1}$ & $\overline{48.7}$. & $\overline{53.8}$ & $\overline{51.1}$ & $\overline{47.9}$ \\
\hline $10: 50$ & 67.7 & 66.2 & 64.2 & 67.8 & 64.9 & 66.4 & 57.7 & 50.5 & 54.5 \\
\hline $11: 10$ & 67.7 & 58.0 & 62.2 & 61.4 & 58.9 & 59.0 & 58.3 & 51.0 & 46.6 \\
\hline $11: 30$ & 67.5 & 54.9 & 58.0 & 57.3 & 55.1 & 54.9 & 58.2 & 51.3 & 47.3 \\
\hline $11: 50$ & 68.3 & 52.2 & 55.3 & 54.8 & 52.4 & 52.8 & 57.2 & 52.2 & 48.9 \\
\hline $12: 30$ & 67.9 & 50.1 & 51.9 & 51.1 & 50.0 & 49.8 & 55.7 & 53.2 & 50.7 \\
\hline $12: 50$ & 67.6 & 49.7 & 51.4 & 50.7 & 50.0 & 49.7 & 57.0 & 54.3 & 51.6 \\
\hline $1: 10$ & 68.3 & 49.8 & 51.0 & 50.8 & 49.5 & 50.1 & 56.2 & 54.3 & 51.6 \\
\hline $1: 30$ & 68.3 & 49.9 & 51.1 & 50.4 & 50.8 & 50.6 & 56.6 & 55.0 & 52.4 \\
\hline $1: 50$ & 68.1 & 49.8 & 51.2 & 50.1 & 50.0 & 49.8 & 57.5 & 55.4 & 52.9 \\
\hline $2: 10$ & 68.1 & 50.2 & 50.8 & 50.0 & 50.4 & 50.1 & 58.0 & 56.7 & 53.6 \\
\hline $2: 30$ & 68.5 & 50.3 & 51.4 & 50.3 & 51.1 & 50.7 & 59.1 & 56.5 & 55.0 \\
\hline $2: 50$ & 67.9 & 50.3 & 51.1 & 50.7 & 50.9 & 50.8 & 59.0 & 57.0 & 54.4 \\
\hline
\end{tabular}

$\frac{\text { Time }}{11: 51} \quad \frac{\text { Pressure (psia) }}{0.1922}$

Average flowrates (gpm)

Spray: 0.55 Cold: 3.5

Corrected Hot Cycle Temperatures

\begin{tabular}{|c|c|c|}
\hline Time & \multicolumn{2}{|c|}{ Condenser } \\
\hline & out & Mix \\
\hline $3: 10$ & $\overline{69.8}$ & $\overline{68.8}$ \\
\hline $3: 30$ & 66.6 & 60.2 \\
\hline $3: 50$ & 65.8 & 63.5 \\
\hline $4: 10$ & 62.7 & 62.9 \\
\hline $4: 30$ & 65.5 & 61.6 \\
\hline $4: 50$ & 63.5 & 62.6 \\
\hline $5: 10$ & 62.7 & 68.8 \\
\hline
\end{tabular}

$\frac{\text { Time }}{5: 06} \quad \frac{\text { Pressure (psia) }}{0.1829}$

Average Flowrates (gpm) Spray: 0.55 Condenser: 3.6 Hot: 3

Total condensate removed this hot cycle (Ibs): 5.995

\begin{tabular}{ccc}
\multicolumn{3}{c}{ Receiver } \\
\hline C1 & $\frac{\text { CO }}{51.9}$ & $\frac{\text { SUR }}{61.8}$ \\
59.5 & 60.1 & 66.1 \\
63.6 & 63.7 & 65.5 \\
63.1 & 62.0 & 66.0 \\
62.7 & 62.7 & 66.8 \\
64.3 & 63.1 & 67.6 \\
61.4 & 60.8 & 65.6
\end{tabular}

\begin{tabular}{|c|c|}
\hline$\overline{B R}$ & 00 \\
\hline 58.9 & $\frac{11}{62.8}$ \\
\hline 60.6 & 65.0 \\
\hline 62.7 & 66.3 \\
\hline 63.9 & 67.2 \\
\hline 65.4 & 68.3 \\
\hline 65.5 & 8.4 \\
\hline 65.8 & 67.9 \\
\hline
\end{tabular}

FIGURE B-8-d. Data Printout 
Date: February 28, 1984
a $26.6 \mathrm{lbs} / 100 \mathrm{lbs}$
a" $2.67 \mathrm{lbs} / 100 \mathrm{lbs}$
a' $26.6 \mathrm{lbs} / 100 \mathrm{lbs}$
b $26.2 \mathrm{lbs} / 100 \mathrm{lbs}$
b" $26.0 \mathrm{lbs} / 100 \mathrm{lbs}$
b' $26.0 \mathrm{lbs} / 100 \mathrm{lbs}$
c $22.6 \mathrm{lbs} / 100 \mathrm{lbs}$
c" $22.6 \mathrm{lbs} / 100 \mathrm{lbs}$
$c^{\prime} 22.3$ lbs/100 ibs
d $19.7 \mathrm{lbs} / 100$ lbs
d" $20.4 \mathrm{lbs} / 100 \mathrm{lbs}$
d' 20.4 lbs $/ 100$ lbs
$\mathrm{b}-\mathrm{c}=3.6 \mathrm{lbs}$
$b^{\prime \prime}-c^{\prime \prime}=3.7 \mathrm{lbs}$
$b^{\prime}-c^{\prime}=3.7$ lbs
$\mathrm{a}-\mathrm{d}=6.9 \mathrm{lbs}$
$\mathrm{a}^{\prime \prime}-\mathrm{d}^{\prime \prime}=6.2 \mathrm{lbs}$
measured 1.43 lbs
$a^{\prime}-d^{\prime}=6.3 \mathrm{lbs}$
measured 1.24 lbs

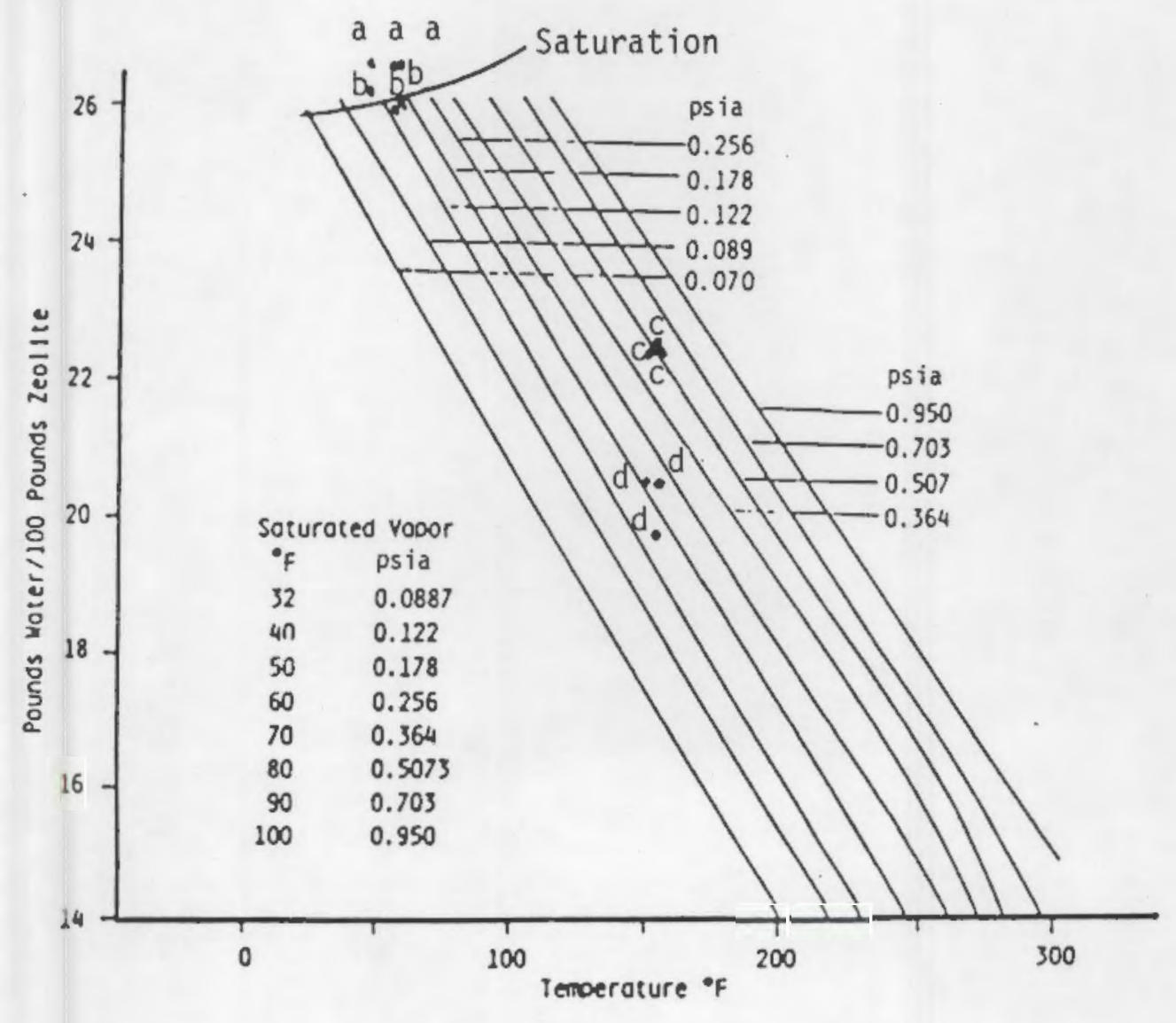

FIGURE B-9-a. Zeolite Isobars 

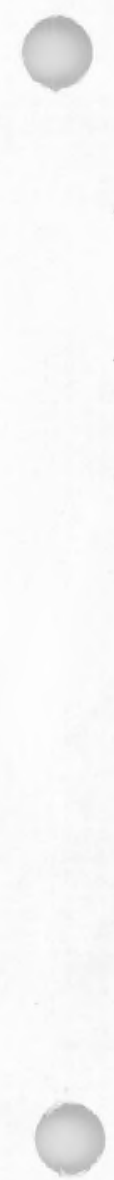
Start Z-tank filling 0915 tull of cold water 0925 upen 3 valve 0925

Start Z-tank drain 1030

Close 3" valve 1030

Start 2-tank fllling 1037

Full of hot water 1047

Condenser flow 1101

Oratn: 0.36 ibs

Orain: 0.18 los $\quad 1123$

Orain: 0.8 los 1147

Measured: 0.76 Ibs 1147

Start Z-tank drain 1147

Start Z-tank filling 1152

Full cold water

Open $3^{\text {" valve }}$

Start Z-tank drain 130

close 3" valve $\quad 1306$

start Z-tank filling 1314

Full of hot water 1323

Condenser fiow 1323

Drain: 0.70 los 1338

Drain: 0.51 lbs 1358

Ora1n: 0.18 ibs 1428

Measured: 1.24 lbs 1428

Start Z-tank filling 1434

Full of cold water 1443

Open $3^{\prime \prime}$ value 1443

Start Z-tank drain 1600

Start 2-tank friling 1609

Full of hot water

Condenser fow las

Dratn: 0.23 ibs

Dratn: 0.23 ibs

Drain 7-tank 1720

cold water flow, $3.5 \mathrm{gpm}$

Desorption:

cold water flow, $3.6 \mathrm{gpm}$

hot water flow, $3.0 \mathrm{gpm}$

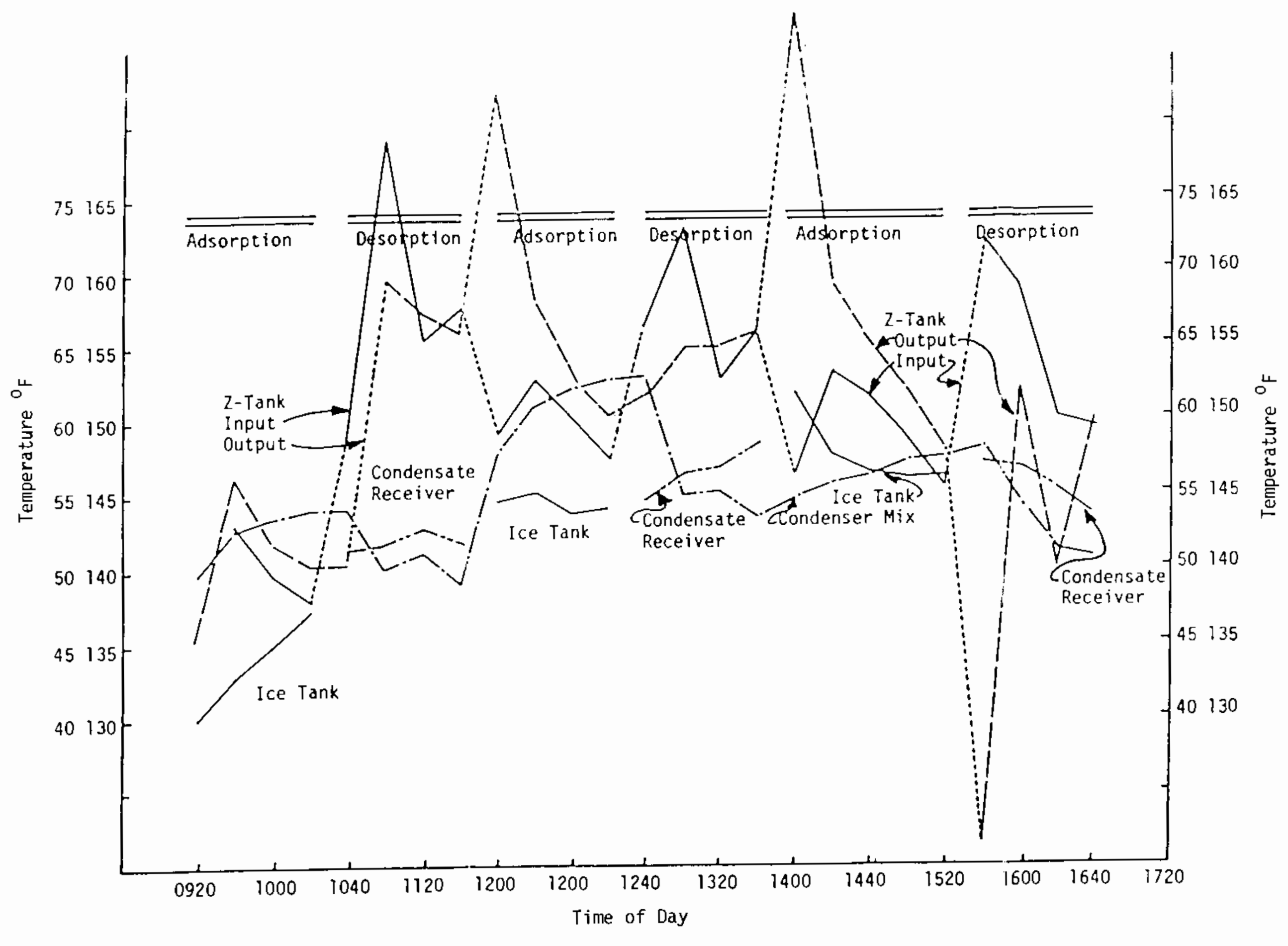

FIGURE B-9-b. Data Runs, February 28, 1984 


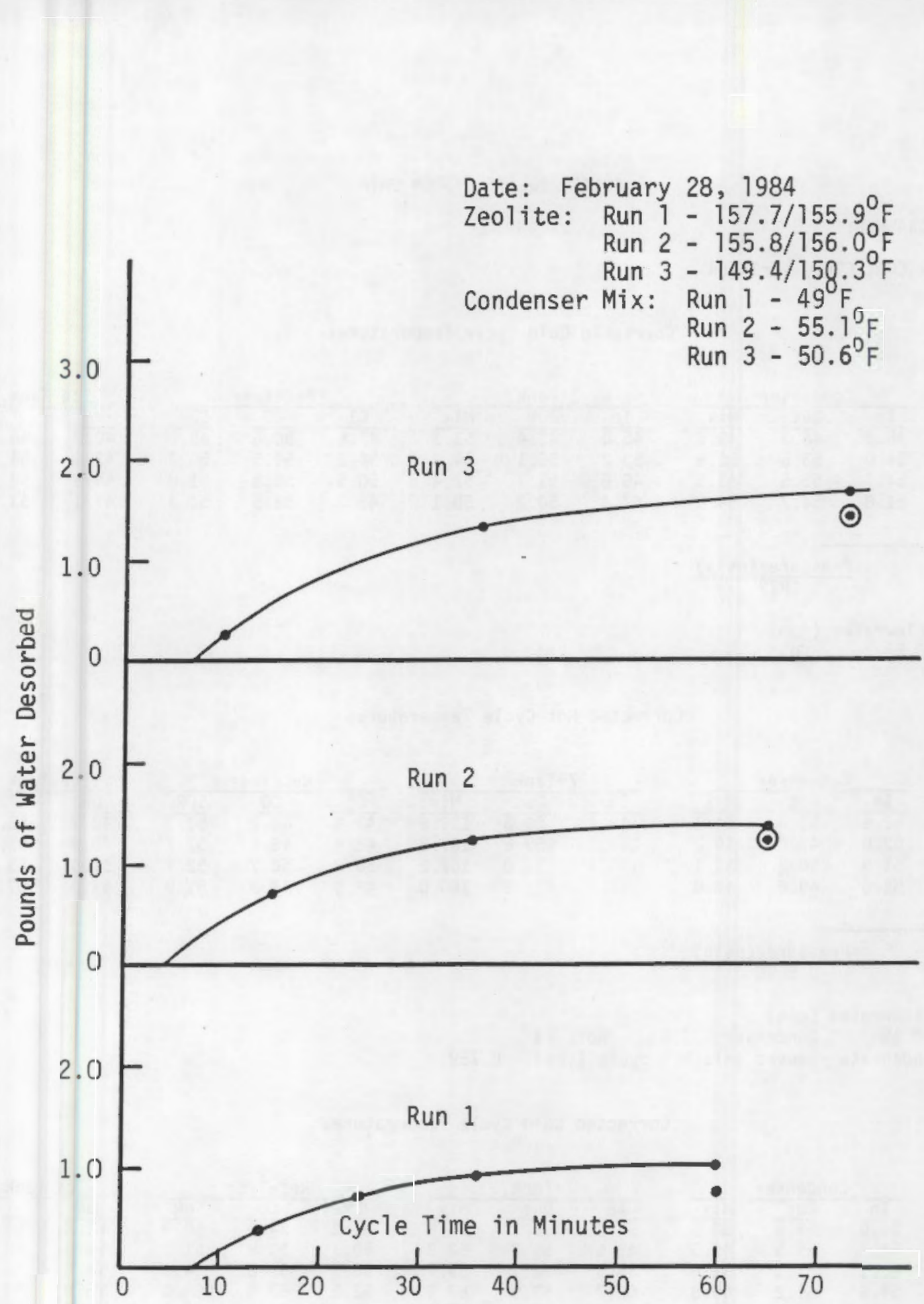

Figure B-9-C. Desorption Response 
DATE PROGRAMMED: $\quad 3-5-84$

DATE DATA COLLECTED: $2-28-84$

Corrected Cold Cycle Temperatures

\begin{tabular}{|c|c|c|c|c|c|c|}
\hline Time & \multicolumn{3}{|c|}{ Condenser } & \multicolumn{3}{|c|}{ Z-Tank } \\
\hline & In & Out & Mix & In & out & Mix \\
\hline $9: 20$ & $\overline{48.8}$ & $\overline{48.3}$ & $\overline{49.8}$ & $\overline{45.0}$ & $\overline{45.4}$ & $\overline{51.3}$ \\
\hline $9: 2$ & 54.0 & 53.6 & 52.6 & 53.2 & 56.1 & 54.9 \\
\hline 10: & 54.7 & 55.5 & 53.5 & 49.6 & 51.7 & 52.4 \\
\hline $10: 2$ & 51.8 & 54.7 & 54.0 & 47.4 & 50.2 & 50.1 \\
\hline
\end{tabular}

\begin{tabular}{ccc}
\multicolumn{3}{c}{ Receiver } \\
\hline$\frac{\text { C1 }}{47.6}$ & $\frac{\text { CO }}{50.6}$ & $\frac{\text { SUR }}{45.6}$ \\
54.2 & 54.5 & 50.9 \\
50.5 & 50.8 & 51.8 \\
48.7 & 58.5 & 51.3
\end{tabular}

\begin{tabular}{|c|c|}
\hline$\overline{B R}$ & TR \\
\hline 40.0 & 48.9 \\
\hline 42.8 & 84.3 \\
\hline 44.9 & 52.9 \\
\hline & \\
\hline
\end{tabular}

$\frac{\text { Time }}{10: 30} \quad \frac{\text { Pressure (psia) }}{0.1829}$

Average Flowrates (gpm)

Spray: 0.55 Cold: 3.6

Corrected Hot Cycle Temperatures

\begin{tabular}{|c|c|c|c|}
\hline Time & \multicolumn{3}{|c|}{ Condenser } \\
\hline & In & Out & Mix \\
\hline $10: 40$ & 52.6 & $\overline{55.4}$ & $\overline{54.1}$ \\
\hline $11: 00$ & 52.6 & 49.0 & 50.2 \\
\hline $11: 20$ & 51.9 & 50.2 & 51.1 \\
\hline $11: 40$ & 52.6 & 49.6 & 49.0 \\
\hline
\end{tabular}

\begin{tabular}{lrr}
\multicolumn{3}{c}{ Z-Tank } \\
\hline$\frac{\text { In }}{149.1}$ & $\frac{\text { Out }}{50.3}$ & $\frac{\text { Mix }}{139.5}$ \\
169.0 & 159.6 & 167.8 \\
155.4 & 157.0 & 162.2 \\
157.7 & 155.9 & 160.0
\end{tabular}

\begin{tabular}{ccc}
\multicolumn{3}{c}{ Receiver } \\
\hline$\frac{\text { C1 }}{47.8}$ & $\frac{\text { CO }}{48.2}$ & $\frac{\text { SUR }}{51.3}$ \\
48.8 & 48.6 & 51.7 \\
50.8 & 50.7 & 52.7 \\
48.9 & 48.8 & 51.9
\end{tabular}

\begin{tabular}{|c|c|}
\hline$B R$ & $\mathrm{TR}$ \\
\hline 48.7 & 53.4 \\
\hline 49.9 & 55.4 \\
\hline 51.3 & 55.8 \\
\hline 53.0 & 57.6 \\
\hline
\end{tabular}

$\frac{\text { Time }}{11: 23} \quad \frac{\text { Pressure (psia) }}{0.5086}$

Average Flowrates (gpm)

Spray: 0.55 Condenser: 3.6 Hot: 3

Total condensate removed this hot cycle (lbs): 0.759

\section{Corrected Cold Cycle Temperatures}

\begin{tabular}{|c|c|c|c|}
\hline \multirow[t]{2}{*}{ Time } & \multicolumn{3}{|c|}{ Condenser } \\
\hline & In & 0ut & Mix \\
\hline $9: 40$ & $\overline{54.0}$ & $\overline{53.6}$ & $\overline{52.6}$ \\
\hline $10: 00$ & 54.7 & 55.5 & 53.5 \\
\hline $12: 00$ & 53.2 & 61.1 & 57.6 \\
\hline $12: 20$ & 54.6 & 61.2 & 60.8 \\
\hline $12: 40$ & 55.6 & 61.3 & 62.0 \\
\hline
\end{tabular}

\begin{tabular}{ccc}
\multicolumn{3}{c}{ Z-Tank } \\
\hline In & $\frac{\text { Out }}{56.2}$ & $\frac{\text { Mix }}{54.9}$ \\
49.6 & 51.7 & 52.3 \\
58.9 & 82.1 & 69.7 \\
62.7 & 67.9 & 67.9 \\
59.8 & 62.8 & 62.4 \\
57.2 & 60.1 & 58.8
\end{tabular}

\begin{tabular}{ccc}
\multicolumn{3}{c}{ Receiver } \\
\hline C1 & $\frac{\text { CO }}{54.2}$ & $\frac{\text { SUR }}{50.9}$ \\
50.5 & 50.8 & 51.8 \\
55.5 & 55.8 & 54.9 \\
62.1 & 62.8 & 54.0 \\
60.4 & 60.0 & 52.6 \\
57.5 & 57.2 & 53.0
\end{tabular}

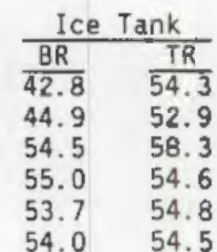

$\frac{\text { Time }}{12: 04} \quad \frac{\text { Pressure (psia) }}{0.1690}$

Average Flowrates (gpm)

Spray: 0.55 Cold: 3.5

FIGURE B-9-d. Data Printout 
FIGURE B-9-d. (continued)

Corrected Hot Cycle Temperatures

\begin{tabular}{|c|c|c|c|c|c|c|c|c|c|c|c|}
\hline Time & \multicolumn{3}{|c|}{ Condenser } & \multicolumn{3}{|c|}{ Z-Tank } & \multicolumn{3}{|c|}{ Receiver } & \multicolumn{2}{|c|}{ Ice Tank } \\
\hline & $\frac{\text { In }}{58 ?}$ & Out & Mix & In & Out & $\frac{M i x}{12 \pi}$ & $\frac{\mathrm{Cl}}{56 \mathrm{O}}$ & $\frac{\mathrm{CO}}{55^{2}}$ & SUR & $\frac{\mathrm{BR}}{56}$ & $\frac{T R}{59 \theta}$ \\
\hline $\begin{array}{l}1: 20 \\
1: 40\end{array}$ & $\begin{array}{l}58.2 \\
61.1\end{array}$ & $\begin{array}{l}61.1 \\
56.4\end{array}$ & $\begin{array}{l}62.7 \\
54.8\end{array}$ & $\begin{array}{l}156.5 \\
162.9\end{array}$ & $\begin{array}{r}61.3 \\
154.6\end{array}$ & $\begin{array}{l}124.4 \\
161.5\end{array}$ & $\begin{array}{l}50.0 \\
55.3\end{array}$ & $\begin{array}{l}56.2 \\
54.5\end{array}$ & $\begin{array}{l}34.3 \\
56.3\end{array}$ & 57.7 & 61.6 \\
\hline $2: 00$ & 61.9 & 56.3 & 55.1 & 152.5 & 154.6 & 156.0 & 55.0 & 55.0 & 56.7 & 58.4 & 62.4 \\
\hline
\end{tabular}

$\frac{\text { Time }}{1: 58} \quad \frac{\text { Pressure (psia) }}{0.5168}$

Average Flowrates (gpm)

Spray: 0.55 Condenser: 3.6 Hot:

Total condensate removed this hot cycle (lbs): 1.243

Corrected Cold Cycle Temperatures

\begin{tabular}{|c|c|c|c|c|c|c|c|c|c|c|c|}
\hline Time & \multicolumn{3}{|c|}{ Condenser } & \multicolumn{3}{|c|}{$z-\operatorname{Tan} k$} & \multicolumn{3}{|c|}{ Receiver } & \multicolumn{2}{|c|}{ Ice Tank } \\
\hline & In & out & Mix & In & Out & Mix & CI & $\mathrm{CO}$ & SUR & $\frac{\mathrm{BR}}{12}$ & TR \\
\hline $9: 40$ & 54.0 & 53.8 & $\overline{52.6}$ & $\overline{53.2}$ & $\overline{56.1}$ & $\overline{54.9}$ & $\overline{54.2}$ & $\overline{54.5}$ & 50.9 & $\overline{42 . \overline{8}}$ & 54.3 \\
\hline $10: 00$ & 54.7 & 55.5 & 53.5 & 49.6 & 51.7 & 52.4 & 50.5 & 50.8 & 51.8 & 44.9 & 52.9 \\
\hline $2: 40$ & 66.5 & 56.5 & 54.7 & 56.0 & 93.7 & 70.0 & 53.6 & 53.2 & 57.1 & 61.7 & 62.8 \\
\hline $3: 00$ & 67.0 & 60.6 & 55.7 & 63.0 & 68.8 & 68.5 & 61.6 & 62.4 & 55.3 & 56.5 & 53.3 \\
\hline $3: 20$ & 66.2 & 61.6 & 56.6 & 61.4 & 64.9 & 63.9 & 61.7 & 61.5 & 55.5 & 56.2 & 54.6 \\
\hline $3: 40$ & 63.6 & 62.2 & 57.1 & 58.5 & 61.6 & 59.9 & 58.9 & 58.6 & 56.8 & 55.9 & 50.8 \\
\hline $4: 00$ & 62.6 & 61.6 & 57.3 & 55.2 & 57.9 & 56.5 & 56.4 & 55.7 & 57.0 & 56.1 & 54.2 \\
\hline
\end{tabular}

$\frac{\text { Time }}{4: 00} \quad \frac{\text { Pressure (psia) }}{0.1685}$

Average Flowrates (gpm)

Spray: 0.5 Cold: 3.5

Corrected Hot Cycle Temperatures

\begin{tabular}{|c|c|c|c|c|c|c|c|c|c|c|c|}
\hline Time & & ndens & & & -Tank & & & ceiv & & ICE & ank \\
\hline & In & Out & Mix & In & out & Mix & $\mathrm{Cl}$ & $\mathrm{CO}$ & SUR & $\overline{B R}$ & TR \\
\hline & $\overline{61.2}$ & 59.5 & $\overline{58.0}$ & $\overline{161.7}$ & $\overline{121.4}$ & $\overline{136.9}$ & 55.0 & $\overline{54.4}$ & $\overline{56.9}$ & $\overline{56.8}$ & $\overline{58.9}$ \\
\hline & 59.9 & 54.0 & 54.3 & 158.8 & 151.6 & 162.0 & 53.4 & 53.3 & 56.6 & 57.5 & 59.3 \\
\hline $5: 0$ & 58.5 & 50.6 & 51.1 & 149.8 & 140.2 & 150.8 & 51.0 & 51.1 & 55. & 57.8 & 59.1 \\
\hline $5: 2$ & 57.8 & 51.8 & 50.6 & 149.4 & 150.3 & 152.4 & 51.2 & 50.7 & 53.5 & 58.3 & 59.2 \\
\hline
\end{tabular}

$\frac{\text { Time }}{5: 00} \quad \frac{\text { Pressure (psia) }}{0.5168}$

Average Flowrates (gpm)

Spray: 0.5 Condenser: 3.6 Hot: 3

Total condensate removed this hot cycle (ibs): 1.4322

FIGURE B-9-d. Data Printout (continued) 
Date: March 1, 1984

a $26.9 \mathrm{lbs} / 100 \mathrm{lbs}$

b $26.3 \mathrm{lbs} / 100 \mathrm{lbs}$

c $22.3 \mathrm{lbs} / 100 \mathrm{lbs}$

d $21.0 \mathrm{lbs} / 100 \mathrm{lbs}$

$b-c=4$ lbs

$\mathrm{a}-\mathrm{d}=5.9$ lbs

measured 6.15 lbs

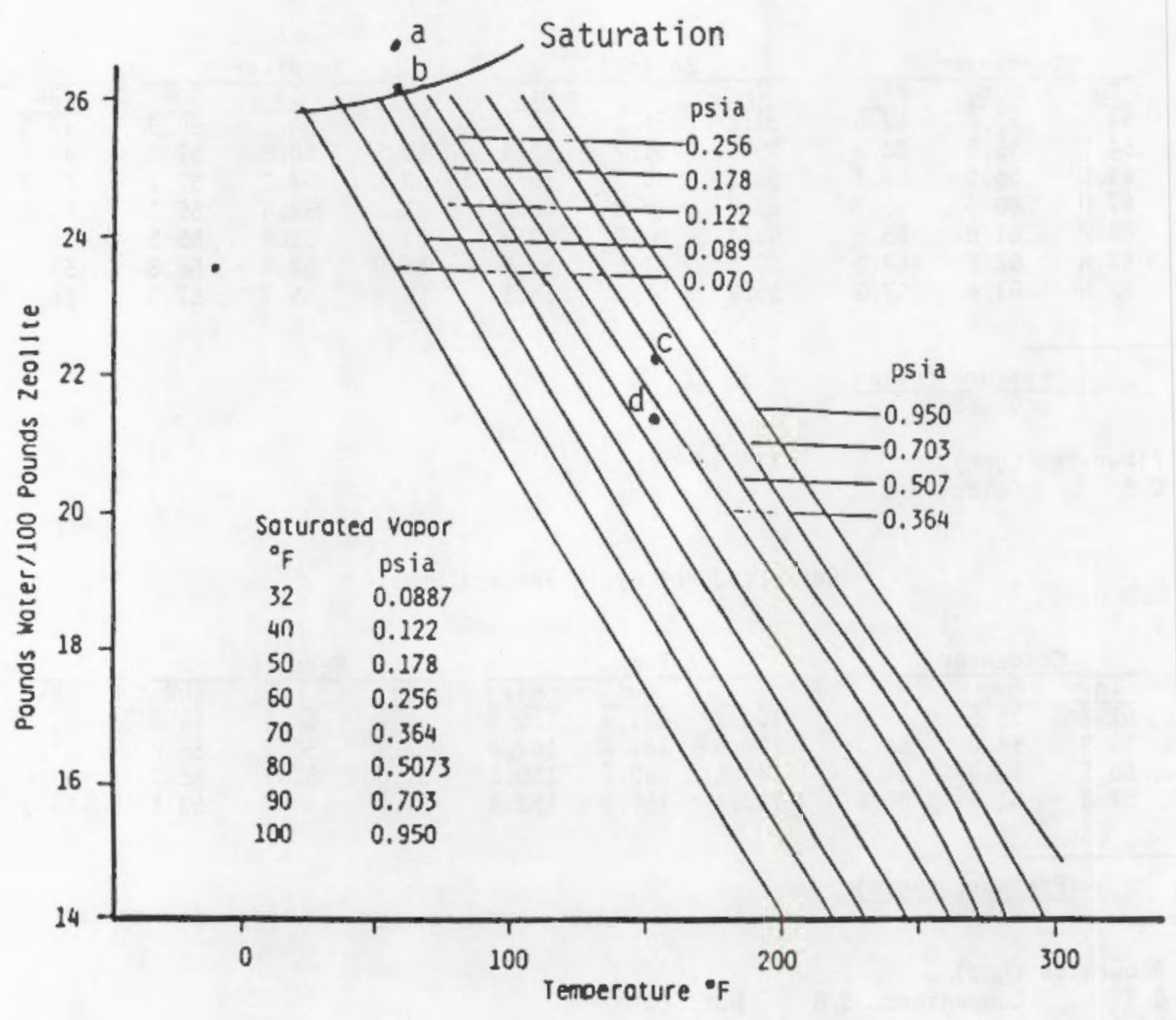

FIGURE B-10-a. Zeolite Isobars 


\begin{tabular}{|c|c|c|c|c|c|c|}
\hline $\begin{array}{l}\text { Start } 2 \text {-tank filling } \\
\text { Full of cold water } \\
\text { Open } 3^{\prime \prime} \text { valve } \\
\text { Start } 2 \text {-tank drain } \\
\text { Close } 3^{\prime \prime} \text { valve } \\
\text { Start } 2 \text {-tank f1lling }\end{array}$ & $\begin{array}{l}1300 \\
1320 \\
1320 \\
1624 \\
1624 \\
1633\end{array}$ & $\begin{array}{l}\text { Full of hot water } \\
\text { Drain: } 1.36 \text { lbs } \\
\text { Orain: } 1.36 \text { ibs } \\
\text { Orain: } 1.36 \text { ibs } \\
\text { Measured: } 5.19 \text { lbs } \\
\text { Orain: } 0.563 \text { ibs }\end{array}$ & $\begin{array}{l}1643 \\
1643 \\
1654 \\
1711 \\
1711 \\
1734\end{array}$ & $\begin{array}{l}\text { Orain: } 0.286 \\
\text { Drain: } 0.286 \\
\text { Measured: } 95 \\
\text { Adsorption: } \\
\text { Desorption: }\end{array}$ & $\begin{array}{l}6 \text { lbs } \\
6 \text { lbs } \\
57 \text { los } \\
\text { cold water } \\
\text { cold water } \\
\text { hot water }\end{array}$ & $\begin{array}{l}1745 \\
1802 \\
1802 \\
\text { flow, } 3.8 \mathrm{gpm} \\
\text { flow, 3.6 gpm } \\
\text { flow, 3.0 gpm }\end{array}$ \\
\hline
\end{tabular}

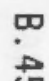

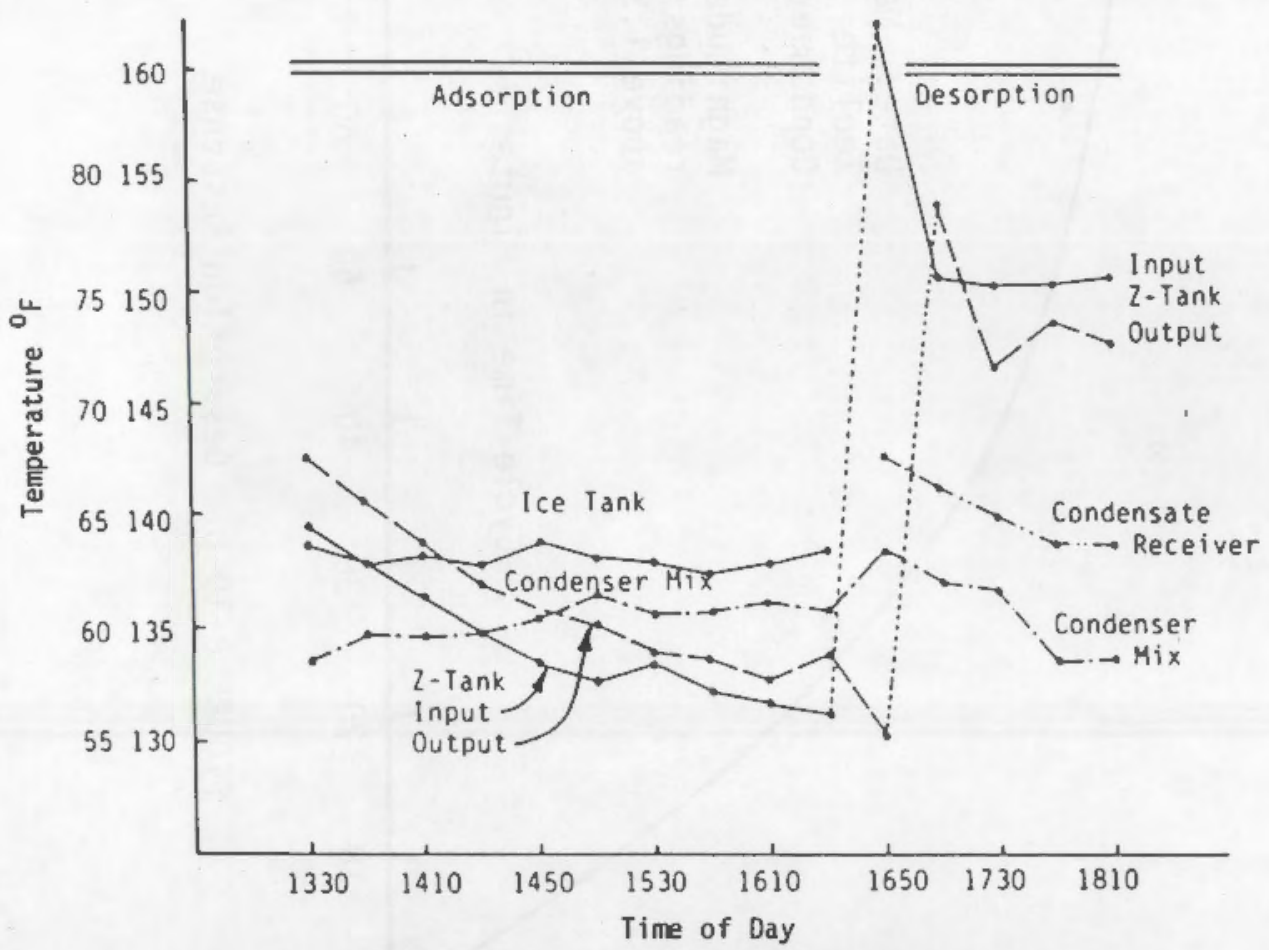

FIGURE B-10-b. Data Run, March 1, 1984 


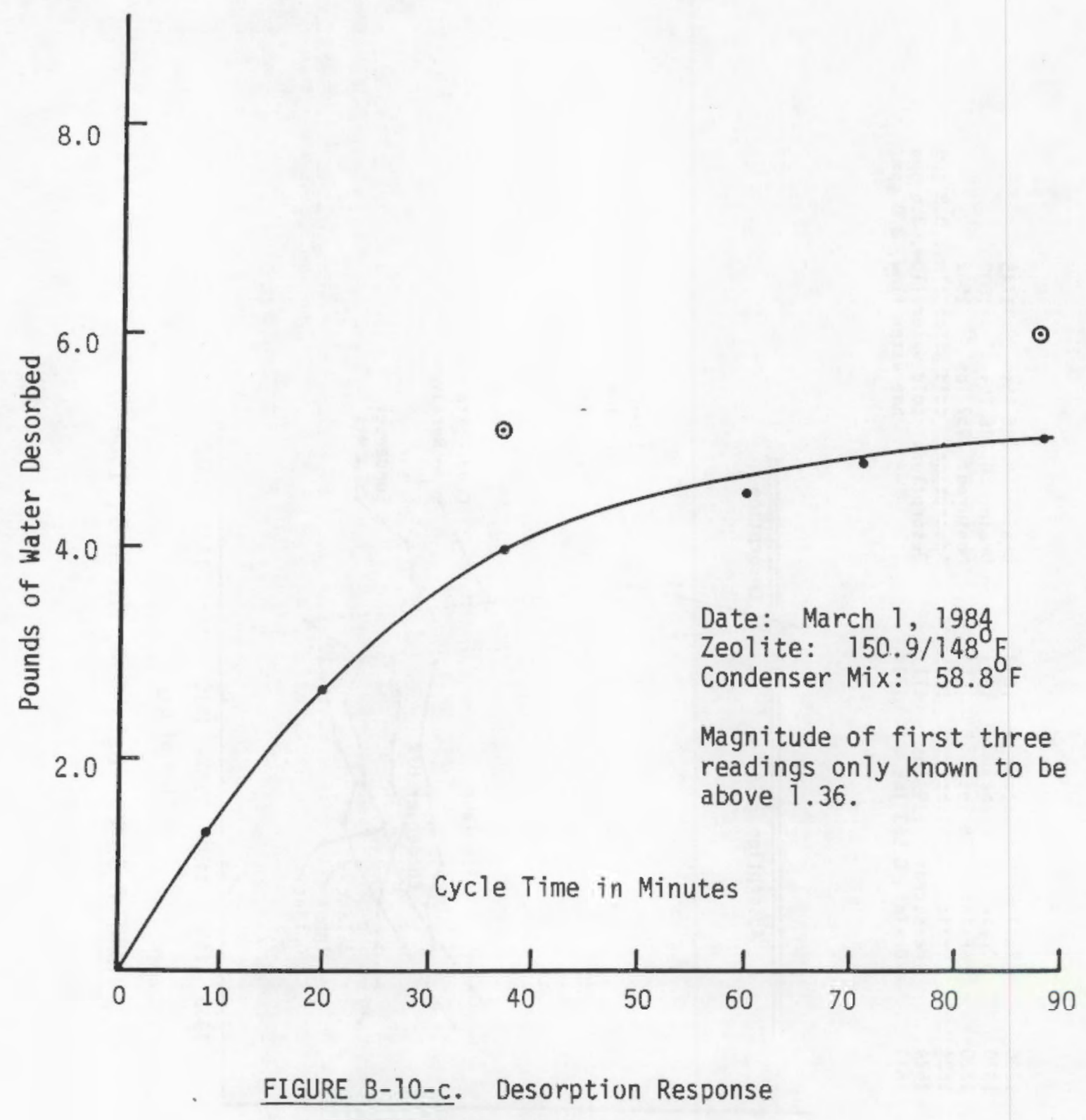

B. 46 
DATE PROGRAMMED: $\quad 3-6-84$

DATE DATA COLLECTED: $\quad 3-1-84$

Corrected Cold Cycle Temperatures

\begin{tabular}{|c|c|c|c|}
\hline Time & $\mathrm{Co}$ & ser & \\
\hline $\begin{array}{l}1: 30 \\
1: 50 \\
2: 10 \\
2: 30 \\
2: 50 \\
3: 10 \\
3: 30 \\
3: 50 \\
4: 10\end{array}$ & Out & $\begin{array}{l}\frac{\text { Mix }}{58.7} \\
59.8 \\
59.7 \\
59.8 \\
60.6 \\
61.7 \\
60.8 \\
50.9 \\
61.4\end{array}$ & $\begin{array}{l}\frac{1 \pi}{64 .} \\
63 . \\
61 . \\
59 . \\
58 . \\
57 . \\
58 . \\
57 . \\
56 .\end{array}$ \\
\hline $\begin{array}{l}\text { Time } \\
1: 20 \\
1: 21 \\
4: 24\end{array}$ & \multicolumn{3}{|c|}{$\begin{array}{l}\text { Pressure (psia) } \\
0.1576 \\
0.2234 \\
0.1905\end{array}$} \\
\hline
\end{tabular}

Average Flowrates (gpm)

Spray: 0.475 Cold: 3.7

Z-Tank

Out $\frac{\text { Mix }}{67.3}$

$\frac{047.3}{67.6}$

$65.8 \quad 65.1$

$63.8-63.4$

$62.1 \quad 61.6$

$61.0 \quad 59.9$

$60.2 \quad 59.3$

59.1

58.8

57.9

\section{5}

57.3

57.0

\begin{tabular}{ccc}
\multicolumn{3}{c}{ Receiver } \\
\hline$\frac{\text { C1 }}{64.3}$ & $\frac{\text { CO }}{64.3}$ & $\frac{\text { SUR }}{64.0}$ \\
64.1 & 63.2 & 65.6 \\
62.5 & 62.3 & 66.6 \\
61.1 & 60.6 & 67.6 \\
60.5 & 60.1 & 67.3 \\
58.9 & 59.0 & 66.9 \\
58.8 & 58.2 & 66.8 \\
57.4 & 57.9 & 66.9 \\
57.6 & 57.3 & 66.7
\end{tabular}

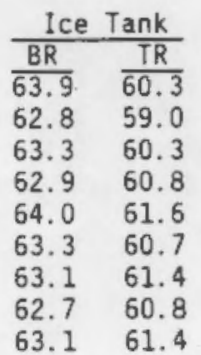

Corrected Hot Cycle Temperatures

\begin{tabular}{|c|c|c|}
\hline Time & \multicolumn{2}{|c|}{ Condenser } \\
\hline & out & Mix \\
\hline $4: 50$ & 70.0 & 63.7 \\
\hline $5: 10$ & 64.7 & 62.2 \\
\hline $5: 30$ & 62.3 & 61.9 \\
\hline $5: 50$ & 61.6 & 58.6 \\
\hline $6: 10$ & 61.5 & 58.8 \\
\hline
\end{tabular}

\begin{tabular}{|c|c|c|}
\hline & $Z$-Tank & \\
\hline$\frac{\text { In }}{162}$ & $\frac{\text { Out }}{1304}$ & $\frac{\operatorname{Mix}}{138}$ \\
\hline 150.9 & 154.2 & 155.3 \\
\hline 150.5 & 146.9 & 149.7 \\
\hline 150.7 & 148.9 & 150.3 \\
\hline 150.9 & 148.0 & 150.7 \\
\hline
\end{tabular}

\begin{tabular}{ccc}
\multicolumn{3}{c}{ Receiver } \\
\hline$\frac{\text { C1 }}{59.6}$ & $\frac{\text { CO }}{59.3}$ & $\frac{\text { SUR }}{67.9}$ \\
63.3 & 63.2 & 66.4 \\
61.2 & 61.0 & 65.1 \\
59.0 & 59.0 & 63.8 \\
58.9 & 58.3 & 63.8
\end{tabular}

\begin{tabular}{|c|c|}
\hline BR & $T$ \\
\hline$\frac{51}{67.1}$ & $\frac{1 \pi}{69.6}$ \\
\hline 67.9 & 69.9 \\
\hline 68.6 & 69.3 \\
\hline 67.3 & 66.8 \\
\hline 66.4 & 65.9 \\
\hline
\end{tabular}

$\frac{\text { Time }}{6: 02} \quad \frac{\text { Pressure (psia) }}{0.5028}$

Average Flowrates (gpm)

Spray: 0.45 Condenser: 3.5 Hot: 3

Total condensate removed this hot cycle (1bs): 6.149

\section{FIGURE B-10-d. Data Printout}


Date: March 6, 1984

a $26.3 \mathrm{lbs} / 100 \mathrm{lbs}$

b $25.7 \mathrm{lbs} / 100 \mathrm{lbs}$

c $21.5 \mathrm{lbs} / 100 \mathrm{lbs}$

d $20.5 \mathrm{lbs} / 100 \mathrm{lbs}$

$\mathrm{b}-\mathrm{c}=4.2 \mathrm{lbs}$

$\mathrm{a}-\mathrm{d}=5.8 \mathrm{lbs}$

measured 5.5 lbs

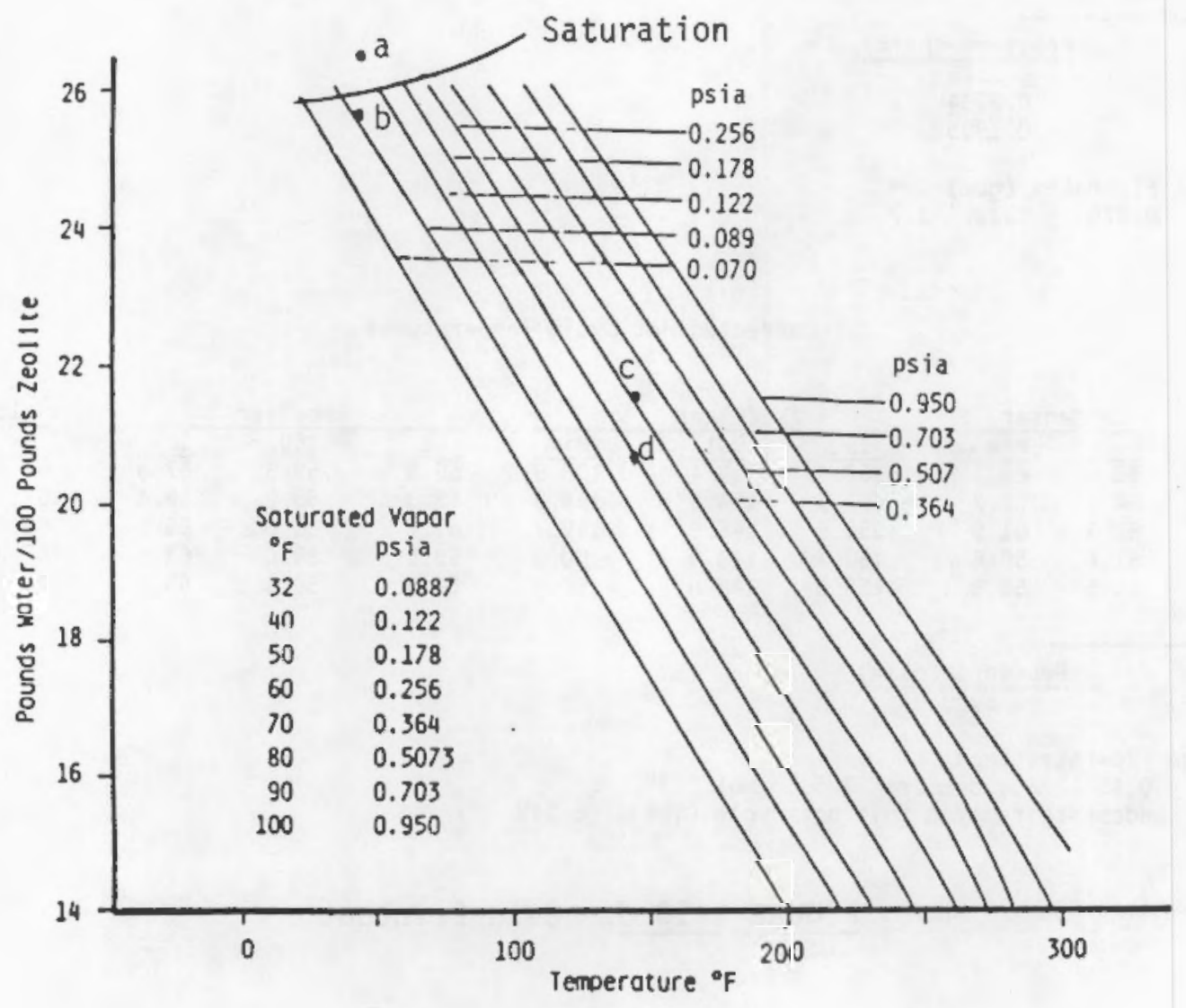

FIGURE B-11-a. Zenlite Isobars 


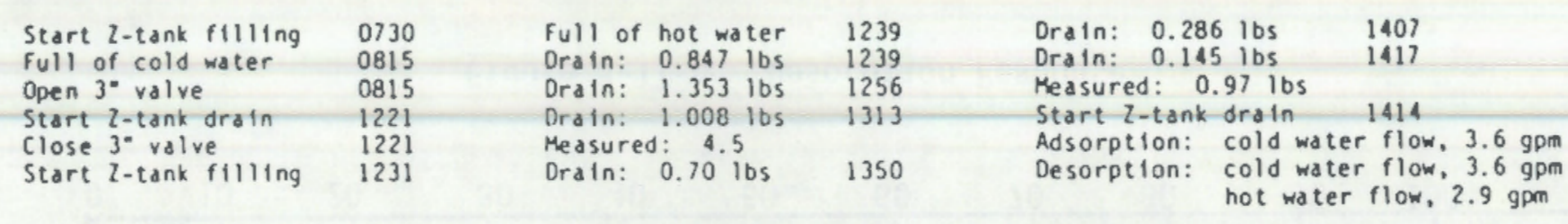

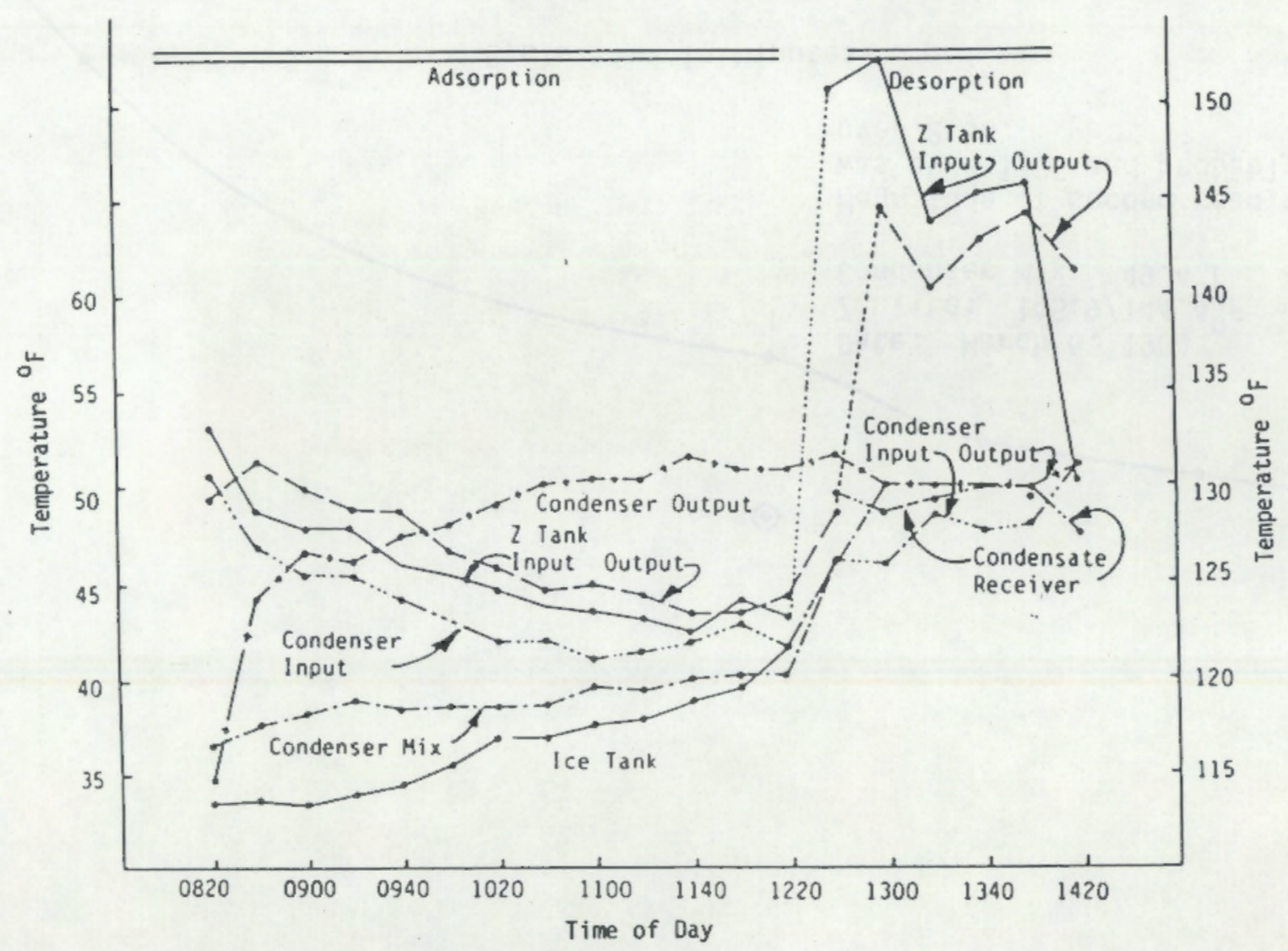

FIGURE B-11-b. Data Run, March 6, 1984 


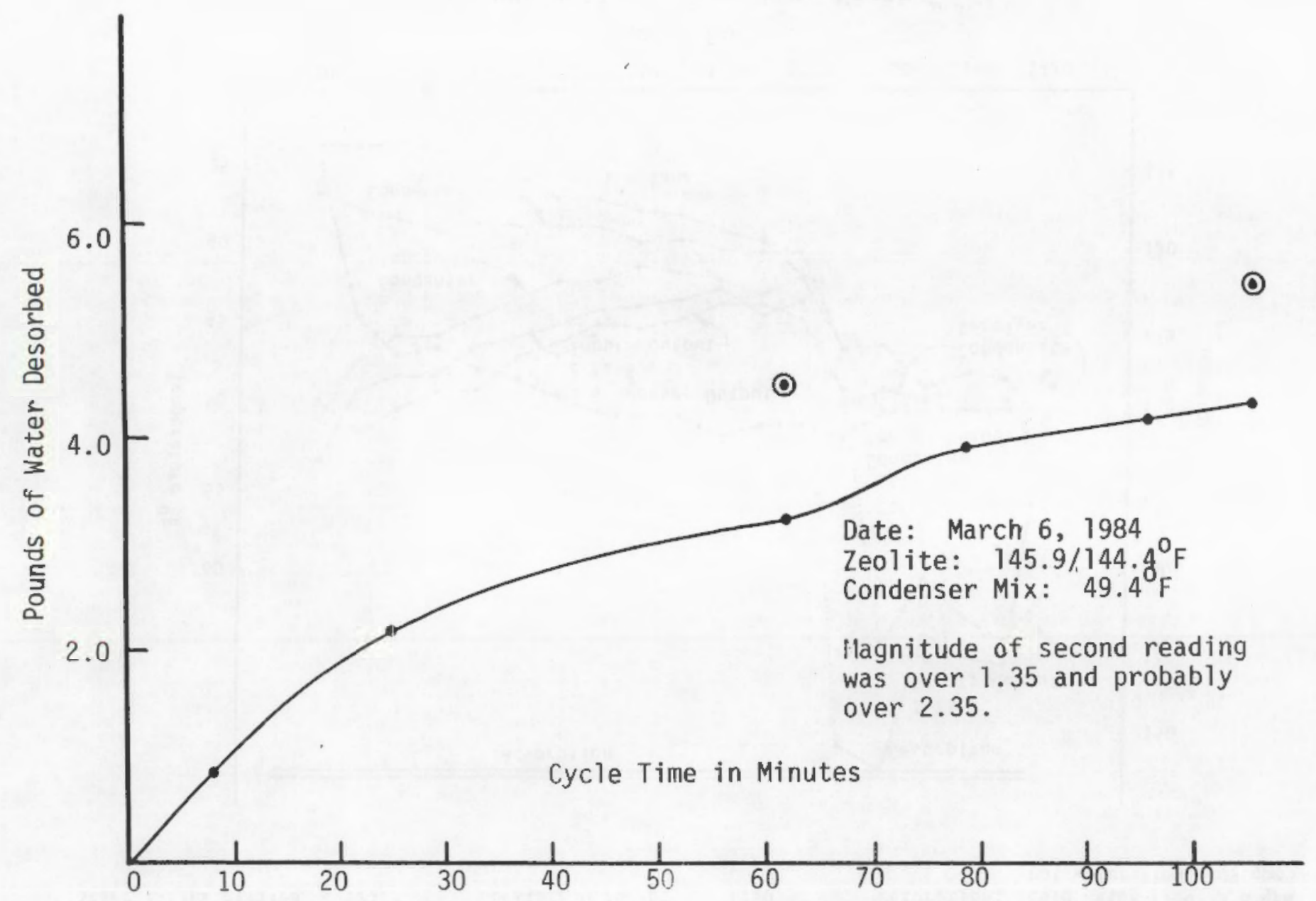

Figure B-11-C. Desorption Response 
DATE PROGRAMMED: $\quad 3-8-84$

DATE DATA COLLECTED: 3-6-84

Corrected Cold Cycle Temperatures

\begin{tabular}{|c|c|c|c|c|c|c|c|c|c|c|}
\hline Time & \multicolumn{2}{|c|}{ Condenser } & \multicolumn{3}{|c|}{ Z-Tank } & \multicolumn{3}{|c|}{ Receiver } & \multicolumn{2}{|c|}{ Ice Tank } \\
\hline & In Out & $\frac{\text { Mix }}{\frac{1}{5}}$ & In & Out & Mix & $\frac{\mathrm{Cl}}{5 \mathrm{Cl}^{2}}$ & $\mathrm{CO}$ & $\frac{\text { SUR }}{127}$ & $\frac{B R}{324}$ & $\frac{T R}{25.4}$ \\
\hline $\begin{array}{l}8: 20 \\
8: 40\end{array}$ & $\begin{array}{l}50.6 \\
46.9\end{array}$ & $\begin{array}{l}36.5 \\
37.6\end{array}$ & $\begin{array}{l}53.1 \\
48.7\end{array}$ & $\begin{array}{l}49.3 \\
51.4\end{array}$ & $\begin{array}{l}49.8 \\
51.7\end{array}$ & $\begin{array}{l}50.3 \\
48.3\end{array}$ & $\begin{array}{l}52.8 \\
49.0\end{array}$ & $\begin{array}{l}42.7 \\
45.9\end{array}$ & $\begin{array}{l}33.4 \\
33.7\end{array}$ & $\begin{array}{l}25.4 \\
36.7\end{array}$ \\
\hline $9: 00$ & 45.6 & 38.2 & 47.9 & 49.9 & 50.2 & 47.3 & 48.4 & 45.9 & 33.3 & 43.6 \\
\hline 9:20 & 45.3 & 38.9 & 47.9 & 48.9 & 48.9 & 46.9 & 47.2 & 47.7 & 34.0 & 47.6 \\
\hline $9: 40$ & 44.2 & 38.5 & 46.0 & 47.6 & 47.4 & 46.0 & 45.9 & 47.2 & 34.3 & 51.7 \\
\hline $10: 00$ & 43.0 & 38.7 & 45.5 & 46.7 & 47.4 & 45.1 & 45.3 & 46.4 & 35.5 & 51.1 \\
\hline $10: 20$ & 42.0 & 38.6 & 44.7 & 45.9 & 46.0 & 44.5 & 44.8 & 45.1 & 37.0 & 51.2 \\
\hline $10: 40$ & 42.0 & 38.7 & 43.9 & 44.7 & 45.8 & 43.9 & 44.2 & 45.0 & 37.0 & 51.5 \\
\hline $11: 00$ & 41.1 & 39.7 & 43.6 & 44.8 & 45.2 & 43.1 & 43.1 & 44.5 & 37.6 & 51.5 \\
\hline $11: 20$ & 41.3 & 39.4 & 43.1 & 44.3 & 44.5 & 42.8 & 43.7 & 44.0 & 37.9 & 52.0 \\
\hline $11: 40$ & 41.8 & 40.2 & 42.3 & 43.4 & 44.4 & 42.7 & 43.2 & 44.4 & 38.9 & 52.4 \\
\hline $12: 00$ & 42.3 & 40.2 & 44.2 & 43.5 & 43.6 & 43.7 & 43.6 & 44.5 & 39.7 & 52.3 \\
\hline $12: 20$ & 41.7 & 40.1 & 43.3 & 44.4 & 44.1 & 43.4 & 43.5 & 45.1 & 41.6 & 53.5 \\
\hline
\end{tabular}

\begin{tabular}{|c|c|}
\hline $\begin{array}{l}\frac{\text { Time }}{12: 21} \\
12: 31\end{array}$ & $\begin{array}{c}\text { Pressure (psia) } \\
0.0935 \\
0.1067\end{array}$ \\
\hline $\begin{array}{l}\text { Avera } \\
\text { Soray }\end{array}$ & $\begin{array}{l}\text { Flowrates (gpm) } \\
0.4 \quad \text { Cold: }\end{array}$ \\
\hline
\end{tabular}

Corrected Hot Cycle Temperatures

\begin{tabular}{|c|c|c|c|c|c|c|c|c|c|c|c|}
\hline Time & & Conde & & & $z-T$ ank & & & ceiv & & Ic & ank \\
\hline & In & Out & Hix & In & out & Mix & $\mathrm{Cl}$ & $\mathrm{CO}$ & SUR & $\overline{B R}$ & TR \\
\hline $12: 40$ & 46.0 & 51.7 & 45.7 & $\overline{150.8}$ & 48.8 & $\overline{108.7}$ & $\overline{43.7}$ & $\overline{44.3}$ & 49.7 & $\overline{42.4}$ & $\overline{54.6}$ \\
\hline $1: 00$ & 46.0 & 50.0 & 50.3 & 152.5 & 144.6 & 147.4 & 47.1 & 47.9 & 48.7 & 42.5 & 55.6 \\
\hline $1: 20$ & 48.5 & 50.1 & 49.9 & 143.9 & 140.4 & 141.9 & 48.4 & 50.1 & 49.3 & 43.6 & 56.5 \\
\hline $1: 40$ & 48.2 & 50.1 & 49.4 & 145.5 & 142.9 & 144.9 & 49.4 & 49.7 & 49.8 & 44.3 & 56.1 \\
\hline 2:00 & 48.5 & 49.9 & 49.4 & 145.9 & 144.4 & 146.3 & 49.3 & 49.2 & 49.9 & 45.5 & 56.4 \\
\hline $2: 20$ & 51.1 & 51.1 & 50.9 & 130.4 & 141.4 & 145.5 & 49.2 & 50.2 & 47.5 & 46.2 & 54.4 \\
\hline
\end{tabular}

\begin{tabular}{cc}
\hline Time & Pressure (psía) \\
$\frac{0.2135}{12: 39}$ & 0.2711 \\
$12: 56$ & 0.2743 \\
$1: 13$ & 0.2743 \\
$1: 23$ & 0.2776 \\
$1: 41$ & 0.2776 \\
$1: 50$ & 0.2730 \\
$2: 07$ & 0.2743 \\
$2: 14$ & 0.2743 \\
$2: 17$ &
\end{tabular}

Average Flowrates (gpm)

Spray: 0.4 Condenser: 3.5 Hot: 2.9

Total condensate removed this hot cycle (lbs): 5.489

FIGURE B-11-d. Data Printout 
Date: March 11, 1984
a $26.5 \mathrm{lbs} / 100 \mathrm{lbs}$
b 25.7 lbs/100 lbs
c $22.5 \mathrm{lbs} / 100 \mathrm{lbs}$
d $22.2 \mathrm{lbs} / 100 \mathrm{lbs}$
$\mathrm{b}-\mathrm{c}=3.2 \mathrm{ibs}$
$\mathrm{a}-\mathrm{d}=4.3 \mathrm{lbs}$
measured $1.64 \mathrm{lbs}$

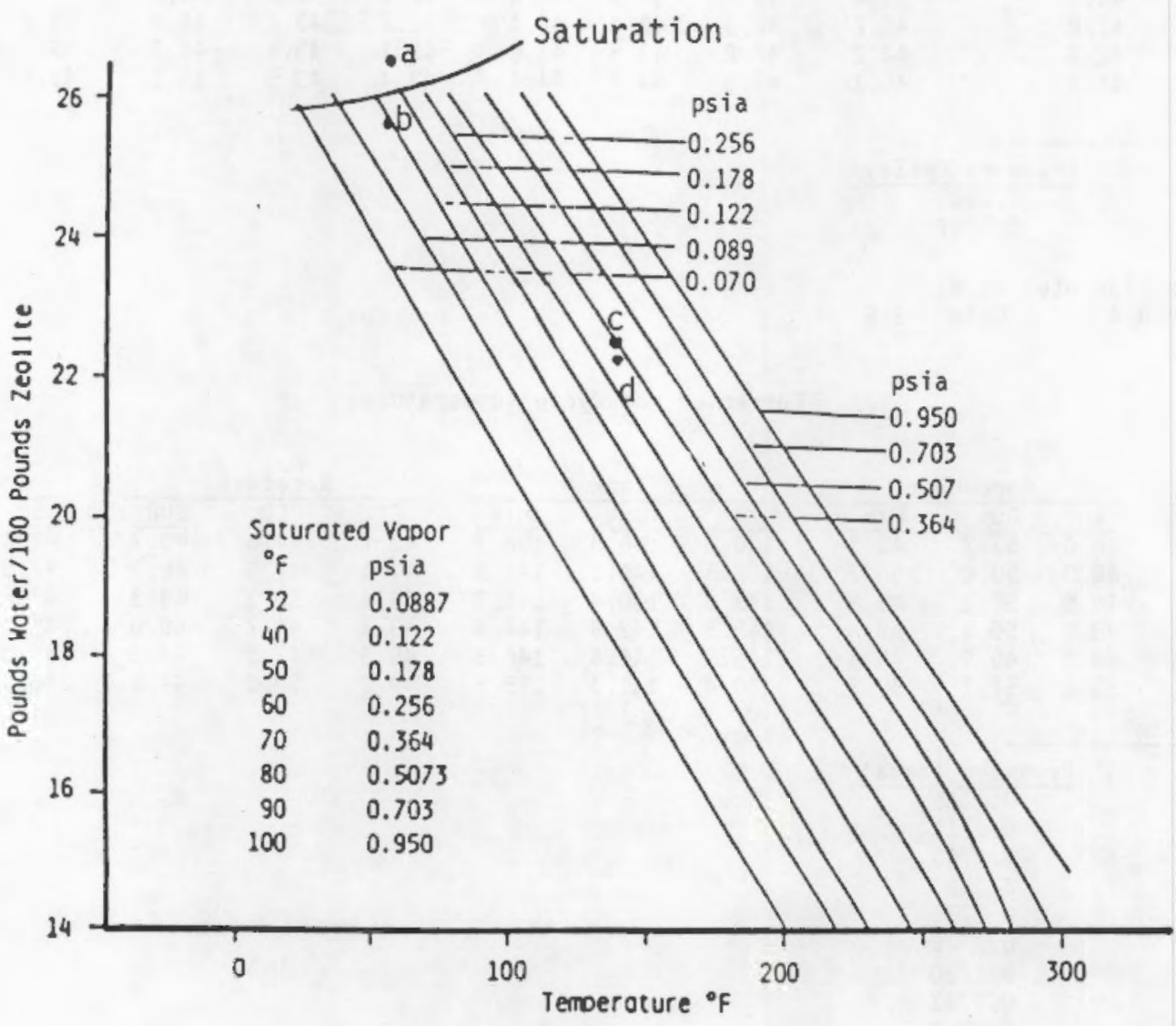

FIGURE B-12-a. Zeolite Isobars 


\begin{tabular}{|c|c|c|c|c|}
\hline $\begin{array}{l}\text { Start } 2 \text {-tank f1lling } \\
\text { Full of cold water } \\
\text { Open 3" valve }\end{array}$ & $\begin{array}{l}0922 \\
0932 \\
0933\end{array}$ & $\begin{array}{l}\text { Full hot water } \\
\text { Condenser flowing }\end{array}$ & 1401 & $\begin{array}{l}\text { Drain: } 0.12 \text { lbs } \quad 1601 \\
\text { Measure: } 1.64 \text { ibs }\end{array}$ \\
\hline Close $3^{n}$ value & 1342 & $\begin{array}{l}\text { Orain: } 0.85 \text { ibs } \\
\text { Orain: } 0.67 \text { lbs }\end{array}$ & $\begin{array}{l}1413 \\
1439\end{array}$ & $\begin{array}{l}\text { Adsorption: cold water flow, } 3.5 \mathrm{gpm} \\
\text { Desorption: cold water flow. } 3.6 \mathrm{gpm}\end{array}$ \\
\hline Start $z$-tank filling & 1351 & $0.23 \mathrm{lbs}$ & 1526 & hot water flow, $3.0 \mathrm{gpm}$ \\
\hline
\end{tabular}

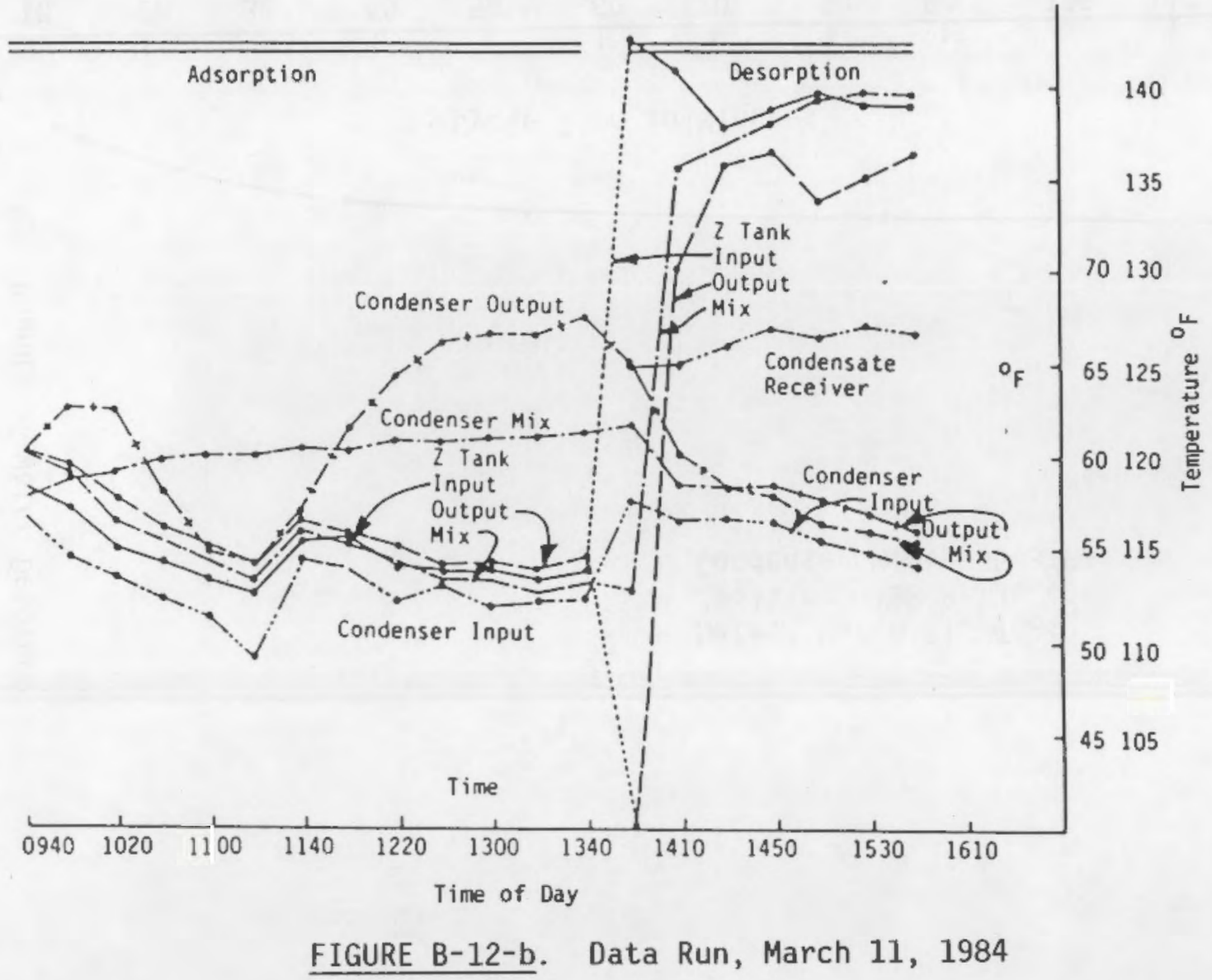


एా

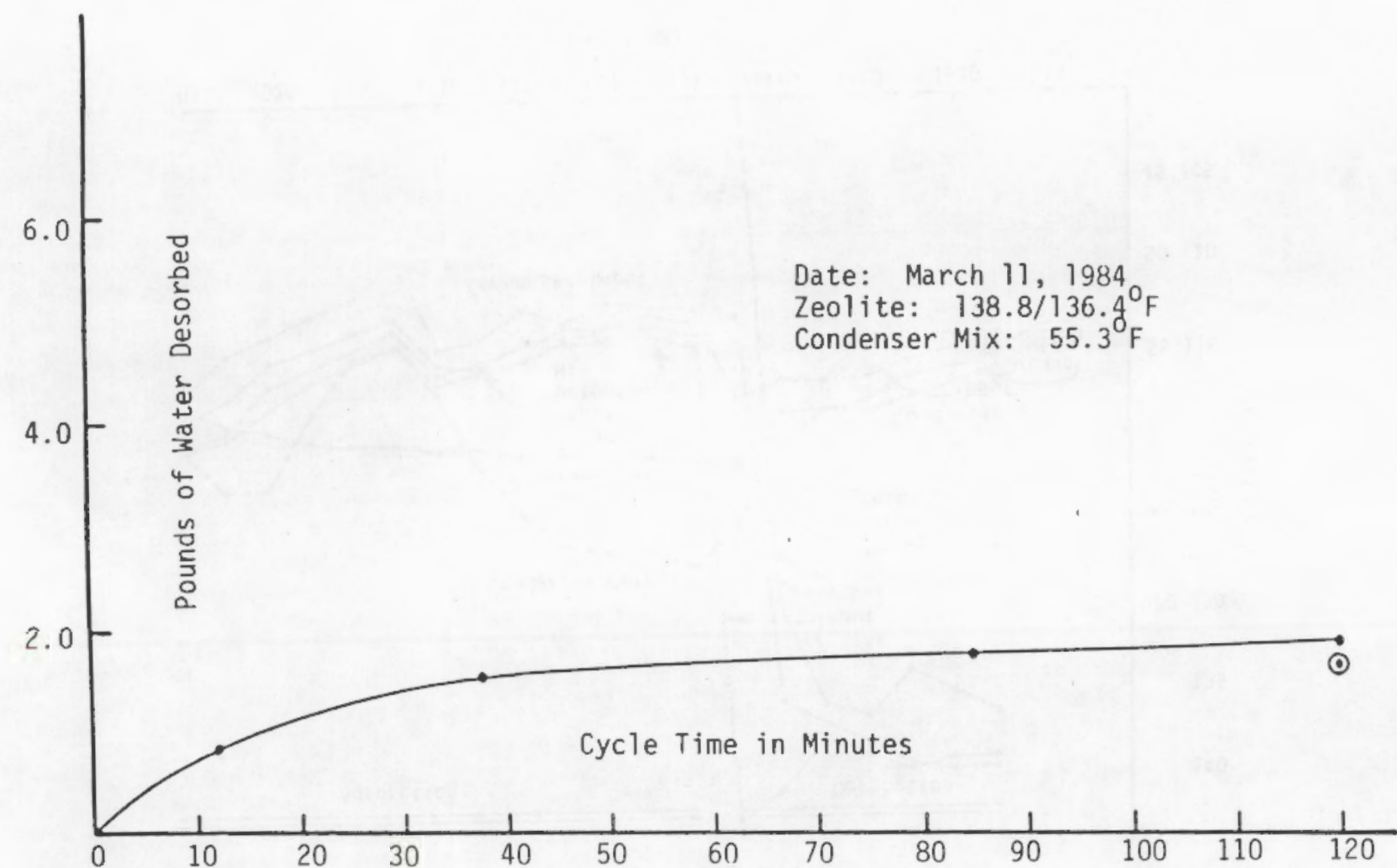

FIGURE B-12-c. Desorption Response 
SOLAR ZEOLITE SYSTEM DATA

DATE PROGRAMED: $\quad 3-11-84$

DATA DATA COLLECTED: $3-11-84$

Corrected Cold Cycle Temperatures

Time

9:40

10:00

10: 20

$10: 40$

11: 00

11: 20

11: 40

12: 00

$12: 20$

$12: 40$

$1: 00$

$1: 20$

$1: 40$

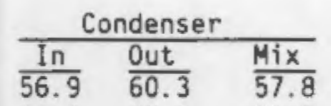

$\begin{array}{lll}54.6 & 62.6 & 58.7\end{array}$

$\begin{array}{lll}53.5 & 62.4 & 59.0\end{array}$

52.458 .2

$51.3 \quad 54.8$

$49.1 \quad 54.1$

$54.3 \quad 57.0$

53.961 .4

52.164 .2

$52.9 \quad 66.1$

$51.8 \quad 66.6$

52.266 .5

52.1

59.8

59.8

60.0

60.4

60.1

60.6

60.6

60.8

61.0

$67.5 \quad 61.2$

\begin{tabular}{rc}
\hline Time & Pressure (psia) \\
\hline $9: 32$ & 0.0886 \\
$9: 33$ & 0.1182 \\
$11: 22$ & 0.1165 \\
$1: 42$ & 0.1198
\end{tabular}

Average Flowrates (gpm)

Spray: 0.9 Cold: 3.5

\begin{tabular}{|c|c|c|}
\hline & - Tank & \\
\hline$\frac{\text { In }}{58.2}$ & $\frac{\text { out }}{602}$ & $\frac{\operatorname{Mix}}{603}$ \\
\hline $\begin{array}{l}38.2 \\
57.1\end{array}$ & $\begin{array}{l}0.2 .2 \\
59.5\end{array}$ & $\begin{array}{l}60.3 \\
59.2\end{array}$ \\
\hline 55.0 & 57.7 & 56.3 \\
\hline 54.3 & 56.1 & 55.3 \\
\hline 53.3 & 55.1 & 54.2 \\
\hline 52.6 & 54.1 & 53.4 \\
\hline 55.5 & 56.6 & 55.8 \\
\hline 55.5 & 55.9 & 55.2 \\
\hline 54.0 & 55.1 & 54.1 \\
\hline 53.7 & 54.0 & 53.3 \\
\hline 53.9 & 54.2 & 53.2 \\
\hline 53 & 53.9 & 52.5 \\
\hline & 54.5 & 53.0 \\
\hline
\end{tabular}

\begin{tabular}{ccc}
\multicolumn{3}{c}{ Receiver } \\
$\frac{C 1}{57.6}$ & $\frac{C O}{59.3}$ & $\frac{\text { SUR }}{60.6}$ \\
57.8 & 58.0 & 61.4 \\
56.8 & 56.4 & 62.0 \\
55.4 & 55.1 & 60.5 \\
54.1 & 53.6 & 60.5 \\
53.3 & 53.0 & 59.8 \\
56.4 & 56.0 & 61.4 \\
58.2 & 58.0 & 62.8 \\
54.0 & 54.0 & 61.8 \\
54.6 & 53.7 & 62.2 \\
54.5 & 53.8 & 62.5 \\
54.8 & 53.1 & 63.8 \\
55.1 & 54.0 & 63.6
\end{tabular}

$\frac{\text { Ice }}{\frac{\text { Tank }}{48.4}} \frac{\frac{T R}{41.9}}{47.8}$

$47.8 \quad 41.6$

$47.4 \quad 42.8$

$47.8 \quad 43.9$

$48.0 \quad 44.5$

$47.3 \quad 45.0$

$47.3 \quad 46.2$

$47.2 \quad 47.4$

$48.0 \quad 48.4$

$48.4 \quad 49.4$

$48.8 \quad 49.9$

$49.3 \quad 50.3$

$50.5 \quad 51.6$

Corrected Hot Cycle Temperatures

\begin{tabular}{|c|c|c|c|}
\hline Time & & Conder & \\
\hline 2.00 & $\frac{\text { In }}{57}$ & Out & Mix \\
\hline $2: 10$ & 56.4 & $\begin{array}{l}60.4 \\
60.1\end{array}$ & $\begin{array}{l}61 . \\
58.4\end{array}$ \\
\hline $2: 30$ & 56.5 & 58,4 & 58.5 \\
\hline 2:50 & 56.2 & 58.2 & 57.9 \\
\hline $3: 10$ & 55.5 & 57.6 & 56.3 \\
\hline $3: 30$ & 54.7 & 56.7 & 55.8 \\
\hline $3: 50$ & 54.0 & 55.8 & 55.3 \\
\hline Time & & ssure & sia) \\
\hline$\overline{2: 01}$ & & 0.25 & \\
\hline 2.06 & & 0.30 & \\
\hline 2.13 & & 0.33 & \\
\hline 2.39 & & 0.34 & \\
\hline 3.26 & & 0.35 & \\
\hline
\end{tabular}

Average Flowrates (gpm)

Spray: 0.95 Condenser: 3.5 Hot: 3

Total condensate removed this hot cycle (lbs): 1.639

\section{FIGURE B-12-d. Data Printout}


Date: March 12, 1984

a $26.0 \mathrm{lbs} / 100 \mathrm{lbs}$

b $24.6 \mathrm{lbs} / 100 \mathrm{lbs}$

c $23 \mathrm{lbs} / 100 \mathrm{lbs}$

d $22.7 \mathrm{lbs} / 100 \mathrm{lbs}$

$\mathrm{b}-\mathrm{c}=1.6 \mathrm{lbs}$

$\mathrm{a}-\mathrm{d}=3.3 \mathrm{lbs}$

measured $4.74 \mathrm{lbs}$

Adsorption pressure below mech. gauge scale.

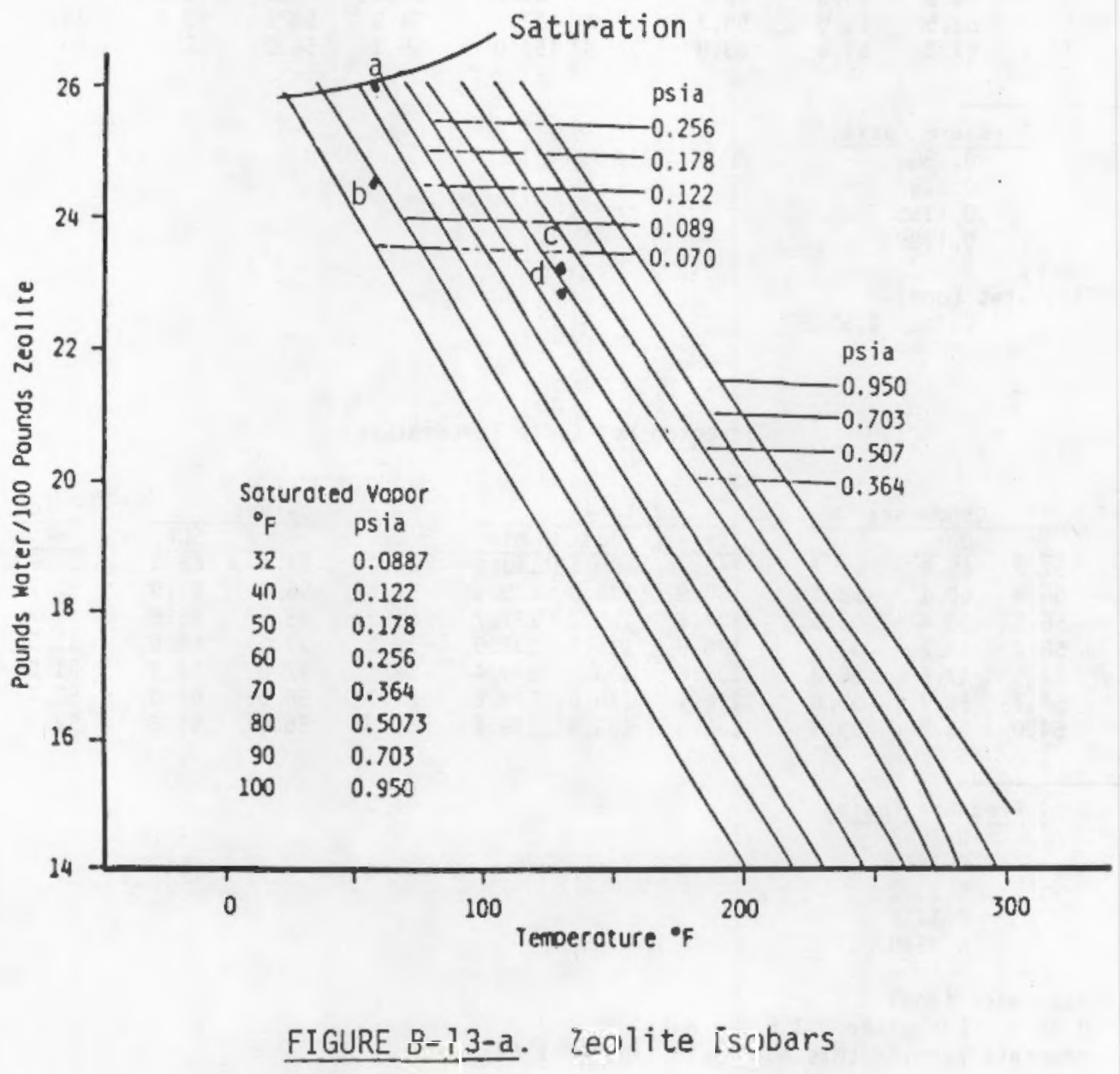




\begin{tabular}{|c|c|c|c|c|}
\hline $\begin{array}{l}\text { Start } 2 \text {-tank filling } \\
\text { Open } 3^{\text {" valve }} \\
\text { Start Z-tank drain } \\
\text { Close } 3^{\text {" valve }} \\
\text { Start Z-tank filling } \\
\text { Full of hot water }\end{array}$ & $\begin{array}{l}1114 \\
1122 \\
1537 \\
1537 \\
1547 \\
1554\end{array}$ & $\begin{array}{l}\text { Condenser flowing } \\
\text { Drain: .85 los } \\
\text { Drain: } 1.01 \text { lbs } \\
\text { Drain: .85 lbs } \\
\text { Orain: } .37 \text { bs } \\
\text { Orain: } .46 \text { lbs }\end{array}$ & $\begin{array}{l}1554 \\
1606 \\
1620 \\
1652 \\
1717 \\
1804\end{array}$ & $\begin{array}{l}\text { Measures: } 3.03 \text { lbs } 1804 \\
\text { Ice tank vapor between } \\
29.8^{\circ} \mathrm{F} \text { and } 41.2^{\circ} \mathrm{F} \\
\text { Adsorption: cold water flow, } 3.5 \mathrm{gpm} \\
\text { Desorption: cold water flow, } 3.6 \mathrm{gpm} \\
\text { hot water flow, } 3.0^{\circ} \mathrm{gpm}\end{array}$ \\
\hline
\end{tabular}

iv

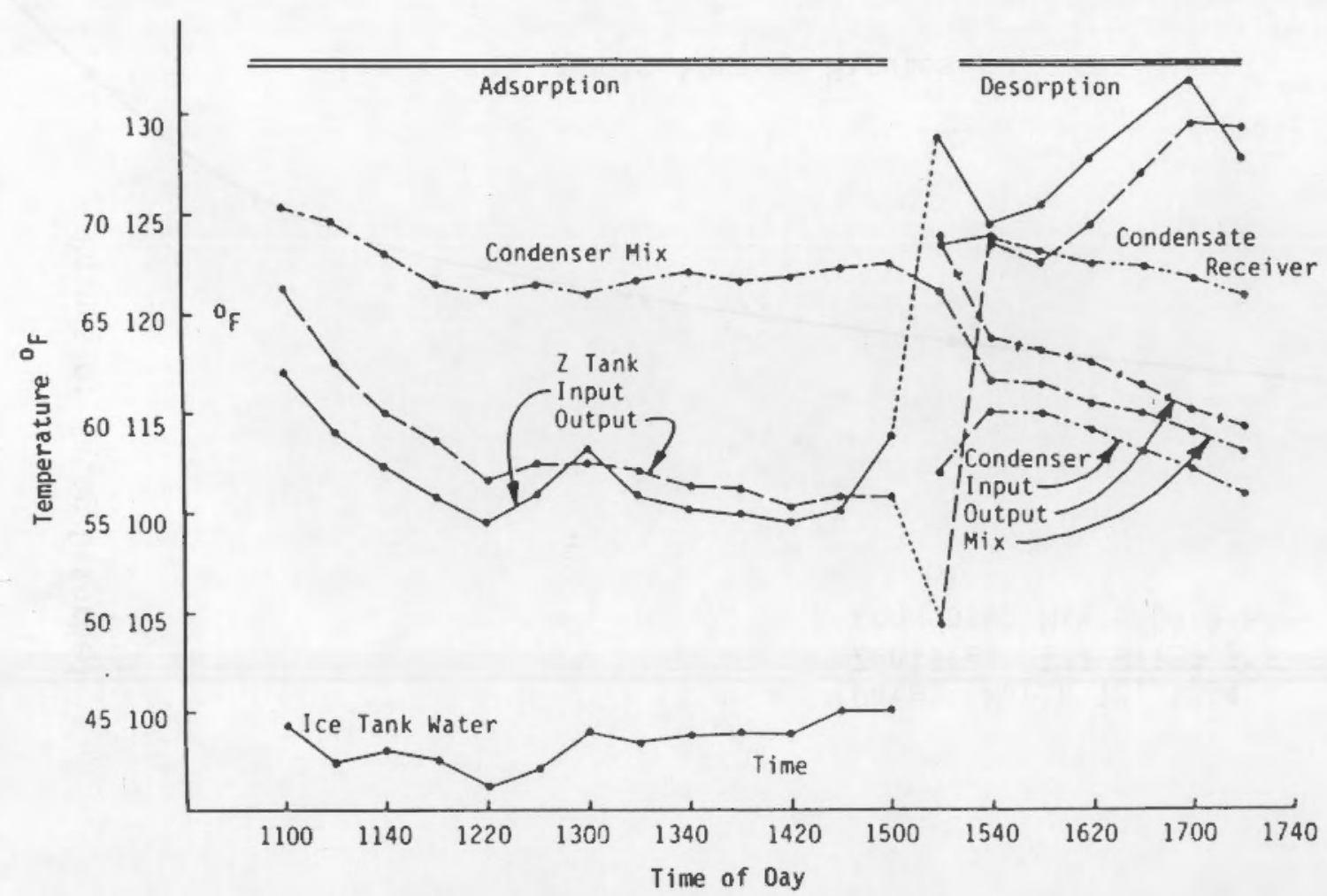

FIGURE B-13-b. Data Run, March 12, 1984 


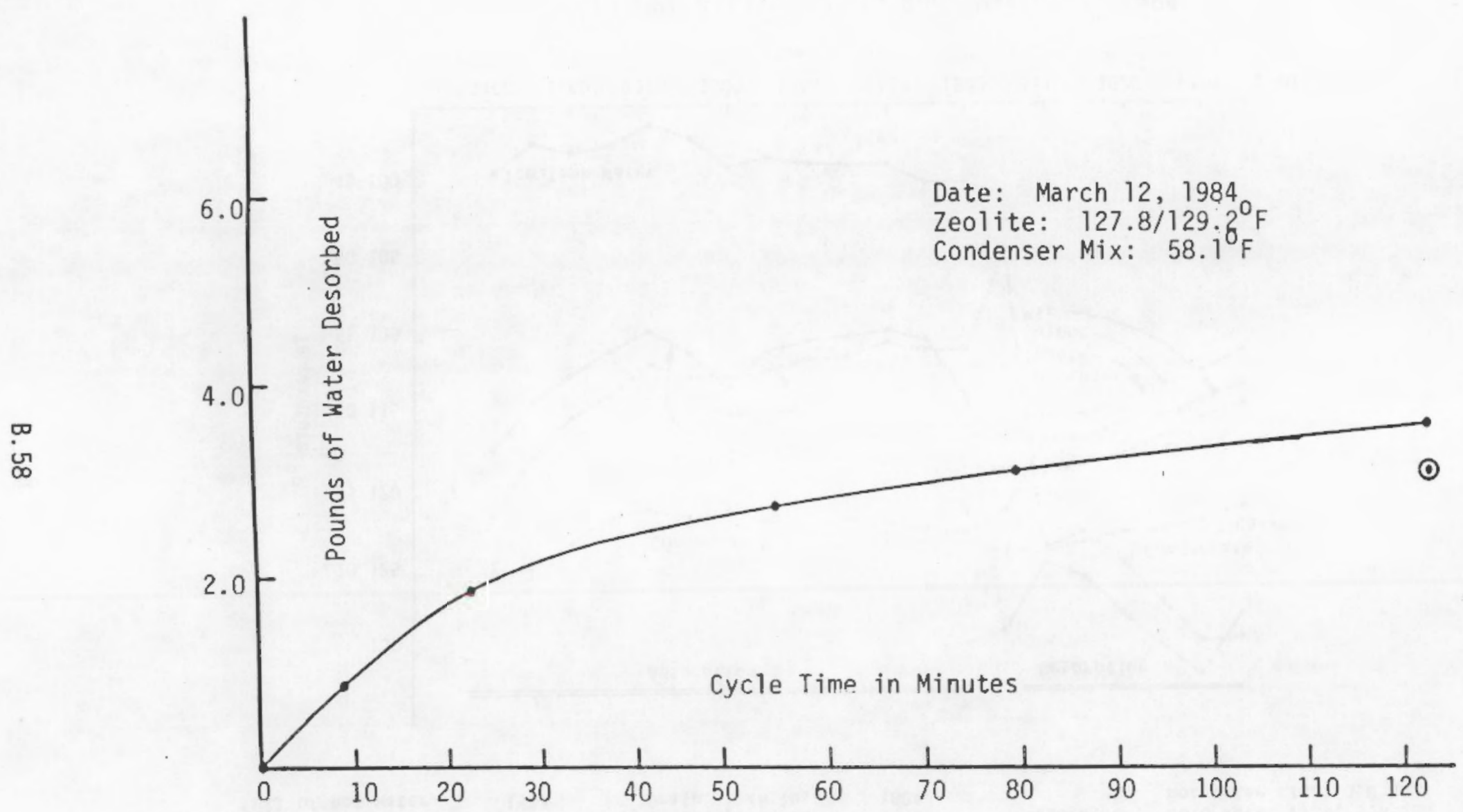

FIGURE 8-13-c. Desorption Response 


\section{SOLAR ZEOLITE SYSTEM DATA}

DATE PROGRAMED: $3-13-84$

DATA DATA COLLECTED: $3-12-84$

Corrected Cold Cycle Temperatures

\begin{tabular}{|c|c|c|c|}
\hline Time & & Conde & \\
\hline & In & Out & Mix \\
\hline $11: 00$ & $\overline{60.6}$ & 76.4 & 70. \\
\hline $12: 00$ & 56.9 & 77.3 & 69. \\
\hline $12: 20$ & 55.4 & 78.6 & 68. \\
\hline $12: 40$ & 53.6 & 76.9 & 66. \\
\hline $1: 00$ & 52.7 & 71.5 & 66. \\
\hline $1: 20$ & 54.6 & 70.6 & 66. \\
\hline $1: 40$ & 56.5 & 70.3 & 66. \\
\hline 2:00 & 54.6 & 71.0 & 66. \\
\hline 2: 20 & 53.6 & 71.0 & 67. \\
\hline $2: 40$ & 53.6 & 72.6 & 66. \\
\hline $3: 00$ & 53.6 & 71.7 & 66. \\
\hline $3: 20$ & 53.5 & 71.5 & 67. \\
\hline Time & & ssure & sia) \\
\hline $10: 45$ & & 0.10 & \\
\hline 3. 37 & & 0.08 & \\
\hline
\end{tabular}

Average Flowrates (gpm)

Spray: 0.8 Cold: 3.5

\begin{tabular}{|c|c|c|}
\hline \multicolumn{3}{|c|}{ Z Tank } \\
\hline$\frac{\text { In }}{62 \sqrt{25}}$ & $\frac{\text { out }}{66.3}$ & $\frac{\operatorname{Mix}}{678}$ \\
\hline 59.0 & 62.6 & 61.6 \\
\hline 57.3 & 60.1 & 59.2 \\
\hline 55.8 & 58.8 & 57.5 \\
\hline 54.5 & 56.6 & 55.8 \\
\hline 55.9 & 57.5 & 56.2 \\
\hline 58.2 & 57.7 & 57.0 \\
\hline 55.9 & 57.2 & 56.4 \\
\hline 55.2 & 56.4 & 55.7 \\
\hline 55.0 & 56.3 & 54.9 \\
\hline 54.7 & 55.3 & 54.6 \\
\hline 5 & 56.0 & 53.9 \\
\hline
\end{tabular}

\begin{tabular}{ccc}
\multicolumn{3}{c}{ Receiver } \\
\hline$\frac{\text { Cl }}{62.5}$ & $\frac{\text { CO }}{62.9}$ & $\frac{\text { SUR }}{67.0}$ \\
59.6 & 59.6 & 65.9 \\
57.5 & 58.4 & 64.5 \\
56.4 & 56.0 & 64.0 \\
56.7 & 56.2 & 64.5 \\
60.2 & 59.8 & 66.3 \\
59.6 & 58.8 & 67.6 \\
56.9 & 56.4 & 66.5 \\
56.4 & 55.9 & 66.9 \\
56.2 & 55.0 & 69.1 \\
55.9 & 54.6 & 67.8 \\
55.8 & 54.8 & 68.9
\end{tabular}

$\frac{\text { Ice Tank }}{\frac{B R}{44.4}} \frac{T R}{\frac{T R}{31.3}}$

$42.5 \quad 30.4$

$43.1 \quad 28.9$

$\begin{array}{ll}42.7 & 29.8\end{array}$

$\begin{array}{ll}41.2 & 30.7\end{array}$

$42.2 \quad 33.4$

$44.0 \quad 34.1$

$43.5 \quad 37.3$

$43.8 \quad 38.2$

$44.0 \quad 39.2$

$44.0 \quad 40.1$

$45.1 \quad 41.2$

CORRECTED HOT CYCLE TEMPERATURES

\begin{tabular}{|c|c|c|c|}
\hline Time & & Conder & \\
\hline 4:00 & $\frac{\text { In }}{57.2}$ & $\frac{\text { Out }}{68.9}$ & $\frac{\text { Mix }}{66}$ \\
\hline $4: 20$ & 60.2 & 63.9 & 61.6 \\
\hline $4: 40$ & 60.0 & 63.2 & 61.5 \\
\hline 5:00 & 59.3 & 62.7 & 60.5 \\
\hline $5: 20$ & 58.2 & 61.5 & 60.0 \\
\hline $5: 40$ & 57.2 & 60.2 & 59.2 \\
\hline $6: 00$ & 56.0 & 59.4 & 58.1 \\
\hline Time & & isure & sia) \\
\hline$\overline{3: 54}$ & & 0.280 & \\
\hline $4: 20$ & & 0.36 & \\
\hline & & 0.371 & \\
\hline
\end{tabular}

Average Flowrates (gpm)

Spray: 0.7 Condenser: 3.5 Hot: 3

Total condensate removed this hot cycle (lbs): 3.025

\begin{tabular}{|c|c|c|}
\hline \multicolumn{3}{|c|}{ Z Tank } \\
\hline$\frac{\text { In }}{1289}$ & $\frac{\text { Out }}{1043}$ & $\frac{\text { Mix }}{1106}$ \\
\hline 124.5 & 123.6 & 125.4 \\
\hline 125. & 122 & 123. \\
\hline 127.9 & 124 & 126.2 \\
\hline & 127 & 128.0 \\
\hline & 129.5 & 130.3 \\
\hline 127. & 129.2 & 129. \\
\hline
\end{tabular}

\begin{tabular}{ccc}
\multicolumn{3}{c}{ Receiver } \\
\hline$\frac{\text { C1 }}{57.9}$ & $\frac{\text { CO }}{57.9}$ & $\frac{\text { SUR }}{68.5}$ \\
62.4 & 61.6 & 68.8 \\
61.8 & 61.1 & 68.2 \\
60.8 & 60.6 & 67.5 \\
60.4 & 60.2 & 67.4 \\
59.1 & 58.6 & 66.8 \\
58.3 & 57.2 & 66.0
\end{tabular}

\begin{tabular}{|c|c|}
\hline$B R$ & TR \\
\hline 47.1 & 49. \\
\hline 47.1 & \\
\hline 48.0 & \\
\hline 48.7 & . \\
\hline 49.7 & \\
\hline 50.1 & 0.2 \\
\hline 50.5 & \\
\hline
\end{tabular}

FIGURE B-13-d. Data Printout 
Date: March 13, 1984
a 25.3 lbs/100 lbs
b 24.3 lbs/100 lbs
c 21.15 lbs/100 lbs
d 21.25 lbs/100 lbs
$\mathrm{b}-\mathrm{c}=3.15 \mathrm{lbs}$
$\mathrm{a}-\mathrm{d}=4.05 \mathrm{lbs}$
measured 4.75 lbs

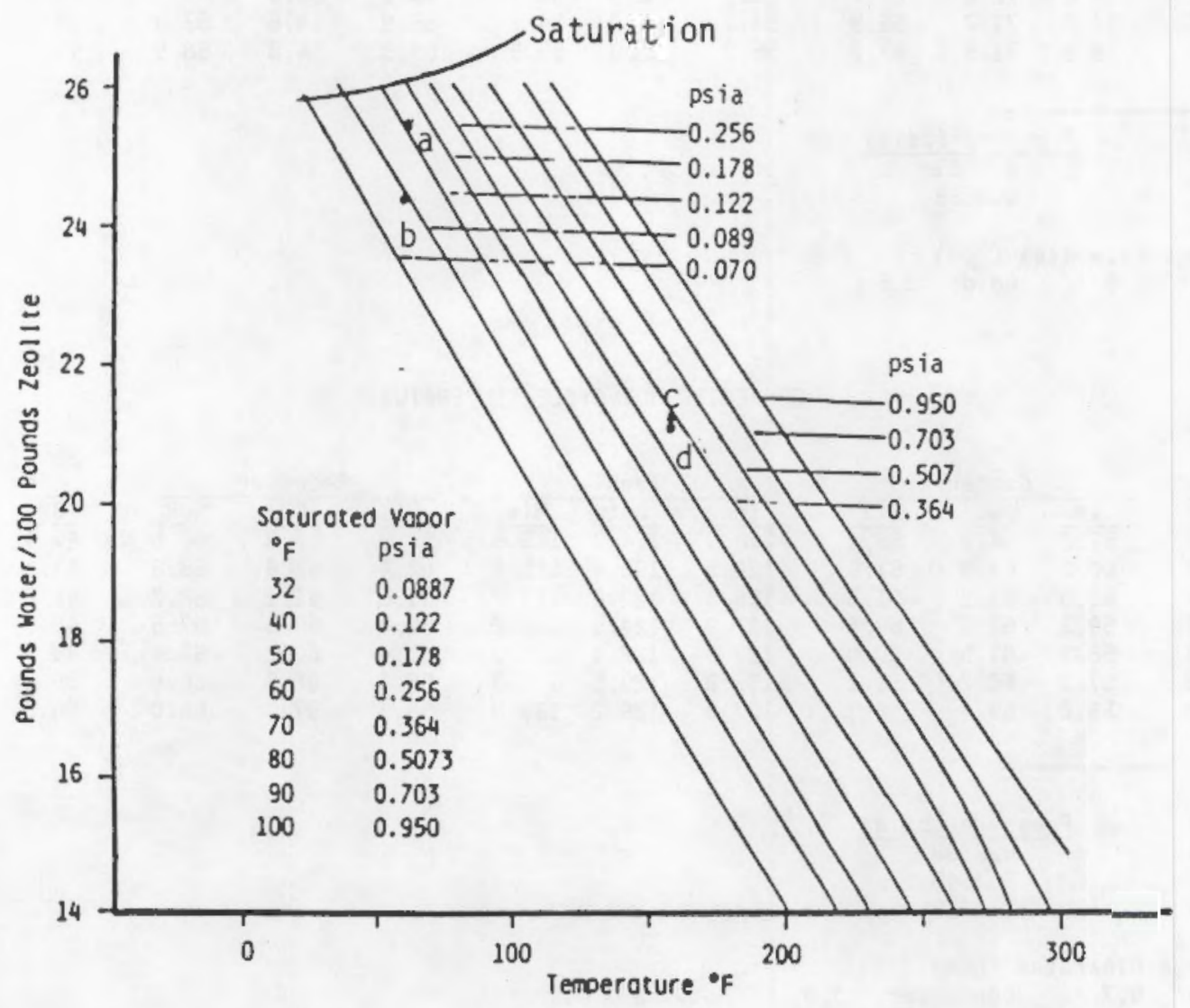

FIGURE B-14-a. Zeolite Isobars 


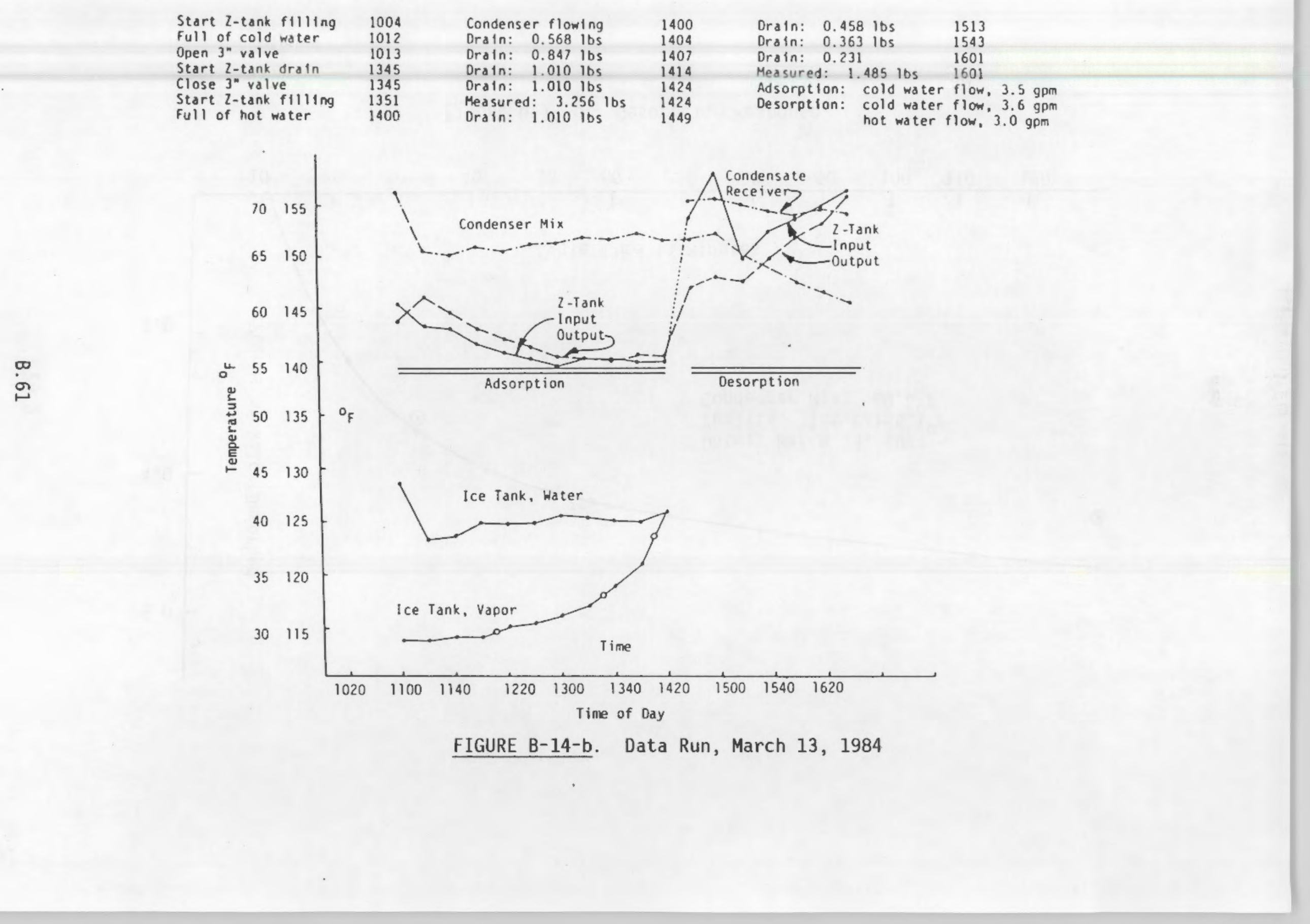




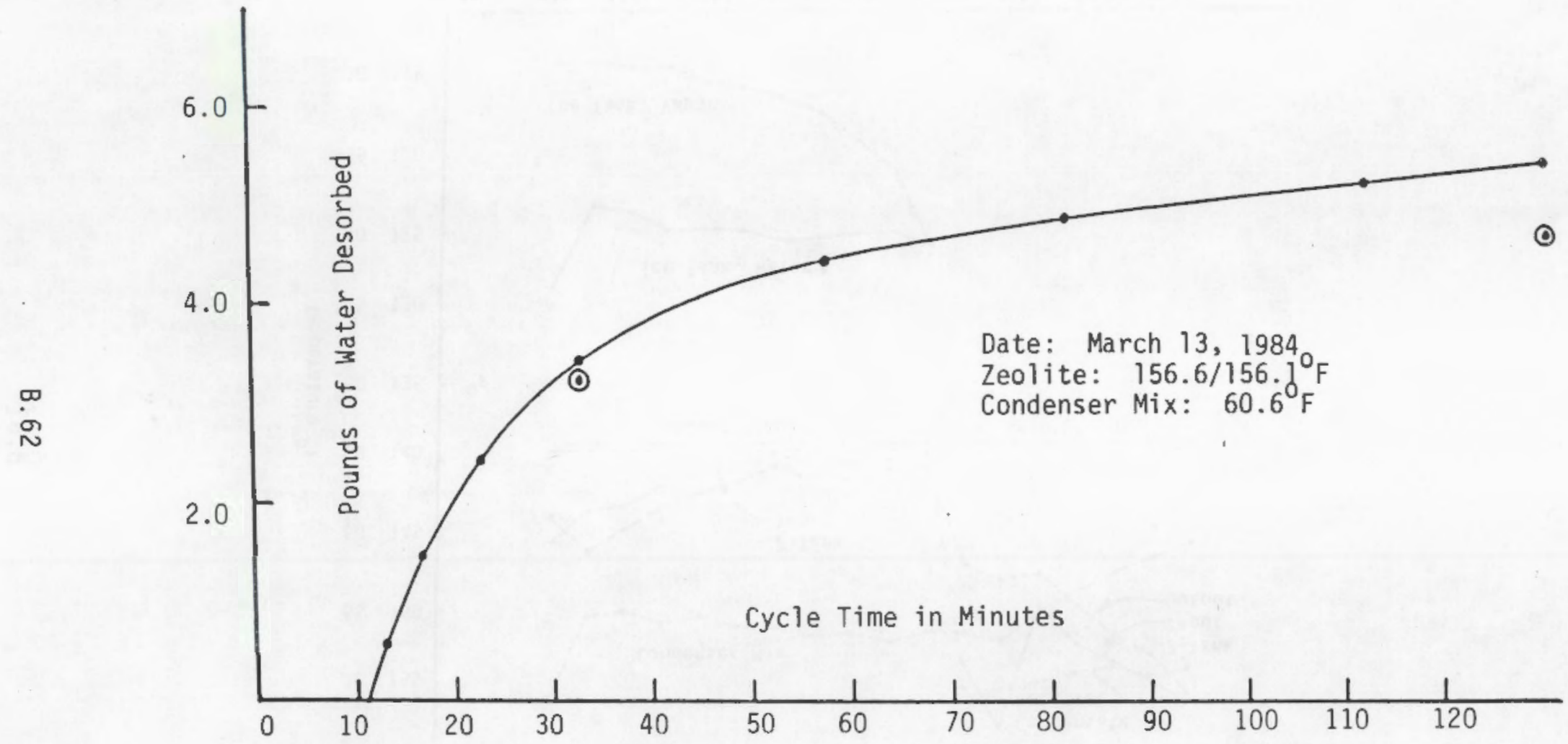

FIGURE B-14-c. Desorption Response 
DATE PROGRAMMED: $\quad 3-13-84$

DATE DATA COLLECTED: $\quad 3-13-84$

Corrected Cold Cycle Temperatures

Time
10: 20
$10: 40$
$11: 00$
$11: 20$
$11: 40$
$12: 00$
$12: 20$
$12: 40$
$1: 00$
$1: 20$
$1: 40$

\begin{tabular}{ccc}
\multicolumn{3}{c}{ Condenser } \\
\hline$\frac{\text { In }}{59.1}$ & $\frac{\text { Out }}{78.9}$ & $\frac{\text { Mix }}{71.3}$ \\
56.2 & 82.1 & 65.6 \\
55.7 & 76.6 & 65.2 \\
54.8 & 73.4 & 66.1 \\
54.0 & 74.2 & 65.7 \\
53.2 & 73.9 & 66.3 \\
52.3 & 73.7 & 66.4 \\
52.9 & 74.5 & 67.1 \\
53.8 & 73.4 & 66.8 \\
53.7 & 74.0 & 67.4 \\
53.6 & 74.4 & 66.6
\end{tabular}

\begin{tabular}{ccc}
\multicolumn{3}{c}{ Z-Tank } \\
\hline$\frac{\text { In }}{60.5}$ & $\frac{\text { Out }}{58.8}$ & $\frac{\text { Mix }}{58.5}$ \\
58.4 & 61.2 & 59.9 \\
58.2 & 59.7 & 58.7 \\
56.6 & 58.2 & 57.6 \\
55.9 & 57.1 & 56.7 \\
55.3 & 56.5 & 55.6 \\
54.7 & 55.6 & 54.8 \\
55.3 & 55.5 & 54.7 \\
55.4 & 55.2 & 54.5 \\
55.0 & 55.6 & 54.2 \\
55.1 & 55.6 & 54.4
\end{tabular}

\begin{tabular}{ccc}
\multicolumn{3}{c}{ Receiver } \\
\hline$\frac{\text { CI }}{57.3}$ & $\frac{\text { CO }}{59.8}$ & $\frac{\text { SUR }}{63.3}$ \\
58.7 & 58.8 & 64.4 \\
58.0 & 58.2 & 64.9 \\
56.7 & 56.5 & 63.8 \\
56.7 & 56.3 & 64.4 \\
55.5 & 54.9 & 63.9 \\
55.1 & 54.3 & 63.5 \\
55.4 & 54.5 & 65.1 \\
55.9 & 54.9 & 66.1 \\
57.3 & 56.5 & 66.4 \\
57.7 & 57.1 & 66.9
\end{tabular}

$\begin{array}{cc}\frac{}{2} \text { Ice } & \text { Tank } \\ \frac{B R}{43.6} & \frac{T R}{28.9} \\ 38.3 & 28.8 \\ 38.7 & 29.1 \\ 39.9 & 29.1 \\ 39.8 & 30.2 \\ 39.8 & 30.4 \\ 40.7 & 31.2 \\ 40.5 & 32.1 \\ 40.2 & 33.8 \\ 40.0 & 36.0 \\ 41.0 & 41.6\end{array}$

Time
$\frac{\text { Pressure (psia) }}{0.0836}$
$\begin{array}{ll}\text { Average Flowrates (gpm) } \\ \text { Spray: } 0.7 & \text { Cold } 3.5\end{array}$

CORRECTED HOT CYCLE TEMPERATURES

\begin{tabular}{|c|c|c|c|}
\hline Time & \multicolumn{3}{|c|}{ Condenser } \\
\hline & In & Out & Mix \\
\hline $2: 00$ & $\overline{69.6}$ & $\overline{74.7}$ & $\overline{66.8}$ \\
\hline $2: 20$ & 63.4 & 69.2 & 67.3 \\
\hline $2: 40$ & 63.8 & 67.9 & 65.3 \\
\hline $3: 00$ & 62.2 & 66.1 & 64.0 \\
\hline $3: 20$ & 61.1 & 66.0 & 62.7 \\
\hline $3: 40$ & 60.0 & 64.7 & 61.7 \\
\hline $4: 00$ & 59.9 & 64.2 & 60.6 \\
\hline
\end{tabular}

\begin{tabular}{crr}
\multicolumn{3}{c}{$Z$-Tank } \\
\hline$\frac{\text { In }}{154.0}$ & $\frac{\text { Out }}{62.1}$ & $\frac{\text { Mix }}{117.1}$ \\
158.3 & 148.4 & 150.8 \\
150.1 & 147.7 & 149.1 \\
152.7 & 149.9 & 151.5 \\
153.9 & 152.0 & 152.8 \\
155.2 & 153.4 & 154.8 \\
156.6 & 156.1 & 156.8
\end{tabular}

\begin{tabular}{ccc}
\multicolumn{3}{c}{ Receiver } \\
\hline C1 & $\frac{\text { CO }}{50.5}$ & $\frac{\text { SUR }}{70.7}$ \\
64.1 & 63.9 & 70.8 \\
65.5 & 65.2 & 70.2 \\
63.5 & 63.3 & 69.7 \\
63.4 & 62.7 & 69.2 \\
62.0 & 61.6 & 69.8 \\
61.5 & 60.5 & 69.4
\end{tabular}

\begin{tabular}{|c|c|}
\hline $8 \mathrm{R}$ & TR \\
\hline 39.6 & 48.4 \\
\hline 39.3 & 50.4 \\
\hline 40.0 & 53.8 \\
\hline 40.3 & 4.0 \\
\hline 39. & \\
\hline 41. & 1.8 \\
\hline 43. & \\
\hline
\end{tabular}

\begin{tabular}{cc}
\hline Iime & Pressure (osia) \\
\hline $2: 00$ & 0.3220 \\
$4: 01$ & 0.3401
\end{tabular}

Average Flowrates (gpm)

Spray: 0.8 Condenser: 3.6 Hot: 3

Total condensate removed this hot cycle (10s): 4.741

FIGURE B-14-d. Data Printout 
DATE PROGRAMMED: 3-15-84

DATE OATA COLLECTED: $3-14-84$

Corrected Cold Cycle Temperatures

\begin{tabular}{|c|c|c|c|c|c|c|c|c|c|c|c|}
\hline Time & & Conder & & & $Z-\operatorname{Tan}$ & & & eceive & & Ice & ank \\
\hline $8: 18$ & $\frac{\operatorname{In}}{48.7}$ & $\frac{\text { Out }}{510}$ & $\frac{\text { Mix }}{66.8}$ & In & $\frac{0 u t}{532}$ & Mix & CI & $\frac{C 0}{50-5}$ & SUR & $\frac{26}{B R}$ & $\frac{T R}{25}$ \\
\hline $8: 23$ & 52.2 & 52.2 & 67.3 & $56 . \frac{1}{3}$ & 53.2 & 83.4 & $\begin{array}{l}49.7 \\
51\end{array}$ & $\begin{array}{l}50.5 \\
5 ? 7\end{array}$ & $\begin{array}{l}54.1 \\
55.1\end{array}$ & $\begin{array}{l}52.2 \\
52.6\end{array}$ & $\begin{array}{l}52.5 \\
52.8\end{array}$ \\
\hline $8: 28$ & 54.5 & 53.3 & 68.4 & 57.6 & 54.8 & 83.7 & 52.6 & 53.2 & 56.7 & 53.0 & $\begin{array}{l}52.8 \\
53.1\end{array}$ \\
\hline $8: 33$ & 55.9 & 55.6 & 70.5 & 59.7 & 56.3 & 84.2 & 52.6 & 53.5 & 58.0 & 53.3 & 53.2 \\
\hline $8: 38$ & 57.1 & 58.1 & 72.4 & 62.2 & 57.9 & 82.6 & 53.3 & 53.5 & 59.4 & 53.0 & 53.4 \\
\hline $8: 43$ & 58.5 & 60.6 & 75.5 & 64.7 & 58.5 & 83. 9 & 53.5 & 54.3 & 59.2 & 53.0 & 53.7 \\
\hline $8: 48$ & 59.2 & 61.0 & 76.0 & 66.0 & 59.5 & 83.5 & 53.5 & 53.9 & 60.4 & 53.4 & 54.2 \\
\hline $8: 53$ & 60.8 & 63.4 & 76.8 & 67.9 & 60.6 & 89.8 & 53.7 & 54.2 & 59.8 & 45.9 & 33.7 \\
\hline $8: 58$ & 51.7 & 64.8 & 76.0 & 53.8 & 66.8 & 57.7 & 53.5 & 53.3 & 60.9 & 45.2 & 41.5 \\
\hline $9: 03$ & 50.7 & 66.4 & 74.5 & 52.7 & 65.2 & 57.6 & 52.9 & 52.9 & 62.1 & 45.9 & 44.1 \\
\hline 9:08 & 51.5 & 68.0 & 72.7 & 53.7 & 60.3 & 58.9 & 53.1 & 53.4 & 62.1 & 41.4 & 23.5 \\
\hline $9: 13$ & 53.8 & 69.5 & 71.8 & 54.6 & 60.4 & 59.1 & 53.9 & 54.8 & 61.8 & 37.5 & 25.4 \\
\hline $9: 18$ & 55.0 & 69.5 & 70.5 & 55.8 & 60.6 & 60.2 & 55.3 & 55.8 & 62.1 & 37.9 & 28.1 \\
\hline $9: 23$ & 55.7 & 70.0 & 70.0 & 57.2 & 60.5 & 59.5 & 56.0 & 57.2 & 63.3 & 38.1 & 28.0 \\
\hline $9: 28$ & 55.9 & 71.3 & 69.8 & 57.3 & 60.2 & 59.8 & 56.5 & 57.4 & 63.5 & 37.6 & 27.3 \\
\hline $9: 33$ & 55.6 & 71.4 & 69.1 & 57.5 & 61.1 & 60.6 & 57.5 & 58.0 & 64.4 & 38.1 & 26.9 \\
\hline $9: 38$ & 56.8 & 73.2 & 69.6 & 58.3 & 60.6 & 59.8 & 57.7 & 58.4 & 65.1 & 37.9 & 28.1 \\
\hline $9: 43$ & 56.9 & 74.0 & 70.0 & 58.8 & 60.6 & 59.5 & 58.1 & 58.2 & 65.1 & 37.3 & 26.9 \\
\hline $9: 48$ & 56.7 & 75.5 & 70.5 & 58.4 & 60.2 & 59.3 & 58.4 & 58.4 & 66.0 & 37.5 & 28. 0 \\
\hline $9: 53$ & 56.5 & 76.6 & 70.3 & 58.2 & 60.2 & 59.2 & 58.2 & 58.6 & 65.1 & 38.4 & 28.0 \\
\hline $9: 58$ & 56.2 & 76.8 & 69.4 & 57.6 & 60.1 & 59.5 & 58.5 & 58.4 & 65.5 & 37.0 & 28.0 \\
\hline $10: 03$ & 55.7 & 77.9 & 69.1 & 58.2 & 59.6 & 58.5 & 58.4 & 58.5 & 65.2 & 37.8 & 27.3 \\
\hline $10: 08$ & 56.1 & 78.4 & 68.2 & 57.7 & 59.6 & 58.5 & 58.2 & 57.9 & 65.7 & 37.9 & 28.5 \\
\hline $10: 13$ & 55.9 & 78.4 & 67.6 & 57.5 & 59.2 & 58.3 & 57.6 & 57.8 & 65.4 & 37.9 & 28.9 \\
\hline $10: 18$ & 56.1 & 78.7 & 67.0 & 57.3 & 58.9 & 57.9 & 58.0 & 58.0 & 65.6 & 38.8 & 28.9 \\
\hline $10: 23$ & 55.5 & 79.0 & 66.5 & 57.5 & 58.5 & 57.7 & 57.8 & 57.4 & 66.3 & 39.0 & 28.8 \\
\hline $10: 28$ & 55.7 & 80.8 & 63.4 & 57.3 & 58.8 & 57.1 & 57.7 & 57.6 & 66.2 & 38.9 & 29.1 \\
\hline $10: 33$ & 56.2 & 81.1 & 62.5 & 57.4 & 58.3 & 57.5 & 57.4 & 57.8 & 66.9 & 38.8 & 29.8 \\
\hline $10: 38$ & 62.2 & 82.1 & 62.1 & 63.6 & 60.6 & 59.3 & 62.5 & 63.8 & 67.7 & 39.2 & 31.6 \\
\hline $10: 43$ & 58.8 & 82.3 & 62.8 & 60.8 & 62.4 & 62.1 & 60.9 & 61.1 & 67.6 & 39.3 & 33.0 \\
\hline $10: 48$ & 58.5 & 76.9 & 62.7 & 60.9 & 61.4 & 60.9 & 60.7 & 60.8 & 67.1 & 39.7 & 33.5 \\
\hline $10: 53$ & 58.2 & 75.1 & 63.2 & 59.6 & 61.3 & 60.1 & 60.4 & 60.0 & 66.9 & 39.6 & 33.2 \\
\hline $10: 58$ & 58.2 & 73.8 & 63.1 & 59.6 & 60.6 & 59.9 & 59.6 & 59.9 & 67.7 & 40.0 & 33.7 \\
\hline $11: 03$ & 57.6 & 73.2 & 62.8 & 59.4 & 60.2 & 59.8 & 59.6 & 59.2 & 68.6 & 40.1 & 34.4 \\
\hline $11: 08$ & 57.8 & 72.0 & 63.1 & 58.9 & 60.0 & 59.2 & 59.8 & 59.3 & 69.6 & 39.2 & 34.5 \\
\hline $11: 03$ & 57.2 & 71.4 & 63.4 & 58.7 & 59.9 & 59.1 & 59.3 & 59.0 & 70.3 & 40.0 & 34.5 \\
\hline $11: 18$ & 57.3 & 70.7 & 63.3 & 58.4 & 59.7 & 59.2 & 59.6 & 58.8 & 70.2 & 40.7 & 34.9 \\
\hline $11: 23$ & 57.0 & 70.3 & 62.8 & 59.1 & 59.8 & 58.4 & 59.8 & 59.0 & 69.9 & 40.0 & 36.3 \\
\hline $11: 28$ & 56.7 & 70.2 & 63.2 & 58.2 & 59.2 & 58.5 & 59.5 & 59.1 & 70.5 & 40.1 & 37.0 \\
\hline $11: 33$ & 56.8 & 70.6 & 63.7 & 58.4 & 59.1 & 58.1 & 59.2 & 58.9 & 68.5 & 39.6 & 38.1 \\
\hline $11: 38$ & 61.6 & 70.9 & 63.2 & 64.1 & 59.3 & 58.6 & 63.6 & 64.0 & 69.7 & 39.9 & 37.3 \\
\hline $11: 43$ & 59.3 & 69.2 & 63.6 & 61.5 & 61.1 & 61.5 & 61.9 & 62.0 & 69.0 & 39.4 & 39.7 \\
\hline $11: 48$ & 59.0 & 66.9 & 63.6 & 61.1 & 61.5 & 60.5 & 61.0 & 60.8 & 70.4 & 39.8 & 42.5 \\
\hline $11: 53$ & 58.9 & 66.3 & 63.5 & 59.9 & 62.0 & 60.1 & 60.4 & 60.3 & 70.1 & 39.9 & 45.2 \\
\hline $11: 58$ & 58.7 & 66.0 & 63.3 & 60.0 & 60.8 & 59.5 & 60.9 & 60.8 & 71.1 & 40.7 & 46.5 \\
\hline $12: 03$ & 58.2 & 66.3 & 63.2 & 59.2 & 60.2 & 59.6 & 61.0 & 59.4 & 71.2 & 41.4 & 47.7 \\
\hline $12: 08$ & 58.4 & 66.1 & 63.6 & 59.7 & 60.6 & 59.4 & 60.6 & 59.8 & 71.5 & 42.4 & 49.0 \\
\hline $12: 13$ & 58.5 & 66.7 & 63.7 & 58.6 & 60.8 & 58.9 & 60.9 & 60.2 & 72.0 & 43.1 & 49.5 \\
\hline $12: 18$ & 57.8 & 68.6 & 63.7 & 59.3 & 60.3 & 59.0 & 60.7 & 60.0 & 71.7 & 43.0 & 50.8 \\
\hline
\end{tabular}

FIGURE B-15-d. Data Printout 
Corrected Cold Cycle Temperatures

Time
$12: 23$
$12: 28$
$12: 33$
$12: 38$
$12: 43$
$12: 48$
$12: 53$
$12: 58$
$1: 03$
$12: 58$
$1: 03$
$1: 08$
$1: 13$
$1: 18$
$1: 23$
$1: 28$

\begin{tabular}{ccc}
\multicolumn{3}{c}{ Condenser } \\
\hline$\frac{\text { In }}{53.2}$ & $\frac{\text { Out }}{69.8}$ & $\frac{\text { Mix }}{63.9}$ \\
59.1 & 70.4 & 63.6 \\
58.8 & 71.3 & 64.3 \\
59.2 & 71.7 & 64.0 \\
58.5 & 72.4 & 64.0 \\
58.4 & 72.3 & 63.9 \\
58.7 & 72.7 & 63.8 \\
58.8 & 72.7 & 64.0 \\
58.0 & 72.7 & 64.0 \\
58.8 & 72.7 & 64.0 \\
58.0 & 72.7 & 64.0 \\
58.1 & 72.4 & 63.8 \\
58.1 & 73.4 & 64.0 \\
58.3 & 72.9 & 64.7 \\
62.6 & 73.6 & 64.8 \\
65.1 & 73.2 & 64.7
\end{tabular}

\begin{tabular}{ccc} 
& Z Tank \\
\hline In & Out & Mix \\
\hline 64.0 & 59.6 & 59.0 \\
53.7 & 61.1 & 59.9 \\
60.2 & 60.7 & 60.3 \\
60.0 & 60.6 & 60.0 \\
60.0 & 60.6 & 59.8 \\
60.6 & 61.0 & 59.2 \\
60.3 & 60.3 & 59.6 \\
60.0 & 60.3 & 59.7 \\
59.8 & 60.0 & 59.4 \\
60.0 & 60.3 & 58.7 \\
59.8 & 60.0 & 59.4 \\
59.7 & 59.6 & 59.3 \\
59.8 & 59.7 & 59.1 \\
59.3 & 61.1 & 59.2 \\
63.2 & 60.2 & 59.5 \\
67.6 & 62.1 & 59.7
\end{tabular}

\begin{tabular}{lcc}
\multicolumn{3}{c}{ Receiver } \\
\hline$\frac{\text { C1 }}{61.7}$ & $\frac{\text { CO }}{62.8}$ & $\frac{\text { SUR }}{72.4}$ \\
62.6 & 61.6 & 71.9 \\
61.5 & 60.6 & 72.0 \\
61.1 & 60.6 & 72.8 \\
61.4 & 60.9 & 73.0 \\
61.5 & 60.9 & 72.6 \\
61.2 & 60.4 & 72.6 \\
61.4 & 60.9 & 73.3 \\
61.1 & 60.5 & 71.9 \\
61.4 & 60.9 & 73.3 \\
61.1 & 60.5 & 71.9 \\
60.7 & 60.5 & 72.6 \\
61.1 & 60.0 & 72.5 \\
61.0 & 60.3 & 72.9 \\
61.2 & 60.0 & 72.6 \\
61.0 & 60.0 & 71.5
\end{tabular}

\begin{tabular}{|c|c|}
\hline BR & TR \\
\hline$\overline{43.4}$ & $\overline{52.2}$ \\
\hline 44.1 & 53. \\
\hline 43.0 & 3.7 \\
\hline 42.4 & 34.5 \\
\hline 41.7 & 55.4 \\
\hline 41.8 & 56.6 \\
\hline 42.3 & 57.2 \\
\hline 42.1 & 57.1 \\
\hline 41.7 & \\
\hline 42.1 & 7.1 \\
\hline 41.7 & 58. \\
\hline 41.3 & 57.8 \\
\hline 41.1 & 55.0 \\
\hline 42.4 & \\
\hline 42.7 & \\
\hline 41.6 & \\
\hline
\end{tabular}

\begin{tabular}{lc}
\hline Time & Pressure (psia) \\
\hline $1: 19$ & 0.0771 \\
$1: 29$ & 0.0836
\end{tabular}

Average Flowrates (gpm)

Spray: 0.6 Cold 3.5

\section{CORRECTED HOT CYCLE TEMPERATURES}

\begin{tabular}{llll} 
Time & \multicolumn{3}{c}{ Condenser } \\
\cline { 2 - 4 } $1: 33$ & $\frac{\text { In }}{67.8}$ & $\frac{\text { Out }}{73.4}$ & $\frac{\text { Mix }}{63.9}$ \\
$1: 38$ & 60.6 & 71.7 & 68.5 \\
$1: 43$ & 60.6 & 71.3 & 68.2 \\
$1: 48$ & 63.4 & 70.4 & 67.4 \\
$1: 53$ & 64.3 & 70.2 & 67.3 \\
$1: 58$ & 64.4 & 69.7 & 68.4 \\
$2: 03$ & 65.0 & 69.4 & 67.7 \\
$2: 08$ & 64.4 & 68.2 & 66.4 \\
$2: 13$ & 64.6 & 68.1 & 66.6 \\
$2: 18$ & 63.6 & 67.4 & 65.3 \\
$2: 23$ & 63.6 & 67.4 & 65.5 \\
$2: 28$ & 63.5 & 66.7 & 64.9 \\
$2: 33$ & 62.4 & 66.5 & 64.9 \\
$2: 38$ & 61.7 & 65.9 & 64.1 \\
$2: 43$ & 61.9 & 65.3 & 63.6 \\
$2: 48$ & 61.1 & 64.9 & 62.6 \\
$2: 53$ & 61.1 & 64.8 & 62.6 \\
$2: 58$ & 60.6 & 64.5 & 62.3 \\
$2: 33$ & 62.4 & 66.5 & 64.9 \\
$2: 38$ & 61.7 & 65.9 & 64.1 \\
$2: 43$ & 61.9 & 65.3 & 63.6
\end{tabular}

\begin{tabular}{lll}
\multicolumn{3}{c}{ Z Tank } \\
\hline$\frac{\text { In }}{169.3}$ & $\frac{\text { Out }}{64.6}$ & $\frac{\text { Mix }}{133.8}$ \\
175.0 & 124.0 & 140.2 \\
177.1 & 143.4 & 151.8 \\
177.9 & 158.3 & 164.5 \\
177.1 & 159.6 & 168.6 \\
174.6 & 167.1 & 171.5 \\
167.1 & 166.7 & 171.4 \\
163.5 & 163.5 & 167.7 \\
164.2 & 162.9 & 165.8 \\
164.8 & 159.8 & 165.0 \\
165.0 & 159.2 & 164.8 \\
165.2 & 159.8 & 164.6 \\
164.4 & 160.2 & 165.4 \\
165.1 & 162.6 & 165.7 \\
164.0 & 162.5 & 166.1 \\
163.8 & 162.4 & 165.7 \\
163.9 & 162.3 & 166.1 \\
164.0 & 162.1 & 165.0 \\
164.4 & 160.2 & 165.4 \\
165.1 & 162.6 & 165.7 \\
164.0 & 162.5 & 166.1
\end{tabular}

\begin{tabular}{ccc}
\multicolumn{3}{c}{ Receiver } \\
\hline$\frac{\text { C1 }}{61.9}$ & $\frac{\text { CO }}{61.0}$ & $\frac{\text { SUR }}{73.0}$ \\
61.4 & 60.4 & 71.9 \\
62.3 & 61.5 & 71.9 \\
63.9 & 63.6 & 70.3 \\
65.3 & 65.6 & 70.7 \\
66.2 & 65.7 & 71.5 \\
66.7 & 66.2 & 71.2 \\
67.0 & 66.5 & 71.3 \\
66.9 & 66.1 & 71.7 \\
66.6 & 65.6 & 72.0 \\
66.1 & 64.6 & 70.6 \\
65.5 & 64.6 & 72.1 \\
64.8 & 64.6 & 71.6 \\
64.0 & 63.6 & 71.1 \\
64.8 & 63.0 & 71.2 \\
64.4 & 63.3 & 70.0 \\
63.7 & 62.8 & 72.6 \\
63.9 & 62.1 & 70.2 \\
64.8 & 64.6 & 71.6 \\
64.0 & 63.6 & 71.1 \\
64.8 & 63.0 & 71.2
\end{tabular}

\begin{tabular}{|c|c|}
\hline$B R$ & $\overline{T R}$ \\
\hline 41. & 50.2 \\
\hline 40. & 48. \\
\hline 40. & 48.5 \\
\hline 40.8 & 48.7 \\
\hline 40.2 & 49.9 \\
\hline 39.8 & 46.8 \\
\hline 40. & 47.3 \\
\hline 41. & 48.7 \\
\hline 41. & 48.8 \\
\hline 41. & 48.7 \\
\hline 42. & 49.0 \\
\hline 41.8 & \\
\hline 41. & 51.4 \\
\hline 41. & 50.2 \\
\hline 42. & 46. \\
\hline 42. & 5.5 \\
\hline 42. & 46. \\
\hline 43. & 47.9 \\
\hline 41.7 & .2 \\
\hline 41. & \\
\hline 3 & \\
\hline
\end{tabular}

FIGURE B-15-d. Data Printout (continued) 
CORRECTED HOT CYCLE TEMPERATURES

Time
$2: 48$
$2: 53$
$2: 58$
$3: 03$
$3: 08$
$3: 13$
$3: 18$
$3: 23$
$3: 28$
$3: 33$
$3: 38$
$3: 43$
$3: 48$

\begin{tabular}{|c|c|c|}
\hline \multicolumn{3}{|c|}{ Condenser } \\
\hline $\ln$ & Out & Mix \\
\hline $\begin{array}{ll}61.1 \\
61.1\end{array}$ & $\begin{array}{l}64.9 \\
64.8\end{array}$ & $\begin{array}{l}62.6 \\
62.6\end{array}$ \\
\hline 60.6 & 64.5 & 62.3 \\
\hline 60.4 & 64.1 & 61.7 \\
\hline 60.0 & 64.1 & 61.8 \\
\hline 60.0 & 63.1 & 61.2 \\
\hline 59.5 & 63.5 & 60.7 \\
\hline 59.4 & 62.3 & 60.4 \\
\hline 58.7 & 62.9 & 59.9 \\
\hline 5 & 63.1 & 60.0 \\
\hline 5 & 62.4 & \\
\hline & 62.9 & 59.9 \\
\hline 62.6 & 63.0 & 59.5 \\
\hline
\end{tabular}

\begin{tabular}{lll}
\multicolumn{3}{c}{2 Tank } \\
In & $\frac{\text { Out }}{162.4}$ & $\frac{M i x}{165.7}$ \\
$\frac{163.8}{163.9}$ & 162.3 & 166.1 \\
164.0 & 162.1 & 165.0 \\
164.2 & 162.6 & 165.3 \\
164.6 & 162.2 & 165.4 \\
163.9 & 162.7 & 165.3 \\
164.0 & 162.6 & 165.5 \\
164.3 & 163.0 & 165.7 \\
164.7 & 163.0 & 166.2 \\
165.1 & 163.7 & 165.7 \\
165.4 & 163.6 & 166.1 \\
165.3 & 164.0 & 165.1 \\
158.7 & 163.5 & 166.8
\end{tabular}

\begin{tabular}{lcc}
\multicolumn{3}{c}{ Receiver } \\
$\frac{\text { C1 }}{64.4}$ & $\frac{\text { CO }}{63.3}$ & $\frac{\text { SUR }}{70.0}$ \\
63.7 & 62.8 & 72.6 \\
63.9 & 62.1 & 70.2 \\
63.1 & 61.8 & 70.2 \\
63.0 & 61.8 & 69.9 \\
62.4 & 61.6 & 69.4 \\
62.3 & 61.2 & 69.9 \\
61.8 & 61.2 & 70.2 \\
63.2 & 60.4 & 69.2 \\
61.7 & 61.1 & 71.9 \\
61.5 & 60.5 & 71.4 \\
61.8 & 60.3 & 70.7 \\
62.1 & 60.6 & 70.7
\end{tabular}

\begin{tabular}{c|c}
\multicolumn{2}{c}{ Ice Tank } \\
\hline BR & TR \\
\hline 42.0 & 45.5 \\
42.4 & 46.4 \\
43.0 & 47.9 \\
42.7 & 48.9 \\
42.0 & 48.6 \\
43.5 & 49.8 \\
43.3 & 50.3 \\
43.0 & 51.2 \\
43.2 & 51.3 \\
42.8 & 52.0 \\
42.2 & 51.1 \\
43.0 & 51.9 \\
43.3 & 52.0
\end{tabular}

\begin{tabular}{lc} 
Time & Pressure (PS1A) \\
\hline$: 38$ & 0.3352 \\
$2: 54$ & 0.3237 \\
$3: 15$ & 0.3187 \\
3.46 & 0.3138
\end{tabular}

Average Flowrates (GPH)

Spray: 0.6 Condenser: 3.6 Hot: 2.8

Total condensate removed this hot cycle (los): 5.06

FIGURE B-15-d. Data Printout (continued) 


\section{APPENDIX C}

\section{CALIBRATIONS}



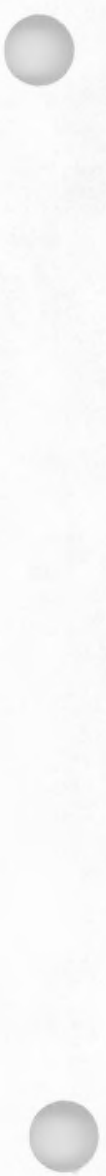


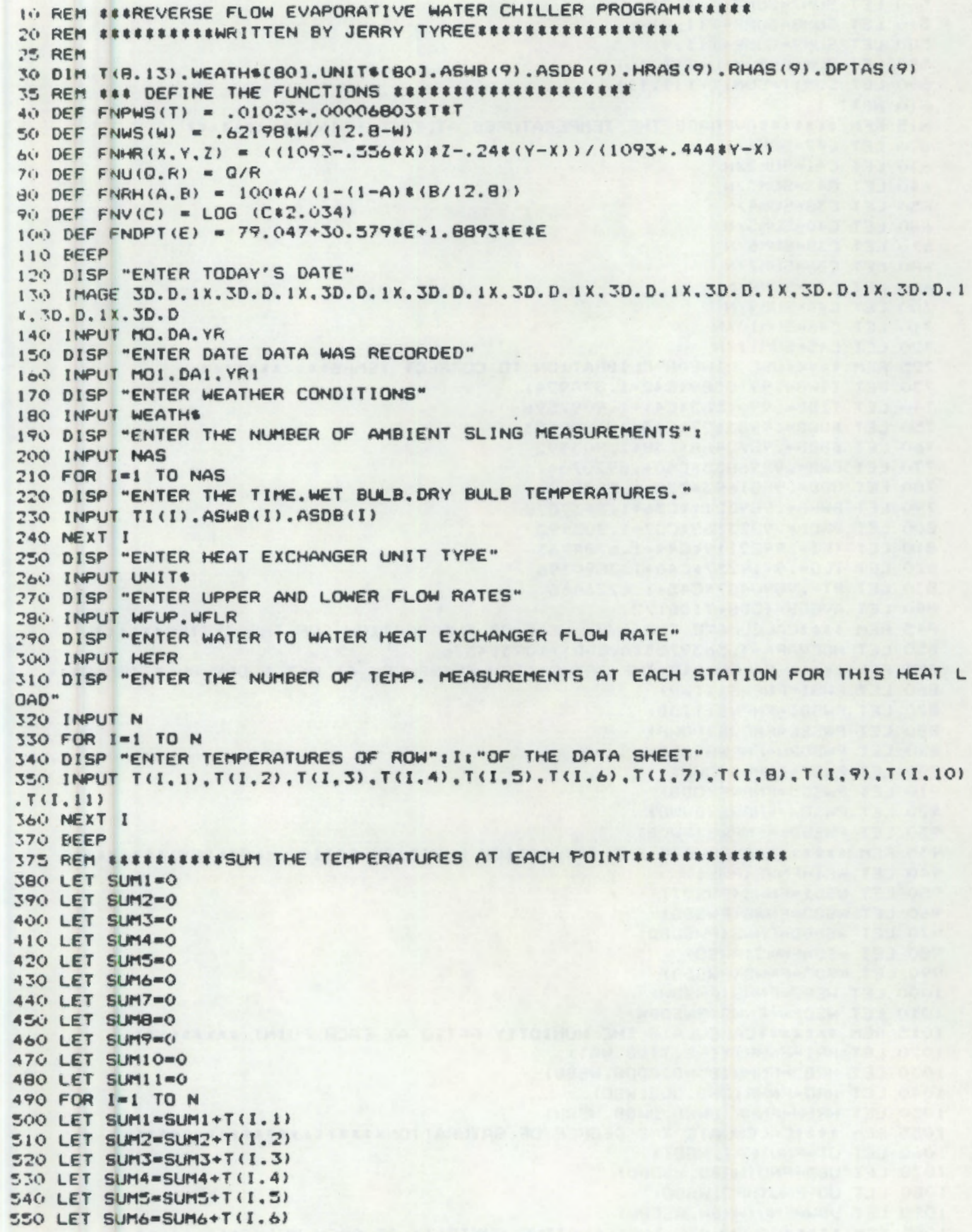

FIGURE C-1. Temperature Calibrations 
Sin LET SUM $7=5 U M 7+T(1,7)$

$5 .:$ LET SUMB $=$ SUMB + T $(1, \theta)$

SBU LET SUMO=SUM9+T $(1.9)$

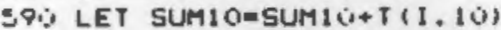

Grii) LET SUM $11=$ SUM $11+T(1,11)$

- $1 \therefore$ NEXT

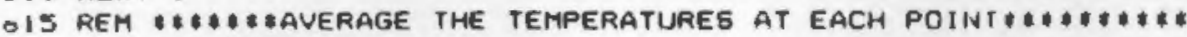

0.1 LET $C 42=5 U M 1 / N$

oli LFT CAI=SUMZ/N

BAO LET $C 43=S U M B / N$

BEO LET C YB=SUM4/N

6GC LET CAON=SUME/N

$67:$ LET $C 39=5 U M 6 / N$

ABO L.ET $C 36=S U M 7 / N$

BO.: LET C.S7 $=5 U M B / N$

7ini LET $C 44=S U M O / N$

7 I.) I.ET $C 46=5 U M I 0 / N$

720 LET C4S=SUM11/N

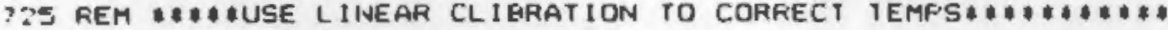

730 LET TIWE $=.99103894 C 42+1.8749241$

$74 \%$ LET TIDR=.99015620C41+1.90197596

75. LET $8 D W E=.9933127 * C 43+1.6809583$

7601 LET GDDE $=.9872468 * C 38+1.9013992$

770 LET OWB $=.9996835 * C 40+.8920704$

780 LET ODE $=.9881693 * C 39+1.5692001$

790 LET BWWE $=.9893211 * C 36+1.843702 \theta$

B(0) LET RWDE $=.9873368: C 37+1.903992$

810 LET TLI $=.9922119 \div 644+1.6784763$

G:O LET TLO $=.9919257 \times C 46+1.3890396$

BTi LET PT $=.9894487+C 45+1.6226466$

BAI LET AVGOEE: (ODE+TIDE) $/ 2$

HAS FEM : $:$ CALCULATE THE AVG. HEAT OF EVAFORATION FOR THE SYSTEM\#*\#**

85:) LET HOEVAP $=-(.5639753 * A V G D B)+1093.4376$

OSS REM W: CALCULATE THE SATURATION PRESSUFES AT WET \& DRY GULR TEMPS:

B6O LET PWSI =FNPWS (TIWE)

B> LET PWSDI =FNPWS ( $T 1 D B)$

880 LET PWSED=FNPWS (EDWR)

QPO LET PWSDED=FNPWS (EDDB)

QUO LET PWSO=FNFWS (OWE)

Q10 LET FWSDO=FNPWS (ODE)

920 LET PWSBW=FNPWS (EWWB)

Q T.: LET PWSDEWEFNPWS (EWDE)

Q3\%, REM *:***:CALCULATE THE SATURATION HUMIDITY RATIOS (WET\&DRY)******

940 LET WSI =FNWS (FWSI)

950 LET WSDI $=$ FNWS (PWSDI)

960 LET WSBD=FNWS (PWSED)

970 LET WSDED=FNWS (FWSDED)

989 LET WSO=FNWS (PWSO)

Q9O LET WSDO=FNWS (PWSDO)

( W) LET WSEW=FNWS (FWSEW)

1010 LET WSDEW=FNWS (PWSDEW)

$1: 15$ REM **:**:CALCULATE THE HUMIDTIY RATIO AT EACH FOINT *******

1020 LET HRI IFNHR (TIWB, TIDB, WSI)

1.030 LET HRBD=FNHR (EDWB, BDDB, WSBD)

104O LET HRO=FNHR (OWE. ODE. WSO)

1050 LET HRBW=FNHR (BWWB, BWDB, WSEW)

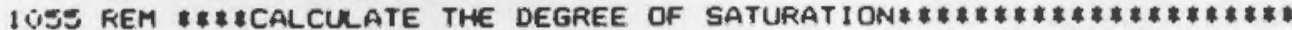

1060 LET UI $=F N U$ (HRI, WSDI)

1070 LET UBD=FNU (HRED. WSDBD)

1080 LET UO=FNU (HRO. WSDO)

$1090^{\circ}$ LET UBW=FNU (HRBW, WSDEW)

1095 REM * * *CALCULATE THE RELATIVE HUMIDITY AT EACH POINT******** 


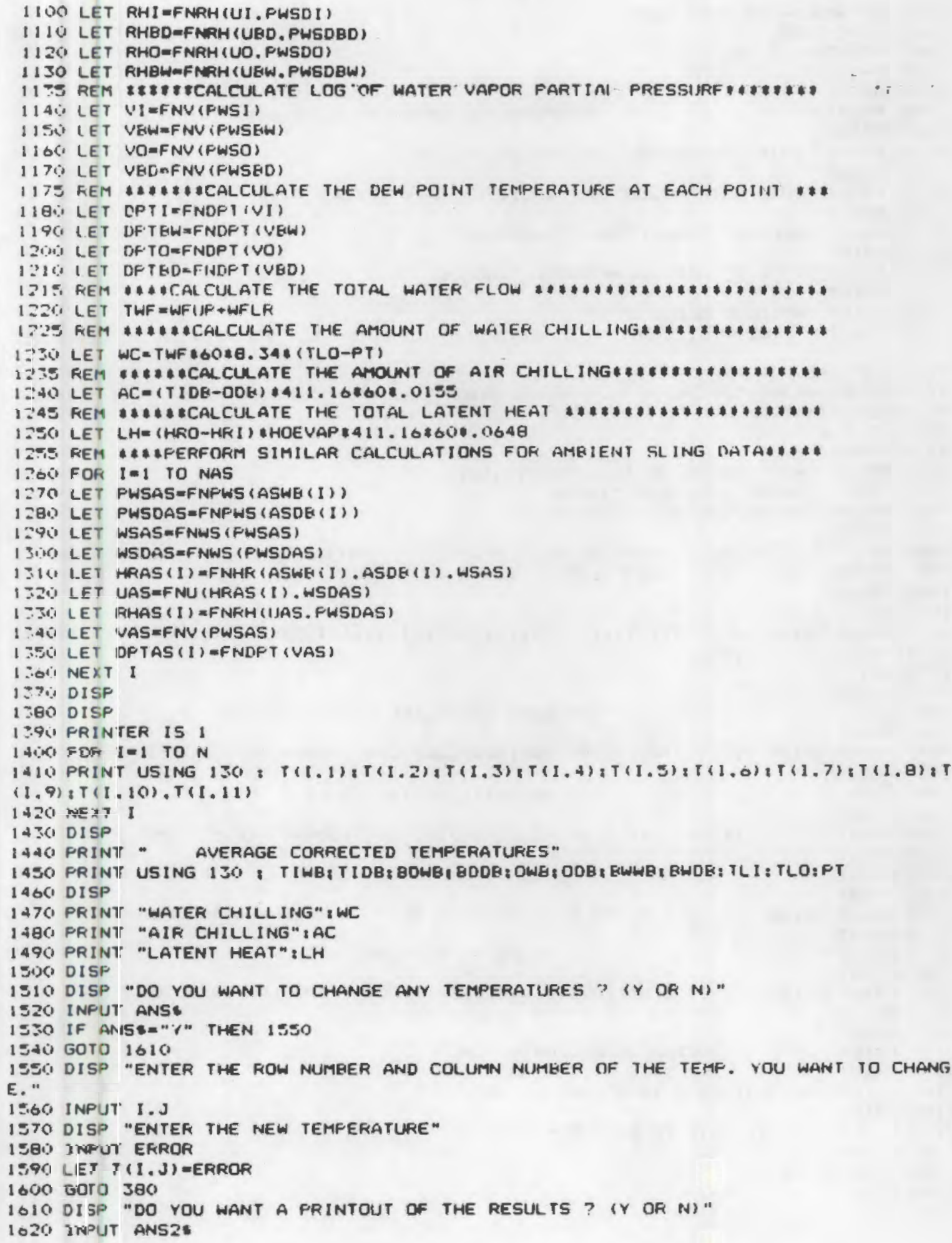




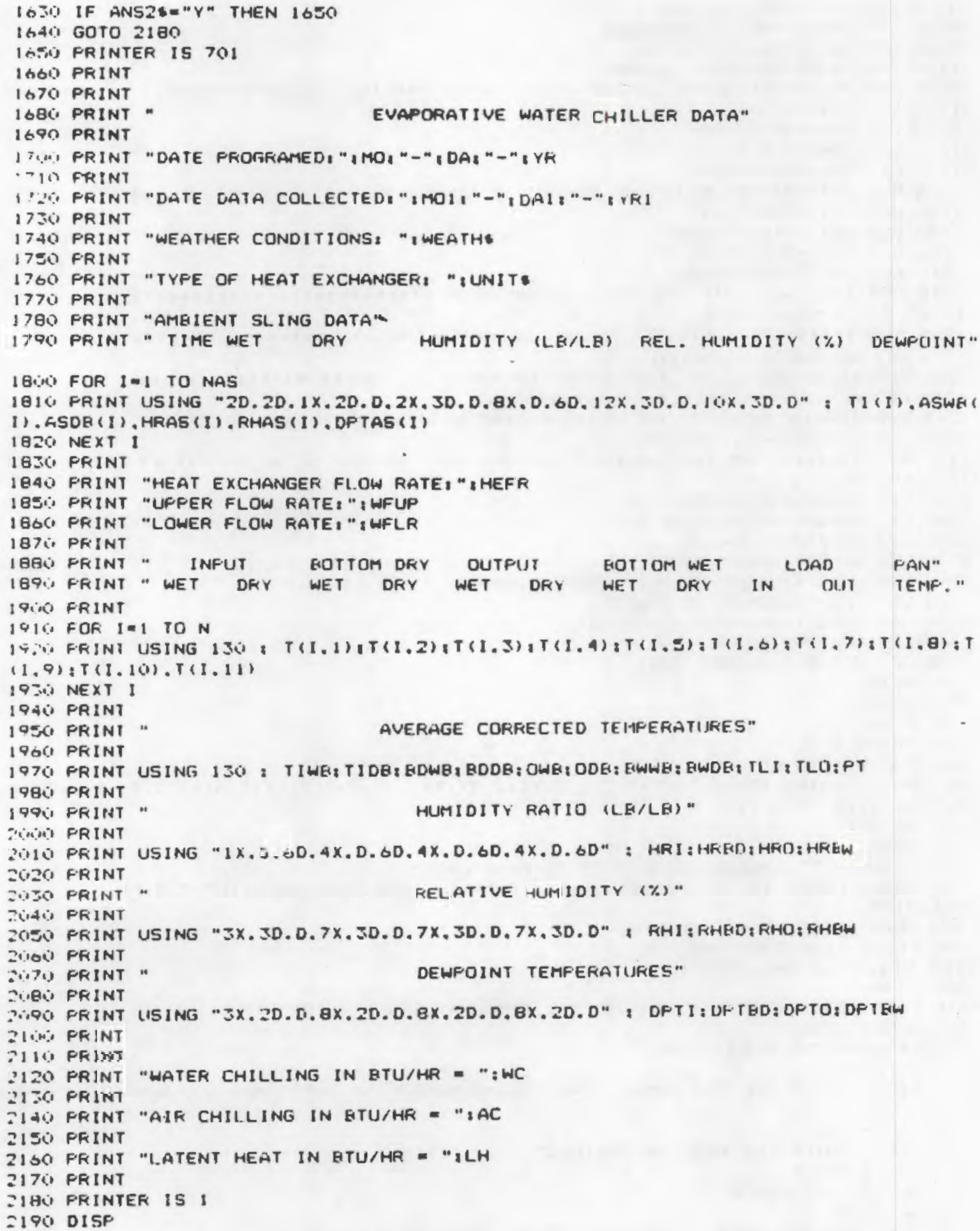


Z200 DISP "DO YOU WANT TO RUN MORE DATA FOR THIS DAY (SAME WEATHER CONDITIONS)?"

2210 INPUT ANSJ*

$\because \%$ IF ANSI $=$ " $Y "$ THEN 290

$2 \because 30$ EEEP

2240 END

147469

C. 7 


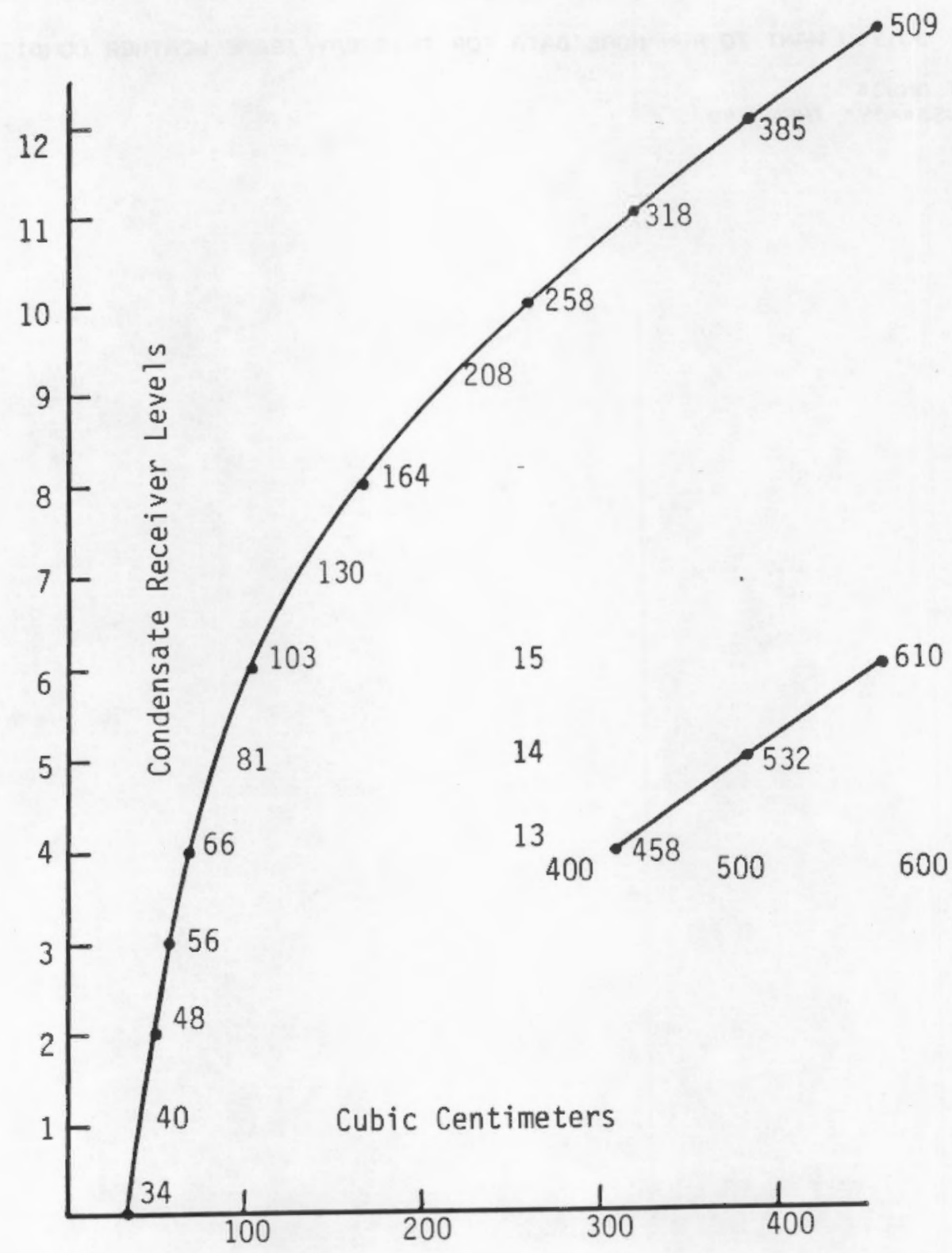

FIGURE C-2. Condensate Receiver Calibration 


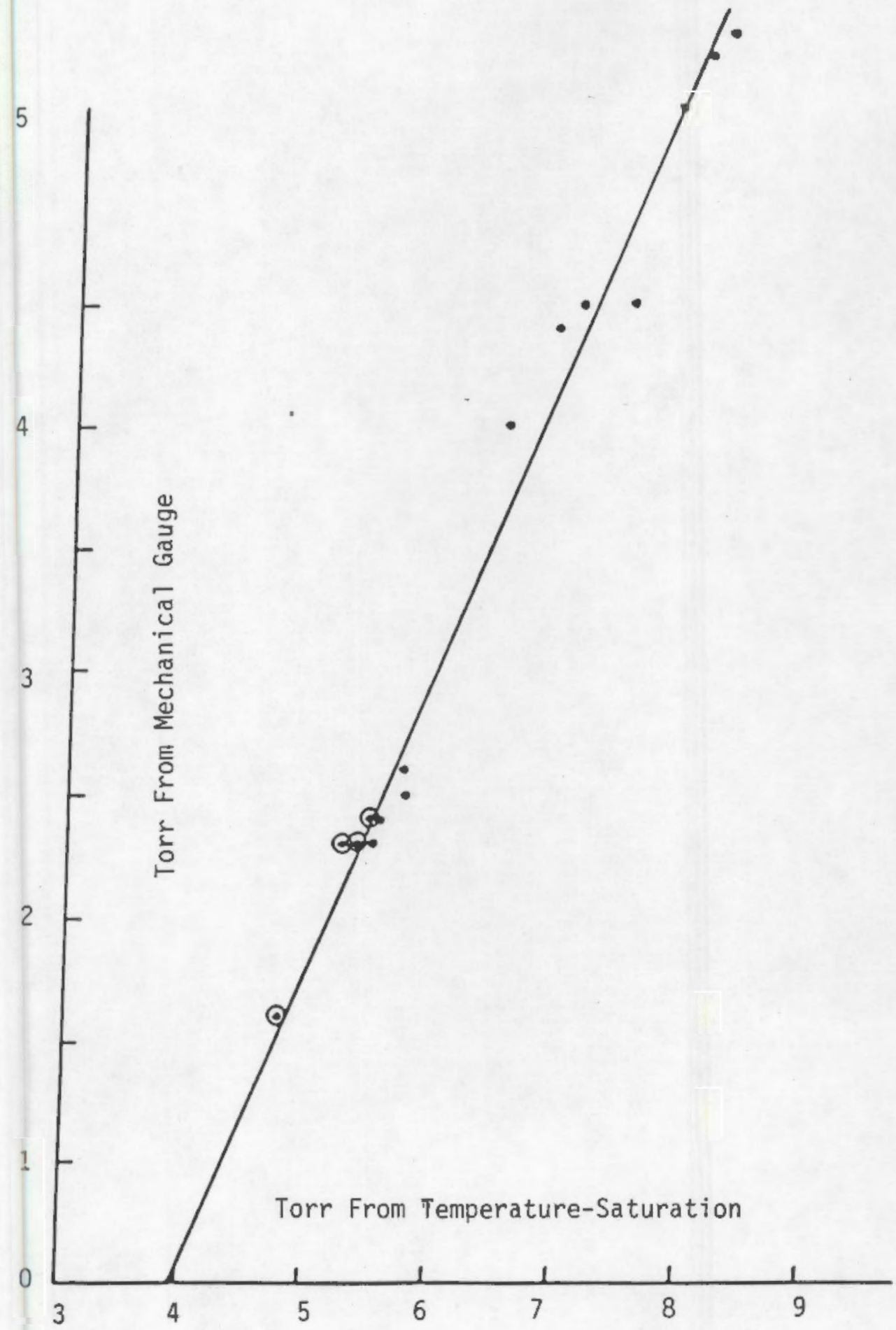

FIGURE C-3. Mechanical Pressure Gauge Calibration

C. 9 


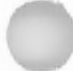


APPENDIX D

DETAILS OF CONSTRUCTION 

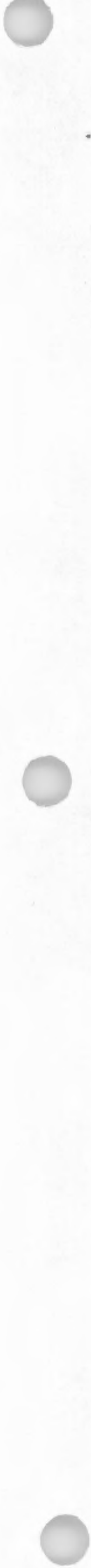


\section{DETAILS OF CONSTRUCTION}

Figures D-1 through $0-3$ give the physical arrangement of the ZCAT system. Copper and stainless steel were used in the manufacture of the system because contamination of the zeolite is known to be a critical problem. The zeolite tubes, manifold, condenser, condensate receiver, and connection to the ice tank are all copper except the 5-inch diameter cap, tee, coupler, and 3 -inch vacuum valve, which are brass. The ice tank is constructed from 12-inch diameter 304 stainless steel. All copper connections were made with Sil-Fos brazing. Parts other than those in the zeolite section can probably be made of less costly materials as long as the material does not outgas under vacuum conditions.

The zeolite tubes, condenser tubes, and manifold are mounted within an 18-inch by 7-foot fiberglass tank (see Figure D-1). The evaporative water chiller is mounted on the north of the sealed system, and the solar water heating panel is mounted just south of the sealed system. Drainback tanks are installed to conserve hot and cold water and allow repetitive cycling during a day. An 80-galion, 4500-watt electric water heater was added to expedite testing.

\section{Evaporative Water Chiller}

The chilled water system consists of a Des Champs Z-Duct heat exchanger mounted with blower on an airflow turn-around duct. A block of Munters CELdek installed in the turn-around duct furnishes an air-water interface where both are evaporatively cooled. Ambient air is blown into one side of the Z-Duct then to the CELdek. The evaporatively cooled air then is exhausted through the second side of the Z-0uct. The evaporatively cooled air cools the dry ambient input air via heat exchange. As the wet air extracts heat from the dry air, additional water is evaporated from water sprayed into the exhaust side of the Z-Duct, which further extracts heat out of the input side air. This heat exchange lowers the wet bulb and dry bulb temperature of the dry air, which then allows the evaporative cooling in the CELdek to approach lower temperatures. Figure 0-4 presents a psychrometric plot of the evaporative water cooling. The dry cooling of 

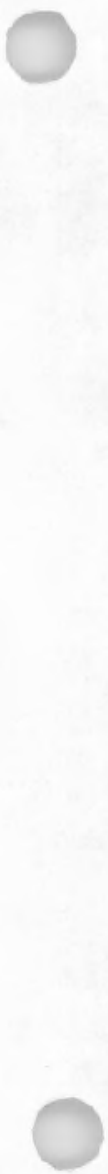


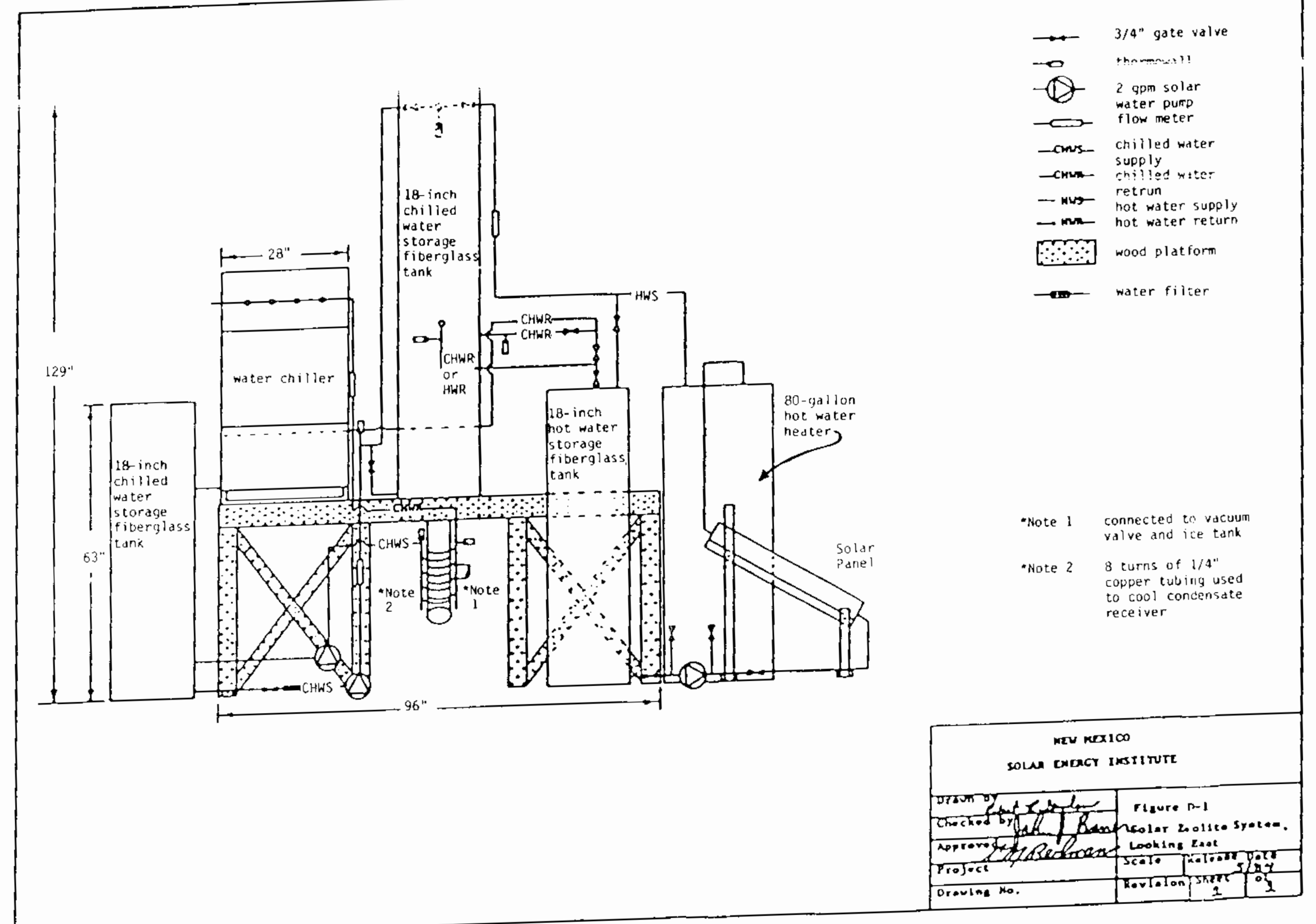

FIGURE D-1. Solar Zeolite System, Looking East 



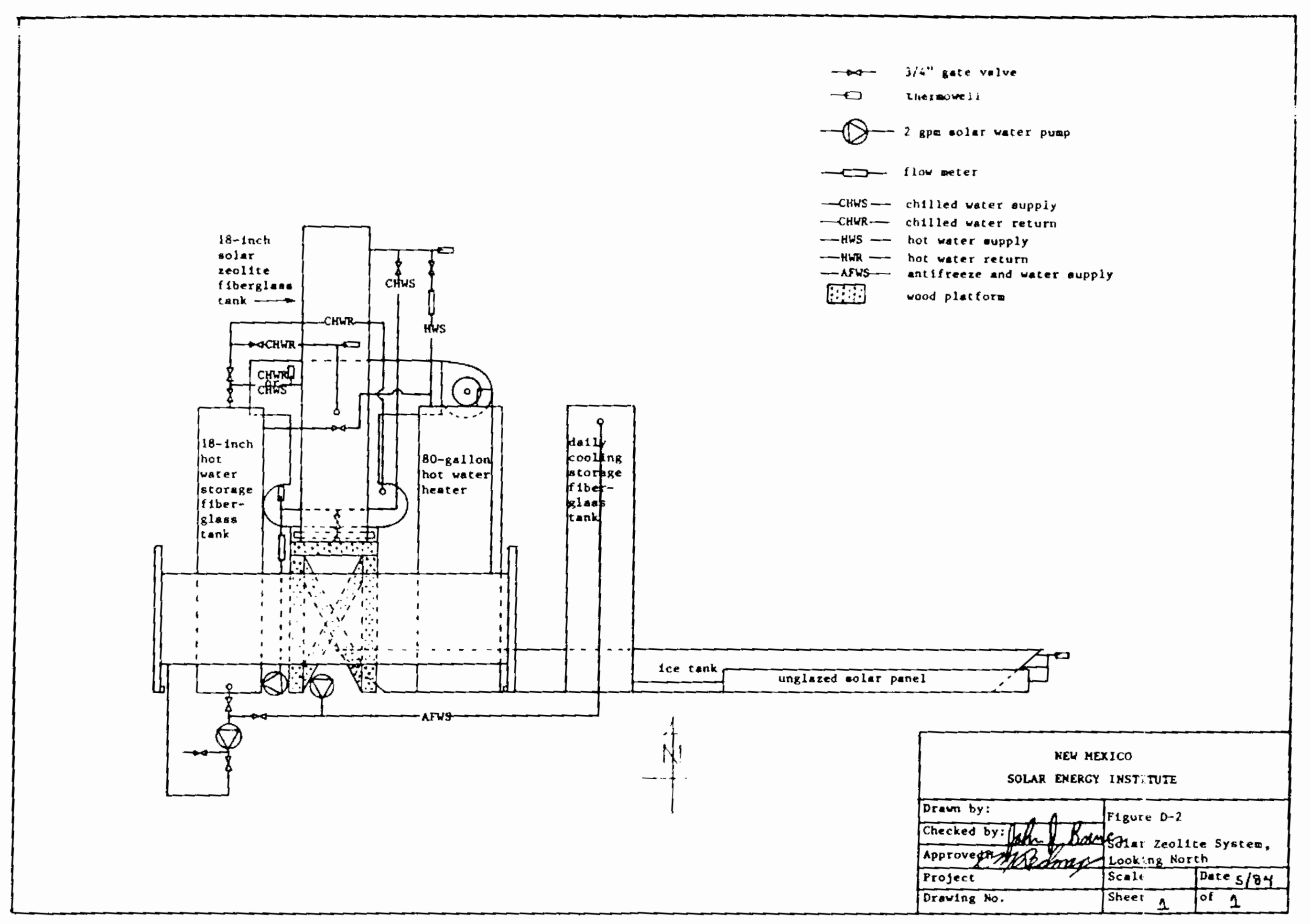

FIGURE 0-2. Solar Zeolite System, Looking North 



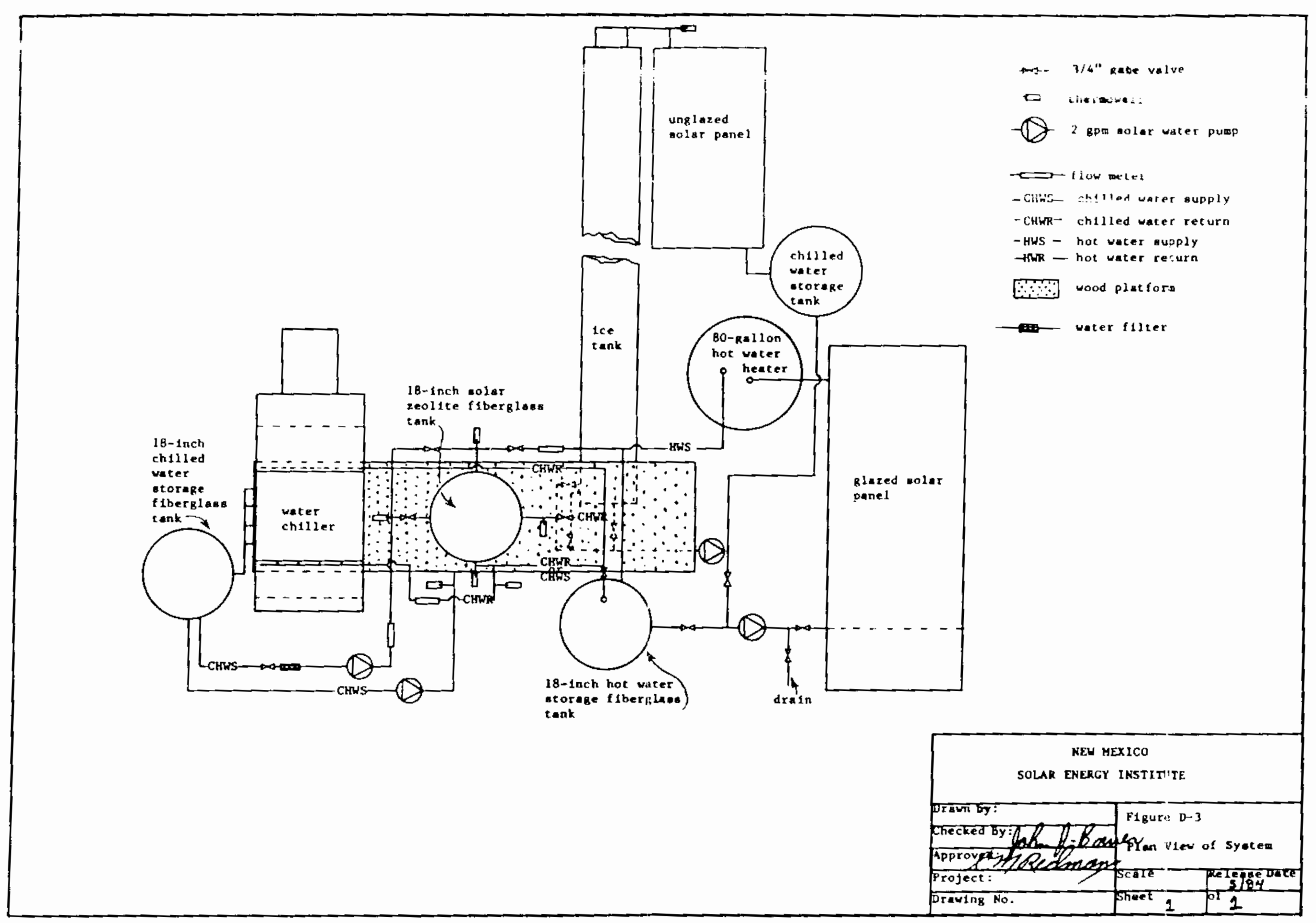

FIGURE $0-3$. Plan View of System 
. 


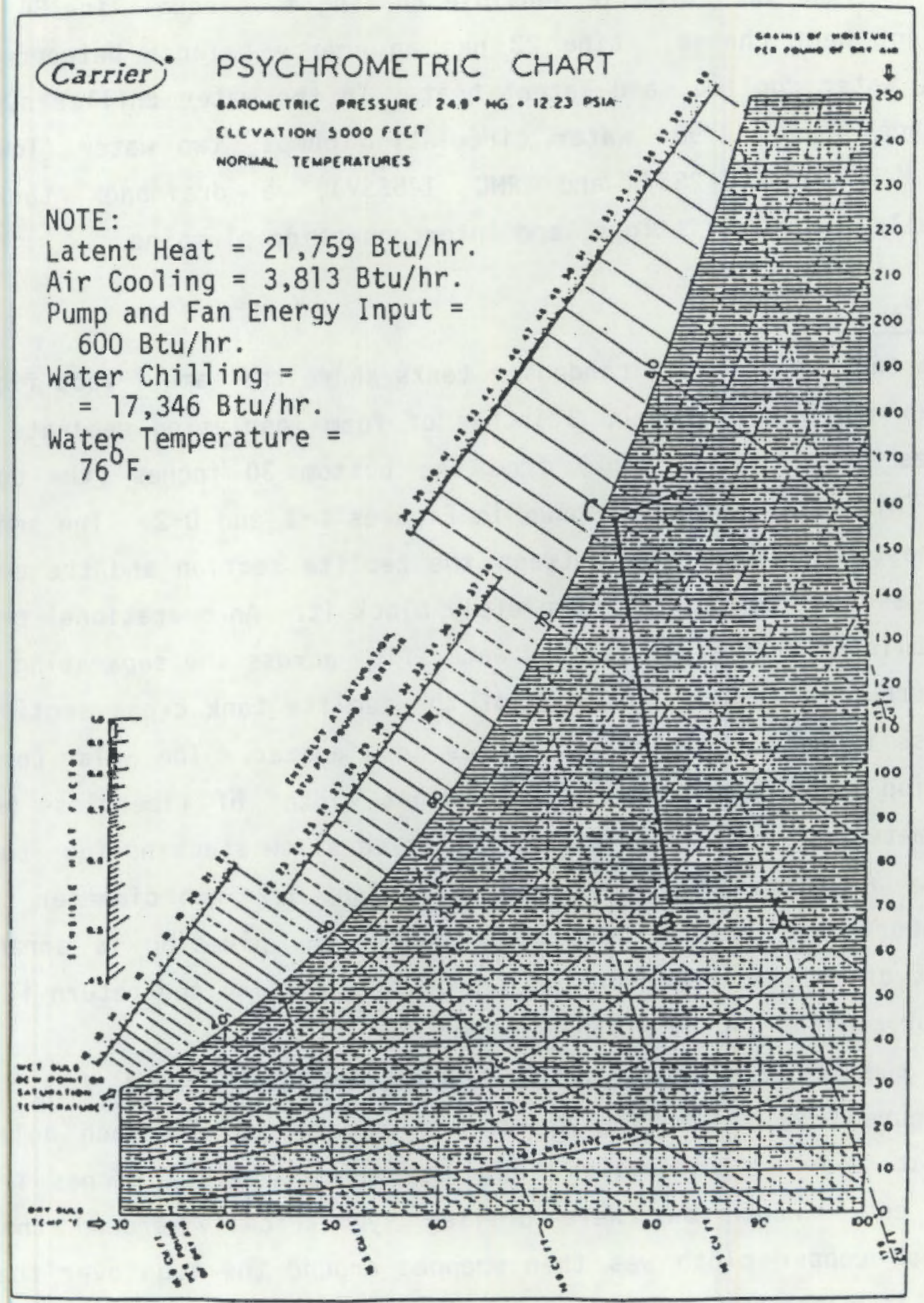

FIGURE D-4. Hypotheticai Performance, Psychrometric Plot 
the air is line 12 . Line 12 sensible cooling must equal line 34 sensible and latent heat change. Line 23 has an energy balance between the air cooling, water cooling, and latent heat. In the water chiller system are two Richdel Mode1 R798A water circulating pumps, two water flow meters (Dwyer Mode1s RMC142SSV and RMC 145SSV), a drainback tank, four thermowel1s, valves, fittings, and interconnecting plumbing.

\section{Zeolite Tank}

The zeolite tank and condenser tanks share the same 7-foot fiberglass tank. An aluminum plate and 3 inches of foam insulation separate the top 54 inches (the zeolite tank) from the bottom 30 inches (the condenser tank). This arrangement is shown in Figures $D-1$ and $D-2$. The separating plates restrict water flow between the zeolite section and the condenser manifold section but do not completely block it. An operational procedure was established that minimized any water flow across the separating plates.

Figure D-5 shows the details of the zeolite tank cross section. The fiberglass tank is a nominal 18 inches in diameter. The Solar Components Corporation makes the tanks out of 5-foot widths of fiberglass but uses four diameters in increments of $3 / 8$ inches to allow stacking four tubes for shipping. An aluminum plate along with eight 1/2-inch diameter threaded rods support the 64 zeolite filled tubes. The plumbing is arranged to enter hot or chilled water in the top of this section and return it to the heating or cooling system at the bottom.

For the zeolite tubes, a 1/2-inch copper tube was cut 51-1/4 inches long (Figure D-9). Starting 1 inch from one end, 1/8-inch holes were drilled at $1 / 2$-inch intervals along the tube to $2-1 / 2$ inches from the opposite end. Four rows were drilled symmetrically around the tube. Thirty-mesh copper cloth was then wrapped around the tube over the holes and held in place with fine copper wire. A 1-1/2-inch bell reducer was then brazed to one end of a 48-inch section of 1-1/2-inch copper pipe. The 2-1/2-inch hole-free end of the 1/2-inch pipe was then brazed to the bell (Figure 2). A 1-1/2-inch bell reducer was then slipped over the opposite end of the tube assembly and brazed to the 1-1/2-inch tube leaving the $1 / 2$-inch tube extending into the neck of the bell but not brazed to it. 


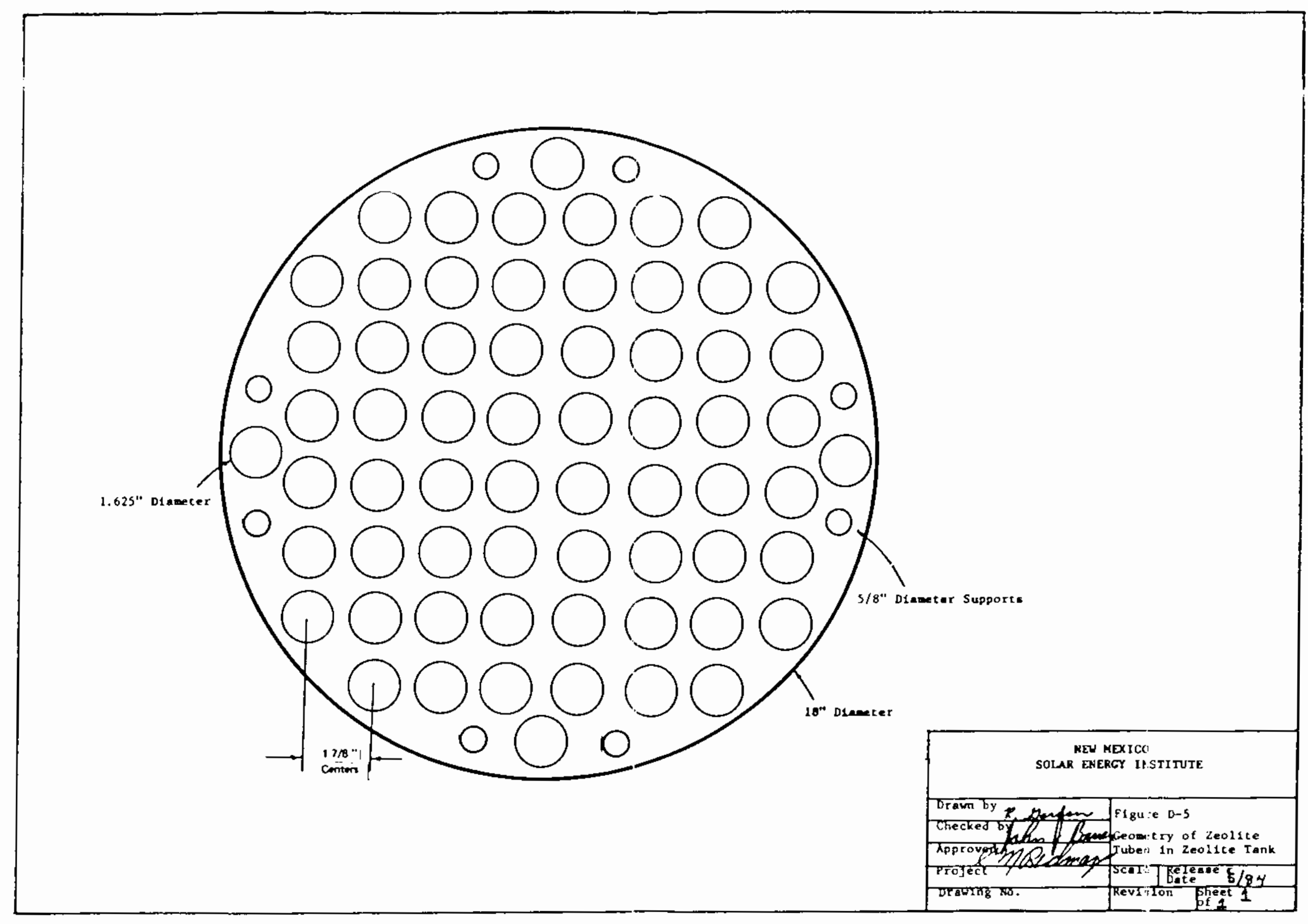

FIGURE D-5. Geometry of Zeolite Tubes in Zeolite Tank 

Bell reducers typically have a small lip extending around the inside of the small end. This lip was removed to allow the $1 / 2$-inch pipe to extend through it. A 4-inch long section of 1/2-inch pipe was then brazed in place and capped. The 4-inch section became the top of the assembly. The main 1/2-inch tube was free to move in the top bell reducer. This allowed for differential expansion between the 1-1/2-inch and the 1/2-inch pipes. The tube system was sealed except for the open botton end. It was then tested for air leaks by connecting a vacuum pump to the open end. After a 1/4-inch hole was drilled in the tube assembly, it was flushed with distilled water and filled with molecular seive $13 X$ zeolite through the 1/4-inch hole. The system was then flushed again with distilled water and a 1/4-inch plug brazed into the hole. Sixty-four tube assemblies were constructed.

\section{Condenser Manifold}

In this application, vapor desorbed from the zeolite must be condensed to keep internal pressure low while heating the zeolite. Each zeolite tube was connected through a silicone tube thermal break to a 1/2-inch condenser tube. The 64 condenser tubes were then manifolded into one vertical 5-inch copper pipe to allow condensate to flow readily downward to the bottom of the condensate collector. An acrylic viewing window on a $45^{\circ}$ bevel and a condensate drain with vacuum valve were installed on the condensate receiver. The window was for observation of condensate. The purpose of the bevel is to allow freezing of up to 1.8 pounds of condensate without straining the pipe. There is a 5 -inch by 5 -inch by 3 -inch copper tee between the manifold and condensate receiver. The third outlet is connected, through a vacuum valve, to the ice tank.

Figure D-6 gives the plan view of the manifold. The 64 condenser tubes were connected (brazed) to the manifold as shown by the small circles or elipses. Eight condenser tubes were brazed to the cap of the 5-inch diameter pipe. Seven 1-1/2-inch pipes radiate from the 5-inch pipe. Each of the seven pipes has eight $1 / 2$-inch condenser pipes brazed as shown. A conflict between two 1-1/2-inch pipes and the 1/2-inch threaded rods caused a shortening of the pipes and a change in where the condenser pipes were 


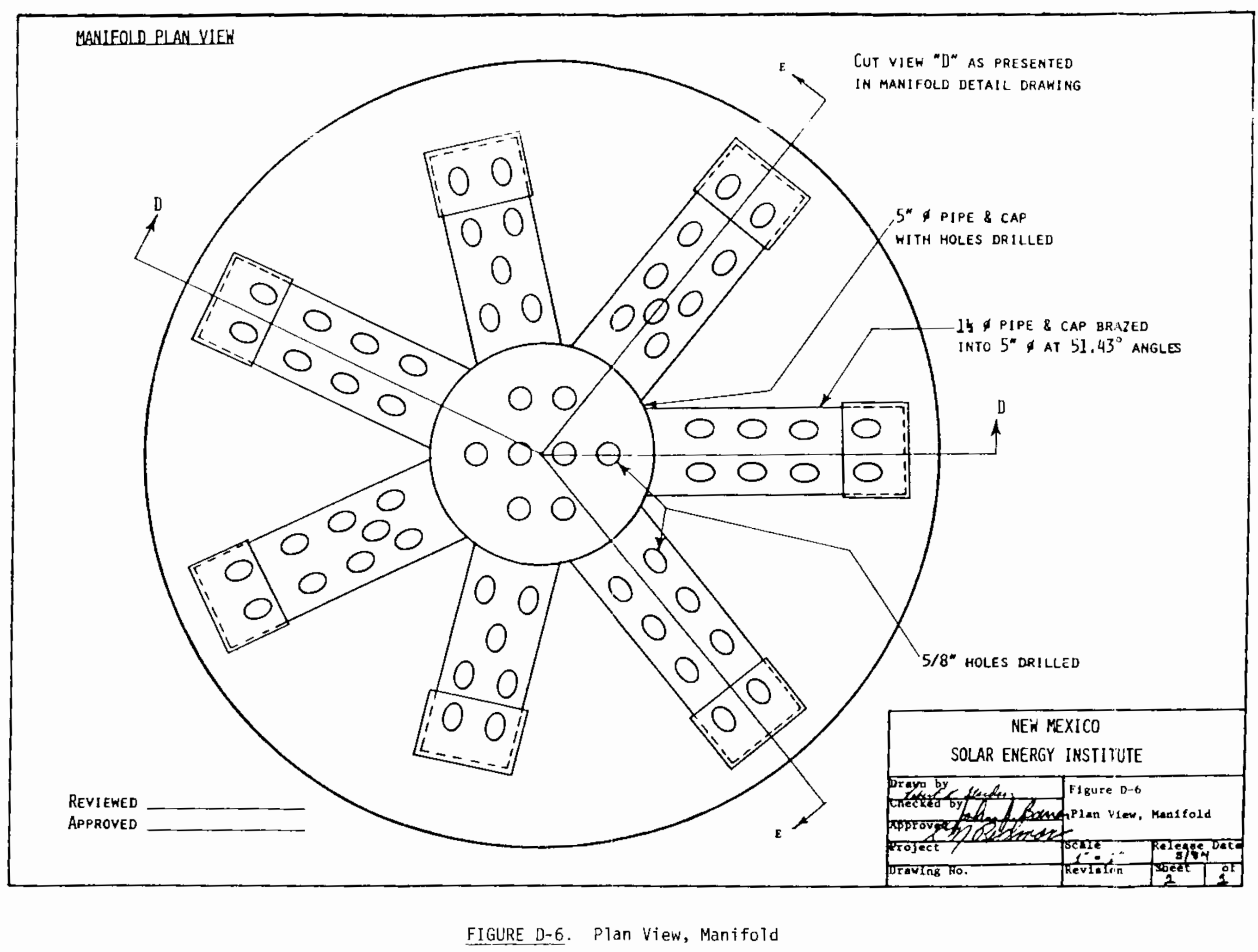



brazed. Figure $0-7$ shows the tank and table cut along condenser-manifold section DD (of Figure $0-5$ ). Figure $D-8$ shows the tank and table cut along condenser-manifold section EE (of Figure D-6).

The central part of the manifold, condensate receiver, and connecting tee are made of 5 -inch plumbing. A brass cap at the top was brazed to 5-inch copper pipe which in turn was brazed to a brass coupler. The coupler was then brazed to another short section of pipe, for a total length of 20-15/16 inches. A flange of $1 / 2$-inch brass was then brazed onto the low part of the section 3-1/2 inches from the end. The brass flange has six symmetrical holes for 5/16-inch bolts for clamping to the lower section. Eight 0.625 -inch holes were drilled in the brass cap for condenser tubes as shown in Figure $0-6$. The 5-inch coupler had seven 1.625-inch holes drilled symmetrically around it. Seven 1-1/2-inch diameter pipes 7 inches long were inserted into these holes and brazed at a $5^{\circ}$ angle (Figures $D-7$ and $D-8$ ) to assure good draining of the condensate. The 1-1/2-inch pipes were inserted into the 5-inch pipe to avoid exceeding a radius of $8-5 / 8$ inches. Two were inserted further in to 5 -inch pipe to clear the $1 / 2-i n c h$ threaded rods that hold the system together. Each 1 1/2-inch pipe was capped and drilled for 1/2-inch copper pipe as shown in Figure $0-6$.

Three vacuum valves are shown in Figures $0-7$ and $0-8$. The main valve, or 3-inch valve, is in the 3 -inch piping between the 5 -inch by 5 -inch by 3-inch brass tee in the condensate receiver and the ice tank. This valve is in a 3-inch pipe section, has two $90^{\circ}$ bends. One bend is required, but because of the way the valve was designed, second bend was made to allow for other equipment not involved in this project. This vaive was available and was used as built. Included in the valve was a flexible section to allow some flexing between the ice tank and the condensate receiver. However, the flexible section was made of stainless steel and was found to leak. It was replaced with a flexible copper section. A second vacuum valve, a l-inch valve mounted above the tee, is used to pump air from the system. The third valve is described below. 



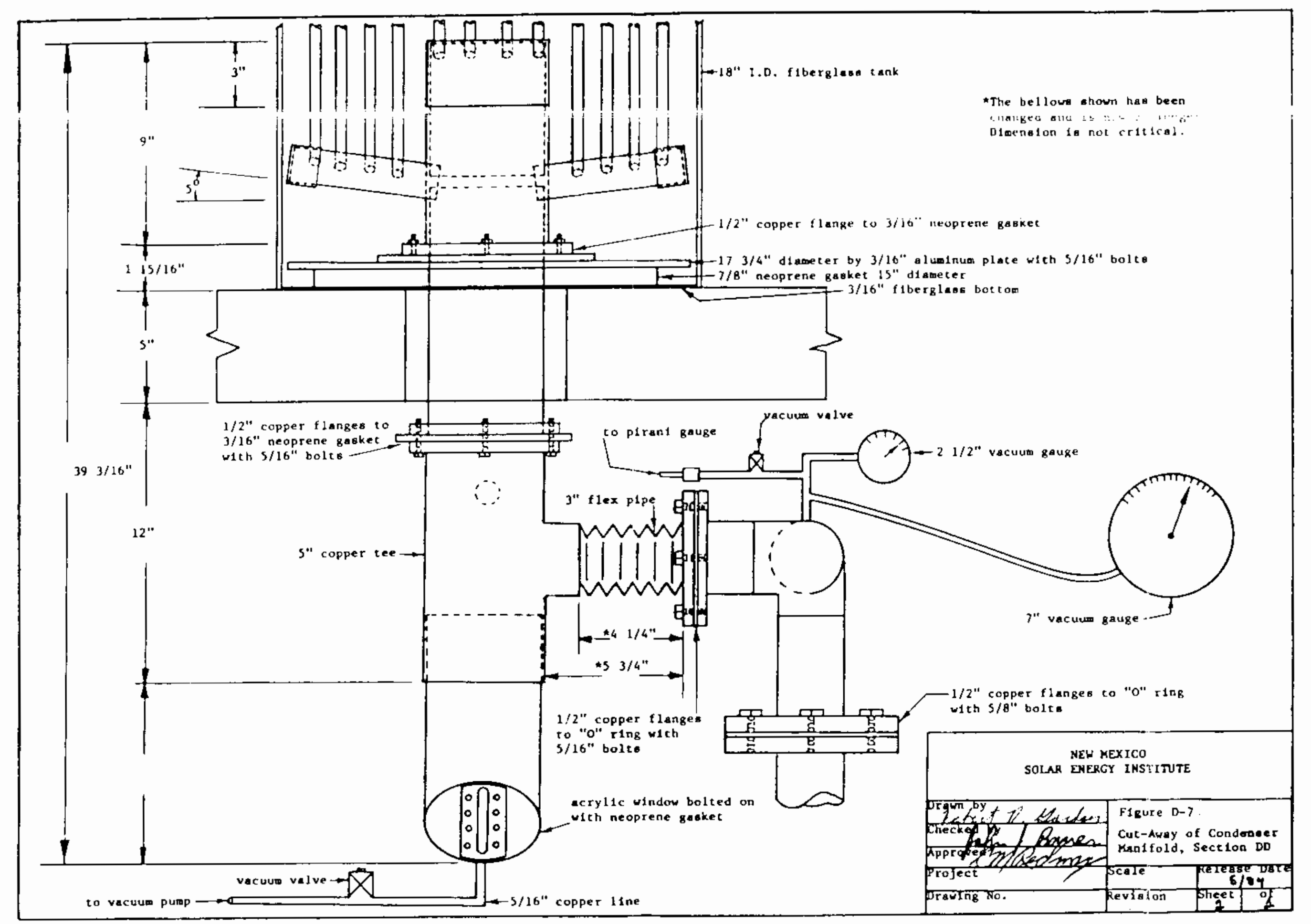

FIGURE D-7. Cut-Away of Condenser Manifold, Section DD 



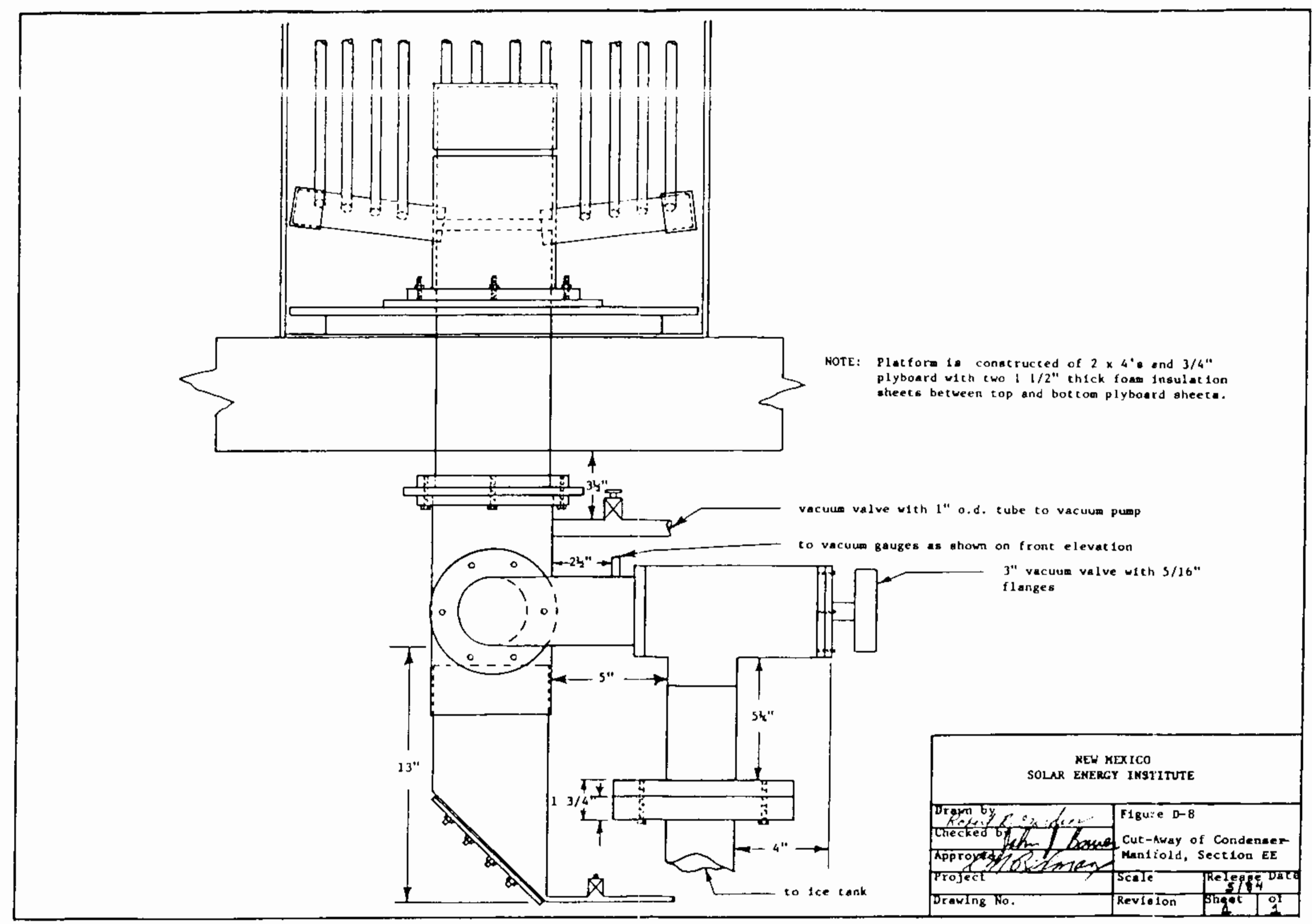

FIGURE D-8. Cut-Away of Condenser-Manifold, Section EE 



\section{Condensate Recejver}

The condensate receiver is a 7.8-inch section of 5-inch copper pipe with a $45^{\circ}$ bevel on the bottom and a view window with 15 fiducial marks for estimating the amount of water. A 5/16-inch copper line with vacuum valve extends from the bottom of the receiver to allow condensate to be drained.

\section{Solar System}

The solar water heating system, which is not optimized for this project, is adequate for daily cycling. The solar water heating system includes a locally fabricated solar panel, circulating water pump, and drainback tank. A 4500-watt electric water heater is included to expedite desorption speed of response testing.

\section{Vacuum Gauges}

Ouring initial vacuum testing of the system, three vacuum gauges were installed as shown in Figure $\mathrm{D}-7$. One, a General Instrument Corporation 6001 gauge (with a scale of -30 inches of mercury to 0 to +15 psia) was used to give a rough measurement. This gauge is noted as the 2-1/2-inch vacuum gauge on Figure $D-7$. The second was a mechanical gauge with a 7-inch diameter and a nonlineal scale of 1.0 torr to 400 torr with 30 torr at the one-half scale position. The third was a pirani gauge, which gives good readings from 0 to 4 torr. The electronics for the pirani gauge failed when there was not sufficient time for repair and recalibration, so the mechanical gauge was utilized.

\section{Ice Tank}

Figure 0-9 gives construction details of the ice tank. The tee in the vertical 5-inch diameter pipe system connects through the 3 -inch diameter port, bellows section (flexible), and vacuum valve to the ice tank. The 10-inch long bellows section relieves any mechanical strain between the tank and the 5-inch pipe. The valve allows testing without the ice tank and isolates the ice tank while vapor is being condensed in the condenser manifold. Acrylic windows at each end of the ice tank allow monitoring of the inside of the tank. 



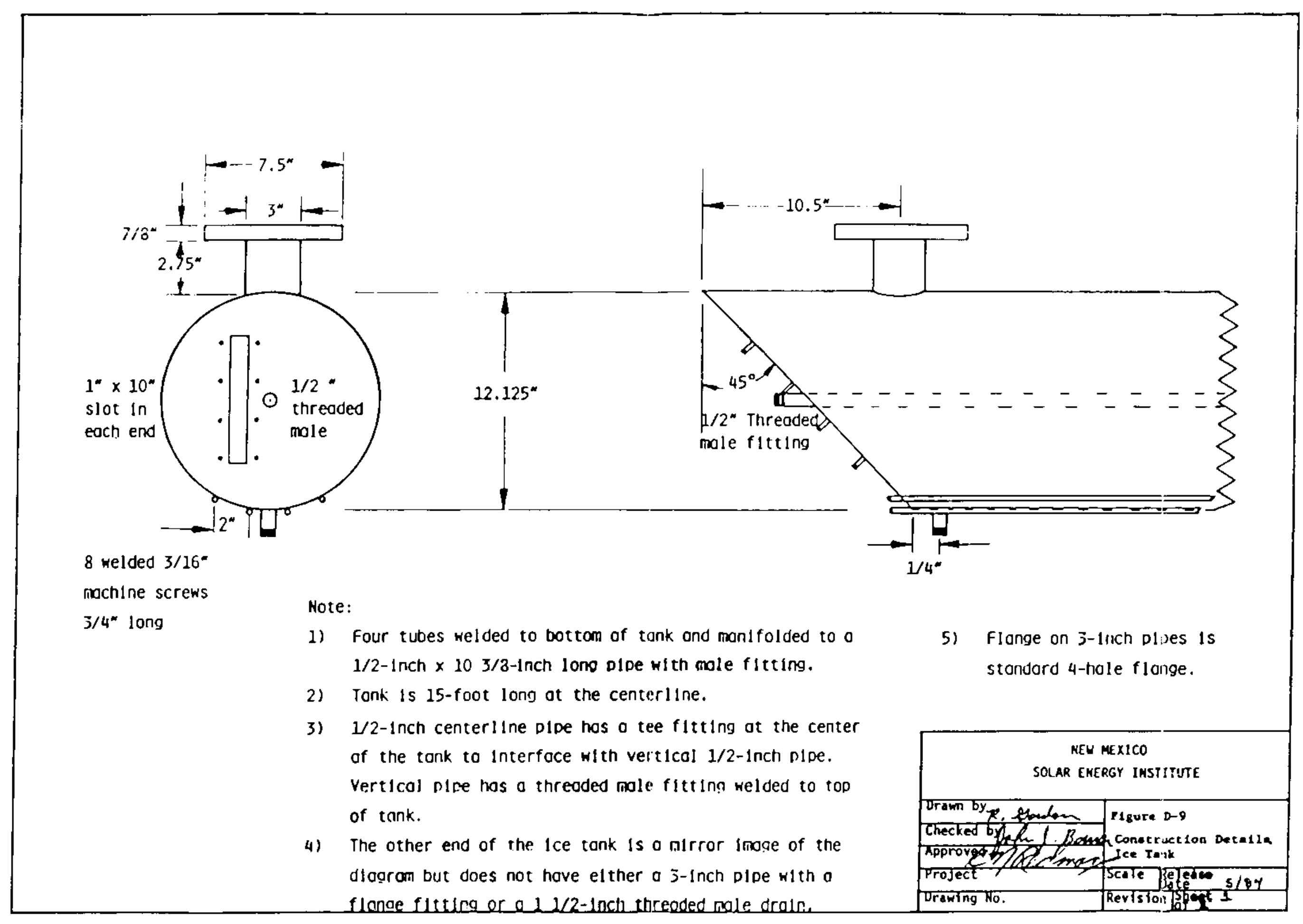

FIGURE D-9. Construction Details, Ice Tank 
A fiberglass tank 5 feet high and 18 inches in diameter and a circulating system with antifreeze solution allow extraction of daily use cooling in summer and extraction of heat in winter to freeze the water in the ice tank. The circulating system includes an 18-square foot unglazed solar panel to radiate heat from the system.

The stainless steel ice tank was constructed to assure that no air leaks existed. Because the ice tank was fastened to the rest of the system by flanges and is remote from the zeolite, other materials should be applicable as long as no outgassing occurs and the ice tank does not collapse under 14 psi pressure in compression. The ends were beveled at $45^{\circ}$ and capped with flat stainless steel welded to the bevel. The 1-inch by 10-inch windows at each end were covered with a gasket and acrylic. A 1/2-inch stainless steel pipe runs the 15-foot length of the center line of the tank with a tee at the center for support. This pipe allows freezing of water concentrically so that the tank can be mostly filled with ice without stressing the pipe. Four stainless steel pipes were spot welded the length of the pipe to the bottom of the tank at about 4-inch intervals. They were manifolded at each end to $1 / 2-i n c h$ headers. This set of four pipes allows heat exchange with the tank to give a more efficient heat transfer than would a single pipe.

Figure D-10 gives details of the ice tank system in a plan view. The ice tank has a drain or fill via vacuum valve $V_{1}$. The ice tank drain/fill and each heat exchanger are connected through valves $V_{1}, V_{2}$, and $V_{3}$ to the ice tank circulating pump $P I$, which circulates an antifreeze solution through the 66-gallon fiberglass tank, the heat-radiating unglazed solar panel, and the heat exchangers. Valve $V_{1}$ and valve $V_{4}$ are normally closed. Valves $V_{2}$ and $V_{3}$ are set according to which heat exchangers are in use. Valves $V_{4}$ and $V_{5}$ allow the ice tank circulating pump $P I$ to operate in series with hot water circulating pump $\mathrm{PH}$. Opening valves $V_{1}, V_{4}$, and $V_{5}$ and closing valves $v_{2}, V_{3}, V_{6}, v_{7}$, allows the two pumps to operate in series and work against atmospheric pressure to evacuate water from the ice tank.

Fiqure $D-11$ gives temperatures of a black absorber, tar coating, and clear fiberglass with respect to ambient air temperature and time over a 



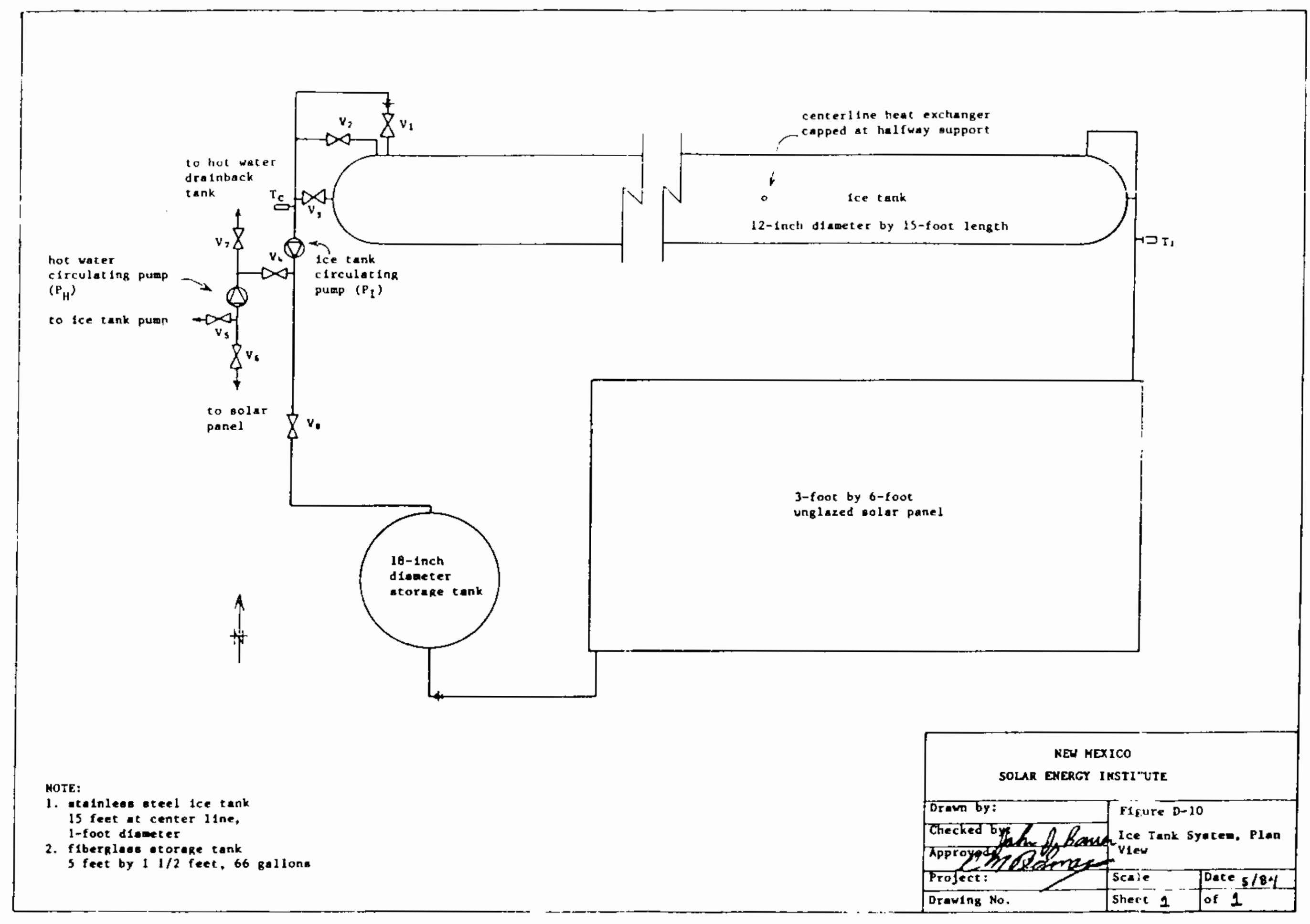

FIGURE D-10. Ice Tank System, Plan View 



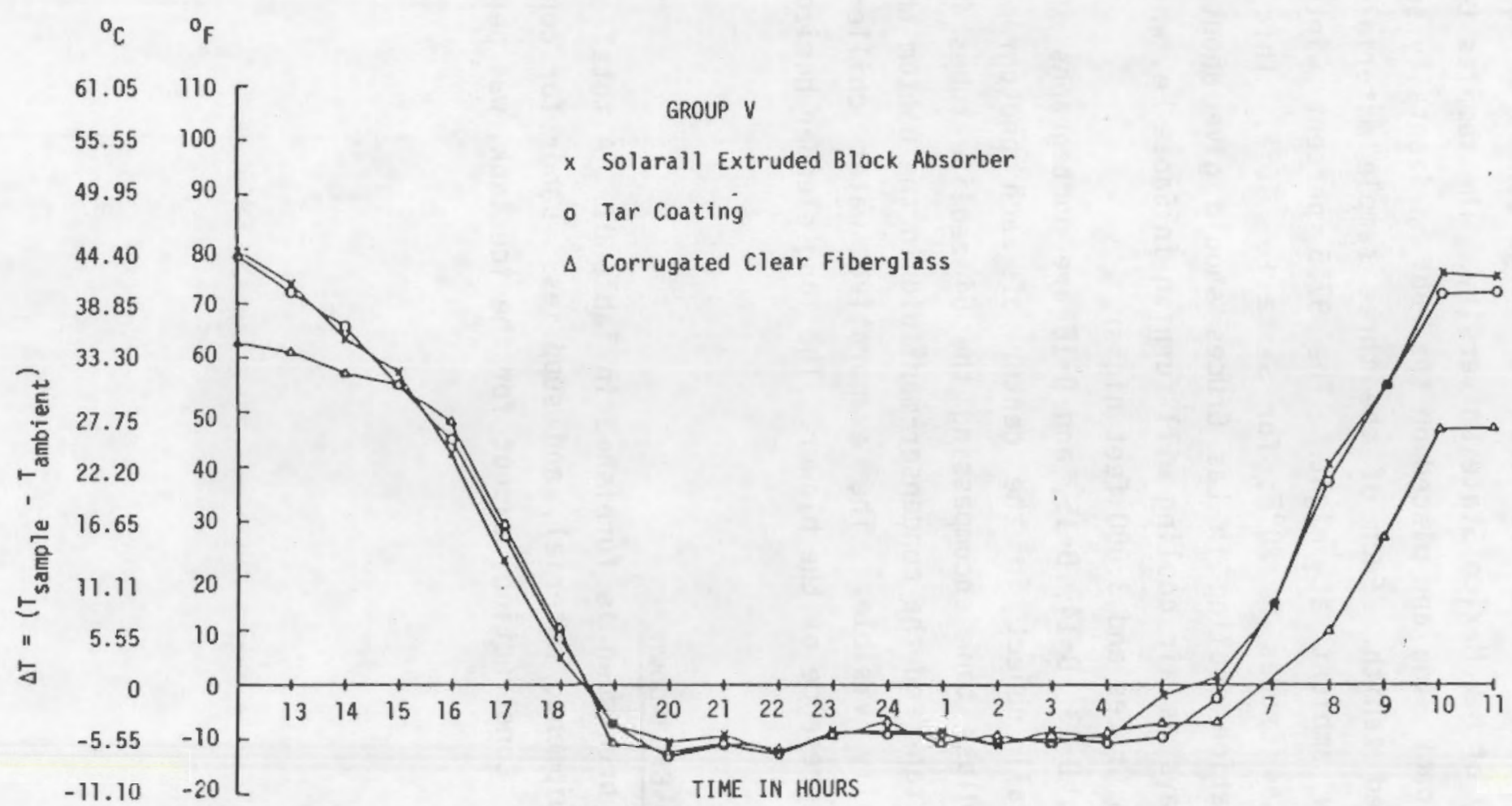

FIGURE D-11. Variation of $\Delta T$ Versus Time for Miscellaneous Material Samples 
24-hour period. This data was measured by George Conrad of the Physical Science Laboratory of New Mexico State University. The samples tested were insulated on the back side and placed on the roof horizontally so that the test surface faced zenith. Each of the three sample materials went to about $10^{\circ} \mathrm{F}$ below ambient at night. The 97.5 percent winter design temperature for Las Cruces is $20^{\circ} \mathrm{F}$; for Santa $\mathrm{Fe}, 10^{\circ} \mathrm{F}$. This indicates that use of radiation cooling in Las Cruces should give about the same freezing degree days as air cooling will furnish in Santa Fe, which is 280 miles north of Las Cruces and 3,000 feet higher.

Figures $D-12, D-13, D-14, D-15$, and $D-16$ are photographs of the ZCAT facility. The tall object in the center of each photograph is the translucent fiberglass tank encompassing the 64 zeolite tubes in the top two-thirds of the tank and the condenser-manifold in the bottom third. The tubes are partially visible. The evaporative water chiller can be identified by the presence of the blower. The long slender horizontal tank is the ice tank.

\section{Labor and Material Breakdown}

The material breakdown is furnished in Table D1. A total of $\$ 18,800$ was spent for equipment, material, and supplies. Labor for construction was about $\$ 8,904$. Construction, except for the ice tank, was performed by NMSU students. 
$\underset{\omega}{\omega}$

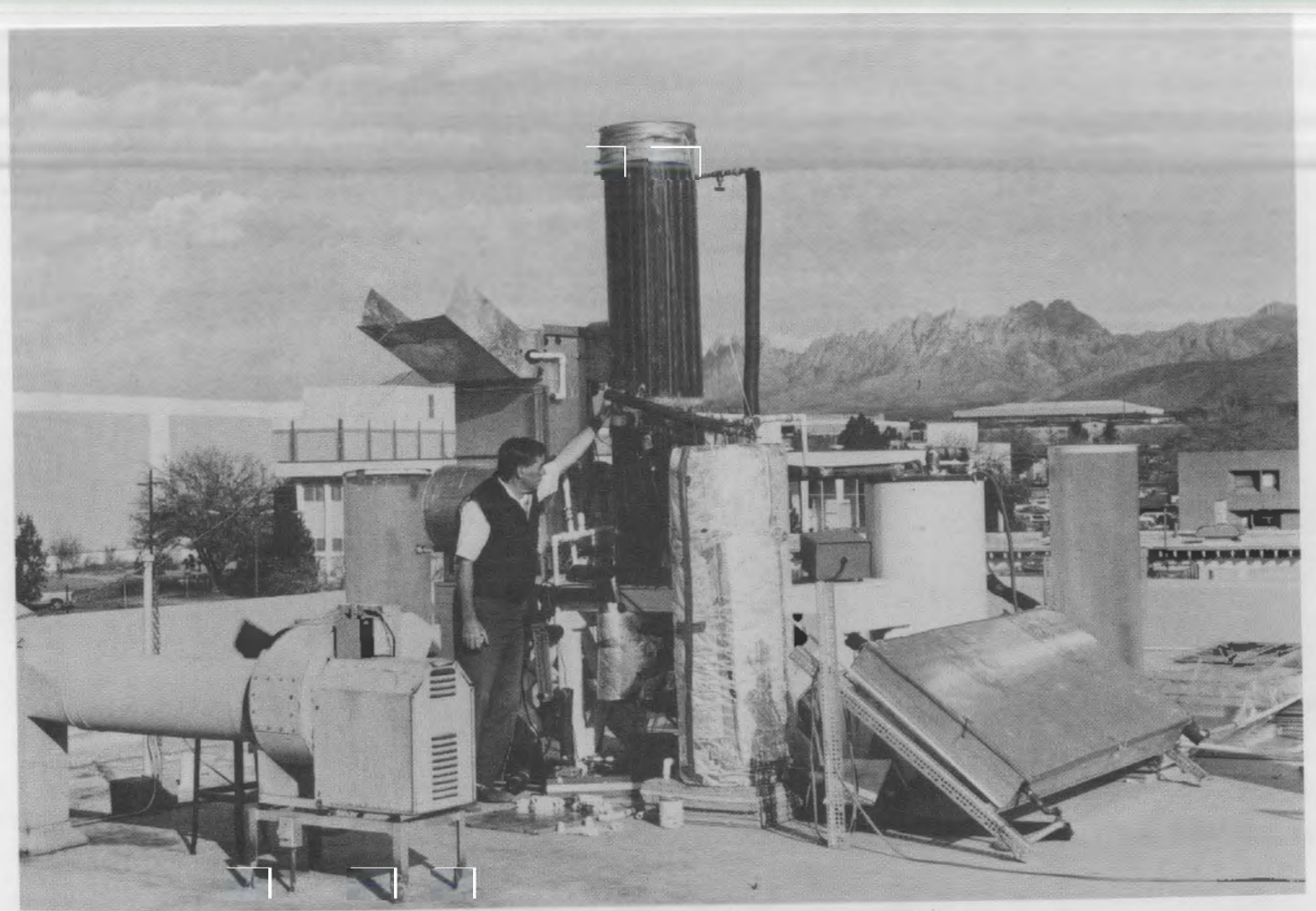

FIGURE D-12. System, Looking East 


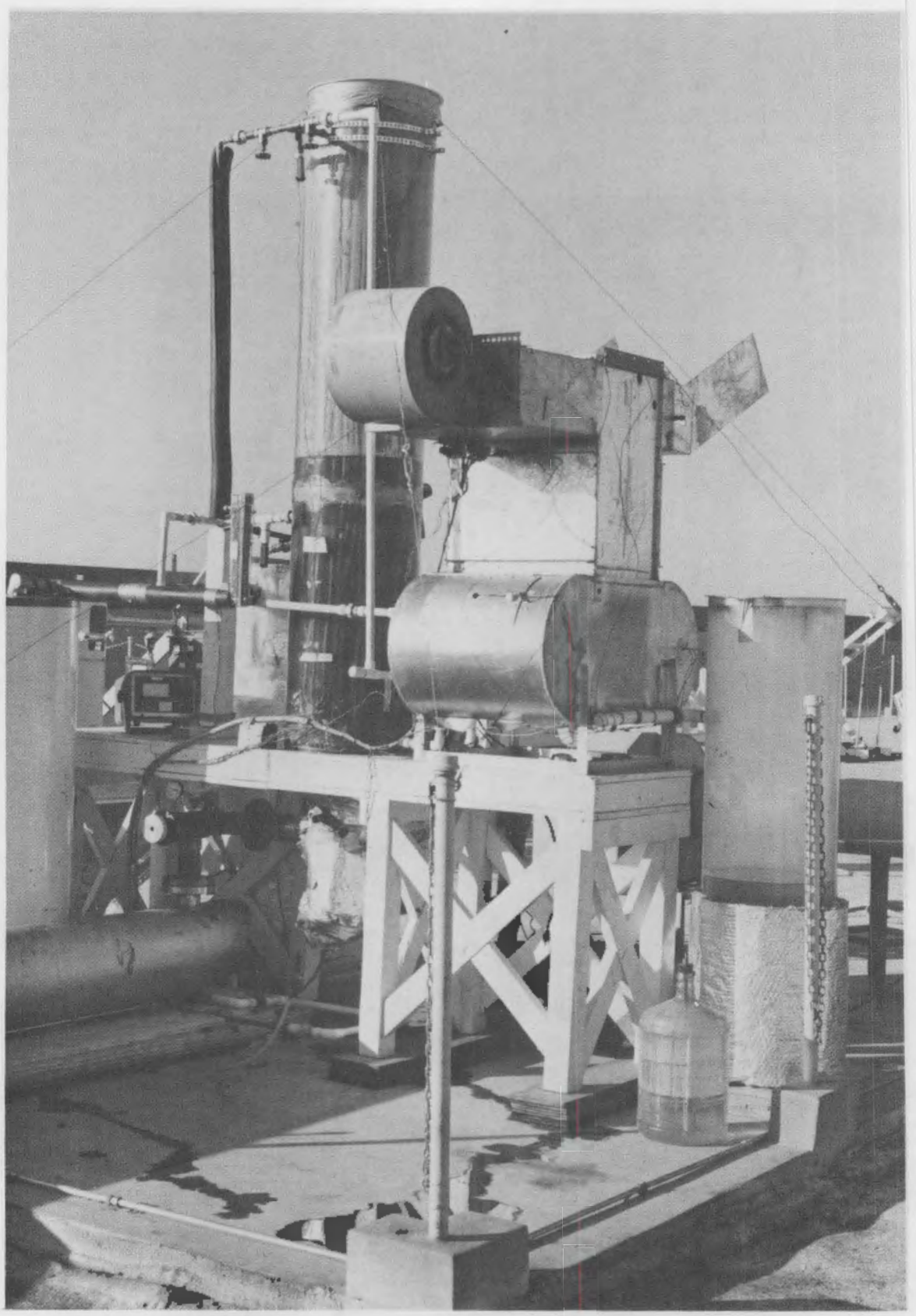

FIGURE D-13. System, Looking West

D. 36 


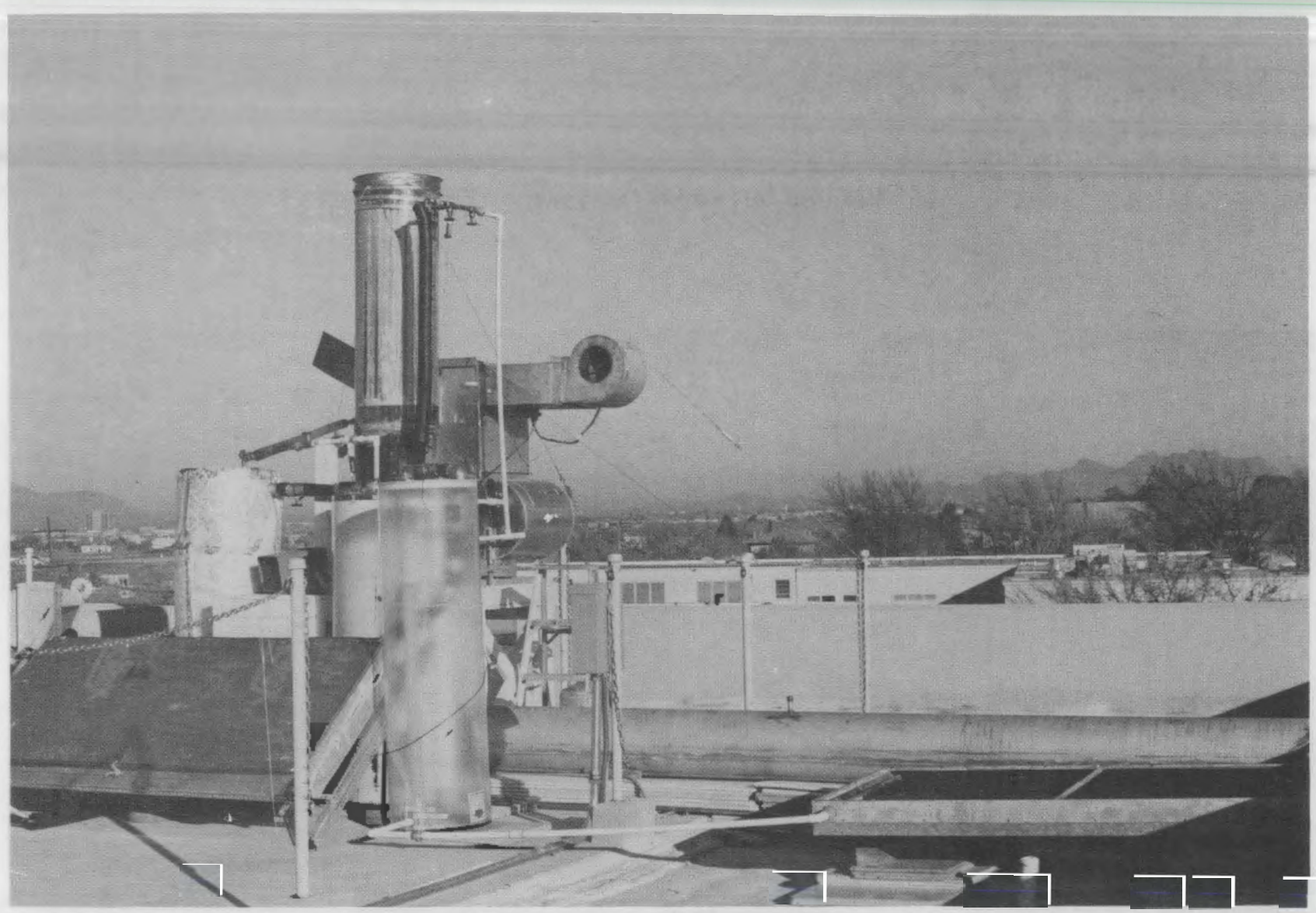

FIGURE D-14. System, Looking North 


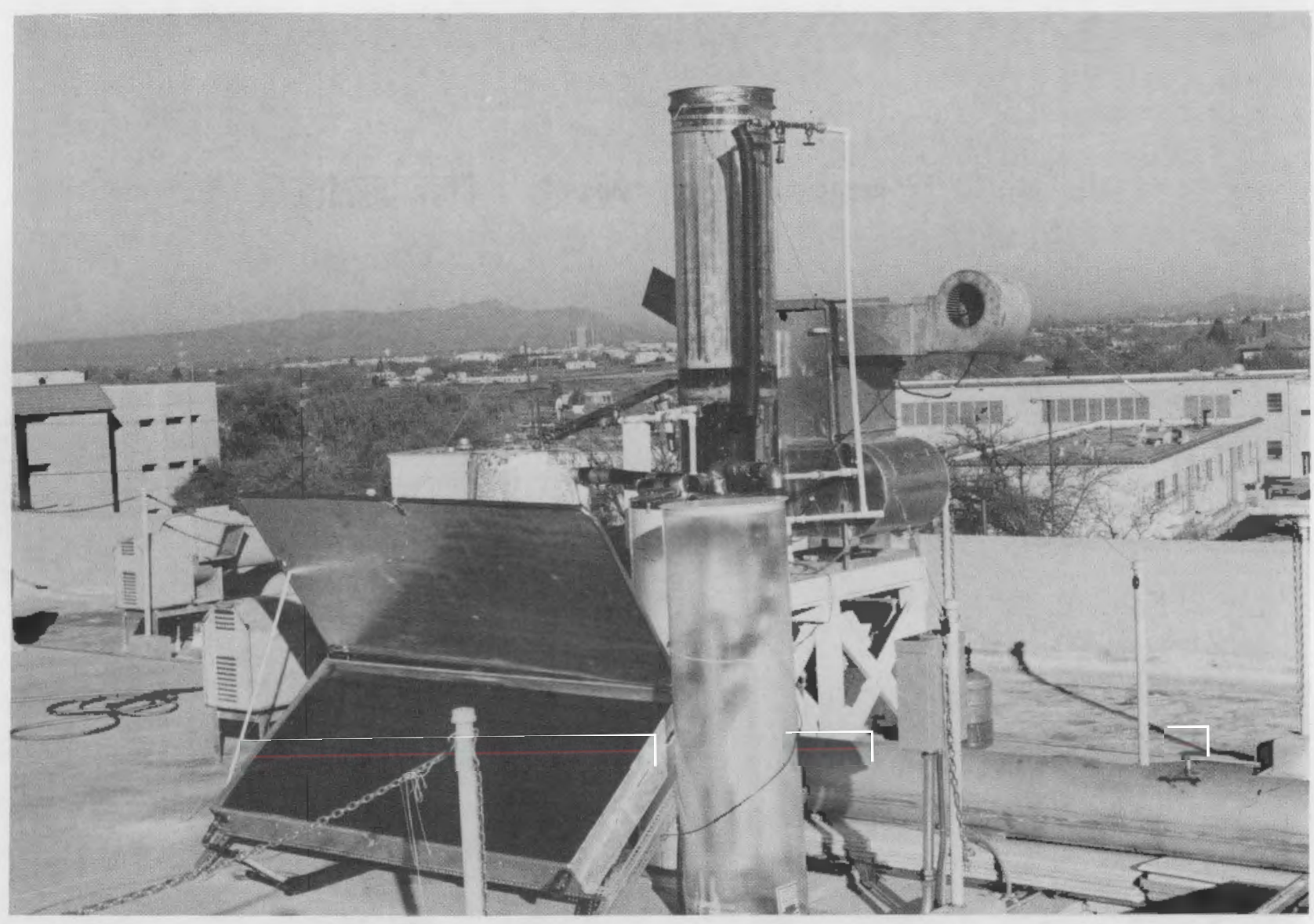

FIGURE D-15. System, Looking Northwest 
w

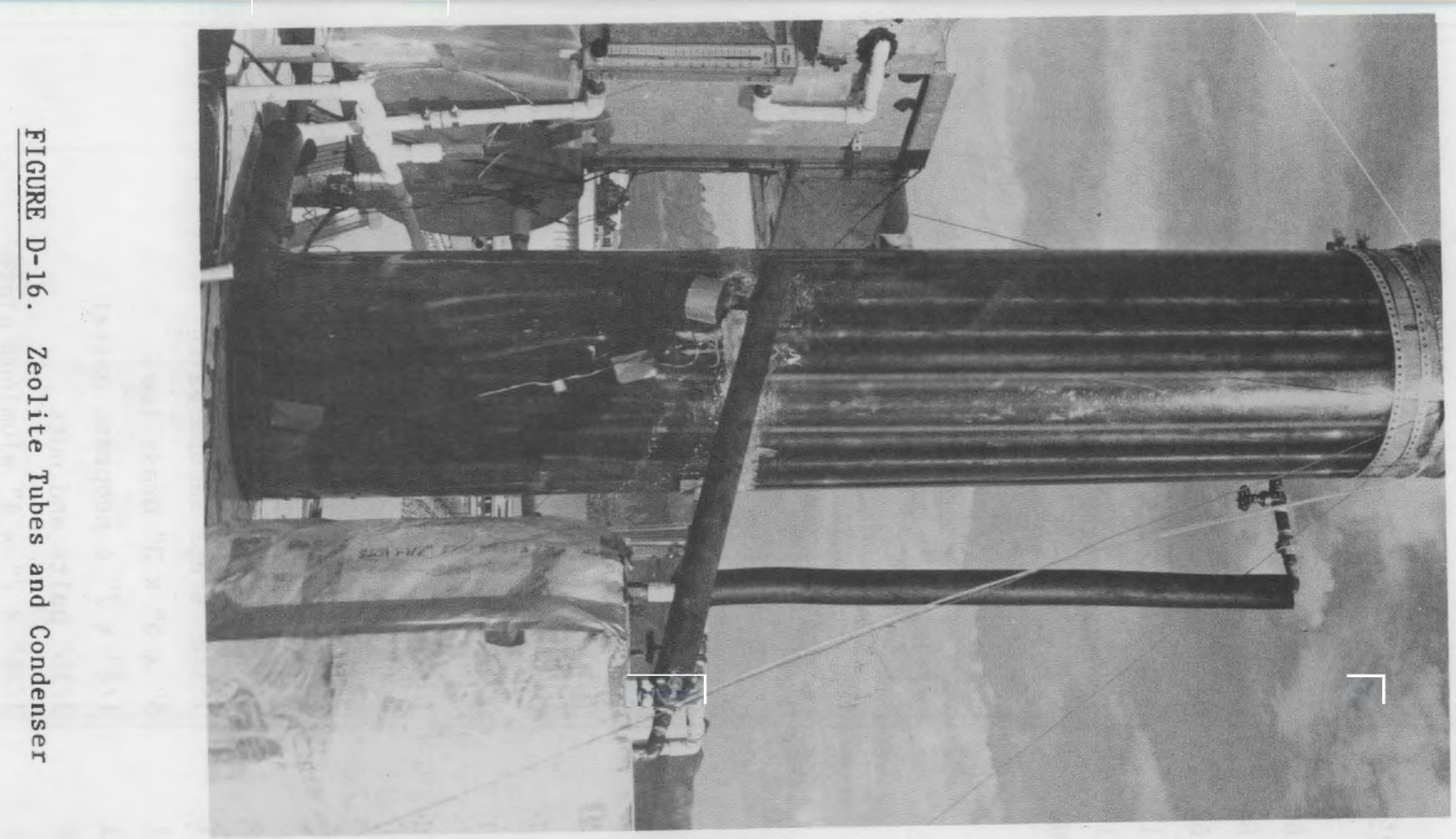


TABLE D-1. Materials Breakdown, ZCAT Facility

Qty

Zeolite Tank

2

$1 / 4^{\prime \prime} \times 18^{\prime \prime}$ aluminum plate

64

$11 / 2^{\prime \prime} \times 4^{\prime}$ copper pipe

64

$1 / 2^{\prime \prime} \times 5^{\prime}$ copper tubing

64

$1 / 2^{\prime \prime}$ copper caps

$15^{\prime}$

30 mesh $\times 4^{\prime}$ copper screen

$16^{\prime}$

$3 / 4^{\prime \prime}$ I.D. silicon tubing

100\#

$13 \times$ molecular sieve zeolite

\section{Condenser Tank}

64

$1 / 2^{11} \times 18^{\prime \prime}$ copper tubing

1

$1 / 2^{\prime \prime} \times 7^{\prime \prime} \times 7^{\prime \prime}$ brass plate

$1 \quad 5^{\prime \prime} \phi$ brass cap

15 " $\quad 5^{\prime \prime}$ copper coupler

$1 \quad 5^{\prime \prime} \phi \times 9^{\prime \prime}$ copper pipe

$7 \quad 1-1 / 2^{\prime \prime} \times 6^{\prime \prime}$ copper pipe

$7 \quad 1-1 / 2^{\prime \prime}$ copper caps

$13 / 16^{\prime \prime} \times 17-3 / 4^{\prime \prime}$ steel plate

$17 / 8^{\prime \prime} \times 15^{\prime \prime}$ neoprene gasket

$13 / 16^{\prime \prime} \times 6^{\prime \prime}$ neoprene gasket

\section{Receiver Section}

$155^{\prime \prime} \phi \times 9^{\prime \prime}$ copper pipe

$1 \quad 5^{\prime \prime} \phi \times 12^{\prime \prime}$ copper pipe

$2 \quad 1 / 2^{\prime \prime} \times 7^{\prime \prime} \times 7^{\prime \prime}$ brass flange

$11-1 / 2^{\prime \prime}$ brass vacuum valve

$15^{\prime \prime} \times 5^{\prime \prime} \times 3^{\prime \prime}$ brass tee

$1 \quad 1 / 2^{\prime \prime} \times 7^{\prime \prime} \phi$ neoprene gasket

$83 / 16^{\prime \prime}$ bolts and nuts

$13 / 16^{\prime \prime} \times 7^{\prime \prime} \times 4^{\prime \prime}$ aluminum plate

$13 / 16^{\prime \prime} \times 7^{\prime \prime} \phi$ neoprene gasket

$13 / 16^{\prime \prime} 7^{\prime \prime} \times 4^{\prime \prime}$ acrylic plate 


\section{TABLE D-1. (continued)}

$\begin{array}{ll}2 & 5 / 16^{\prime \prime} \text { vacuum vale } \\ 1 & 3^{\prime \prime} \phi \text { copper bellows } \\ 2 & 1 / 2^{\prime \prime} \times 6^{\prime \prime} \phi \text { brass flanges } \\ 1 & 3^{\prime \prime} \phi \text { vacuum valve } \\ 1 & 3^{\prime \prime} \phi \times 6^{\prime \prime} \text { copper pipe } \\ 1 & 3^{\prime \prime} \phi \text { copper elbow } \\ 1 & 1 / 2^{\prime \prime} \times 6^{\prime \prime} \phi \text { brass flange } \\ 1 & 5 / 16^{\prime \prime} \text { brass tee } \\ 1 & 5 / 16^{\prime \prime} \text { vacuum valve } \\ 1 & 3 / 8^{\prime \prime} \times 10^{\prime} \text { copper tubing } \\ & \\ 1 & 12^{\prime \prime} \phi \times 15^{\prime \prime} \text { stainless steel tank w/bevel cut edges, } \\ 2 & 3 / 16^{\prime \prime} \times 7^{\prime \prime} \times 4^{\prime \prime} \text { aluminum plate } \\ 2 & 3 / 16^{\prime \prime} \times 6^{\prime \prime} \phi \text { neoprene gasket } \\ 2 & 3 / 16^{\prime \prime} \times 7^{\prime \prime} \times 4^{\prime \prime} \text { acrylic plate } \\ & 18^{\prime \prime} \phi \times 10^{\prime \prime} \text { fiberglass tank } \\ 1 & 18^{\prime \prime} \phi 5^{\prime} \text { fteel tank } \\ 3 & \quad \text { Exterior Tanks } \\ 1 & \end{array}$

Misc. Plumbing, Parts and Systems

$\begin{array}{rl}7 & 3 / 4^{\prime \prime} \text { thermal wells } \\ 10 & 3 / 4^{\prime \prime} \text { valves } \\ 1 & 1 / 2^{\prime \prime} \text { vacuum valve } \\ 10 & \text { PVC pipe } 3 / 4^{\prime \prime} \times 10^{\prime} \\ 1 & \text { Evaporative water chiller } \\ 10 & 2^{\prime} \times 8^{\prime} \text { aluminum covered insulation batts } \\ 2 & 3^{\prime} \times 6^{\prime} \text { solar collector } \\ 1 & 80 \text { gallon hot water heater }\end{array}$




\section{TABLE D-1. (continued)}

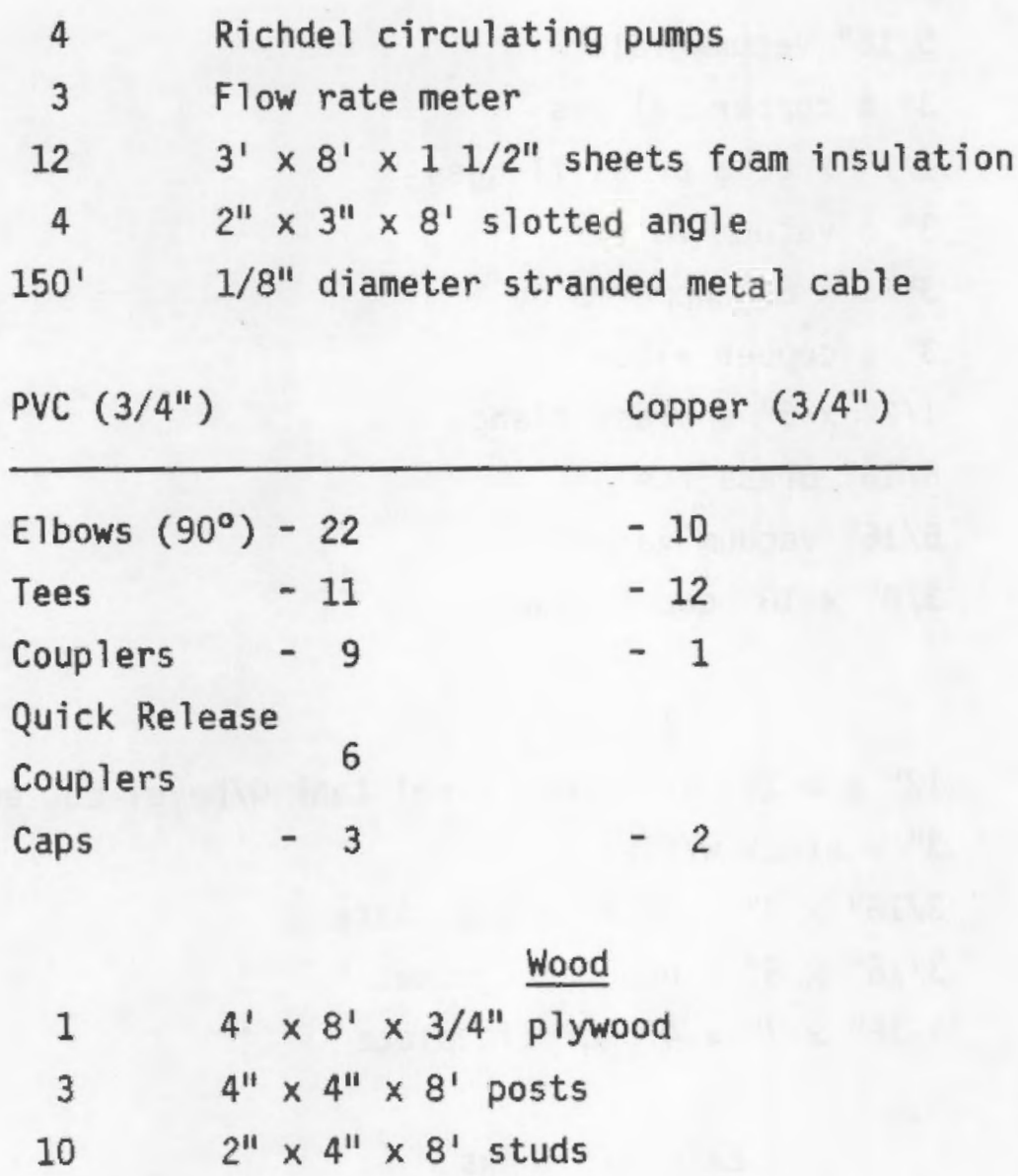

\section{Misc.}

6 1b. Sil-Fos \#5 brazing alloy

$12-1 / 2^{\prime \prime}$ vacuum guage

6 5/16" pirani transducer

1 Televac pirani vacuum guage electronics

11 torr to 400 torr vacuum gauge

1 OMEGA 24 TX2OPP, 24 pair thermocouple cable $125 \mathrm{ft}$.

1 Austron data logger

1 Vacuum pump

1 Mass spectrometer helium leak detector 


\section{Data Collection}

A11 temperature measurements were tabulated automatically by a data logger manufactured by Austron, Inc. Flows of hot water and chilled water were set according to specific test requirements and the information hand recorded. The pirani and dial pressure gauges were monitored and readings hand recorded. The airflow in the evaporative water chiller was measured with a TSI anemometer and hand recorded. Climatological data were obtained from the office of the state climatologist at the New Mexico Department of Agriculture at Las Cruces, New Mexico.

The Physical Science Laboratory, at New Mexico State University maintains a secondary standard quartz thermometer for calibration of thermocouples. This secondary standard was used to measure the temperature of a water bath. Test tubes with silicon oil were immersed in the water bath and the thermocouples were immersed in the oil. The thermocouples were calibrated at 15 temperatures.

Pressure gauge calibration in vapor was performed in the ZCAT facility by pumping the pressure down until water in the condensate receiver started to boil. The temperature of the water was then related to the saturation line on the steam chart, and the pressure at that point was recorded. The pirani gauge was calibrated in air at the NASA White Sands Test Facility.

Transducer locations are shown in Figures $1,8,9,10$, and 14 . A list of all measurements is given in Table $D-2$.

The initial proposal for this project did not include any electrical power consumption measurements since the main concern was for the performances of the zeolite, condenser, manifold, and ice tank. However, a Watt Probe 2,000 A was procured and used to measure the power used by the circulating pumps and the blower. These pumps and blower were designed to be cost competitive and are very inefficient. The Richdel Model R798A pumps were rated at 80 watts in company literature. It took 86 watts to circulate water through the solar panel, electric hot water heater, drainback tank, and related plumbing. Adding the zeolite tank to the water loop raised the power used to 95 watts. The chilled water spray pump used 80 watts to circulate water through the condensate receiver cooling coils, plumbing, and sprays. The chilled water circulating pump used 85 watts to 
TABLE D-2. System Performance Measurements

Channe 1

Number

\section{Parameter}

Air Temperatures

07

Chiller air output, wet bu1b

08

Chiller air output, dry bulb

09

Chiller air input, wet bulb

10

Chiller air input, dry bulb

11

Chiller air, bottom, wet bulb

12

Chiller air, bottom, dry bulb

13

Chiller air, bottom, wet bulb

14

Chiller air, bottom dry, dry bulb

Ambient air, wet bulb

Ambient air, dry bulb

\section{Water Temperatures}

$00\left(\mathrm{~T}_{0}\right)$

Condenser tank input

$01\left(T_{1}\right)$

Condenser tank output

$02\left(T_{2}\right)$

Zeolite tank, input

$03\left(T_{3}\right)$

Zeolite tank, output

$04\left(\mathrm{~T}_{4}\right)$

Condensate cooler, input

$05\left(T_{5}\right)$

Condensate cooler, output

$06\left(\mathrm{~T}_{6}\right)$

Condensate receiver

17 (T17)

Condenser tank mix 1

$18\left(\mathrm{~T}_{18}\right)$

Zeolite tank mix ${ }^{2}$

Ice tank, bottom north west

Ice tank, bottom south west

\section{Vapor Temperatures}

Ice tank vapor exit, north

21

Ice tank vapor exit, south 3

22

Ice tank vapor, east of exit ${ }^{3}$ 
TABLE D-2. (continued)

\title{
Water Flow
}

$\left(F_{1}\right) \quad$ Chilled water supply

$\left(F_{2}\right) \quad$ Condensate receiver cooling

$\left(F_{3}\right) \quad$ Hot water flow

$\mathrm{F}_{4} \quad$ Air flow through evaporative water cooler

Pressure

$P_{1} \quad$ Sealed system pressure measurement

\begin{abstract}
1 The condenser mix thermocouple was placed 3 inches from the top center of the condenser tank for purposes of monitoring the condenser water before any hot water could infiltrate from the zeolite tank.

2 The zeolite tank mix thermocouple was placed 3 inches from the bottom center of the zeolite tank for purposes of monitoring the zeolite water before any cooling water could infiltrate from the condenser tank.

3 These transducers were later moved to check the condenser input water temperature.

( ) Transducer designations in parenthesis correspond to Figure 1. Tranducer designations without parentheses correspond to data logger channels.
\end{abstract}

circulate water through the condenser tank, chilled water evaporation CELdek, and plumbing and 87 watts to circulate water through the zeolite tank. The ice tank circulating pump used 81 watts to circulate water through the ice tank center-line heat exchanger, radiating panel, and storage tank. The blower used 285 watts to drive air through both sides of the Z-Duct and the CELdek; the air flow was 485 cubic feet per minute. The static pressure of the Z-Duct CELdek and ducting was 1 inch of water pressure. The efficiency of the blower was 40 percent, based on the above 
figures. The impedances of the water flow paths were not measured. For a measured rate of 3 gallons per minute of hot water flow through the zeolite tank and based on information from the manufacturer's literature, the pumping head would be 12 feet. Thus the pump had an efficiency of 7 percent. A good electrically driven pump can be over 60 percent efficient.

\section{Test Control}

Two parameters can be partially controlled, the temperature of the heated water and the temperature of the chilled water. However, the temperature of the evaporatively chilled water is subject to ambient atmosphere dew point and dry bulb temperatures. Likewise, the temperature of the solar-heated water is subject to insolation, air temperature, and wind. An 80-galion 4500-watt electrical hot water heater was added to speed testing.

It was difficult to obtain the desired higher water temperatures needed to dry the zeolites because the fiberglass tanks used would not hold up if the water exceeded $175^{\circ} \mathrm{F}$ and the volume of water in the system was not adequate for the necessary heat storage. There were 80 gallons of water stored in the electric hot water heater, 50 gallons in the drainback tank (the original 66-gallon fiberglass tank was replaced with a 60-gallon iron tank) and about 5 gallons in the plumbing and solar water heater. Total weight of water was 1126 , pounds which stores $1126 \mathrm{Btu} /{ }^{\circ} \mathrm{F}$. Meating the mass of the zeolite tubes required $71.7 \mathrm{Btu} /{ }^{\circ} \mathrm{F}$ as calculated and somewhat less according to test data. Heating the zeolite tubes by $100^{\circ} \mathrm{F}$ between the adsorption and desorption phases, therefore, required $7170 \mathrm{Btu}$ and a $6.3^{\circ} \mathrm{F}$ drop in stored water temperature. Desorption during the first 10 minutes of that phase typically dropped the water temperature another 3.5. These elements combined to drop the temperature about $10^{\circ} \mathrm{F}$ and limited the testing to $165^{\circ} \mathrm{F}$ or below. Desorption testing was performed with hot water varying from $130^{\circ} \mathrm{F}$ to $165^{\circ} \mathrm{F}$.

Chilled water storage furnished $440 \mathrm{Btu} /{ }^{\circ} \mathrm{F}$, which limited the adsorption and condensation operation of the lower matrix points. 
The volumes of storage of hot and cold water, while limiting the magnitude of speed of response testing, were still adequate to allow acquisition of good speed of response testing. 



\section{DISTRIBUTION}

No of

Copies

OFFSITE

US Department of Energy

Attn: I. Gyuk

Office of Energy Systems Res,

Forrestal B1dg, CE-141 5E-052

Washington, OC 20585

US Department of Energy

Attn: R. Shivers

Office of Energy Systems Res.

Forrestal B1dg, CE-141 5E-052

Washington, OC 20585

27 DOE Technical Information Center

Argonne National Laboratory

Solar Thermal Storage Program

Attn: A. Michaels

Building 362

9700 S. Cass Avenue

Argonne, IL 60439

Auburn University

Attn: F. J. Molz

School of Engineering

Auburn, AL 36830

Wal ter Hausz

4520 Via Vistosa

Santa Barbara, CA 93110

Lawrence Berkeley Laboratory

Attn: C. F. Tsang

University of California

Bldg. 90, Room 1012-H

1 Cyclotron Road

Berkeley, CA 94720
No of

Copies

Charles F. Meyer

1141 Cima Linda Lane

Santa Barbara, CA 93108

10 New Mexico Solar Energy Institute

Attn: V.V. Risser

New Mexico State Univ.

PO Box 3, SOL

Las Cruces, NM 88003

New York State Energy Research \& Development Agency

Attn: Director

Rockefeller Plaza

Albany, NY 12223

New York State Energy Research \& Development Agency

Attn: Gunnar Walmet

Rockefeller Plaza

Albany, NY 12223

Oak Ridge National Laboratory

Attn: J. F. Martin

PO BOX Y

Oak Ridge, TN 37830

Office of Congressman

Sid Morrison

Kevin Billings Legislative Assist. 1330 Longworth Bldg.

Washington, DC 20515

Rocket Research

Attn: L. B. Katter

York Center

Redmond, WA 98052 
No of

Copies

Union Carbide Corporation

Nuclear Division

Attn: Library

$Y-12$ Plant

PO BOX Y

Dak Ridge, TN 37830

US Army Corps of Engineers

Attn: Library

PO Box 59

Louisville, KY 40202

US Department of Interior

Attn: Natural Resources

Library

Serials Branch ( $G / E$ )

Washington, DC 20240

FOREIGN

Bengt Hidemark Gosta Danielson Arkitekter SAR

Attn: A. Boysen

Jarntorget 78

S-11 29 Stockholm

Sweden

Public Works of Canada

Attn: E. L. Morofsky

C456 Sir Charles Tupper Bldg.

Riverside $\mathrm{Dr}$. and Heron Rd.

Ottawa, Ontario

KIA OM2 Canada

\section{ONSITE}

DOE Richland Operations off.

H. E. Ransom/D. R. Segna

22 Pacific Northwest Laboratory

L. D. Kannberg (15)

Technical Information (5)

Publishing Coordination (2) 